\title{
Assessment of Database for Interaction of Tritium with ITER Plasma Facing Materials
}

\author{
T. J. Dolan
}

R. A. Anderl

September 1994

Idaho National Engineering Laboratory

EG\&G Idaho, Inc.

Idaho Falls, Idaho 83415

Prepared for the

U.S. Department of Energy

Office of Fusion Energy

Under DOE Idaho Operations Office

Contract DE-AC07-76ID01570

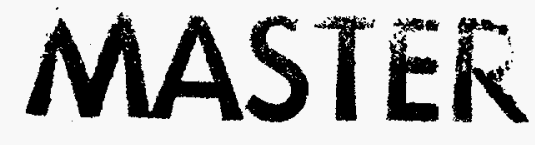




\section{DISCLAIMER}

This report was prepared as an account of work sponsored by an agency of the United States Government. Neither the United States Government nor any agency thereof, nor any of their employees, make any warranty, express or implied, or assumes any legal liability or responsibility for the accuracy, completeness, or usefulness of any information, apparatus, product, or process disclosed, or represents that its use would not infringe privately owned rights. Reference herein to any specific commercial product, process, or service by trade name, trademark, manufacturer, or otherwise does not necessarily constitute or imply its endorsement, recommendation, or favoring by the United States Government or any agency thereof. The views and opinions of authors expressed herein do not necessarily state or reflect those of the United States Government or any agency thereof. 


\section{DISCLAIMER}

Portions of this document may be illegible in electronic image products. Images are produced from the best available original document. 


\section{Abstract}

The present work surveys recent literature on hydrogen isotope interactions with $\mathrm{Be}, \mathrm{SS}$ and Inconels, $\mathrm{Cu}, \mathrm{C}$, and $\mathrm{V}$, and alloys of $\mathrm{Cu}$ and $\mathrm{V}$. The goals are (1) to provide input to the International Thermonuclear Experimental Reactor (ITER) team to help with tritium source term estimates for the Early Safety and Environmental Characterization Study and (2) to provide guidance for planning additional research that will be needed to fill gaps in the present materials database.

Properties of diffusivity, solubility, permeability, chemical reactions, Soret effect, recombination coefficient, surface effects, trapping, porosity, layered structures, interfaces, and oxides are considered. Various materials data are tabulated, and a matrix display shows an assessment of the quality of the data available for each main property of each material.

Recommendations are made for interim values of diffusivity and solubility to be used, pending further discussion by the ITER community.

The following values of tritium diffusivity and solubility are recommended:

For polycrystalline beryllium:

$$
\begin{array}{ll}
D=6.7 \times 10^{-9} \exp \left(-0.294 \mathrm{eV} / \mathrm{kT} \text { ) } \mathrm{m}^{2} / \mathrm{s}\right. & \text { (Abramov et al. 1990) } \\
\mathrm{S}=0.0578 \exp \left(-1.0 \mathrm{eV} / \mathrm{kT} \text { ) atom fraction } / \mathrm{Pa}^{1 / 2}\right. & \text { (Swansiger 1986) }
\end{array}
$$

For $\mathrm{BeO}$

$$
\begin{array}{llr}
D=1.19 \times 10^{-9} \exp (-1.335 \mathrm{eV} / \mathrm{kT}) & \mathrm{m}^{2} / \mathrm{s} & \text { (Longhurst et al. 1994) } \\
\mathrm{S}=1.25 \times 10^{-11} \exp (+0.8 \mathrm{eV} / \mathrm{kT}) & \text { atom fraction/ } \mathrm{Pa}^{1 / 2} & \text { (Longhurst et al. 1994) }
\end{array}
$$

For SS 316L:

$$
\begin{aligned}
& D=5.9 \times 10^{-7} \exp (-0.54 \mathrm{eV} / \mathrm{kT}) \quad \mathrm{m}^{2} / \mathrm{s} \\
& \mathrm{S}=5.8 \times 10^{-6} \quad \exp (-0.14 \mathrm{eV} / \mathrm{kT}) \quad \text { atom fraction } / \mathrm{Pa}^{1 / 2}
\end{aligned}
$$

(Reiter et al. 1993)

For Inconel 625:

$$
\begin{aligned}
& D=2.2 \times 10^{-6} \exp (-0.60 \mathrm{eV} / \mathrm{kT}) \quad \mathrm{m}^{2} / \mathrm{s} \\
& S=2.2 \times 10^{-6} \exp (-0.11 \mathrm{eV} / \mathrm{kT}) \quad \text { atom fraction } / \mathrm{Pa}^{1 / 2}
\end{aligned}
$$

(Reiter et al. 1993)

(Reiter et al. 1993)

For copper:

$$
\begin{aligned}
& D=6.6 \times 10^{-7} \exp (-0.387 \mathrm{eV} / \mathrm{kT}) \quad \mathrm{m}^{2} / \mathrm{s} \\
& S=3.70 \times 10-5 \exp (-0.572 \mathrm{eV} / \mathrm{kT}) \quad \text { atom fraction } / \mathrm{Pa}^{1 / 2}
\end{aligned}
$$

For copper alloys:

At the present time, there are no diffusivity and solubility data available specifically for the copper alloy under consideration for use in ITER. However, in section 4 of this report, we provide data from experimental testing of copper with various alloying elements, including $\mathrm{Cr}$ and $\mathrm{Ti}$. This information can be used as a guide to estimate the diffusivities and solubilities for the ITER-relevant alloy.

For isotropic graphite:

$$
D=9.3 \times 10^{-5} \exp (-2.8 \mathrm{eV} / \mathrm{kT}) \quad \mathrm{m}^{2} / \mathrm{s} \text {. }
$$


For vanadium:

$$
\begin{array}{lll}
D=5.6 \times 10^{-8} & \exp (-0.094 \mathrm{eV} / \mathrm{kT}) & \mathrm{m}^{2} / \mathrm{s} \\
S=2.1 \times 10^{-6} & \exp (-0.334 \mathrm{eV} / \mathrm{kT}) & \text { atom fraction } / \mathrm{Pa}^{1 / 2}
\end{array}
$$

For vanadium alloys:

At the present time, there are no diffusivity and solubility data available specifically for the vanadium alloy under consideration for use in ITER. However, in section 6 of this report, we provide data from experimental testing of vanadium with various alloying elements, including $\mathrm{Gr}$ and $\mathrm{Ti}$. This information can be used as a guide to estimate the diffusivities and solubilities for the ITER-relevant alloy.

$$
\begin{array}{llll}
D=1.14 \times 10^{-8} & \exp (-0.110 \mathrm{eV} / \mathrm{kT}) & \mathrm{m}^{2} / \mathrm{s} & (\mathrm{V}-15 \mathrm{Cr}-5 \mathrm{Ti}) \\
D=3.10 \times 10^{-7} & \exp (-0.218 \mathrm{eV} / \mathrm{kT}) & \mathrm{m}^{2} / \mathrm{s} & (\mathrm{V}-20 \mathrm{Ti})
\end{array}
$$

(Reiter et al. 1993)

Areas needing additional research are discussed. 


\section{Table of Contents}

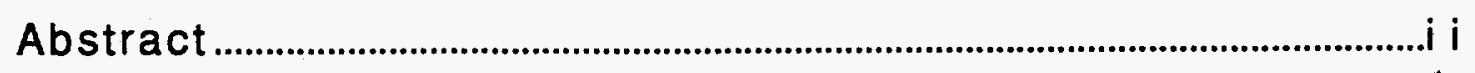

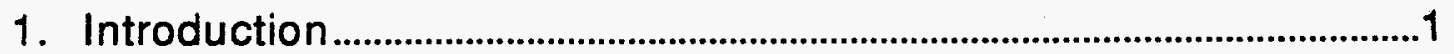

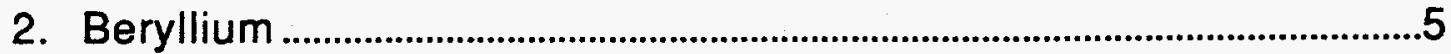

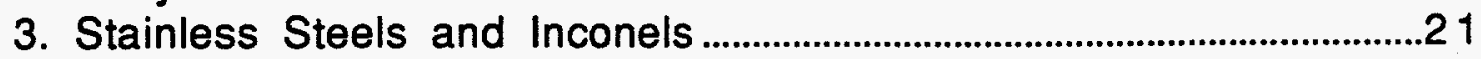

4. Copper And Copper Alloys................................................................................. 33

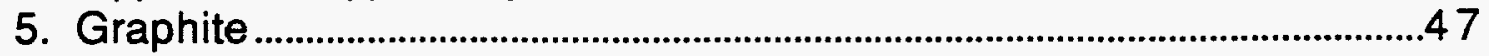

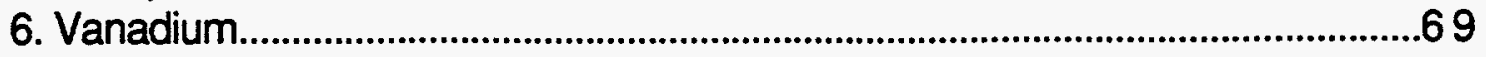

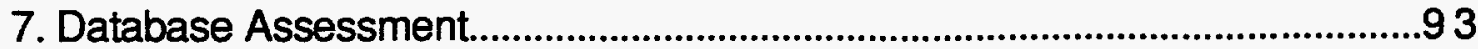

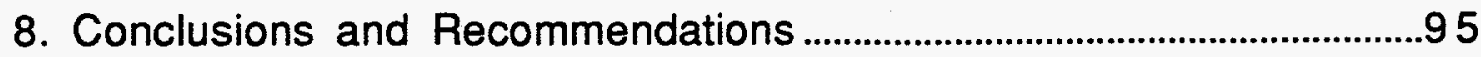

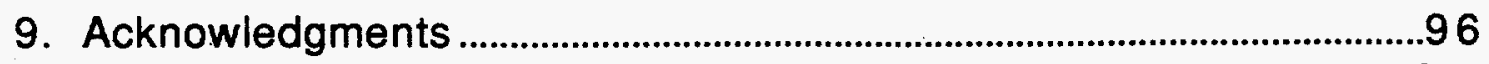

Appendix A. Bibliography on Beryllium A-1

Appendix B. Bibliography on Stainless Steel and Inconel B-1

Appendix C. Bibliography on Copper and Copper Alloys C-1

Appendix D. Bibliography on Graphite D-1

Appendix E. Bibliography on Vanadium E-1 


\section{Introduction}

The International Thermonuclear Experimental Reactor (ITER) will demonstrate ignition and sustained burn of a deuterium-tritium plasma. To ensure the safety of the workers and public, thorough safety analyses are being done in conjunction with the ITER design. One key safety issue is the magnitude of the radioactive isotope source terms, such as tritium, that might be mobilized and released during an accident. The goal of the present work is to survey the available data on tritium properties in candidate ITER plasma facing materials (PFM), to assess the adequacy of the present database for ITER needs, and to point out areas where more information is needed. Other materials used in the blanket, shield, and elsewhere are beyond the scope of this assessment. The available data, especially those on beryllium, will be used in the tritium source term estimate for the ITER Early Safety and Environmental Characterization Study (ESECS).

The word hydrogen as used here includes protium, deuterium, and tritium. The candidate PFM considered here are beryllium, stainless steel and Inconel, copper alloy, graphite, and vanadium.

The following properties of hydrogen in materials are considered relevant to estimation of the potential ITER tritium source term.

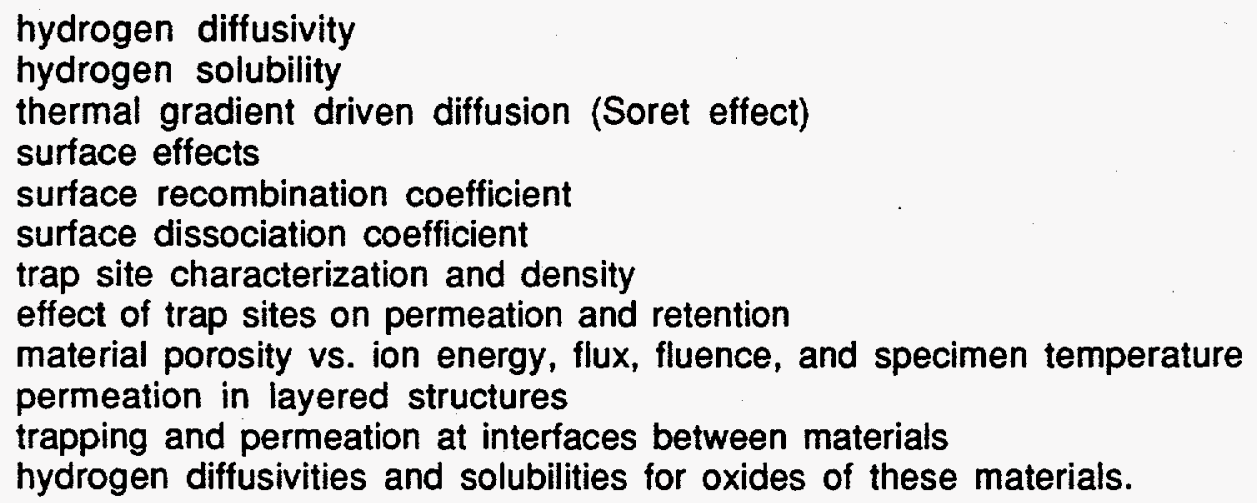

For each material, the English language literature has been surveyed to determine how well each of these data needs is satisfied by currently available information. The literature was gathered in three ways:

(1) Using material already in our files and working back through literature cited there.

(2) Using a computerized literature search of words in titles, key words, and abstracts via seven abstracting services. For example, for beryllium we used the Boolean string

(beryllium) + (hydrogen or deuterium or tritium) + (permea* or trap* or diffus* or solub* or retent* or recomb*),

where - denotes any following character string.

This search turned up several hundred titles for beryllium, from which about 80 abstracts were chosen for inspection. 
(3) We requested information from 47 scientists working in this field and received responses from about half of them enclosing about 130 articles.

Nevertheless, it is likely that we are still missing some significant references, and we invite further information from interested readers.

The present work deals primarily with experimental data. Theoretical models of some hydrogen properties in materials are given by Alefeld \& Völkl (1978) and Lässer (1989). The effect of stress gradients (Gorsky Effect) on tritium transport in PFM is not assessed here, and it remains to be studied in the future. An excellent review of tritium properties in fusion reactor materials was given by Reiter, Forcey and Gervasini (1993).

There are three regimes of transport in materials (Brice and Doyle 1984) distinguished by the transport parameter

$$
W=\left(\phi k_{r}\right)^{1 / 2 R / D_{1}}
$$

where $\phi=$ penetrating implantation flux, $k_{r 1}=$ front surface recombination coefficient, $R=$ implantation range, $D_{1}=$ diffusion coefficient at front surface. The regimes are:

W > 1: diffusion limited throughout, nearly linear concentration profile. (called DD)

$\gamma^{2} \alpha<W<1$ : recombination limited at front, diffusion limited at back surface; concentration approximately uniform. (called RD) Here $\alpha$ is the effective ratio of implant depth to wall thickness, and $\gamma$ is the effective ratio of inner and outer surface recombination coefficients.

$W<\gamma^{2} \alpha \sim 10^{-6}$ : recombination limited on both surfaces, concentration peak near $x=R$. (called RR)

These regimes are illustrated in Figure 1.1

Computer codes like PERI, DIFFUSE, and TMAP4 can be used to estimate tritium inventory and permeation losses in experiments such as INTOR, JET, TFTR, ITER, and DEMO. (for example, see Wienhold, Waelbroeck, and Winter 1982)

Hydrogen release from a surface is often governed by the surface recombination coefficient $k_{r}$. It is best to use experimental values of $k_{r}$, when available, keeping mind that surface conditions may vary widely from a laboratory experiment to a fusion reactor. If experimental data are lacking, then theoretical models may be used. Baskes (1980) and Pick \& Sonnenberg (1985) derived equations for that coefficient. Richards (1988) critically reviewed those two models and found some difficulties with the Baskes model. The Pick and Sonnenberg model is recommended here. For high surface coverage, the more general Richards model should be used. In view of the great variability of surface conditions, an order of magnitude accuracy would be considered good.

In applying the Pick and Sonnenberg model care must be taken with the value of $E_{c}$. Setting $E_{c}=$ 0 may lead to results that are inconsistent with experimental data, as in Børgeson et al (1986). An example of fitting an appropriate value of $E_{c}$ is found in Nagasaki et al. (1992). Most of the data can be described by a pre-exponential $\sim 10^{18} \mathrm{~cm}^{4} / \mathrm{s}$ and an activation energy $2 E_{s}-2 E_{c}$, with $0.03 \mathrm{eV}<E_{c}<0.57 \mathrm{eV}$.(P. Andrew and $M$. A. Pick, private communication, 1994) The majority of the data from uncleaned surfaces have $0.35 \mathrm{eV}<E_{c}<0.57 \mathrm{eV}$. The value $E_{c}=0$ is applicable only if the surface is perfectly clean. 


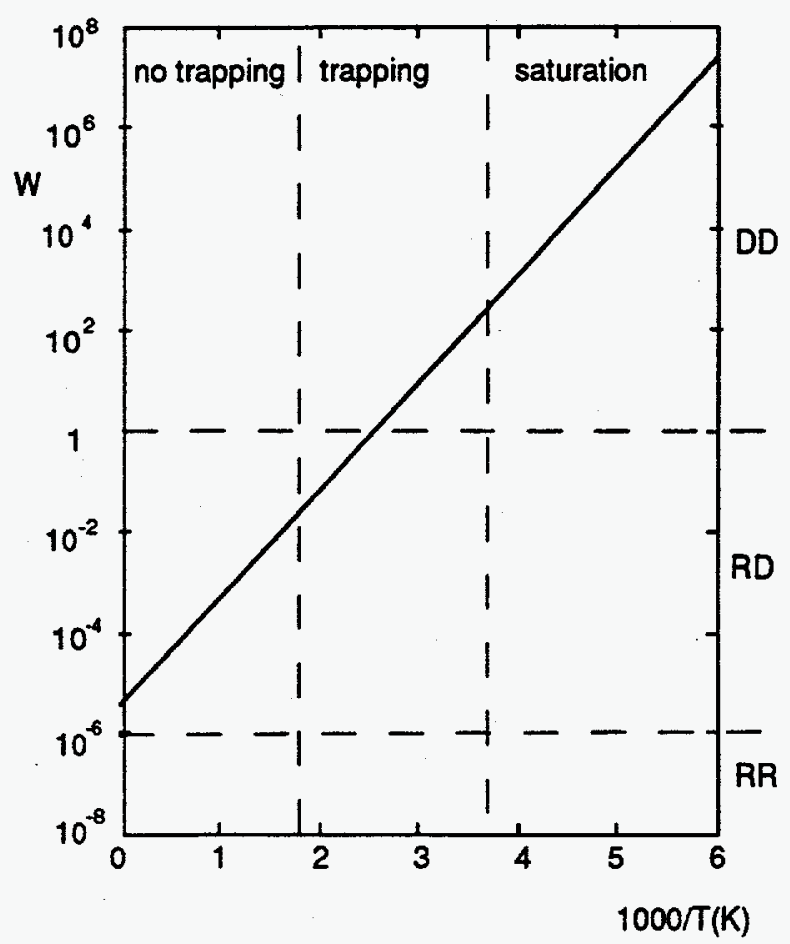

Figure 1.1. The transport classification curve of Brice and Doyle (1984) for the parameters of SS 304 in the INTOR reactor.

Roberto and Behrisch (1984) discussed possible synergistic effects on hydrogen behavior in materials caused by the simultaneous influences of reactive ions, surface modification, temperature, radiation damage, and external fields.

The results of this work are:

* a section on each of the five PFM materials, including an assessment of the sufficiency of the hydrogen behavior data.

- an overview of the database, including a matrix display indicating the quantity of data available for each material and property.

- an assessment of the database, and recommendations on how to fulfill the ITER data needs.

- Appendices A-E containing bibliographies of recent literature on each material. 


\section{References for Introduction}

G. Alefeld and J. Völkl, Editors (1978) Hydrogen in Metals, Basic Properties; and Hydrogen in Metals II Application-Oriented Properties, Springer-Verlag, Berlin.

M. I. Baskes (1980) "A calculation of the surface recombination rate constant for hydrogen isotopes on metals," Journal of Nuclear Materials 92, 318-324.

P. Børgesen, B.M.U. Scherzer and W. Möller, (1986) "Surface recombination of deuterium implanted into SS304", Nuclear Instruments and Methods in Physics Research B15, pp. 540545.

D. K. Brice, and B. L. Doyle, (1984) "Steady state hydrogen transport in solids exposed to fusion reactor plasmas," Journal of Nuclear Materials 120, pp. 230-244.

R. Lässer (1989) Tritium and Helium-3 in Metals, Springer-Verlag, Berlin.

T. Nagasaki, R. Yamada and H. Ohno, (1992) "Recombination coefficients of deuterium on metal surfaces evaluated from ion-driven permeation", Journal of Nuclear Materials 191194, pp. 258-262.

M. A. Pick and K. Sonnenberg (1985) "A model for atomic hydrogen-metal interactions application to recycling, recombination and permeation," Journal of Nuclear Materials 131, 208-220.

F. Reiter, K. S. Forcey, and G. Gervasini, "A compilation of tritium-material interaction parameters in fusion reactor materials," EUR 15217 EN (1993).

P. M. Richards (1988) "Surface-limited hydrogen release and uptake in metals," Journal of Nuclear Materials 152, 246-258.

J. B. Roberto and R. Behrisch (1984) "Synergistic effects in plasma-surface interactions," Journal of Nuclear Materials 128 \& 129, 764-774.

P. Wienhold, F. Waelbroeck, and J. Winter (1982) "Ways to reduce the permeation through, inventory in, and outgassing out of the first wall of iNTOR," Journal of Nuclear Materials $111 \& 112$, 248-250. 


\section{Beryllium}

\section{Hydrogen Transport}

Beryllium has a very close-spaced lattice, and the effective "solubility" of hydrogen in Be is very low. Most of the hydrogen retained must be trapped in lattice defects, by chemical traps, or in bubbles. Many phenomena affect hydrogen transport in beryllium:

(1) Fabrication method (refined, cast, sintered, rolled, forged, plasma sprayed,...) A wide variety of fabrication methods have been used in past experiments. Lattice defects produced by cold work are potential hydrogen trapping sites.

(2) Single crystal or polycrystalline. Recent measurements with single crystal Be have found low diffusivities, and measurements with polycrystalline Be have found higher diffusivity. The difference may be due to rapid transport along grain boundaries.

(3) Grain size. It takes hydrogen and helium longer to diffuse out of large grains to the grain boundary, where transport may be faster.

(4) Annealing. Heat treatment affects hydrogen trapping site mobility and agglomeration. At low temperature hydrogen is trapped in lattice defects. At high temperatures it may be trapped more in helium bubbles, if significant helium is present.

(5) Actual density and initial porosity. Hydrogen is less mobile in full density beryllium. Because the lattice spacing in $\mathrm{Be}$ is small, $\mathrm{Be}$ solubility and diffusivity in pure, fully-dense $\mathrm{Be}$ are low. Plasma-sprayed Be may have high porosity, permitting rapid transport of hydrogen.

(6) Impurities in the $\mathrm{Be}$ and chemical trapping. One likely process is the formation of beryllium ditritoxide (Longhurst 1990):

$$
2 \mathrm{BeO}+2 \mathrm{H} \rightarrow \mathrm{Be}(\mathrm{OH})_{2}+\mathrm{Be}+0.704 \mathrm{eV} / \mathrm{H} \text {. }
$$

This reaction occurs with atomic hydrogen, but not with molecular hydrogen. Early measurements showing low diffusivities may have been dominated by the surface $\mathrm{BeO}$ layer and trapping effects. No systematic study has been done of other impurity effects in $\mathrm{Be}$ or $\mathrm{BeO}$, but they may be important. For example, Fowler (1977) found that $0.2 \% \mathrm{MgO}$ in $\mathrm{Al}_{2} \mathrm{O}_{3}$ increased its tritium diffusivity by $4-5$ orders of magnitude.

(7) Irradiation by neutrons or ions. Ion bombardment and low-temperature neutron irradiation produce lattice defects that trap hydrogen. The impact of neutron irradiation at high temperatures is not yet well understood. Ion irradiation also induces surface-connected porosity to a depth about an order of magnitude greater than the theoretical mean ion range.

(8) Helium introduced by injection or by transmutations. Some helium will be injected into ITER Be as energetic alpha particles produced by D-T fusion reactions and as energetic chargeexchange He neutrals. He and tritium will be produced by transmutations via the following reactions:

$$
\begin{aligned}
& { }^{9} \mathrm{Be}(n, 2 \mathrm{n}) 2 \alpha \\
& { }^{9} \mathrm{Be}(n, \alpha){ }^{6} \mathrm{He}
\end{aligned} \quad \text { (1.85 MeV threshold) }
$$


and

$$
\begin{aligned}
& { }^{6} \mathrm{He} \rightarrow{ }^{6} \mathrm{Li}+\beta \\
& { }^{6} \mathrm{Li}(n, t)^{4} \mathrm{He}
\end{aligned}
$$

$$
\begin{aligned}
& { }^{9} \mathrm{Be}(n, t)^{6} \mathrm{Li} \\
& { }^{6} \mathrm{Li}(\mathrm{n}, \mathrm{t})^{4} \mathrm{He},
\end{aligned}
$$

and by interactions with lithium impurities present in the Be. The ratio of $\mathrm{He} / \mathrm{T}$ produced is on the order of 17 in a thermal fission spectrum. At high temperatures interstitial helium gas migrates towards grain boundaries. The time for this process is related to the Be self-diffusion coefficient $D_{s}=5.2 \times 10^{-5} \exp (-1.63 \mathrm{eV} / \mathrm{kT}) \mathrm{m}^{2} / \mathrm{s}$. Times for self-diffusion to a grain boundary with radius $12 \mu \mathrm{m}$ are $36 \mathrm{~h}\left(500^{\circ} \mathrm{C}\right)$ and $0.68 \mathrm{~h}\left(650^{\circ} \mathrm{C}\right)$. Thus, at higher temperatures helium could easily agglomerate into bubbles, creating hydrogen trapping sites, and interconnect along grain boundaries, providing rapid transport pathways. Such bubble agglomeration has been observed experimentally, and it is also associated with "breakaway swelling." In some cases large hydrogen releases were observed when helium bubbles or blisters burst. For one case, Longhurst (1990) estimated that about $90 \%$ of the hydrogen would be trapped as molecules in the He bubbles, with a few percent trapped chemically by BeO, and practically none in solution.

(9) Surface conditions. The surface conditions affect the sticking probability, dissociation rate and recombination rate. Impurities on the surface affect hydrogen adsorption rates. For example, carbon assists hydrogen codeposition. A BeO film is usually present, and it may dominate hydrogen uptake and retention in some cases. Surface conditions change during the course of an experiment. In some experiments the oxide layer grows faster than it is sputtered away by ion bombardment.

As the specimen temperature is increased, several regimes of hydrogen release may be observed, based on current understanding. The early release may be from hydrogen bound in lattice defects and chemical traps near the surface. At low flow rates the release may be limited by a second-order recombination process at the surface. If a sweep gas contains hydrogen, the recombination may be a faster first-order process. For other cases the surface recombination rate may be high enough that diffusive flow from the bulk metal is the limiting process. The diffusion process would gradually vent hydrogen evicted from lattice defects and hydrogen generated by decomposition of $\mathrm{Be}(\mathrm{OH})_{2}$. Longhurst (1990) provides information on how to distinguish the dominant mechanism limiting hydrogen release (diffusion, first-order recombination, or second-order recombination) from the time variation of the release rate. At higher temperatures, helium bubble agglomeration causes swelling. When the swelling reaches about $10 \%$, bubble interconnection facilitates "breakaway" swelling and burst release of tritium.

\section{Diffusivity}

Diffusivity is roughly proportional to the inverse square root of the hydrogen isotope mass. In view of the wide variation of the measured diffusion coefficients for hydrogen in Be, this work does not distinguish the different isotopes. Some representative data are listed in Table 2.1 and illustrated in Figure 1. 
Table 2.1. Diffusivity of hydrogen isotopes in $B e . \quad D=D_{0} \exp \left(-E_{d} / k T\right)$.

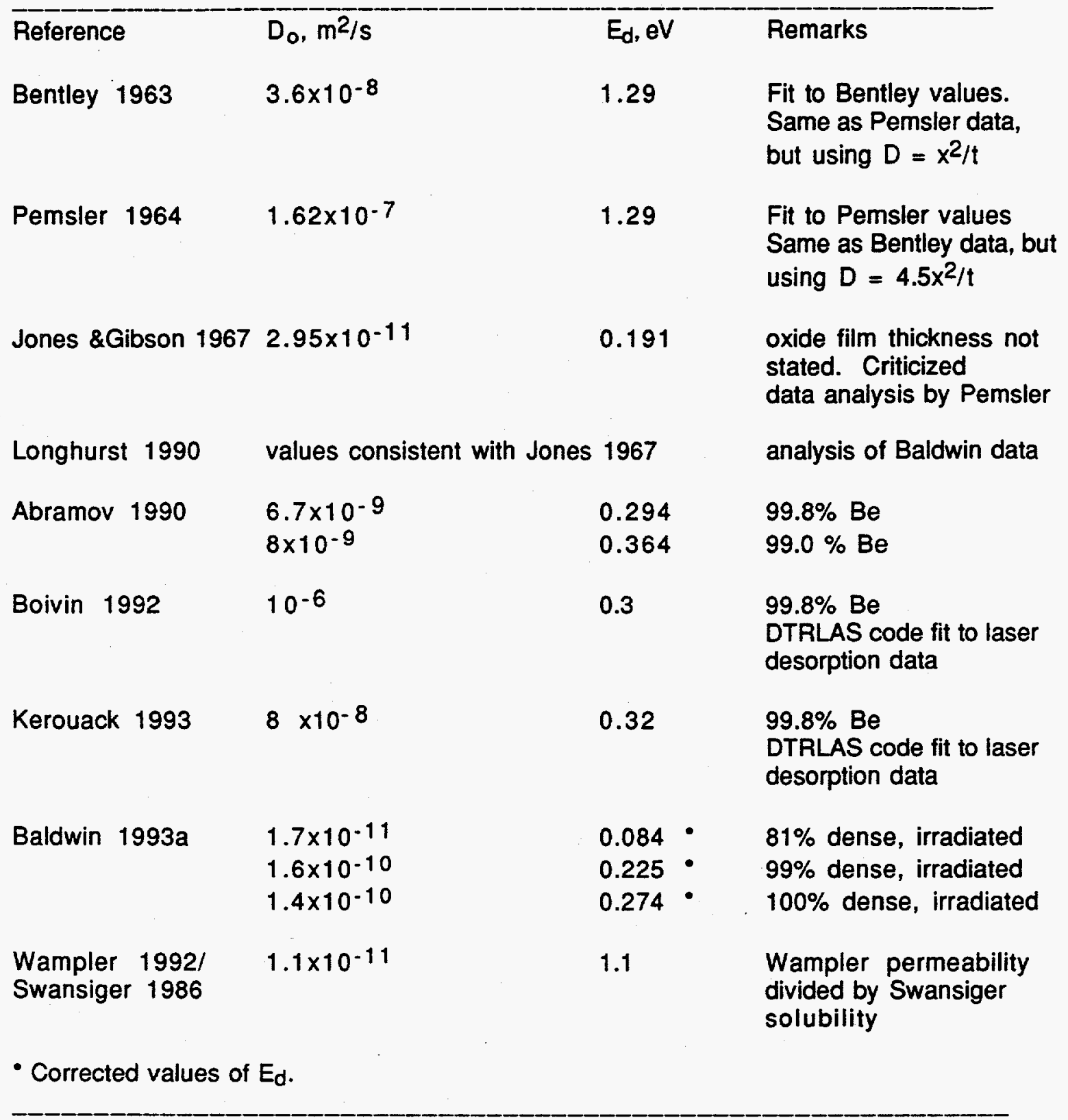




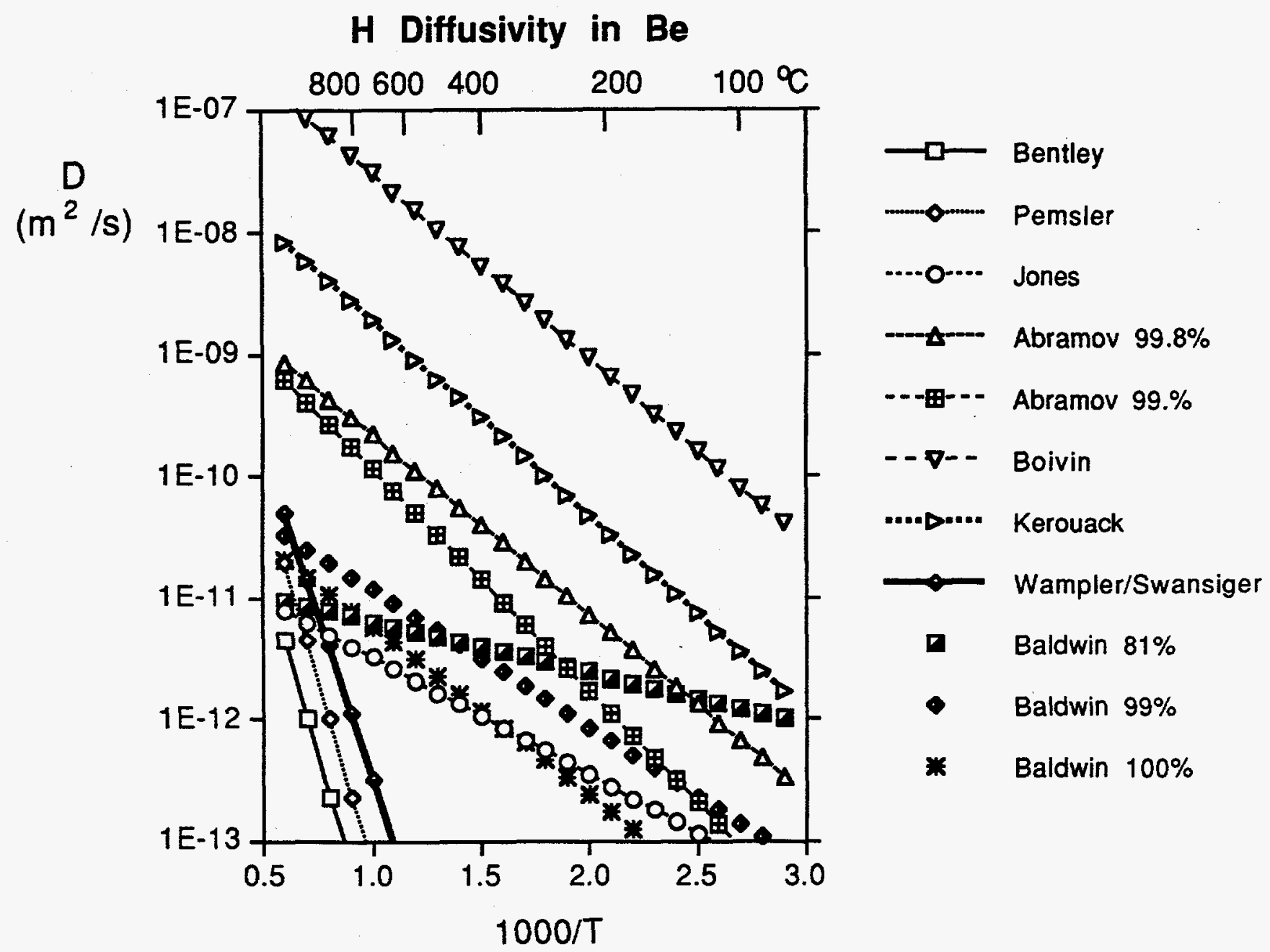

Figure 2.1. Diffusion coefficient of hydrogen in beryllium. (Note that Abramov $99 \%$ refers to purity, while Baldwin $99 \%$ refers to density.)

The Bentley and Pemsler data are not well documented, so there is less confidence in them. For example, the thickness of the oxide film was not measured or accounted for. For many years the Jones and Gibson 1967 data were widely used. Abramov et al. (1990) measured the approximate thickness of the oxide layer and used a mathematical approximation to correct for its effects. The Abramov diffusivity has been the most widely used value recently. The Kerouack et al. (1993) and Boivin et al. (1992) measurements were done on very fast times scales $(<1 \mathrm{~ms})$ by laser desorption of shallowly implanted deuterium. Kerouack et al. suggested the possibility of microcracks reducing the effective diffusion distance, so their estimates of diffusivity should be taken as upper limits. The Baldwin $99 \%$ and $100 \% \mathrm{Be}$ data on irradiated Be intersect the Abramov $99.8 \%$ curve near $300^{\circ} \mathrm{C}$, but are about an order of magnitude lower than the Abramov curve at high temperatures. The diffusivity labeled "Wampler/Swansiger" was estimated from the quotient of the Wampler (1992) permeability

$D S=2 \times 10^{-6} \exp (-2.1 \mathrm{eV} / \mathrm{kT})$ atom fraction $\mathrm{cm}^{2} / \mathrm{s} \mathrm{atm}^{1 / 2}$ 
divided by the Swansiger (1986) solubility

$\mathrm{S}=18 \exp (-1.0 \mathrm{eV} / \mathrm{kT}) \quad$ atom fraction/atm $1 / 2$

yielding $D=1.1 \times 10^{-7} \exp (-1.1 \mathrm{eV} / \mathrm{kT}) \quad \mathrm{cm} / \mathrm{s}$.

This value is recommended by Macaulay-Newcombe (personal communication) as a best estimate for bulk diffusivity of tritium in single-crystal $\mathrm{Be}$.

We recommend the data of Abramov et al. (1990) for unirradiated polycrystalline $\mathrm{Be}$, and the data of Baldwin and Billone (1993) for irradiated polycrystalline Be. Longhurst et al. 1994 show that the diffusivity values of Jones and Gibson can be reconciled with those of Abramov et al. accounting for trapping effects.

\section{Solubility}

Very high atomic densities of $\mathrm{Be}$ and $\mathrm{BeO}$ make interstitial He and tritium energetically unfavorable, so diffusivities and solubilities are very low. Early attempts to measure solubility using gas-driven permeation were unreliable, due to the rate-limiting $\mathrm{BeO}$ surface film. Pemsler and Rapperport (1964) implanted 7.5 MeV protons into Be and observed agglomeration of implanted hydrogen into bubbles, instead of dissolution in the lattice. They determined a hydrogen "solubility limit" $<0.83 \mathrm{ppm}$ in the temperature range $350-1050^{\circ} \mathrm{C}$, but this information cannot be converted into a solubility coefficient relating to equilibrium with external gas pressure.

The Jones and Gibson (1967a) solubility data are shown as the six triangles in Figure 2.2. Their lowest temperature datum (at $287^{\circ} \mathrm{C}$ ) in their Table 1 appears to be inconsistent with their Figure 7, and saturation was not achieved in that sample. They only used one sample thickness $(0.79 \mathrm{~mm})$ and did not take precautions to remove the oxide film or to measure its thickness. 


\section{Solubility of Hydrogen in Beryllium}

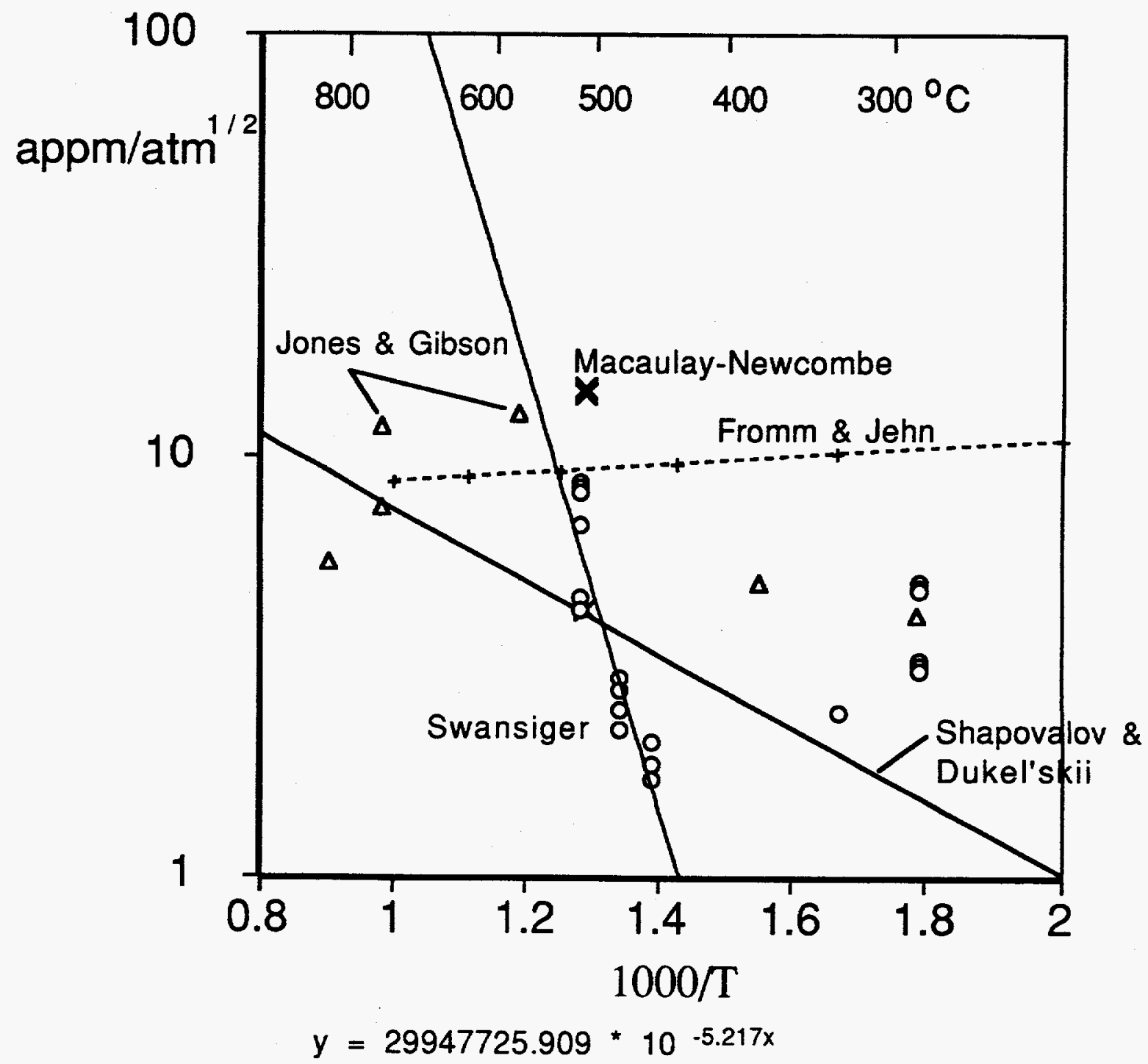

Figure 2.2. Solubility of hydrogen in beryllium as a function of temperature.

The amount of deuterium present in experiments by Liu (1979) was about 100 times that expected using Pemsler solubility. The authors hypothesized that deuterium in tiny bubbles may explain the apparent increased solubility.

Shapovalov and Dukel'skii (1988) measured the solubility of Be from 673 to $1473 \mathrm{~K}$. For the alpha phase they found linear variation of $S$ with $p^{1 / 2}$ and an Arrhenius relation with $T$ :

$$
\begin{aligned}
& S=5.6 \times 10^{-5} \exp (-0.17 \mathrm{eV} / \mathrm{kT}) \text { atom fraction/atm }{ }^{1 / 2} \\
& =1.76 \times 10^{-7} \exp (-0.17 \mathrm{eV} / \mathrm{kT}) \text { atom fraction } / \mathrm{Pa}^{1 / 2}
\end{aligned}
$$

This equation is shown as a solid line in Figure 2.2. 
A solubility measurement is valid only if variations of the sample thickness and charging time do not make significant changes in the measured values. Swansiger (1986) used sample thicknesses from 0.05 to $0.3 \mathrm{~mm}$, and charging times from 2 to 18 days. He also used acid to remove the BeO film prior to measuring solubility. His solubility data, indicated by circles in Figure 2, should be considered more accurate than the earlier data of Jones and Gibson. Solubility measurements at $440-510^{\circ} \mathrm{C}$ showed an endothermic heat of solution about $1 \mathrm{eV}$. At $T<350^{\circ} \mathrm{C}(1000 / \mathrm{T}>1.6)$ the Swansiger data have an exothermic slope, presumed to be caused by trapping. Data of Macaulay-Newcombe (1992) are also shown in Figure 2.

A fit to the Swansiger high-temperature data $\left(T>440^{\circ} \mathrm{C}\right.$ ) gives the equation (Wilson 1990)

$$
\begin{aligned}
S & =18.4 \exp (-1.0 \mathrm{eV} / \mathrm{kT}) \text { atom fraction } / \mathrm{atm}^{1 / 2} \\
& =0.0578 \exp (-1.0 \mathrm{eV} / \mathrm{kT}) \text { atom fraction } / \mathrm{Pa}^{1 / 2} \\
& =7.14 \times 10^{27} \exp (-1.0 \mathrm{eV} / \mathrm{kT}) \text { atoms } / \mathrm{m}^{3}-\mathrm{Pa}^{1 / 2}
\end{aligned}
$$$$
\left(\mathrm{T}>440^{\circ} \mathrm{C}\right)
$$

We recommend the use of this equation for solubility. Baldwin's tritium release data and Swansiger's $440-500{ }^{\circ} \mathrm{C}$ solubility data both can be interpreted as showing a $78 \mathrm{~kJ} / \mathrm{mole}$ $\left(0.81 \mathrm{eV}\right.$ ) activation energy (Longhurst 1991). BeO is hygroscopic, and $\mathrm{BeO} \cdot \mathrm{H}_{2} \mathrm{O}$ may interchange with $\mathrm{Be}(\mathrm{OH})_{2}$. The difference between this $0.81 \mathrm{eV}$ and the $0.70 \mathrm{eV}$ given above in item (6) under "Hydrogen Transport" (p.5), may be due to different chemical bonding configurations $\left(\mathrm{BeO}-\mathrm{OH}_{2}\right.$ and $\left.\mathrm{OH}-\mathrm{Be}-\mathrm{OH}\right)$. The discrepancy with the Shapovalov-Dukelskii 1998 data is not yet understood and needs further study.

Wampler (1992) studied single crystal Be and concluded that the oxidized Be surface did not limit the deuterium release, and that permeability in Be is much lower than previously published values.

\section{Thermal-Gradient-Driven Diffusion (Soret effect)}

The Soret effect is transport driven by a temperature gradient. The particle flux including both ordinary diffusion and thermal-gradient-driven diffusion may be written

$$
J=-D\left[\nabla n+\left(n Q^{*} / R T^{2}\right) \nabla T\right]
$$

where $D=$ diffusion coefficient, $n=$ concentration of solute, $Q^{*}=$ heat of transport, $R=$ universal gas constant, and $T=$ temperature. No data on $Q^{*}$ for beryllium have been found, but this transport process could be significant in plasma facing components under high heat fluxes.

\section{Oxide layer effects}

E. Abramov et al. (1990) measured diffusion coefficients in Be foils with BeO layers about 2.1 $\mathrm{nm}$ thick. By using multilayer diffusion theory, they were able to eliminate the effects of the oxide layer mathematically in solving for the diffusion coefficient in Be metal.

Causey et al. (1990) studied plasma driven permeation in the Tritium Plasma Experiment (plasma $99 \% \mathrm{D}, 1 \% \mathrm{~T}$ ) with bombarding energies of $100-200 \mathrm{eV}$, fluence $\sim 2 \times 10^{20} / \mathrm{cm}^{2}$ onto $99.8 \%$ Be hot rolled foils, $0.0505,0.127$, and $0.254 \mathrm{~mm}$ thick at $T=673,723,773$, and $823 \mathrm{~K}$. No permeation was seen below $673 \mathrm{~K}$. There were $\mathrm{BeO}$ layers $0.9 \mu \mathrm{m}$ thick on the upstream side (with some carbide present) and $0.4 \mu \mathrm{m}$ thick on the downstream side of the $\mathrm{Be}$ foil. Most of the hydrogen may have been trapped in the rear oxide layer $(0.2 \%)$. 
Hsu et al. (1990) studied a Penning discharge plasma interaction with a Be disc cathode, implanting hydrogen atoms. Initial Penning discharge plasmas had an oxide film on the beryllium cathode providing good secondary electron emission, and the bias voltage required to sustain the discharge was $300 \mathrm{~V}$. After several runs, the oxide film was removed by sputtering. The resulting cleaner metal surface had a lower secondary emission coefficient, and the required bias voltage increased to $1000 \mathrm{~V}$. With the oxide film the gas release vs. time was proportional to $t^{-0.3}$, and with a clean beryllium surface, proportional to $t^{-1}$. The DIFFUSE code modeled the release using the Jones (1967) diffusivity. Gas release was not diffusion limited.

From analysis of the JET tokamak limiter it was found that Be segregates through the BeO layer and provides a fresh Be surface to trap oxygen from the plasma.(Martinelli et al. 1992) Langley (1979) implanted $2.5 \mathrm{keV}$ deuterons into polycrystalline Be specimens at $298 \mathrm{~K}$ with fluences up to $10^{23} / \mathrm{m}^{2}$. The oxide layer thickness increased linearly with deuterium fluence. Be probably diffused by radiation enhanced diffusion from the bulk through the BeO surface layer and combined with oxygen to produce more $\mathrm{BeO}$ at a rate faster than sputtering losses. Blistering was studied for implanted $\mathrm{He}$, but not observed for $\mathrm{D}$ implantation.

Macaulay-Newcombe et al. (1991) implanted $90 \mathrm{keV} \mathrm{D}{ }^{+}$at $298 \mathrm{~K}$ to fluences $\sim 10^{20} / \mathrm{m}^{2}$ in nominally-99\%-pure Be specimens and measured deuterium retention by ${ }^{3} \mathrm{He}-\mathrm{D}$ nuclear reaction analysis. They also pre-implanted some samples with $30 \mathrm{keV}{ }^{4} \mathrm{He}^{+}$ions to a fluence of $10^{21} / \mathrm{m}^{2}$ to produce additional trapping sites. Comparison of data with theoretical models showed that oxide layer effects were significant. The oxide layer thickness grew from $2-10 \mathrm{~nm}$ before implantation to $10-20 \mathrm{~nm}$ after implantation, due to water vapor in the vacuum system. The temperature of the deuterium release peak increased with oxide layer thickness.

Moller et al. (1985) implanted monoenergetic deuterons at $0.06-10 \mathrm{keV} / \mathrm{atom}$ into polycrystalline Be samples at 293 - $920 \mathrm{~K}$, monitored the deuterium emission, and measured the deuterium retained in the specimens by nuclear reaction analysis. Thermal desorption spectra showed two release stages. The surface BeO layer was $\sim 20$ monolayers thick, in spite of very low residual gas pressure. The fluence where saturation occurred was $\sim 4 \times 10^{21} / \mathrm{m}^{2}$, with lower saturation fluences at lower beam energies or larger beam incidence angles relative to the normal. At high temperatures $(>920 \mathrm{~K}$ ) very little deuterium stayed in the beryllium.

Scherzer et al. (1979) implanted BeO layers on Be with $5 \mathrm{keV}$ deuterons and measured the retained deuterium by nuclear reaction analysis with ${ }^{3} \mathrm{He}$ ions. The maximum detrapping yields were $17 \mathrm{D} / 3 \mathrm{He}$ and $0.8 \mathrm{D} / \mathrm{H}$. The authors concluded that the observed radiation detrapping was caused by electronic excitation, rather than by nuclear collision cascades. Deuterium diffusion in $\mathrm{BeO}$ films was much more rapid at high $\mathrm{D}$ concentrations. Radiation enhanced diffusion may have contributed to the deuterium depth profile being much wider than the implantation range.

Early attempts to measure solubility using gas-driven permeation failed due to the ratelimiting BeO surface film. (Swansiger 1986)

\section{Other Surface Effects}

Surface effects are known to influence adsorption, desorption, dissociation, recombination, and sticking probability. Pick and Sonnenberg (1985) gave a general theory of hydrogen interaction with metal surfaces, including a discussion of previous treatments by Waelbroeck and by Livshits. For a perfectly clean surface, $\mathrm{H}$ and $\mathrm{H}_{2}$ should interact in the same way. For 
contaminated surfaces, the sticking probably of $\mathrm{H}_{2}$ can be reduced many orders of magnitude, and a dissociation activation energy barrier arises. This barrier reduces the front surface recombination coefficient, increasing the concentration and permeation rate for a given incident ion or atom flux.

Bergsáker at al.(1990) used surface probes exposed to plasma to study tokamak scrape-off layer plasma, pumping of deuterium, and deuterium co-deposition with carbon and Be. Beryllium seemed to enhance deuterium co-deposition with carbon.

Carbon on the surface greatly increased deuterium surface coverage. (Macaulay-Newcombe et al. 1994)

Deuteron bombardment of $\mathrm{Be}$ may create a hygroscopic surface reminiscent of bombarded $\mathrm{Al}_{2} \mathrm{O}_{3}$. There was little isotopic exchange between $\mathrm{H}_{2} \mathrm{O}$ and $\mathrm{D}$ at the surface. (Liu 1979)

V. Lossev and J. Küppers (1992) studied adsorption and desorption of gas atoms at $1600 \mathrm{~K}$ on clean, well-defined, single-crystal Be surfaces at 320-450 K. Desorption followed second order kinetics with activation energies of $59 \mathrm{~kJ} / \mathrm{mol}$ (oxygen on surface) and $84 \mathrm{~kJ} / \mathrm{mol}$ (clean $\mathrm{Be}$ surface). At high surface coverages desorption approached first-order kinetics. Adsorption of $\mathrm{H}_{2}$ on Be was endothermic, and Be-hydride formation was not observed. The saturation surface coverage was about 0.5 . Outgassing was apparently not limited by diffusion or desorption.

In the area of surfaces, ion-channeling analysis has yielded information on the lattice positions of chemisorbed hydrogen on a variety of metals. Additionally, ion-implantation experiments have quantified surface-limited uptake and release for bare, chemisorbed, and oxidized metal surfaces. (Myers et al. 1989)

R. Sartori et al. (1990) compared the deuterium release after each JET tokamak discharge with the deuterium used for fueling to infer the amount held up in the walls. The amount of deuterium released after a non-disruptive discharge was essentially independent of the discharge history. Fueling requirements and gas releases increased after the transition from $\mathrm{C}$ to Be coatings. Be walls provided faster gas pumping and higher fractional gas release $(80 \%)$ than $C$ walls $(40 \%)$ between shots. The fractional recovery of tritium was about half that of deuterium. Surface effects dominated the gas releases.

K. Touhouche and B. Terreault (1994) implanted Be foils with $1.5 \mathrm{keV}$ deuterons at $\mathrm{T}=293$ $983 \mathrm{~K}$ to fluences up to $1.2 \times 10^{22}$ atoms $/ \mathrm{m}^{2}$, which greatly exceeds the saturation fluence $\left(1.8 \times 10^{21}\right.$ atoms $\left./ \mathrm{m}^{2}, \mathrm{D} / \mathrm{Be} \approx 30 \%\right)$. They found blisters in saturated samples even at the highest temperatures, but no blisters were seen at deuterium atom fractions $<20 \%$. In samples with grain growth, blisters decorated grain boundaries and interconnected with each other. Blisters coalesced at higher temperatures, and their diameters increased. Release kinetics were modeled by the equation $\mathrm{dC} / \mathrm{dt}=-\mathrm{v}_{\mathrm{O}} \mathrm{C} \exp \left(-E_{\mathrm{B}} / \mathrm{kT}\right)$ where $v_{0}=10^{13} / \mathrm{s}$ and $E_{B} \approx 3 \mathrm{eV}$.

H. Verbeek and W. Eckstein (1974) implanted monoenergetic $\mathrm{H}^{+}, \mathrm{D}^{+}$, and $\mathrm{He}^{+}$ions into SS, Mo, and $B e$ at 15 and $150 \mathrm{keV}$. The observed blistering in $B e$ at $D$ and He fluences above $2 \times 10^{21}$ $/ \mathrm{m}^{2}$.

Some samples were deliberately corroded, to determine the effect of surface contamination on $\mathrm{He}$ release.(Zakaria 1993) Those samples had an additional broad thermal desorption peak above $950 \mathrm{~K}$, indicating that the increased surface oxide layer contained additional trapping sites that delay helium release. Similar effects could be expected for hydrogen. 


\section{Surface recombination coefficient and dissociation coefficient}

Anderl et al.(1992) implanted $3 \mathrm{keV} \mathrm{D}_{3}+$ ions at fluences up to $1.9 \times 10^{24} \mathrm{D} / \mathrm{m}^{2}$ into samples of hot-pressed powder metallurgy $99.6 \%$ pure Be and of hot-rolled, cast $99.96 \%$ pure Be. Using a conventional diffusion-limited flow analysis, they estimated the permeating fraction would be about 0.005 to 0.01 , but the maximum permeation flux was $3.7 \times 10^{-6}$ of the implantation flux. Using Fowler diffusivity in BeO and the measured $4 \mathrm{~nm}$ oxide film thickness on the downstream side, they estimated a concentration $\sim 10^{25} \mathrm{D} / \mathrm{m}^{3}$ in the downstream oxide film, and found that the concentration in the metallic Be was $\approx 4 \times 10^{23} \mathrm{D} / \mathrm{m}^{3}$ at the interface and practically uniform throughout the metal. The recombination coefficient at the interface was found to be $k_{r} \approx 10^{-30} \mathrm{~m}^{3} / \mathrm{s}$, which is within the range predicted by the Baskes model and by the $D / 2 k_{r}$ measurements of Hsu et al.(1990) and of Andrew et al.(1992).

R. A. Causey and K. L. Wilson (1993) used the DIFFUSE code to model ITER components with Abramov diffusivity and Swansiger solubility values. They assumed $1.8 \mathrm{eV}$ traps with 0.001 fraction in bulk, 0.01 fraction near surface. For the recombination coefficient they used three values: optimistic Baskes (surface coefficient $=1$ ), conservative Baskes $(0.001)$, and intermediate empirical value "best estimate" derived from Andrew's value of $D / k_{r}$. The resulting first wall tritium inventories were: optimistic $=30 \mathrm{~g}$; pessimistic $=0.9 \mathrm{~kg}$ with about $1 \mathrm{~kg} /$ day permeation. Similar estimates for divertor and limiter. The total end-of-life ITER tritium inventory was between 1 and $4.4 \mathrm{~kg}$, depending upon recombination and trapping assumptions.

J. Ehrenberg et al. (1990) derived effective $D$ and $k_{r}$ from plasma discharge data and found $D / k_{r}=10^{21}-10^{22} \mathrm{~m}^{-2}$, which is larger than expected from existing data. They considered both diffusion-dominated and recombination-dominated regimes in their equations. From the data it was not clear which regime is dominant.

From their Penning discharge studies with a Be cathode Hsu et al. (1990) inferred a ratio $\mathrm{D} / \mathrm{k}_{\mathrm{r}}$ $\sim 10^{18} / \mathrm{m}^{2}$, which is much smaller than found for JET data by Ehrenberg (1990). The difference may be due to oxide layer effects.

Saibene et al. (1990) found $D / 2 k_{\mathrm{f}} \sim 6$ to $2 \times 10^{20} \mathrm{~m}^{-2}$ at $\mathrm{T}=373$ to $553 \mathrm{~K}$, with an activation energy of $0.26 \pm 0.1 \mathrm{eV}$ for deuterium. This parameter was input to the PERI code to simulate deuterium flows, assuming that bulk diffusion in Be and surface recombination are the dominant processes. The deuterium fluxes from plasma facing components were simulated accurately by this technique.

Lossev and Küppers (1993) observed desorption at about $450 \mathrm{~K}$ from clean Be surfaces with an activation energy of $20 \mathrm{kcal} / \mathrm{mol}$, and at around $320 \mathrm{~K}$ from oxygen-covered Be surfaces, with an activation energy of $14 \mathrm{kcal} / \mathrm{mol}$.

Andrew, Peacock, and Pick (1992b) inferred the value of $D / 2 k_{p}$ from data of Hsu (1990) and compared three theoretical models. The DIFFUSE code used by Hsu assumes the Baskes model of $k_{r}$ and gives incorrect results. In some experiments it is easier to determine the value of the ratio $D / 2 k_{r}$ than it is to measure either $D$ or $k_{r}$ directly. The PERI code, which adjusts the value of $k_{r}$, gives two sets of results for $D / 2 k_{r}$ that agree with the data: a "high" and "low" $D / 2 k_{r}$ case. The low case 


$$
D / 2 k_{r}=2.3 \times 10^{20} \exp (-0.08 \mathrm{eV} / \mathrm{kT}) \quad \mathrm{m}^{-2}
$$

appears to be correct, but the high case cannot be ruled out. Further data are needed to clarify the role of diffusion from the implantation zone to the surface, which may be enhanced by porosity. When the Abramov $99.8 \%$ Be diffusivity is used with this equation, the recombination coefficient is found to be

$$
k_{r}=1.46 \times 10^{-29} \exp (-0.214 \mathrm{eV} / \mathrm{kT}) \text { molecules- } \mathrm{m}^{4} / \text { ato }^{2}-\mathrm{s} .
$$

We recommend using this value. Using a heat-transfer analogy M. C. Billone, C. C. Lin, and D. L. Baldwin (1991) extracted a tritium release rate from Baldwin data. Surface recombination coefficients vary over 8 orders of magnitude, and are sensitive to surface conditions.(M. C. Billone, et al. 1994)

\section{Trap site characterization and effects}

Baldwin et al. (1989) irradiated $98.26 \%$ Be rods $(1.7 \% \mathrm{BeO})$ at $\mathrm{T}<348 \mathrm{~K}$ to a fast fluence $5 \times 10^{22} \mathrm{n} / \mathrm{cm}^{2}$, producing 24,000 appm (He) and many trapping sites.

They performed thermal desorption measurements at 573 to $973 \mathrm{~K}$ (100 K increments) in flowing $\mathrm{H}_{2}$-doped $\mathrm{He}$ and measured residual tritium afterwards during melting. The data had good reproducibility. A large-burst tritium release occurred at $884 \mathrm{~K}$ during grain-boundary bubble coalescence.

Federici et al. (1994) modeled tritium permeation through Be and $\mathrm{C}$. Traps produced by neutron irradiation were assumed to grow to a saturation level of about $1000 \mathrm{ppm}(1.8 \mathrm{eV})$ at a characteristic damage level of $0.035 \mathrm{dpa}$ (Wampler model). Near-surface traps induced by DT bombardment were assumed to be $1.8 \mathrm{eV}, 0.01$ atomic fraction. The presence of traps lengthened the breakthrough time and increased the inventory, but the equilibrium permeation rate stayed about the same as without trapping. Thermal annealing of lattice defects would be expected at $\mathrm{T}=1500 \mathrm{~K}$. The charge exchange neutral flux would be $\sim 10^{23}$ atoms $/ \mathrm{m}^{2} \mathrm{~s}$. Neutron-induced traps increased the tritium inventory by about $20-30 \%$. If $\mathrm{Be}$ is held at 473 $\mathrm{K}$ for several days, the unbound tritium is released. An oxide layer of 0.5 monolayers decreases the $\mathrm{H}$ surface recombination rate by about two orders of magnitude.

Kéroack et al. (1993b) implanted proton beams at $0.5-5 \mathrm{keV}$ at $\mathrm{T}=293 \mathrm{~K}$ to a concentration of $2-20 \%$ in $99.4 \%$ pure $\mathrm{Be}$, with an equivalent BeO surface film thickness of $1.4 \mathrm{~nm}$. Then they applied a $3 \mathrm{~J} / \mathrm{cm}^{2}$ pulsed ruby laser beam to desorb hydrogen from the Be surface. They modeled concentration profiles and hydrogen emission with the computer code DTRLAS and found that a two-trap model (Low-fluence trapping at $1.7 \mathrm{eV}$, high-fluence, at $1.0 \mathrm{eV}$ ) gave a better fit to the data than a diffusion-limited model. A second-order detrapping model gave better results than a first-order model. The hydrogen apparently migrated directly to the surface after detrapping.

Myers et al. (1989) described studies of trapping by vacancies, vacancy-solute complexes, $\mathrm{He}$ bubbles, and oxide precipitates, together with phase-changing reactions such as hydride formation, hydrogen-bubble precipitation, and hydrogen reduction of precipitated oxides. From experimental data, mechanisms, binding enthalpies, microstructures, and local atomic configurations have been deduced. An analytical treatment of trapping kinetics gave quantitative trapping rates for arbitrary trap volume fraction and arbitrary spatial correlation between traps. (This review article does not have data specifically on beryllium, but it provides valuable information on general processes and experimental methods.) 
Wampler (1992) implanted samples with $2 \times 10^{19} \mathrm{D} / \mathrm{m}^{2}$ at $60 \mathrm{keV}$ and generated additional trap sites by implanting $15 \mathrm{keV} \mathrm{He}$ and $10 \mathrm{keV} \mathrm{H}+$ ions at $4 \times 10^{20} / \mathrm{m}^{2}$ fluences. The measured depth profiles showed that the TRIM code predictions underestimated the D profile widths at 13$40 \mathrm{keV}$. At low concentrations deuterium was trapped at lattice damage sites, and it was thermally detrapped around $450^{\circ} \mathrm{C}$. The energy barrier for detrapping was about $2.3 \mathrm{eV}$, as estimated from transport simulations. At high concentrations $D$ precipitated into gas bubbles. Release of $D$ from the bubbles occurred by permeation from high-pressure $D_{2}$ gas inside the bubbles through the $\mathrm{Be}$ lattice to the surface. The $\mathrm{BeO}$ surface layer did not limit the $\mathrm{D}$ release. The permeability of $D$ through Be was found to be about $2 \times 10^{5} \mathrm{D} /\left(\mathrm{cm} \mathrm{s} \mathrm{atm}{ }^{1 / 2}\right)$ at $600{ }^{\circ} \mathrm{C}$, seven orders of magnitude smaller than the value calculated from published solubility data (Swansiger) and diffusivity data (Abramov).

Zakaria et al. (1993) implanted hot isostatic pressed $99.5 \%$ pure Be foils at $293 \mathrm{~K}$ with 30 $\mathrm{keV} \mathrm{He}$ to fluences up to $10^{21} \mathrm{He} / \mathrm{m}^{2}$. Linear ramp thermal desorption measurements up to $1073 \mathrm{~K}$ were done to study helium trapping mechanisms. (Helium trapping is important to tritium retention, because tritium may be trapped in helium bubbles.) Ramp rates above 3 $\mathrm{K} / \mathrm{min}$ tended to wash out some of the peaks. Some samples were corroded, to determine the effect of surface contamination on $\mathrm{He}$ release. Those samples had an additional broad desorption peak above $950 \mathrm{~K}$, indicating that the increased surface oxide layer contained additional trapping sites that delayed helium release. The threshold temperature for helium release decreased from $955 \mathrm{~K}$ at $10^{20} \mathrm{He} / \mathrm{m}^{2}$ to $650 \mathrm{~K}$ at $10^{21} \mathrm{He} / \mathrm{m}^{2}$, because trapping sites became filled. A detrapping energy of $2.95 \mathrm{eV}$ was ascribed to a He-vacancy dissociation mechanism. At higher fluences a detrapping energy of $2.3 \mathrm{eV}$ was associated with larger He-vacancy clusters. At $1073 \mathrm{~K}$ less than $65 \%$ of the implanted He was released, indicating the presence of deeper traps.

According to R. Macaulay-Newcombe (private communication, 1994) changes in the trapping energy observed by Zakaria with post-implantation room temperature "annealing" indicate that a high chemical potential (due to a high damage level or to high helium concentration) can enhance diffusivity. The traps may have been changing in nature, or helium may have been diffusing from one trap to another. Recent unpublished data show that simply polishing the face of a Be sample before helium implantation can delay the desorption peak in thermal ramping experiments by $200 \mathrm{~K}$. Perhaps the Bielby layer (surface region damaged by polishing) may be trapping $\mathrm{He}$, reducing the effective diffusivity (see Anderl et al., 1992). Or perhaps there were microcracks in the unpolished sample surface from the buffing done by the vendor. Polishing might remove the microcracks, increasing the effective distance over which diffusion occurs.

For $\mathrm{H} / \mathrm{Be}$ concentrations < 14\% the trapping energy was $1.7 \mathrm{eV}$, with diffusion an order of magnitude faster than anticipated from previous work.(Terreault 1994) For $\mathrm{H} / \mathrm{Be}>14 \%$, the trapping energy is 1.0-1.2 eV, with explosive release occurring sometimes.

\section{Porosity vs. ion energy, flux, fluence, and specimen temperature}

R. A. Anderl et al. (1992) implanted $3 \mathrm{keV} \mathrm{D}_{3}+$ ions with fluences up to $1.9 \times 10^{24} \mathrm{D} / \mathrm{m}^{2}$ into samples of hot-pressed powder metallurgy $99.6 \%$ pure Be and of hot-rolled, cast $99.96 \%$ pure Be. Maximum permeation flux was only $3.7 \times 10^{-6}$ of implantation flux. They attributed the low permeation flux to bubbles, voids, and extensive surface-connected porosity in the irradiated samples. Most of the implanted deuterium leaked out the front face of the samples. 
Increasing porosity facilitates tritium release and may reduce swelling, but is poor for thermal performance and ductility. (Billone 1993)

Ross and Terreault (1990) implanted deuterons into 99.5\% pure, hot-rolled, polished Be specimens, used elastic recoil detection to determine the deuteron ranges and variances, and fit an equation of the form $R=R_{0} E^{n}$. The BABOUM code predictions were fairly close to these results, but the TRIM code and the Anderson-Ziegler compilation yielded ranges that were much too short. Similar data were obtained for $\mathrm{C}$ and Si. The authors hypothesized that enhanced penetration of the deuterons may have been due to microstructural effects, such as crystallinity and porosity.

\section{Permeation in layered structures}

Here "layered structures" refers to layers of different metals, such as $\mathrm{Be}, \mathrm{Cu}$, and stainless steel. No data were found for permeation through such layered materials.

\section{Transport along grain boundaries}

BeO coatings could be good tritium barriers if the $\mathrm{BeO}$ integrity could be maintained and rapid grain-boundary transport could be avoided.(Fowler et al. 1977)

Baldwin et al.(1989) studied neutron-irradiated Be samples with fast neutrons to a fluence $5 \times 10^{22} \mathrm{n} / \mathrm{cm}^{2}$, generating about 24,000 appm $(\mathrm{He})$. Thermal desorption spectra at 573 to $973 \mathrm{~K}$ ( $100 \mathrm{~K}$ increments) in flowing $\mathrm{H}_{2}$-doped $\mathrm{He}$ showed a large-burst tritium release at $884 \mathrm{~K}$, during grain-boundary bubble coalescence.

Very high atomic densities of $\mathrm{Be}$ and $\mathrm{BeO}$ make interstitial He and tritium energetically unfavorable, so diffusivities and solubilities are very low. Short-circuit grain-boundary diffusion may account for the rapid diffusion observed in polycrystalline specimens.

(Maienschein 1988, Billone et al. 1994; Macaulay-Newcombe 1994)

Dalle Donne et al. (1993b) extended the ANFIBE code to describe effects of helium bubbles and $\mathrm{BeO}$ on tritium trapping. The equations described tritium concentrations in dynamical solution, in intragranular bubbles, at grain boundaries, and in chemical traps. They compared code predictions with tritium release vs. time and temperature data of Baldwin. Below $450^{\circ} \mathrm{C}$ chemical trapping appeared to be dominant, and above $450^{\circ} \mathrm{C}$ trapping by helium bubbles appeared to be dominant. During simulated EC ITER accident at $700^{\circ} \mathrm{C}$ for 6 hours, only $5 \%$ of tritium was released.

No evidence of hydrogen agglomeration was seen at the end of bombardment, but after annealing agglomerates were observed, especially at grain boundaries, believed to be hydrogen-filled bubbles.(Pemsler and Rapperport 1964)

In samples with grain growth, blisters decorated grain boundaries and interconnected with each other. Blisters coalesced at higher temperatures, and their diameters increased. Release kinetics were modeled by the equation $\mathrm{dC} / \mathrm{dt}=-v_{0} C \exp \left(-E_{B} / k T\right)$ where $v_{0}=10^{13} / \mathrm{s}$ and $E_{B}$ $\approx 3 \mathrm{eV}$.(Touhouche and Terreault 1994)

\section{Trapping and permeation at interfaces between materials}


No data were found in this area, except for those described above relating to oxide layer effects.

\section{Hydrogen diffusivities and solubilities for oxides}

Fowler (1977) irradiated single crystal ( $99.95 \%$ pure), sintered, and powder BeO specimens. Neutron irradiation of a lithium surface layer generated energetic tritons that penetrated into the samples up to a concentration of 0.1 wppm $\mathrm{H}$. Tritium emission was measured during postirradiation heating at $500-1200{ }^{\circ} \mathrm{C}$ (bulk specimens) and $200-700{ }^{\circ} \mathrm{C}$ (powder specimens). Diffusion coefficients were inferred from tritium release vs. time. The release appeared to be diffusion-limited, not trapping-limited. Values for $\mathrm{BeO}$ are:

$\begin{array}{lll} & D_{o}\left(m^{2} / \mathrm{s}\right) & E_{d}(e V) \\ \text { single crystal } & 1.11 E-4 & 2.28 \\ \text { sintered } & 7.0 E-5 & 2.10 \\ \text { powder } & 3.17 E-15 & 0.724 \\ \text { best fit all data } & 1.3 E-10 & 1.36\end{array}$

Previous results for powders were much lower, but previous single crystal results were consistent with these data of Fowler. In other experiments $0.2 \% \mathrm{MgO}$ in alumina increased its tritium diffusivity by 4-5 orders of magnitude. An impurity study is desirable to determine whether similar impurity effects might occur in BeO.

The following paragraphs are from information provided by $R$. Macaulay-Newcombe (private communication, 1994):

Macaulay-Newcombe and Thomson (1994) found that deuterium diffusivity in $\mathrm{BeO}$ was consistent with Fowler values. They estimated the solubility of deuterium in $\mathrm{BeO}$ to be

$$
\begin{aligned}
S & =1.4 \times 10^{-11} \exp (0.8 \mathrm{eV} / \mathrm{kT}) & & \text { atom fraction } / \mathrm{Pa}^{1 / 2} \\
& =10^{18} \exp (0.8 \mathrm{eV} / \mathrm{kT}) & & \text { atoms } / \mathrm{m}^{3}-\mathrm{Pa}^{1 / 2}
\end{aligned}
$$

They suggested that the solubility is linked to the formation of hydroxide bonds, because the activation energy is close to the hydroxide formation energy.

Palmer et al. (1964) irradiated BeO powders with fission neutrons and derived a diffusivity $D$ $\approx 7 \times 10^{-17} \exp (-1.05 \mathrm{eV} / \mathrm{kT}) \mathrm{m}^{2} / \mathrm{s}$. At their high fluences the induced helium would have provided trapping sites for the tritium, lowering the effective diffusivity.

Behrisch et al. (1980) implanted $D$ into BeO thermally grown on single crystals of Be. The fluences were very high, nearing saturation at 0.24-0.34 D/BeO. From nuclear reaction depth profiling they found that the distribution was much deeper than predicted with the diffusivity of Fowler et al. They attributed this to enhanced diffusion of the deuterium during irradiation.

Scherzer et al. (1979) found that the ion beam used for reaction analysis detrapped deuterium, with detrapping rates up to $17 \mathrm{D}$ per incident $790 \mathrm{keV}{ }^{3} \mathrm{He}^{+}$ion. They attributed the detrapping to ionization effects, rather than displacement effects. They noted that the effective diffusivity of $D$ in $B e O$ appeared to increase at high concentrations.

Thus, ionization and defects can enhance tritium diffusion in ceramics by factors as high as $10^{4}$. Trapping can reduce the diffusion rate. Careful measurements are needed to determine the circumstances in which these effects might be important. 
From analysis of INEL data Longhurst et al. 1994 derived the following values

$$
\begin{array}{lll}
D=1.19 \times 10^{-9} \exp (-1.335 \mathrm{eV} / \mathrm{kT}) & \mathrm{m}^{2} / \mathrm{s} & \text { (Longhurst et al. 1994) } \\
\mathrm{S}=1.25 \times 10^{-11} \exp (+0.8 \mathrm{eV} / \mathrm{kT}) & \text { atom fraction } / \mathrm{Pa}^{1 / 2} & \text { (Longhurst et al. 1994) }
\end{array}
$$

We recommend use of these values. This solubility equation is almost identical to the MacaulayNewcombe 1994 equation shown above. This diffusivity equation has an activation energy comparable to the Fowler "best fit" value, and a magnitude about a factor of ten higher than the Fowler values, but within the uncertainty range of his data.

\section{Assessment}

Although there are many orders of magnitude difference among the diffusivity datasets, it is possible that many of them are correct for the conditions of their experiments. Isotopic effects (differences between $H, D$, and $T$ ) are minor, scaling as the square root of the mass ratio. Many conditions need to be considered:

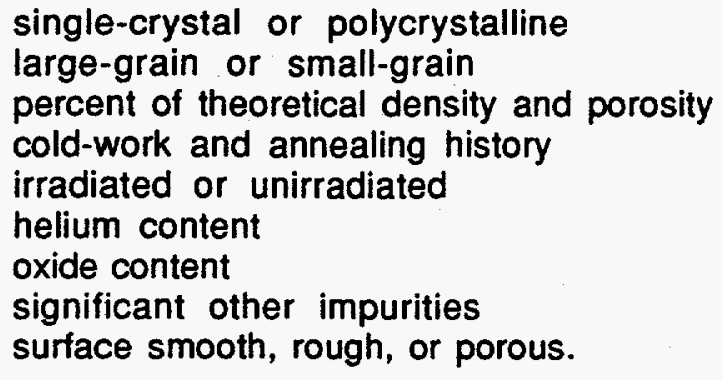

We recommend the following equations for various cases:

single crystal $\quad D=1.1 \times 10^{-11} \exp (-1.1 \mathrm{eV} / \mathrm{kT}) \mathrm{m}^{2} / \mathrm{s} \quad$ (Wampler $/$ Swansiger)

polycrystalline $\quad D=6.7 \times 10^{-9} \exp (-0.294 \mathrm{eV} / \mathrm{kT}) \quad \mathrm{m}^{2} / \mathrm{s} \quad$ (Abramov et al. 1990)

For irradiated polycrystalline Be the values of Baldwin \& Billone 1993 should be considered.

Here we recommend the solubility values of Swansiger :

$$
\mathrm{S}=0.0578 \exp (-1.0 \mathrm{eV} / \mathrm{kT}) \text { atom fraction } / \mathrm{Pa}^{1 / 2}
$$

(Swansiger 1986)

More study is needed to reconcile these values with those derived by other authors, such as Shapovalov and Dukelskii.

An experiment is needed to measure the heat of transport of hydrogen in beryllium. Then we can assess whether the Soret effect is likely to be significant in ITER operating conditions.

Surface effects are clearly significant in determining tritium uptake, trapping, and release. The ubiquitous oxide layer affects diffusivity, solubility, recombination, and trapping. The effects of lattice damage by neutrons at high temperatures $(>500 \mathrm{C}$ ) in possibly producing trapping sites need to be clarified by experimental data. Does the lattice damage anneal out rapidly? Porosity induced by ion bombardment has been shown to have profound effects on 
tritium permeation and release. Such porosity could aid the re-release of tritium to the plasma and greatly reduce its inventory and permeation to the coolant. It might even be worthwhile to manufacture the beryllium tiles with built-in porosity, at the expense of somewhat reduced thermal conductivity. How much porosity is generated as a function of ion energy, fluence, and Be temperature? Would the porosity be maintained under intense heat loads? How does the porosity affect the thermal conductivity? How would the porosity affect the interaction of $\mathrm{Be}$ with steam during an accident and the mobilization of BeO? Surface-effects questions need to be addressed by experiments that expose beryllium tiles to ITER-like plasmas, such as PISCES and the Tritium Plasma Experiment.

Some experiments have operated in regimes where surface recombination is a significant rate-limiting process, and some, in regimes where recombination is not a significant transport limitation.

Lattice damage produced by ion beams and neutrons at low temperatures results in effective hydrogen trapping sites. Data are lacking on trap sites produced by neutron irradiation at high temperatures. Helium bubbles tend to decorate grain boundaries, and they are very effective traps for hydrogen molecules.

More computer modeling is needed, and the models need to be validated by experimental data, in order to be able to predict tritium inventory and release in ITER. Needed input parameters include trap energies, trap site densities vs. irradiation fluence and temperature, impurity concentrations and effects, helium bubble development, heat of transport (Soret effect), trapping escape frequencies, and flow phenomena along grain boundaries. The codes DIFFUSE, PERI, DTRLAS, and TMAP4 have had some successes in modeling hydrogen permeation through multilayered structures, and they have helped interpret and clarify complex experimental phenomena. The ANFIBE code is providing valuable insight into helium migration and bubble phenomena. These one-dimensional codes do not adequately handle cases with cracked oxide films, porosity, or transport along grain boundaries, which are 2-D or 3-D effects. We need either a 2-D code or a clever modifications of 1-D codes. For example, an attempt has begun to model beryllium porosity effects using a modified input to the one-dimensional TMAP4 (Longhurst 1994).

Hydrogen diffusivity and solubility in $\mathrm{BeO}$ data are sparse. The variation from powder to sintered $\mathrm{BeO}$ is orders of magnitude. These data need to be clarified, confirmed, and extended. For interim use we recommend the following values:

$$
\begin{array}{lll}
D=1.19 \times 10^{-9} \exp (-1.335 \mathrm{eV} / \mathrm{kT}) & \mathrm{m}^{2} / \mathrm{s} & \text { (Longhurst et al. 1994) } \\
\mathrm{S}=1.25 \times 10^{-11} \exp (+0.8 \mathrm{eV} / \mathrm{kT}) & \text { atom fraction } / \mathrm{Pa}^{1 / 2} & \text { (Longhurst et al. 1994) }
\end{array}
$$

In summary, the database on beryllium is inadequate to make accurate predictions of tritium permeation and inventory in ITER plasma facing materials.

No parameter can be predicted with confidence better than a factor of three.

Most parameters have orders of magnitude uncertainty.

Some parameters have no data at all for the temperature and fluence range of interest. Unless a vigorous experimental and computational program on beryllium/hydrogen interactions is undertaken, predictions of the ITER and DEMO tritium source terms will have orders of magnitude uncertainty. 


\section{Stainless Steels and Inconels}

Reviews of hydrogen interactions with stainless steels (SS) have been given by Wilson (1979), Waelbroeck, Wienhold, and Winter (1982), Riehm (1986), and Dickson (1990). This discussion of stainless steels also applies to austenitic nickel-based alloys, such as inconels.

Stainless steel and inconel are endothermic occluders: Hydrogen atoms have higher potential energy in the metal than when bound together as gas phase molecules. This results in low bulk concentrations, typically $<100$ appm. To reach such concentrations the hydrogen should be incident as atoms or ions, not as molecules. Atoms in the metal must overcome a recombination barrier at the surface before leaving. The recombination coefficient $k_{r}$ is very sensitive to the surface impurity coverage; $\mathrm{k}_{\mathrm{r}}$ generally decreases with increasing impurity coverage. (Andrew and Pick 1994)

Tritium may exist in four chemical states:

(1) chemically bound, such as $\mathrm{CH}_{3} \mathrm{~T}$ in graphite. This is not seen much in Be or SS.

(2) molecularly trapped, such as HT, HTO, or $\mathrm{T}_{2}$ in voids or bubbles.

(3) trapped in an atomic state, especially at low temperature.

(4) localized in a special part, such as by a reactive minor constituent. For example, the Ti in SS 321 makes it hold much more tritium than SS 316. (Saeki, 1992)

Hydrogen at grain boundaries in SS is in atomic form. Permeation rates are lower for austenitic steels than for ferritic steels, partly because of a higher activation energy for diffusion, usually attributed to the higher atomic concentration of the fcc austenitic structure. Other high-temperature alloys with austenitic structures, such as Inconels and Hastelloys, have similar permeabilities. A variety of surface coatings have been considered to retard hydrogen permeation through stainless steels, including oxidation of the surface layer and addition of low-permeability materials, such as aluminum, $\mathrm{Si}, \mathrm{BN}$, and $\mathrm{Sn}$. Aluminum oxide has very low permeability, but it tends to crack when coated on stainless steel, because of its different coefficient of thermal expansion. A $30 \mathrm{~nm}$ Al layer could in principle retard permeation by a factor of $10^{5}$, but in practice the attainable factor has been limited to less than 1000 . (Dickson 1990)

Tanabe et al. (1984) made Arrhenius plots of D, S, and P for many alloys. They discussed the "Compensation effect", which refers to the proportionality of $\log (P)$ to $E p$, and $\log (D)$ proportional to $E_{d}$ for many alloys. They gave a table of $D, S$, and $P$ values for many alloys, and a graph of activation energy vs. Cr content.

\section{Diffusivity}

Some representative diffusivity values are listed in Table 3.1. A variety of methods have been used in obtaining these data, including time-lag, thermal desorption, and steady-state permeation. For example, Grant, Cummings, and Blackburn (1987) used periodic modulation of driving pressure (by bellows variation of chamber volume) at $0.1-10 \mathrm{mHz}, \pm 10 \%$ amplitude, to derive diffusion parameters, so that the result was independent of fluctuations in the steady state flux.

Katsuta and Furukawa 1981 studied the isotope effect and found values generally less than the classical square root of the mass ratio. For example, at $600^{\circ} \mathrm{C} D_{H} / D_{D}=1.16$, instead of 1.41 . Shan 1991 also observed departure from the classical ratio. 
Deformation of SS 304 produced stress-induced $\alpha^{\prime}$ martensite, which enhanced the effective hydrogen diffusivity:

Annealed: $\quad D=7.69 \times 10^{-3} \exp (-0.552 \mathrm{eV} / \mathrm{kT}) \quad \mathrm{cm}^{2} / \mathrm{s}$,

Deformed: $\quad D=4.94 \times 10^{-4} \exp (-0.414 \mathrm{eV} / \mathrm{kT}) \quad \mathrm{cm}^{2} / \mathrm{s} \quad$ (Perng \& Altstetter 1986)

Table 3.1. Hydrogen diffusivity in various alloys.

\begin{tabular}{|c|c|c|c|c|c|}
\hline Material & Isotope & $\begin{array}{l}\text { Temperature } \\
\text { Ranoe (K) }\end{array}$ & Eq.eV & $\mathrm{D}_{0} \cdot \mathrm{cm}^{2} / \mathrm{s}$ & Source \\
\hline $\begin{array}{l}\text { SS } 304 \\
\text { SS } 304 \\
\text { SS } 304 \\
\text { SS } 304 \\
\text { SS } 304 \\
\text { SS } 304 \\
\text { SS } 304 \\
\text { SS } 304 \\
\text { SS } 304 \text {, etc. } \\
\text { SS } 304,316 \\
\text { SS } 304,316 \\
\text { SS } 304 \\
\text { SS } 304 \\
\text { SS } 304 \\
\text { SS } 304,316\end{array}$ & $\begin{array}{l}H \\
H \\
H \\
H \\
H \\
D \\
D \\
D \\
D \\
D, T \\
D, T \\
T \\
T \\
T \\
T \\
T\end{array}$ & $\begin{array}{l}600-1000 \\
812-1190 \\
373-873 \\
663-780 \\
373-623 \\
273-873 \\
2300-400 \\
812-1190 \\
400-714 \\
298-500 \\
500-1173 \\
373-573 \\
298-498 \\
373-473 \\
298-495\end{array}$ & $\begin{array}{l}0.569 \\
0.540 \\
0.563 \\
0.526 \\
0.552 \\
0.642 \\
0.61 \\
0.521 \\
0.56 \\
0.53 \\
0.616 \\
0.588 \\
0.606 \\
.059 \\
0.63\end{array}$ & $\begin{array}{l}0.012 \\
0.00996 \\
0.0272 \\
0.0032 \\
0.00769 \\
0.18 \\
0.12 \\
0.00661 \\
0.0034 \\
0.0024 \\
0.017 \\
.0124 \\
0.018 \\
0.0072 \\
0.011\end{array}$ & $\begin{array}{l}\text { Grant et al. } 1987 \\
\text { Katsuta et al. } 1981 \\
\text { cited by Katsuta et al. } 1981 \\
\text { Namba, Yamawaki \& Kanno } 1984 \\
\text { Perng \& Altstetter } 1986 \\
\text { Braun et al. } 1980 \\
\text { Wilson \& Baskes } 1978 \\
\text { Katsuta et al. } 1981 \\
\text { cited by Langley } 1984 \\
\text { cited by Langley } 1984 \\
\text { cited by Langley } 1984 \\
\text { cited by Katsuta et al. } 1981 \\
\text { cited by Katsuta et al. } 1981 \\
\text { cited by Langley } 1984 \\
\text { cited by Langley } 1984\end{array}$ \\
\hline $\begin{array}{l}\text { SS } 316 \mathrm{~L} \\
\text { SS } 316 \mathrm{~L} \\
\text { SS } 316-\mathrm{ST} 1 \\
\text { SS } 316 \mathrm{~L} \\
\text { SS } 316 \\
\text { SS } 316 \mathrm{~L}\end{array}$ & $\begin{array}{l}H \\
H \\
H \\
D \\
T \\
T\end{array}$ & $\begin{array}{l}600-900 \\
873-1173 \\
423-723 \\
600-900 \\
603-853 \\
600-900\end{array}$ & $\begin{array}{l}0.619 \\
0.56 \\
0.48 \\
0.602 \\
0.663 \\
0.600\end{array}$ & $\begin{array}{l}0.0299 \\
0.013 \\
0.0047 \\
0.0174 \\
0.042 \\
0.0141\end{array}$ & $\begin{array}{l}\text { Reiter et al. } 1985 \\
\text { Kishimoto et al. } 1985 \\
\text { Hashimoto \& Kino } 1985 \\
\text { Reiter et al. } 1985 \\
\text { Sugisaki et al. } 1985 \\
\text { Reiter et al. } 1985\end{array}$ \\
\hline SS 316L & $\mathbf{T}$ & $500-873$ & 0.157 & $2.3 \times 10^{-6}$ & Shan et al. 1991 \\
\hline $\begin{array}{l}\text { Inconel } 750 \\
\text { Nimonic } 80 A \\
\text { Hastelloy } X \\
\text { Inconel } 600\end{array}$ & $\begin{array}{l}\mathrm{H} \\
\mathrm{H} \\
\mathrm{H} \\
\mathrm{H}\end{array}$ & $\begin{array}{l}873-1173 \\
873-1173 \\
873-1173 \\
873-1173\end{array}$ & $\begin{array}{l}0.55 \\
0.55 \\
0.45 \\
0.44\end{array}$ & $\begin{array}{l}0.016 \\
0.014 \\
0.0049 \\
0.0049\end{array}$ & $\begin{array}{l}\text { Kishimoto et al. } 1985 \\
\text { Kishimoto et al. } 1985 \\
\text { Kishimoto et al. } 1985 \\
\text { Kishimoto et al. } 1985\end{array}$ \\
\hline
\end{tabular}

Causey and Stack 1984 found that, "Gamma irradiation will have little or no effect on the diffusion of tritium in SS components of an operating fusion reactor. It may retard the release of tritium from components disposed of as nuclear waste by the creation of traps in the oxide layer." Doyle and Brice 1987 found that enhancement of permeation by ion bombardment was < $100 \%$ per dpa/day, maybe zero.

Causey, Steck, and Van Namen (1985) measured the following values for Prime Candidate Alloy: 


$$
\begin{aligned}
& D=0.46 \exp (-.71 \mathrm{eV} / \mathrm{kT}) \quad \mathrm{cm}^{2} / \mathrm{s} \\
& S=1.85 \times 10^{23} \exp (-0.109 \mathrm{eV} / \mathrm{kT}) \text { atoms } / \mathrm{m}^{3} \mathrm{~Pa}^{1 / 2}
\end{aligned}
$$

They found a correlation between chrome content and activation energy for solubility: alloys with higher $\mathrm{Cr}$ content had higher $\mathrm{E}_{\mathrm{s}}$.

Polosukhin et al. 1992 found that the diffusivity of stainless steels increased by a factor of 2-3 during neutron/gamma irradiation at a fast neutron flux of $1.8 \times 10^{14} / \mathrm{cm}^{2} \mathrm{~s}$. The activation energy decreased. The increase of diffusivity was greatest at lower temperatures.
unirradiated:
$D_{0}=8.4 \times 10^{-3} \mathrm{~cm}^{2} / \mathrm{s}$,
$E_{d}=0.713 \mathrm{eV}$

during irradiation:

$D_{0}=7.07 \times 10^{-4} \mathrm{~cm}^{2} / \mathrm{s}$,

$E_{d}=0.267 \mathrm{eV}$.

For general use with stainless steels and Inconels the composite values of Reiter et al (1993) are recommended:

SS 316L:

$D=5.9 \times 10^{-3} \exp (-0.54 \mathrm{eV} / \mathrm{kT}) \quad \mathrm{cm}^{2} / \mathrm{s}$

$\mathrm{S}=5.8 \times 10^{-6} \exp (-0.14 \mathrm{eV} / \mathrm{kT})$ atom fraction $/ \mathrm{Pa}^{1 / 2}$

For Inconel 625:

$D=0.022 \exp (-0.60 \mathrm{eV} / \mathrm{kT}) \quad \mathrm{cm}^{2} / \mathrm{s}$

$S=2.2 \times 10^{-6} \exp (-0.11 \mathrm{eV} / \mathrm{kT})$ atom fraction $/ \mathrm{Pa}^{1 / 2}$

\section{Permeability}

According to Le Claire, austenitic stainless steel permeabilities are insensitive to composition variations, and the equation

$$
P=0.0233 \exp (-0.681 \mathrm{eV} / \mathrm{kT}) \quad \mathrm{cc}(\mathrm{STP}) / \mathrm{cm} \mathrm{s} \mathrm{atm}^{1 / 2}
$$

fits all clean-surface stainless steel results within about $\pm 50 \%$. For Inconels 600,617 , and 625 with clean surfaces the equation

$$
P=0.057 \exp (-0.694 \mathrm{eV} / \mathrm{kT}) \quad \mathrm{cc}(\mathrm{STP}) / \mathrm{cm} \mathrm{s} \mathrm{atm}^{1 / 2}
$$

has accuracy better than $\pm 50 \%$. (LeClaire 1983 and 1984). Many similar permeability values are found in the references listed below. Oxide layers greatly impede permeation.

\section{Solubility}

Solubility can be computed from the ratio of permeability to diffusivity: $S=P / D$.

It can also be measured directly, by measuring the uptake during soaking in hydrogen for a time long enough to come to equilibrium. The solubility may be represented by the equation

$$
S=S_{0} \exp \left(-E_{S} / k T\right)
$$

where $E_{s}=$ heat of solution.

A few equations for solubility are given in Table 3.2. 
Table 3.2. Solubility data from various experiments.

\begin{tabular}{|c|c|c|c|c|c|}
\hline Materials & Temp $\mathrm{K}$ & $E_{\text {s. }} \mathrm{eV}$ & $S_{0}$ & Units & Source \\
\hline SS $316+T$ & 703.903 & 0.106 & 0.194 & $\mathrm{~mol}\left(\mathrm{~T}_{2}\right) / \mathrm{m}^{3} \mathrm{~Pa}^{1 / 2}$ & Sugisaki et al. 1984 \\
\hline SS $304+H$ & $873-1173$ & 0.148 & 0.228 & $\mathrm{~mol}\left(\mathrm{H}_{2}\right) / \mathrm{m}^{3} \mathrm{~Pa}^{1 / 2}$ & Katsuta et al.1981 \\
\hline SS $304+D$ & $873-1173$ & 0.165 & 0.245 & $\mathrm{~mol}\left(\mathrm{H}_{2}\right) / \mathrm{m}^{3} \mathrm{~Pa}^{1 / 2}$ & Katsuta et al.1981 \\
\hline$S S+H$ & not stated & 0.11 & 0.201 & $\mathrm{~mol}\left(\mathrm{H}_{2}\right) / \mathrm{m}^{3} \mathrm{~Pa}^{1 / 2}$ & Langley 1984 \\
\hline
\end{tabular}

There is a wide range of heats of solution for hydrogen isotopes in stainless steels in the literature: $0.106,0.121,0.148,0.155,0.165,0.186,0.191,0.211,0.269$, and $0.288 \mathrm{eV}$. The large difference may be partly due to variations in alloy compositions. (Sugisaki et al. 1984)

\section{Soret Effect}

For stainless steels the heat of transport $Q^{*}=-0.065 \mathrm{eV}$. (Baskes 1982) For negative $Q^{*}$ (as for stainless steels) diffusion is to the hotter region, so the Soret effect may reduce permeation through the fusion reactor walls.(Brice \& Doyle 1984; Langley 1984) This account should be taken into account when estimating permeation losses from fusion reactors.

\section{Recombination Coefficient}

According to Wilson (1981) measurements of $k_{r}$ vary with $1000 / T$ as predicted by Baskes, with various sticking coefficients $\alpha$. The values of $k_{r}$ are sensitive to the ion energy distribution and to the surface conditions, such as oxygen concentration. At higher metal temperatures, the traps are thermally depopulated, and recombination may become the ratelimiting process.

In studying SS 304 at 401-1055 K Børgeson et al. (1986). derived $\mathrm{k}_{\mathrm{r}}$ from re-emission data and from permeation data. Their graph of $k_{r}$ vs. 1000/T appeared to be consistent with the Baskes model. (Their comparison with the Pick and Sonnenberg model used $E_{c}=0$, which is not correct for a dirty surface.) A dirty surface had apparent $k_{r}$ values that are $100-10^{4}$ times lower than predicted for a clean surface. Varying pressures of $\mathrm{H}_{2}$ and $\mathrm{H}_{2} \mathrm{O}$ did not affect scatter of data.

A few values of $k_{r}$ used by various researchers are given below:

$$
\begin{array}{lll}
\mathrm{k}_{\mathrm{r}}=5.4 \times 10^{-19} \exp (-0.1262 \mathrm{eV} / \mathrm{kT}) & \text { molecules } \mathrm{cm}^{4} / \mathrm{atom}^{2} \mathrm{~s} & \text { Braun } 1990 \\
\mathrm{kr}=3.2 \times 10^{-19} \exp (-0.582 \mathrm{eV} / \mathrm{kT}) & \text { molecules } \mathrm{cm}^{4} / \text { atom }^{2} \mathrm{~s} & \text { Reiter } 1991 \\
\mathrm{k}_{\mathrm{r}}=1.5 \times 10^{-15} \exp (-1.0 \mathrm{eV} / \mathrm{kt}) \quad \mathrm{cm}^{4} / \mathrm{s} & \text { Doyle \& Brice } 1987 \\
\mathrm{k}_{\mathrm{r}}=1.3 \times 10^{-17} \exp (-.81 \mathrm{eV} / \mathrm{kT}) \mathrm{cm}^{4} / \mathrm{s} \quad \text { electropolished surface } & \text { Myers \& Wampler } 1982
\end{array}
$$


$k_{r}=9.6 \times 10^{-20} \exp (-0.34 \mathrm{eV} / \mathrm{kT}) \mathrm{cm}^{4} / \mathrm{s}$ ion sputtered surface Myers \& Wampler 1982

There was a big difference between the clean electropolished surface results of Myers \& Wampler and their results for a sputtered surface.

Winter et al. 1982 developed a probe with a $0.05 \mathrm{~mm}$ thick pure Fe membrane to measure hydrogen atom flux to the walls of a plasma device. They found that in some cases particle bombardment decreased the permeation flux, which was probably associated with an increase of $\mathrm{k}_{\mathrm{r} 1}$ on upstream side by bombardment cleaning or texturing of the surface.

Measurements of deuterium surface concentration are possible sources of error in $k_{r}$, including near-surface trap sites produced by ion bombardment and oxides. (Braun 1980)

\section{Surface Effects}

Yamawaki et al. 1987 sputter cleaned a $50 \mu \mathrm{m}$ SS 304 foil, measured the surface contamination measured by Auger Electron Scattering, implanted with $3 \mathrm{keV}$ deuterons, and measured the permeation. They found a good correlation of permeation rate with $\mathrm{O}$ and $\mathrm{Si}$ impurity concentrations, but not with $N$ or $P$ impurities.

The values of $k_{r}$ found by Yamawaki et al. 1989 were somewhat closer to predictions of Pick and Sonnenberg equation than those of the Baskes equation. As the surface oxygen concentration was increased from 0 to $20 \%, k_{r 1}$ decreased from $10^{-16}$ to $10^{-18} \mathrm{~cm}^{4} / \mathrm{s}$ as shown in Figure 3.1 . This was represented approximately by

$$
k_{r}=k_{r o} \exp \left(-\eta c_{i}\right)
$$

where $\eta=-0.21$ for oxygen on $304 \mathrm{SS}$, and $c_{j}$ is the impurity (oxygen) concentration, percent. The impurity presence increased $2 E_{c}$, the activation energy of hydrogen chemisorption.

Permeation is strongly influenced by surface roughness. Mechanical polishing reduced the permeation rate by a factor of four from the as-machined condition, and electropolishing, by a factor of twelve. Surface oxidation also tends to make the underlying metal surface smoother. Cold working increases the hydrogen solubility at low temperatures, but has little effect above $300^{\circ} \mathrm{C}$. (Dickson 1990) 


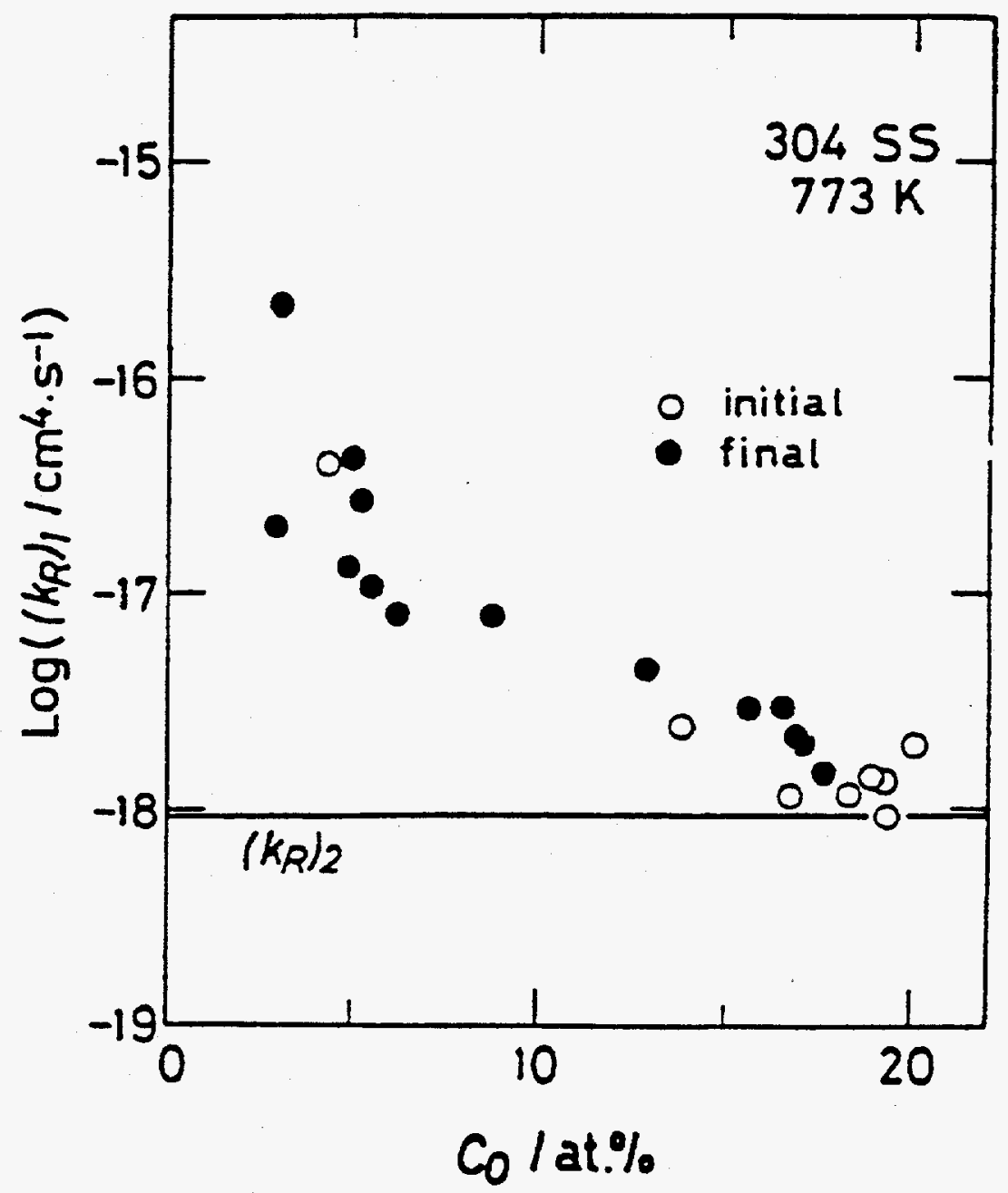

Figure 3.1. Variation of upstream surface recombination coefficient $k_{r 1}$ with oxygen surface contamination fraction $C_{0}$ measured by Yamawaki et al. 1989. 
Stone 1981 reviewed surface coating techniques and effectiveness. Gaseous additives to $\mathrm{H}_{2}$ (ethylene, ethane, $\mathrm{SO}_{2}, \mathrm{CS}_{2}, \mathrm{CO}, \mathrm{CO}_{2}$ ) reduced its permeation rates by factors of 10-50. probably by interfering with surface recombination of hydrogen atoms. Stone tested many sample surface preparation techniques and coatings, and listed the resulting permeabilities.

Surette and McElroy (1988) measured the effectiveness of surface swipes for removal of adsorbed tritium and found that the average removal per swipe, one day apart, was $9.6 \%$ of remaining tritium. Much was collected as $\mathrm{HTO}$, although the exposure had been to $T_{2}$.

Hirabayashi and Saeki (1984) exposed samples to $13.3 \mathrm{kPa}$ of tritium for 7 days at $298 \mathrm{~K}$. About $10^{19} \mathrm{HTO}$ molecules $/ \mathrm{m}^{2}$ became weakly bound on surface. This corresponds to the number of active sites for adsorption on the surface of transition metals. The tightly bound tritium is about $10 \%$ of this amount.

Hirabayashi, Saeki, and Tachikawa (1986) found that gamma irradiation increased the amount of tritium adsorbed from $1.7 \times 10^{16}$ atoms $/ \mathrm{m}^{2}$ (no dose) to $4 \times 10^{16}$ atoms $/ \mathrm{m}^{2}$ at a dose of 100 kGy. Passivation of a surface by oxidation in air at $423-773 \mathrm{~K}$ for $6-24 \mathrm{~h}$ reduced the tritium adsorption by from $8.3 \times 10^{18}$ (no passivation) down to about $4 \times 10^{18} / \mathrm{m}^{2}$. (Hirabayashi et al. 1989)

Johnson (1989) defined a thickness $L_{x}=D / 2 k_{r} c_{\theta}$ above which flow becomes limited by bulk diffusion, instead of recombination. For an ion sputtered SS 316 surface this thickness is 600 $\mathrm{nm}$, and for an electropolished surface, $80 \mu \mathrm{m}$. The parameter $L_{x}$ is related to the parameter $W$ defined in conjunction with Figure 3.

Electron impact on $\mathrm{H}_{2}$ at or near the surface can dissociate the $\mathrm{H}_{2}$ and increase permeation rates. A positive bias on a sample increased the hydrogen permeation rate. (Kim et al. 1992; Okamoto et al. 1988)

Swansiger and Bastasz (1979) found that oxide films 4-15 nm thick on SS reduced permeabilities by $2-3$ orders of magnitude. The upstream surface effects were rate-limiting (determined by comparison with Pd coatings on some samples). Oxides had high activation energies, up to $0.9 \mathrm{eV}$.

Oxygen increases the ratio $D / 2 \sigma \mathrm{k}_{r}$, while carbon decreases it. Vacancy loops caused by ion bombardment may provide easier paths for tritium transport to the metal surface. Surface defects may catalyze recombination of $\mathrm{H}$. Hydrogen atoms may also be ejected by incident particles. (Sharapov et al. 1986)

Aitchison et al (1993) found that exposure to 0.2 Torr of oxygen reduced deuterium permeation through initially clean 403 SS by two orders of magnitude.

\section{Trap Site Characterization and Effects}

Wilson (1979) reviewed hydrogen trapping studies and cited several previous reviews that are not cited here. The trapped fraction of the incident ion beam starts out near one, but falls to zero after the fluence exceeds some saturation value. The saturation fluence decreases with increasing steel temperature. Surface blistering is observed only at low temperatures and high fluences. Above room temperature hydrogen diffusion prevents accumulation of hydrogen in blisters. The data are fit by a model with $E_{d}=0.6 \mathrm{eV}$ and a trapping depth $\sim 0.3 \mathrm{eV}$. At $T>500$ $K$ hydrogen rapidly diffuses out of stainless steels, due to thermal detrapping. Hydrogen 
trapping in nickel alloys, such as inconels, is similar to that in stainless steels, with an even lower trapped fraction of the implanted ion beam at room temperature.

Table 3.3 summarizes some observations of trapping energies induced in stainiess steel samples.

In a comparison of trapping in various materials Wilson and Pontau (1979b) implanted deuterons at $3.3 \mathrm{keV} /$ atom to a standard fluence of $10^{22} / \mathrm{m}^{2}$, then observed emission during thermal ramp desorption at $1.2 \mathrm{~K} / \mathrm{s}$ to $875 \mathrm{~K}$. Depth profiles were measured by nuclear reaction analysis. Inconel 625 retained an order of magnitude less deuterium than stainless steel 304 at $300 \mathrm{~K}$, about a factor of two less at $450 \mathrm{~K}$. This may be related to the high diffusivity of hydrogen in nickel.

Wilson (1981) reviewed hydrogen recycling from the walls of plasma experiments.

First deuterium was implanted, then it was replaced by implanting protium. Gas retained in the target by ion bombardment was well represented by a model having two exponential functions representing trapping sites. The maximum fluence was $1.5 \times 10^{22} \mathrm{~m}^{-2}$. The two cross sections probably represented trapping sites with different locations or energies. For stainless steel $\sigma_{1}$ had a peak of $0.7 \times 10^{-20} \mathrm{~m}^{2}$ at $200 \mathrm{eV}$ and $\sigma_{2}$ about $5 \times 10^{-22} \mathrm{~m}^{2}$ at $400 \mathrm{eV}$. Several possible mechanisms were discussed, but none was clearly indicated by the data. (Abbas 1992)

Deuterium implanted at $1-14 \mathrm{keV}$ and $150 \mathrm{~K}$ reached saturation at $0.5-3 \times 10^{22} / \mathrm{m}^{2}$, depending on energy. Replacement of $D$ by $H$ and vice-versa was represented by a 2-exponential-function equation, limited by detrapping. $\sigma_{1}\left(R_{p}+\Delta R_{p}\right)$ and $\sigma_{2}\left(R_{p}+\Delta R_{p}\right)$ were roughly independent of energy. Both types of traps were probably distributed uniformly with depth. (Blewer et al. 1978)

A trap activation model related trap site creation to irradiation damage by ions and neutrons. The trap density

$$
N_{T}=\gamma N_{F} /\left(1+\gamma N_{F} / N_{S}\right) \sim \gamma N_{F} \sim 2.5 \times 10^{24} \mathrm{~m}^{-3}=25 \text { appm. }
$$

The trap binding energy from $1 \mathrm{keV} D$ injection was about $0.3 \mathrm{eV}$; and from He injection $\sim 0.5$ $\mathrm{eV}$; expected release at $300-500 \mathrm{~K}$. There may also have been deeper traps at $>0.9 \mathrm{eV}$ with lower concentrations $\sim 10^{-4}$. (Brice 1982) 
Table 3.3. Trapping induced in stainless steel specimens.

\begin{tabular}{|c|c|c|c|c|c|c|c|}
\hline \multirow[b]{2}{*}{ ion } & \multirow{2}{*}{$\begin{array}{l}\text { energy } \\
\text { keV }\end{array}$} & \multirow{2}{*}{$\begin{array}{l}\text { fluence } \\
10^{2}=/ \mathrm{m}^{2}\end{array}$} & \multirow{2}{*}{$\begin{array}{l}\text { trap } \\
\text { enerayev }\end{array}$} & \multirow{2}{*}{$\begin{array}{l}\text { conc. } \\
\%\end{array}$} & \multicolumn{2}{|c|}{$\begin{array}{l}\text { Desorption } \\
\text { Temp. }\end{array}$} & \multirow[b]{2}{*}{ Reference } \\
\hline & & & & & ${ }^{\circ} \mathrm{C}$ & remarks & \\
\hline D & $1-5$ & 100 & $\begin{array}{l}0.8 \\
0.89\end{array}$ & & $\begin{array}{l}90 \\
160 \\
220 \\
300\end{array}$ & $\begin{array}{l}\text { vacancies } \\
\text { impurity } \\
\text { dislocations } \\
\text { clusters }\end{array}$ & Yoshida $1988-8$ \\
\hline D & 7.3 & 6 & $\begin{array}{l}0.30 \\
0.32\end{array}$ & $\begin{array}{l}0.017 \\
0.025\end{array}$ & & $\begin{array}{l}\text { SS } 304 \\
\text { SS } 316\end{array}$ & $\begin{array}{ll}\text { Scherzer } 1986 \\
\text { Scherzer } 1986\end{array}$ \\
\hline D & 1 & 50 & 0.64 & & 150 & SS 304 & Thomas 1980 \\
\hline D & $\begin{array}{l}1 \\
10\end{array}$ & $\begin{array}{l}100 \\
100\end{array}$ & $\begin{array}{l}0.29 \\
0.26\end{array}$ & $\begin{array}{l}1 \\
2\end{array}$ & $\begin{array}{l}380 \\
340\end{array}$ & $\begin{array}{l}\text { SS } 316 \\
\text { SS } 316\end{array}$ & $\begin{array}{l}\text { Wilson } 1978 \\
\text { Wilson } 1978\end{array}$ \\
\hline $\begin{array}{l}{ }^{3} \mathrm{He}^{+} \\
\text {and D }\end{array}$ & $\begin{array}{l}300 \\
1\end{array}$ & $\begin{array}{l}10 \\
100\end{array}$ & 0.34 & 0.25 & 460 & SS 316 & Wilson 1978 \\
\hline$D$ & 6 & & $\begin{array}{l}0.1 \\
0.3\end{array}$ & $<1$ & & & Wilson 1981 \\
\hline$D$ & 3.3 & 100 & $\begin{array}{l}0.9 \\
0.5-06\end{array}$ & $\begin{array}{l}\text { near-s } \\
\text { bulk }\end{array}$ & surface & $\begin{array}{l}\text { SS } 304 \\
\text { SS } 304\end{array}$ & $\begin{array}{l}\text { Wilson } 1979 \\
\text { Wilson } 1979\end{array}$ \\
\hline D & 2 & 10 & 0.8 & 2 & & & Pontau 1982 \\
\hline $\begin{array}{l}{ }^{3} \mathrm{He}^{+} \\
\text {and D }\end{array}$ & $\begin{array}{l}8 \\
2\end{array}$ & $\begin{array}{l}1 \\
300\end{array}$ & 1.0 & 0.33 & & SS 304LN & Pontau 1982 \\
\hline $\begin{array}{l}{ }^{3} \mathrm{He}^{+} \\
\text {and D }\end{array}$ & $\begin{array}{l}8 \\
2\end{array}$ & $\begin{array}{l}10 \\
300\end{array}$ & 1.05 & 0.75 & & SS 304LN & Pontau 1982 \\
\hline $\begin{array}{l}{ }^{3} \mathrm{He}^{+} \\
\text {and D }\end{array}$ & $\begin{array}{l}100 \\
2\end{array}$ & $\begin{array}{l}1 \\
300\end{array}$ & 1.07 & 0.1 & & SS 304LN & Pontau 1982 \\
\hline $\begin{array}{l}{ }^{3} \mathrm{He}^{+} \\
\text {and D }\end{array}$ & $\begin{array}{l}100 \\
2\end{array}$ & $\begin{array}{l}10 \\
300\end{array}$ & 1.07 & 0.4 & & SS 304LN & Pontau 1982 \\
\hline $\begin{array}{l}{ }^{3} \mathrm{He}^{+} \\
\& 4 \mathrm{He} \\
\& \mathrm{D}\end{array}$ & $\begin{array}{l}750 \\
15 \\
15\end{array}$ & $\begin{array}{l}6 \\
4 \\
1\end{array}$ & $\begin{array}{l}0.42 \\
0.22\end{array}$ & $\begin{array}{l}\text { He tra } \\
\text { vacanc }\end{array}$ & & SS 304 & Myers 1983 \\
\hline
\end{tabular}




\section{Porosity}

The oxide surface was covered with many pores about $0.5 \mu \mathrm{m}$ diameter, especially along the grain boundaries of the oxide. These pores were preserved at the same positions even after the specimen surface was etched down to the oxide-substrate boundary, revealing that the pores penetrated through the whole oxide film. (Namba, Yamawaki, and Kanno 1984)

\section{Permeation in layered structures}

Coatings of $\mathrm{Au}, \mathrm{W}, \mathrm{Al} 2 \mathrm{O} 3$, or $\mathrm{Si} 10 \mu \mathrm{m}$ thick could in principle reduce permeation by many orders of magnitude.(Baskes 1982) Oxide films could potentially reduce permeation by many orders of magnitude, but they have not achieved their potential in practice. Cracks permit hydrogen penetration. Alloys with a few $\%$ Al have been tried, since $\mathrm{Al}_{2} \mathrm{O}_{3}$ has low permeability. With Fe-20Cr-5Al, initial reduction was three orders of magnitude. Thermal cycling destroyed the barrier, but reoxidation restored it. Aluminum coatings are not as effective as $\mathrm{Al}$ in the bulk at producing lasting protection. Including $0.3 \%$ of $\mathrm{Y}$ helped stabilize the alumina film. Use of a low-solubility coating downstream has also been tried. (Kerst and Swansiger 1984)

Films were applied by chemical vapor deposition. The measured permeability of deuterium through SS $316 \mathrm{~L}$ was reduced by five orders of magnitude after application of TiN and TiC films $2.5 \mu \mathrm{m}$ thick. The resulting permeability was

$P=3.3 \times 10^{-9} \exp (-0.811 \mathrm{eV} / \mathrm{kT}) \quad \mathrm{mol} /\left(\mathrm{m} \mathrm{s} \mathrm{MPa}^{1 / 2}\right)$ with the barrier film present. (Shan et al. 1992)

Hirabayashi et al. (1990 and 1991) found that a coating of $\mathrm{Cr}$ on the surface of SS 316 reduced its tritium adsorption by a factor of 2-2.5, and an order of magnitude reduction of tritium sorption could be attained by a diffusion-coated surface from bath containing $\mathrm{Cr}, \mathrm{NH}_{4} \mathrm{Cl}$, and $\mathrm{Al}_{2} \mathrm{O}_{3}$.

Riehm (1990) found that $\mathrm{NiAl}_{\mathbf{x}}$ layers grown on $\mathrm{Ni}$ are good permeation barriers. Such barriers might also be attainable on SS.

\section{Transport along grain boundaries}

Calder et al. 1973 measured tritium concentration profiles to study grain boundary diffusion. The models of Fisher, Whipple, and Suzuoka predict $b=1,4 / 3$, and $6 / 5$, respectively, in the depth profile equation $C(y)=C_{0} \exp \left(-A y^{b}\right)$. A least squares fit gave $b=1.07 \pm 0.23$, which could fit any of those theories. The results for Fisher and Suzuoka models, respectively are: $D_{0}$ $=0.697$ and $0.517 \mathrm{~m}^{2} / \mathrm{s}, \mathrm{Ed}=0.45$ and $0.43 \mathrm{eV}$. These results differ by about $35 \%$. The diffusivity is about 8 orders of magnitude greater than bulk diffusion coefficient.

Grain-boundary diffusivity $\sim 10^{-10}$ to $10^{-5} \mathrm{~m}^{2} / \mathrm{s}$, which is much faster than ordinary diffusivity. Abraham et al. 1978 wrote the differential equation for grain-boundary diffusion and solved it numerically using measured values of average grain size and boundary width. They mapped tritium concentrations with autoradiographs. The experimentally measured diffusion was less rapid than predicted by the grainboundary diffusion model. This may have been due to grain surface barriers to tritium transport out of the grains, or to lower solubility in the grain boundary. 
J. Yao and J. R. Cahoon [Acta Metall. Mater. 39 (1991) 119] found that in Nickel (and therefore possibly in SS too) the grain boundaries do not act as a diffusion pipe for low concentrations of hydrogen; however, the grain boundary diffusion coefficient increased at large concentrations of hydrogen. Their paper on page 111 of the same journal describes the theory of grain boundary diffusion.

\section{Trapping and permeation at interfaces between materials}

Other than the information above on oxide films ("surface effects") and grain-boundary transport, no data were found.

\section{Hydrogen Diffusivities and Solubilities in Oxides}

Oxide films on SS had very low diffusivities.
For $\alpha-\mathrm{Fe}_{2} \mathrm{O}_{3}$
$D=0.18$ to $6.6 \times 10^{-16} \mathrm{~cm}^{2} / \mathrm{s}$.
For $\mathrm{Cr}_{2} \mathrm{O}_{3}$
$D=9.2 \times 10^{-16} \mathrm{~cm}^{2} / \mathrm{s}$.

The temperature of these measurements was not stated, so it was probably room temperature.(Piggott and Siarkowski 1972)

Grant, Cummings and Blackburn (1989) developed a mathematical model of hydrogen transport through oxide-coated metals and present permeation data. For SS 304

$$
\text { DS }=1.4 \times 10-11 \exp (-0.66 \mathrm{eV} / \mathrm{kT}) \quad \mathrm{mol} / \mathrm{m}-\mathrm{s}-\mathrm{Pa} . \quad(600-900 \mathrm{~K})
$$

Solubility data were not found.

\section{Assessment}

Many plasma experiments operate in the RD trapping regime, with upstream flow limited by surface recombination and downstream flow limited by diffusion, with trapping significant. Diffusivity, recombination coefficients, and trap site parameters are all needed to predict permeation rates and inventories.

Permeation rates and diffusivities of hydrogen in stainless steels can typically be calculated within factor about a factor of two at temperatures of $500-900 \mathrm{~K}$, and the values are not sensitive to the type of stainless steel. This is much better than the situation for beryllium. There is considerable disparity in the literature on the heat of solution $E_{s}$ for stainless steels. This value is needed as an input to the equation for the recombination coefficient.

For general use with stainless steels and Inconels the values of Reiter et al (1993) are recommended:

SS 316L:

$D=5.9 \times 10^{-3} \exp (-0.54 \mathrm{eV} / \mathrm{kT}) \quad \mathrm{cm}^{2} / \mathrm{s}$

$S=5.8 \times 10^{-6} \quad \exp (-0.14 \mathrm{eV} / \mathrm{kT})$ atom fraction $/ \mathrm{Pa}^{1 / 2}$

For Inconel 625:

$D=0.022 \exp (-0.60 \mathrm{eV} / \mathrm{kT}) \quad \mathrm{cm}^{2} / \mathrm{s}$

$S=2.2 \times 10^{-6} \exp (-0.11 \mathrm{eV} / \mathrm{kT})$ atom fraction $/ \mathrm{Pa}^{1 / 2}$ 
The work of Yamawaki et al. (Figure 5 above) helps to quantify the variation of $k_{r}$ with surface impurity content.

Surface coatings and oxide layers have achieved permeation reduction factors of 100-1000 in most cases, with one experiment (Shan et al. 1992) reporting five orders of magnitude.

Durable tritium barriers need to be developed and verified under conditions of radiation damage and thermal cycling.

Several experiments have characterized the trap sites produced in stainless steels by cold work, ion bombardment, and impurities. The dependence of trap energy and concentration on bombardment species, energy, fluence, and temperature is beginning to be understood, but not yet complete.

The gradual replacement of one hydrogen isotope with another in the walls of a plasma experiment chamber is fairly well represented by present models.

One experiment reported porosity of the surface oxide layer. More information on possible porosity generation and effects is needed. Porosity is undesirable in layers that are supposed to act as tritium barriers, but desirable in the plasma-facing surface to permit rapid release of implanted tritium.

A few studies have shown that grain-boundary diffusion of tritium can occur in stainless steels at very rapid rates. More work is needed to clarify the conditions under which grain-boundary diffusion might occur in large tokamaks, such as ITER.

Only one study was found of hydrogen diffusivity in the oxides on stainless steel, and none of hydrogen solubility in the oxides.

Although the tritium diffusivity and permeability in stainless steels are fairly well characterized, most of the other parameters are not so well known. We recommend that an international committee be appointed to assess the situation for stainless steel use in ITER, to assign "best values" where feasible, and to recommend definitive experiments as needed to clarify various processes and parameters. 


\section{Copper And Copper Alloys}

\section{Introduction}

Copper and copper alloys are materials being considered for substrate applications in fusion devices. The primary reason for this stems from their high thermal conductivity. In this application, the plasma-facing component would comprise a suitable plasma-facing material (beryllium, carbon, etc.) bonded to a copper substrate or backing that provides structural integrity. To maintain acceptable temperatures of the plasma-facing material, the copper would be actively cooled.

One aspect of the evaluation of these materials for use in fusion application concerns the material properties for hydrogen transport and retention. Some plasma-facing components will be exposed to high fluxes of hydrogenic (deuterium, tritium) species with the potential for building up significant inventories of these species or transporting them through to the coolant stream. Quantitative estimates of the tritium retained in plasma-facing compounds and that released to coolant streams are required to support safety and environmental analyses for ITER.

In this document, we provide an up-to-date summary and evaluation of the hydrogen transport and retention properties for copper and copper alloys. This information was gleaned from technical reports, journal articles, review papers, and reference books that have been published primarily in the past $20-30$ years. The presentation of this information is arranged according to the following topics: (1) diffusivity, (2) solubility, (3) permeability, (4) effects of impurities and alloying elements, (5) trapping at structural defects, (6) surface effects, and (7) multiple-layered materials.

The following references provide an excellent background to the phenomena and material properties important to understanding hydrogen transport and retention in materials. Two classic references for general properties of hydrogen in materials are the two monographs edited by Alefeld and Völkl (Alefeld 1978a, 1978b). A more recent summary of hydrogen isotope permeability in materials is the report by Steward (Steward 1983). A detailed presentation of theoretical aspects of hydrogen diffusion in materials is the work of Fukai and Sugimoto (Fukai 1985). Lässer has published a recent handbook that focuses on tritium and

${ }^{3} \mathrm{He}$ in materials (Lässer 1989). Issues regarding ion-beam studies of hydrogen-metal interactions are reviewed by Meyers et al. (Meyers 1989). From the perspective of fusion technology development, the following references contain information of importance to understanding hydrogen interactions with materiais. Maroni and Van Deventer present, in some detail, material considerations in tritium handling systems (Maroni 1979). In a data compendium for plasma surface interactions, Wilson addresses hydrogen and helium trapping in materials (Wilson 1984). A formalism for evaluating steady-state hydrogen (tritium) inventory, recycle, and permeation in plasma-facing materials has been described in detail by Doyle and Brice (Doyle 1985). Additional information is tabulated in the reference by Souers (Souers 1985). All of these references served as important guides to the compilation and assessment of the information provided in the following sections.

\section{Hydrogen Diffusivity in Copper}

This section summarizes hydrogen diffusivity information for pure copper. The diffusivities have in general been obtained from two different measurement approaches: (1) equilibriumsaturation of hot, spherical or cylindrical specimens exposed to hydrogen gas at a known 
pressure followed by degassing of the specimens and measurements of the release rates for hydrogen, (2) measurements of the hydrogen permeability through a hot membrane that is exposed to hydrogen gas pressure or a hydrogen ion beam on one side of the membrane. Although both of the approaches are sensitive to surface oxide and bulk trapping effects that could compromise the measurements, precautions were taken in many studies to reduce these effects. Copper in many forms has been studied: single-crystal spheres and cylinders, and polycrystalline cylinders, spheres, and foils or membranes. In general the material was of very high purity.

We provide in Table 4.1 a summary of the relevant hydrogen diffusivity data for pure copper in terms of the pre-exponential, $D_{0}$, and the diffusion activation energy, $E_{S}$, for a standard Arrhenius expression. Both of the earlier data referenced, Eichenauer 1957 and Katz

Table 4.1. Diffusivity data for hydrogen in copper

\begin{tabular}{|c|c|c|c|c|}
\hline Beference & $\begin{array}{l}\text { Temperatur } \\
\text { Range (K) }\end{array}$ & Isotope & $\begin{array}{c}D_{0} \\
\left(\mathrm{~m}^{2} / \mathrm{s}\right) \\
\end{array}$ & $\begin{array}{l}E_{D} \\
(e V) \\
\end{array}$ \\
\hline Eichenauer 1957 & $700-920$ & $H$ & 1.1E-06 & 0.40 \\
\hline Katz 1971 & $720-1200$ & $\begin{array}{l}H \\
D \\
T\end{array}$ & $\begin{array}{l}(11.31-0.40) \mathrm{E}-7 \\
(7.30-1.05) \mathrm{E}-7 \\
(6.12-0.51) \mathrm{E}-7\end{array}$ & $\begin{array}{l}0.403 \pm 0.003 \\
0.382 \pm 0.10 \\
0.378 \pm 0.006\end{array}$ \\
\hline Perkins 1973 & $470-710$ & $H$ & $10.6 \mathrm{E}-07$ & 0.40 \\
\hline Tanabe 1987 & $290-1070$ & $D$ & 8.2E-08 & 0.24 \\
\hline $\begin{array}{l}\text { Eichenauer 1957: } \\
\text { Katz 1971: }\end{array}$ & \multicolumn{4}{|c|}{$\begin{array}{l}\text { Electrolytic Cu spheres,equilibrium absorption/thermal degas measurements. } \\
\text { High purity single crystal spheres, equilibrium absorption/thermal degas } \\
\text { measurements. }\end{array}$} \\
\hline $\begin{array}{l}\text { Perkins 1973: } \\
\text { Tanabe 1987: }\end{array}$ & \multicolumn{4}{|c|}{$\begin{array}{l}\text { OFHC polycrystalline copper membrane, gas-driven permeation measurement. } \\
\text { High purity polycrystalline membrane, ion-beam permeation measurement. }\end{array}$} \\
\hline
\end{tabular}

1971, were obtained from absorption/degas experiments for high purity copper spheres. Katz et al. used single-crystal material, whereas Eichenauer and Pebler used electrolyticallyrefined copper. Because both of these experiments were done at high temperatures, the influence from any bulk trapping phenomena was minimized. In contrast, the data reported in the table for Perkins 1973 was obtained from gas-driven permeation experiments using polycrystalline, oxygen-free high purity (OFHC) copper membranes (Perkins 1972). There is excellent agreement in the diffusivity data for these three experimental studies. In Table 1 we also identify more recent diffusivity data obtained by Tanabe et al. from a deuterium ionbeam driven permeation experiments for polycrystalline copper membranes (Tanabe 1987). The lower diffusivity and activation energy values in this work could be due to modification of the specimen surface or bulk by the $30-\mathrm{keV}^{+}$ions bombarding the specimen. A similar reduction in the diffusivity values was observed by Anderl et al. in ion-beam permeation 
experiments for OFHC copper (Anderl 1990). In that work, permeation transients were measured for 3-keV $\mathrm{D}_{3}{ }^{+}$implantation of copper specimens at $640 \mathrm{~K}$ and $720 \mathrm{~K}$. Simulation calculations were made to fit the measured permeation transients, with the results that the required diffusivity values were about one half those computed using the parameters determined by Katz 1971 for deuterium.

\section{Hydrogen Solubility in Copper}

Measurements of the solubility of hydrogen in copper have been made using one approach or variations of that approach. The method entails the following: (1) gas absorption: charging of a heated specimen to equilibrium saturation by exposing the specimen to a known pressure of hydrogen gas, (2) gas desorption (degassing): measuring the total quantity of hydrogen released from the hot specimen in a vacuum environment. Most measurements were done with large specimens at high temperatures to minimize the influence of surface adsorption and of bulk trapping effects on the solubility determination.

A summary of the relevant solubility data is given in Table 4.2. The table indicates the temperature range over which the measurements were made and the various gas pressures used. Often the experimenters used a range of pressures to verify that the quantities of released gas measured corresponded to solution in the metal according to Sieverts law, namely that the concentration was proportional to the square root of the gas pressure. The solubility data are given as parameters of an Arrhenius experience for which $S_{0}$ is the solubility pre-exponential and $E_{S}$ is the enthalpy of solution.

Table 4.2. Solubility data for hydrogen in copper

\begin{tabular}{|c|c|c|c|c|}
\hline Reference & $\begin{array}{l}\text { Temperature } \\
\text { Range (K) }\end{array}$ & $\begin{array}{l}\text { Pressure } \\
\text { Bange (MP }\end{array}$ & $\begin{array}{c}S_{0} \\
\left(H / m^{3}-P_{a}{ }^{1 / 2}\right.\end{array}$ & $\begin{array}{l}E_{S} \\
(e V)\end{array}$ \\
\hline Eichenauer 1957 & $700-920$ & 0.08 & $4.29 E 23$ & 0.37 \\
\hline Eichenauer 1965 & $700-920$ & $0.01-0.1$ & 5.24E23 & 0.39 \\
\hline Thomas 1967 & $770-1320$ & 0.1 & $1.94 \mathrm{E} 24$ & 0.51 \\
\hline McLellan 1973 & $870-1300$ & 0.1 & $3.10 \mathrm{E} 24$ & 0.57 \\
\hline Wampler 1976 & $770-1070$ & $0.1-9$ & 1.07E24 & 0.44 \\
\hline $\begin{array}{l}\text { Eichenauer 1957: } \\
\text { Eichenaver 1965: }\end{array}$ & \multicolumn{4}{|c|}{$\begin{array}{l}\text { Electrolytic copper spheres, equilibrium absorption/thermal degas } \\
\text { Single crystal cylinders, equilibrium absorption/thermal degas. }\end{array}$} \\
\hline \multicolumn{5}{|c|}{ Thomas 1967: Poly crystalline copper cylinders, absorption/thermal degas. } \\
\hline McLellan 1973: & \multicolumn{4}{|c|}{ MARZ grade cylinders, equilibrium absorption/thermal degas. } \\
\hline Wampler 1976: & \multicolumn{4}{|c|}{ Single crystal cylinders, equilibrium absorption/thermal degas. } \\
\hline
\end{tabular}


Minor variations of the absorption/degas method were used in the work identified in the table. In the works of Eichenauer 1957 and Eichenauer 1965, the specimen was maintained at high temperatures between the gas exposure time and the gas desorption measurements. During this transition time the experiment chamber was quickly evacuated and subsequently isolated so that the pressure rise during degassing could be measured. Hence these experiments required corrections to be made to account for hydrogen lost from the sample during the evacuation step. However, the experimenters could obtain both diffusivity and solubility information from their approach. In contrast, the experiments of Thomas 1967, McLellan 1973, and Wampler 1976 included a fast thermal quench of the specimens after the gas absorption step. This was then followed by the vacuum hot extraction of the gases in the specimen. Hence, losses of the hydrogen from the specimen during the transition from charging to degas were minimized.

More recently Swansiger 1988 conducted experiments to extend the measured solubility data base to lower temperatures. These experiments were done with a high pressure tritium solubility apparatus that was used to charge a specimen with tritium and quickly quench it to liquid nitrogen temperature. Tritium solubilities were determined by two different methods: (1) acid dissolution followed by liquid scintillation counting, and (2) vacuum fusion followed by ${ }^{3} \mathrm{He}$ analysis using mass spectrometry. Valid bulk solubility data were obtained using the acid dissolution techniques only after tritium in the surface oxide layer was removed by acid dissolution. Measurements at $473 \mathrm{~K}, 625 \mathrm{~K}$, and $673 \mathrm{~K}$ were consistent with the extrapolation of McLellan's high temperature data that covered the temperature range $870 \mathrm{~K}$ to $1300 \mathrm{~K}$.

\section{Hydrogen Permeability through Copper}

Steady-state flow of hydrogen through materials is often represented by its permeability for the material. As discussed in Steward 1983 and Perkins 1973, the permeability is the product of the diffusivity and solubility. Measurements of permeability are often obtained in permeation experiments for membrane samples. In such experiments one side of the membrane is exposed to hydrogen gas at a known pressure and the steady-state rate at which it permeates through the opposite surface is measured. For diatomic gases, the permeability, $P$, is given by:

$$
P=J_{S} d / A\left(p_{1} 0.5-p_{2}{ }^{0.5}\right)
$$

where $J_{S}$ is the steady-state flow through a specimen with area $A$ and thickness $d$ and the gas pressure is $p_{1}$ on the upstream side of the specimen and $p_{2}$ on the downstream side. Usually $p_{2}$ is considered to be zero. Similar to diffusivity and solubility, permeability is also represented by an Arrhenius expression with a prefactor $P_{0}$ and an activation energy $E_{p}$ where

$$
E_{p}=E_{d}+E_{s}
$$

In Table 4.3 we present relevant permeability data for hydrogen through copper. With the exception of the data for Eichenauer et al., all other permeability data shown were determined from gas-driven permeation experiments for membrane samples. The permeability values reported for the Eichenauer experiments correspond to calculations of the permeabilities based on diffusivities and solubilities that were determined in the experiments. All of the data show a good consistency between the permeability activation energies but significant variation in the permeability pre-exponentials. The data from Caskey 1976 corresponds to the fit of an Arrhenius expression to a large set of permeability data that were measured for several grades of commercial copper specimens with varying oxygen contents. The lower permeability preexponential could be due to surface oxides in the samples. Steward suggests that the values of Gorman 1962 and Perkins 1973 probably represent the best values for hydrogen permeability in pure copper. 
Table 4.3. Permeability data for hydrogen in copper

\begin{tabular}{|c|c|c|c|c|c|}
\hline Reference & $\begin{array}{l}\text { Temperature } \\
\text { Range (K) }\end{array}$ & $\begin{array}{c}\text { Pressure } \\
\left.\text { Bange (kP }{ }^{a_{2}}\right)\end{array}$ & Isotope & $\begin{array}{l}\text { Permeability } \\
\left(\mathrm{H} / \mathrm{m}-\mathrm{s}-\mathrm{Pa}^{1 / 2}\right)\end{array}$ & $\begin{array}{l}E_{p} \\
(\theta V)\end{array}$ \\
\hline Eichenauer 1957 & $700-920$ & & $H$ & 4.9E17 & 0.77 \\
\hline Eichenauer 1965 & $700-900$ & $0.013-0.1$ & $\begin{array}{l}H \\
D\end{array}$ & $\begin{array}{l}6.3 \mathrm{E} 18 \\
3.8 \mathrm{E} 18\end{array}$ & $\begin{array}{l}0.82 \\
0.83\end{array}$ \\
\hline Gorman 1962 & $620-970$ & 0.1 & $\mathrm{H}$ & 7.1E17 & 0.78 \\
\hline Belyakov 1968 & $800-1000$ & & H & $2.0 \mathrm{E} 18$ & 0.87 \\
\hline Perkins 1973 & $470-710$ & $0.000 B-0.13$ & H & $1.01 E 18$ & 0.80 \\
\hline Caskey 1976 & $370-720$ & $100-500$ & D & $7.0 E 16$ & 0.74 \\
\hline
\end{tabular}

Eichenauer 1957: Electrolytically refined Cu sphere.

Eichenauer 1965: ' Single crystal Cu cylinder.

Gorman 1962: Polycrystalline membrane.

Belyakov 1968: Polycrystalline membrane.

Perkins 1973: Polycrystalline membrane.

Caskey 1976: $\quad$ Poly crystalline membrane.

\section{Effects of Impurities and Alloying Elements}

The presence of impurities and alloying elements can have a significant effect on hydrogen transport and retention in materials and on material properties. As discussed in detail by West in Alefeld 1978b, impurities can contribute to hydrogen trapping in a material. For example, interstitial $\mathrm{O}, \mathrm{N}$, and $\mathrm{C}$ are known to trap hydrogen with trap energies of a few tenths of an $\mathrm{eV}$. Similarly, alloying elements that are hybrid formers can serve as chemical trap sites for hydrogen. In general, indications of such trapping are a reduction in the hydrogen diffusivity for the material relative to the diffusivity in the pure host material, although the permeability may not be altered. In other words, the presence of impurities and alloying elements may significantly alter permeation transients but not change steady-state permeation rates. In addition, several varieties of hydrogen embrittlement of materials have been observed to be related to the strong attractive interaction between diffusing hydrogen and oxide inclusions or oxygen in solution (Caskey 1976). 
This section deals with the impact of impurities and alloying elements on hydrogen transport in copper. A detailed study of the influences of oxygen on hydrogen transport in copper has been reported by Caskey 1976. Wampler $1976 \mathrm{~b}$ has also investigated the influence of impurities on hydrogen transport. The influence of alloying elements on hydrogen transport in copper has been studied by a number of workers including the following: Belyakov 1968, Begeal 1978, Mitchell 1982a, and Mitchell 1982b. Relevant information from these papers in summarized in the following paragraphs.

Caskey 1976 investigated the influences of oxygen on hydrogen transport in copper by means of both solubility measurements and permeability/diffusivity measurements for many different types and commercial grades of copper. Types of copper studied (with oxygen levels indicated) included the following: high purity copper (1 ppm), OFHC and BD copper (10 ppm), low- and high- phosphorous copper (100 ppm), and ETP copper (200-400 ppm). The solubility measurements were made by exposing different cylindrical specimens at elevated temperatures (450K and $535 \mathrm{~K}$ ) to tritium gas at $69 \mathrm{MPa}$ or $0.1 \mathrm{MPa}$. Tritium concentrations in the exposed rods were measured by liquid scintillation counting of solutions obtained by acid dissolution of the specimens. For the samples exposed to $69 \mathrm{MPa}$ of $\mathrm{T}_{2}$, the whole rod was dissolved. Rods exposed at $0.1 \mathrm{MPa}$ were incrementally dissolved so that tritium concentration profiles in the specimens could by determined. The results of these measurements indicated that the average bulk tritium contents correlated with the nominal oxygen content and that the highest purity copper tested $(\sim 1 \mathrm{ppm}$ O) had a tritium content that corresponded to a value predicted using the solubility data by McLellan 1973. Caskey concluded that the lowest solubilities measured corresponded to lattice solubility and the additional tritium contents were associated with trapping at oxygen impurities. The concentration profile measurements indicated that a uniform bulk tritium concentration was not achieved during the exposure time for specimens with highest oxygen impurity levels. Based on a trapping analysis, Caskey concluded that the oxygen impurity interacted with and trapped diffusing tritium, thus causing the effective diffusivity to be smaller than that due to lattice diffusivity alone. Permeability and diffusivity measurements were made for membrane specimens exposed to deuterium gas. Measured permeabilities were a little less than previous measurements over the same temperature range (see Table 3). Permeation transients were not reproducible. However, the evolution transients following termination of steady-state permeation, were quite reproducible. These features are an indication of oxide films on the specimen surface and/or reactions of permeating hydrogen with dissolved oxygen or oxide inclusions. Deuterium diffusivities derived from the evolution transients were below extrapolations of published diffusivities obtained for high purity, single crystal material.

Wampler 1976b evaluated resistivity changes in copper specimens that were subjected to isochronal annealing measurements. By analyzing measurements for both pure copper and copper with impurities, Wampler and coworkers determined that hydrogen could trap at interstitial impurities. They determined a trap binding energy of $0.12 \mathrm{eV}$ for hydrogen binding to impurities.

The work of Belyakov 1968 used the gas-driven permeation technique to measure permeabilities and diffusivities for pure copper and copper with alloying elements over the temperature range $880 \mathrm{~K}$ to $1000 \mathrm{~K}$. Membrane specimens included the following: (1) pure copper, (2) oxidized and restored copper, (3) various bronzes $[\mathrm{Ca} / \mathrm{Sn} / \mathrm{P}, \mathrm{Cu} / \mathrm{Be}, \mathrm{Cu} / \mathrm{Si} / \mathrm{Mn}$, $\mathrm{Cu} / \mathrm{Al} / \mathrm{Fe}$, (4) $\mathrm{Cu}+1.5 \mathrm{wt} \% \mathrm{Si}$, and (5) $\mathrm{Cu}+3 \mathrm{wt} \% \mathrm{Si}$. A significant reduction in hydrogen permeabilities, relative to that for pure copper, was observed for alloys including $\mathrm{Sn}, \mathrm{Be}, \mathrm{Si}$, and Al. The authors concluded that the permeability reduction was due to the formation of thin (30 angstrom) oxides of the alloying elements on the upstream surface. The magnitude of the permeability reduction was related to the thermodynamic stability of the oxide of the alloying element, i.e., $\mathrm{Al}_{2} \mathrm{O}_{3}$ film on the $\mathrm{Cu} / \mathrm{Al} / \mathrm{Fe}$ alloy resulted in a permeability reduction of $1 / 100$ 
whereas that for $\mathrm{SiO}_{2}$ on $\mathrm{Cu} / \mathrm{Si} / \mathrm{Mn}$ resulted in a reduction of $1 / 6$ and that for $\mathrm{BeO}$ on $\mathrm{Cu} / \mathrm{Be}$ resulted in a reduction of $1 / 3$. Arrhenius curve fits to the permeability data indicated that the activation energy changed little $(0.87$ to $0.8 \mathrm{eV})$, whereas the pre-exponential varied by orders of magnitude. These changes in the hydrogen permeability for the alloys is indicative of the presence of the oxide films.

More recently (Begeal 1978), hydrogen and deuterium gas-driven permeation measurements were made for many copper alloy membranes in the temperature range $550 \mathrm{~K}$ to $830 \mathrm{~K}$.

Permeability measurements, made as a function of the gas pressure ranging from $0.01 \mathrm{MPa}$ to $0.1 \mathrm{MPa}$, indicated quite different response for the alloys. The first class of alloys included the following: $\mathrm{Cu}+5 \% \mathrm{Sn}, \mathrm{Cu}+2.3 \% \mathrm{Si}, \mathrm{Cu}+0.15 \% \mathrm{Zr}$,

$\mathrm{Cu}+4 \% \mathrm{Sn}+4 \% \mathrm{~Pb}+4 \% \mathrm{Zr}, \mathrm{Cu}+3 \% \mathrm{Si}$, and $\mathrm{Cu}+7 \% \mathrm{Al}+2 \% \mathrm{Fe}$.

For these alloys, the permeability curves manifested an Arrhenius behavior with little change in permeability activation energy but some reduction in the pre-exponential terms ( the authors concluded that this material had bulk metal permeation behavior). At 573K, the deuterium permeability was reduced by factors of 2.0,2.7, 4.5, 5.3, 5.9, and 7.0, respectively. Only the alloys containing $\mathrm{Si}$ and $\mathrm{Zr}$ had permeabilities varying slightly from the classical $\mathrm{P}^{0.5}$ dependence. For the copper alloy containing $0.15 \mathrm{wt} \% \mathrm{Zr}$, the pressure dependence " $\mathrm{n}$ " ranged from 0.57 to 0.62 , and the Arrhenius parameters for hydrogen permeation were determined to be $0.83 \mathrm{eV}$ for the activation energy and $3.8 \times 10^{17} \mathrm{H} /\left(\mathrm{m} \mathrm{s} \mathrm{Pa}^{\mathrm{n}}\right)$ for the pre-exponential. When $n=0.5$, permeation is limited by diffusion. When $n=1$, permeation is surface limited. For $0.5<n<1$, both bulk diffusion and surface effects play roles in determining the permeation rate. It is possible to work out both the bulk permeability and the effective recombination coefficient of both surfaces. (See Waelbroeck 1982 in App. B).

The second class of alloys (Begeal 1978) was the copper/gold braze alloy group that also exhibited bulk metal permeation behavior with a trend of decreasing permeability (increasing activation energies for permeation) with increasing gold content. For the last class of materials, including $\mathrm{Cu}+2 \% \mathrm{Be}$ and $\mathrm{Cu}+7 \% \mathrm{Al}+2 \% \mathrm{Si}$, the observed permeation measurements did not exhibit bulk metal permeation behavior. In fact, the permeability was controlled by surface oxide layers. For the CuBe alloy, the permeability at $690 \mathrm{~K}$ was $1 / 250$ that for pure copper. Similarly, for CuAlSi, the permeability reduction was $1 / 1000$ at $730 \mathrm{~K}$. The authors postulated that the mechanism for oxide growth was high-temperature reduction of nearby less stable oxides, simultaneous with oxidation of the active metal $\mathrm{Be}$ or Al by trace amounts of water in the hydrogen.

Mitchell 1982a has reported an extensive study of the influence of $\mathrm{Er}, \mathrm{Ti}, \mathrm{Zr}$, and $\mathrm{Cr}$ elements on hydrogen permeation properties of copper alloys containing these elements. The following alloys were studied: $\mathrm{Cu}+2 \% \mathrm{Er}, \mathrm{Cu}+4 \% \mathrm{Ti}, \mathrm{Cu}+4 \% \mathrm{Zr}$, and $\mathrm{Cu}+1 \% \mathrm{Cr}$. Deuterium gasdriven permeation measurements were made for specimens at temperatures ranging from $573 \mathrm{~K}$ to 973K. Both permeabilities and effective diffusivities were obtained by fitting the measured permeation transient data. For the $\mathrm{Cu}-\mathrm{Er}$ and $\mathrm{Cu}-\mathrm{Zr}$ specimens, the measured permeabilities were essentially identical to those for pure copper. However in both cases the derived diffusivities were between 10 and 100 times smaller than for those in pure copper over the temperature range $973 \mathrm{~K}$ to $573 \mathrm{~K}$. In addition, the permeabilities and diffusivities did not change as the gas pressure was varied from $1.33 \mathrm{kPa}$ to $133 \mathrm{kPa}$. Hence surface effects did not seem to affect deuterium transport through these materials. Rather the permeation was indicative of that which is influenced by bulk trapping. Assuming that the $\mathrm{Er}$ and $\mathrm{Zr}$ alloying elements were chemical trap sites, analysis of the effective diffusivities yielded $0.88 \mathrm{eV}$ and $0.83 \mathrm{eV}$ as estimates of the trap binding energies for $\mathrm{Er}$ and $\mathrm{Zr}$, respectively. Here, the trap binding energy corresponds to $\left(E_{T}+E_{D}\right)$ where $E_{D}$ is the activation energy for normal lattice 
deuterium diffusivity and $\mathrm{E}_{\mathrm{T}}$ is the energy of the diffusing species in the traps relative to that in the normal lattice. For these analyses, the trap density was set equal to the atom density of the alloying element and the assumption was made that each site could trap one deuterium atom.

In contrast to the above permeation measurements for $\mathrm{Cu}-\mathrm{Er}$ and $\mathrm{Cu}-\mathrm{Zr}$, the measured deuterium permeabilities and diffusivities for $\mathrm{Cu}-\mathrm{Ti}$ and $\mathrm{Cu}-\mathrm{Cr}$ indicated that surface oxide films were significant for these two materials. In both cases, the measured permeabilities were less than those for pure copper and they manifested some dependence on driving gas pressure, although the variation was greater for $\mathrm{Cu}-\mathrm{Ti}$ than for $\mathrm{Cu}-\mathrm{Cr}$. Measured deuterium diffusivities for $\mathrm{Cu}$-Ti were much less than those for pure $\mathrm{Cu}$, but those for $\mathrm{Cu}-\mathrm{Cr}$ did not deviate as much from pure $\mathrm{Cu}$ values. However, in both cases, the diffusivities were highly sensitive to the driving gas pressure. The authors concluded: surface-oxide effects were important in both cases, bulk trapping was significant in the case of $\mathrm{Cu}-\mathrm{Ti}$, and bulk trapping was not significant for $\mathrm{Cu}-\mathrm{Cr}$. Assuming a trap density equal to the atom density for $\mathrm{Ti}$, and one deuterium atom trapped per site, a trap energy of $0.75 \mathrm{eV}$ was estimated for $\mathrm{Ti}$ in $\mathrm{Cu}$.

In work related to that above, Mitchell 1982b, reported deuterium permeability and diffusivities obtained from gas-driven permeation experiments for membrane samples including: $\mathrm{Cu}+0.88 \% \mathrm{Er}, \mathrm{Cu}+0.042 \% \mathrm{Er}, \mathrm{Cu}+3.6 \% \mathrm{Zr}$ and $\mathrm{Cu}+6.40 \% \mathrm{Ti}$. The results of these measurements were similar to those reported earlier. Additional thermodesorption measurements were made for these specimens. These measurements determined average deuterium-to-dopant atomic ratios for various temperatures and exposure times for a deuterium gas pressure of $100 \mathrm{kPa}$. For the $\mathrm{Er}$ and $\mathrm{Ti}$ doped alloys, deuterium-to-dopant ratios varied from 0.1 to greater than 2, dependent on the exposure time. For the $\mathrm{Zr}$ doped material, the deuterium-to-dopant ratio was much smaller, ranging from 0.007 to about 0.04 for comparable exposure conditions.

\section{Trapping at Structural Defects}

Hydrogen transport and retention in materials is strongly influenced by trapping at structural defects like vacancies, interstitials, vacancy clusters, voids, dislocations, microscopic gas bubbles, etc., (see Ch 8 . Trapping of Hydrogen in Metals by Ch. A. West, Alefeld 1978b). A methodology for treating trapping in materials and brief summaries of trapping information in fusion-relevant materials is found in the article by Wilson 1984. A detailed treatment of trapping as it relates to ion/solid interactions has been published by Meyers 1989 .

In the following paragraphs we summarize the relevant information in the literature as it relates to trapping in copper and copper alloys for fusion applications. All engineered materials have intrinsic defects like dislocations and grain boundaries that are due to processing and fabrication techniques. Caskey 1973 has investigated hydrogen transport and trapping in coldrolled copper. Grain-boundary diffusion has been studied by Maienschein 1983 and 1988 and by Robinson 1960 . Precipitation of hydrogen into microscopic bubbles in copper has been studied by Wampler 1976 and by Johnson 1977 and 1978. Defect trapping in ion-implanted copper has been investigated in detail by Wilson 1987 and by Besenbacher 1984. Wilson 1987 provides a comprehensive bibliography of additional papers dealing with hydrogen trapping in hydrogen-implanted copper. The influence of neutron-induced radiation damage on hydrogen transport and trapping in copper has been studied by Yamakawa 1992 and Shimomura 1992. Relevant information on hydrogen trapping, as gleaned from these references, follows.

Information on grain-boundary diffusion of hydrogen has been obtained from experiments with copper specimens at low temperatures. Robinson 1960 studied diffusion in deuteriumimplanted copper specimens at temperatures ranging from $230 \mathrm{~K}$ to $293 \mathrm{~K}$. Specimens included 
high purity polycrystalline copper (99.999\%), single crystal copper from the melt of the high purity material, and OFHC grade copper. Diffusion in the specimens was studied by counting neutrons from the $D(d, n)^{3} \mathrm{He}$ reaction. Lower diffusion coefficients were obtained from experiments with the single crystal material than from experiments with high-purity polycrystalline material. The authors concluded that grain-boundary diffusion with an activation energy of $0.12 \mathrm{eV} /$ atom was responsible for the higher diffusivity in the high purity polycrystalline copper.

Maienschein 1985 and 1988 used a tritium gas-driven permeation approach to measure the permeabilities of tritium in various grades of copper at relatively low temperatures (323K, $373 \mathrm{~K}$, and $443 \mathrm{~K}$ ). In the earlier work, specimens of unannealed polycrystalline high purity copper $(99.999 \%)$ with palladium coated surfaces were used. Measured permeabilities at $373 \mathrm{~K}$ and $443 \mathrm{~K}$ with these specimens were in reasonable agreement with the works of others, although the permeability activation energy of $0.67 \mathrm{eV}$ was somewhat less. Both annealed and single crystal specimens were studied in the latter work for which measurements at $323 \mathrm{~K}$ and $373 \mathrm{~K}$ were made. A notable increase in grain size resulted for the annealed specimen. Measured permeabilities of the annealed specimen were $1 / 10$ that for the unannealed material. At $323 \mathrm{~K}$, the permeability for the annealed copper was the same as that for the single crystal specimen, whereas at $373 \mathrm{~K}$, the permeability for the single crystal material was slightly lower than that for the unannealed specimen. The authors concluded that the permeability reduction with annealing and its compatibility with single crystal data implied that, at the low temperature, hydrogen transport took place along the grain boundaries. A permeability characterized by an activation energy of $0.56 \mathrm{eV}$ and a pre-exponential of $1.7 \mathrm{E} 14 \mathrm{H} / \mathrm{m} \mathrm{s} \mathrm{Pa} .5$ was determined by this work.

Resistivity measurements and optical and electron microscopy investigations were made by Wampler 1976 to study precipitation and trapping of hydrogen in copper. The resistivity investigation entailed hydrogen loading of high purity single crystal specimens at temperatures between $873 \mathrm{~K}$ and $1273 \mathrm{~K}$ followed by a fast quench to $123 \mathrm{~K}$ and subsequent isochronal and isothermal resistivity annealing measurements. These measurements indicated that supersaturated solutions of hydrogen in copper return to thermodynamic equilibrium either by diffusion through the surface or by precipitation into microscopic bubbles within the metal at temperatures between $273 \mathrm{~K}$ and $323 \mathrm{~K}$. The activation energy for migration of hydrogen to the bubbles was determined to be $0.45 \mathrm{eV}$, the activation energy of the diffusion coefficient obtained from high temperature diffusivity measurements. Optical and electron microscopic analyses were made for both single crystal and polycrystalline samples loaded with hydrogen at elevated temperatures and quenched to ambient temperature(293K) and annealed at that temperature for several hours. Measurements on the single crystal samples showed that hydrogen bubbles $(0.2$ to 0.4 micrometers diameter) precipitated near dense dislocation tangles and were often associated with arrays of prismatic dislocation loops ejected from the bubble. Single crystal samples with smaller dislocation densities had smaller numbers of hydrogen bubbles. Micrographs for the polycrystalline samples indicated that hydrogen bubbles nucleated preferentially along grain boundaries that produce strong local distortion of the lattice. These measurements provided direct evidence of the following: (1) supersaturated solutions of hydrogen in copper precipitate irreversibly into gas bubbles at $293 \mathrm{~K},(2)$ bubble nucleation is enhanced by the presence of grain boundaries and dislocations (dissolved gas atoms are attracted by the strain field of the dislocation causing an increase in gas atom concentration in the neighborhood of the dislocation and preferential nucleation of bubbles at the dislocation).

Studies of deuterium bubble nucleation and coalescence in ion-implanted copper leading to surface blistering have been made by Johnson 1977, 1978. In this work, polycrystalline, high purity copper $(99.999 \%)$ specimens were annealed at $1200 \mathrm{~K}$ and subsequently implanted with 200-keV $D^{+}$ions. Specimen temperature was $350 \mathrm{~K}$. Surface blisters $(4$ micrometer 
diameter) were observed to form at a critical dose of $7 \times 10^{18} \mathrm{D} / \mathrm{cm}^{2}$. Typical D:Cu loadings at the critical dose for blistering were determined to be about 1 at\%.

Trapping of ion-implanted deuterium at lattice defects has been investigated using ion-beam analysis techniques (Besenbacher 1984). MARZ-grade single crystals of copper at 25K and $110 \mathrm{~K}$ were implanted with deuterium at $15 \mathrm{keV}$. The implanted deuterium depth distribution was profiled using the $D\left({ }^{3} \mathrm{He}, \mathrm{p}\right){ }^{4} \mathrm{He}$ reaction and ion-channeling measurements were made to determine the sites of implanted deuterium. Deuterium release measurements were made during linear-ramp-annealing of implanted specimens from $25 \mathrm{~K}$ to $350 \mathrm{~K}$ to determine binding enthalpies for trapped deuterium. These studies revealed that two types of traps were operative, one at $0.42 \mathrm{eV}$ and a second at $0.22 \mathrm{eV}$. A comparison of the experimental results to effective medium theory calculations revealed that the $0.42-\mathrm{eV}$ trap was associated with monovacancies or small vacancy clusters, whereas the $0.22-\mathrm{eV}$ trap was associated with selfinterstitials. These energies are referenced to the energy of solution sites for deuterium in the material. The ion-channeling studies showed that deuterium trapped to vacancies is delocalized with maximum probability between the vacancy and the octahedral site (the normal location for hydrogen in FCC metals is octahedral). The reported value of $0.42 \mathrm{eV}$ for binding to vacancies is inconsistent with that found by Lengeler 1978 using positron-annihilation techniques.

Measurements of hydrogen isotope retention and release from copper under ion bombardment have been reported by Wilson 1987 . Both nuclear reaction analyses and thermal desorption spectroscopy (TDS) were used to investigate deuterium trapping in the near-surface regions of MARZ-grade copper that were implanted at $300 \mathrm{~K}$ with $10-\mathrm{keV} \mathrm{D}_{3}{ }^{+}$ions to fluences approaching $1 E 23 \mathrm{D} / \mathrm{m}^{2}$. Far less than $1 \%$ of the implanted deuterium was retained in the specimen at this temperature and fluence. TDS measurements indicated that the retained deuterium was trapped at sites characterized by two different binding energies. DIFFUSE calculations that considered a $0.5-\mathrm{eV}$ trap with a concentration of 0.5 appm and a 0.93-eV trap with a concentration of 25 at parts /1E9 yielded an approximate fit to the TDS data.

Void formation and the role played by gas atoms in void formation has been reported by Yamakawa 1992 for neutron-irradiated copper and copper/aluminum alloys. These experiments were done using high purity polycrystalline copper and copper alloyed with 1 at $\% \mathrm{Al}$ and with 5 at $\%$ Al. The specimens were given different treatment prior to irradiation, namely: (1) no treatment, (2) vacuum-melted, degassed and resolidified, (3) melted with an argon atmosphere and then resolidified. Specimens were irradiated under three different conditions: (1) $603 \mathrm{~K}$ to a fluence of $5.2 \mathrm{E} 24 \mathrm{n} / \mathrm{m}^{2}$, (2) $663 \mathrm{~K}$ to a fluence of $3 E 25$ $\mathrm{n} / \mathrm{m}^{2}$ and (3) $693 \mathrm{~K}$ to a fluence of $1.3 \mathrm{E} 26 \mathrm{n} / \mathrm{m}^{2}$. Following the irradiation, the specimens were characterized using electron microscopy. The authors reported the following observations: (1) vacuum-melted/degassed material had reduced void densities $(1 / 10)$ compared to as-received material, however void size was larger in the vacuum-melted material; (2) argon-melted Cu/Al alloy had more voids than vacuum-melted; (3) there was a reduced number of voids in the Cu/Al alloy when compared to pure copper; and (4) voids and dislocation line segments were always observed in irradiated copper, and dislocation density increased with fluence. Based on these observations the authors concluded: (1) the addition of $A$ l suppresses void formation, (2) for non-degassed material, the residual gases in the material were major contributors to void formation, (3) for degassed material, the hydrogen and helium generated as transmutation products were instrumental in void formation.

Recently, Shimomura 1992 presented the results of molecular dynamics/embedded atom calculations to elucidate an understanding of the role gas atoms play in void nucleation for ionand neutron- irradiated copper. Experimentally Shimomura and colleagues had observed that, for ion-and neutron-irradiated copper at 0.4 to 0.5 the melting point $\mathrm{T}_{\mathrm{m}}$, voids nucleated at 
vacancy clusters that trap gas atoms such as $\mathrm{H}$ and $\mathrm{He}$. For neutron-irradiated copper at 570K, stacking fault tetrahedral (SFT) were observed, whereas if the irradiation temperature was $670 \mathrm{~K}$, voids were observed in pure copper. Based on the modeling and computational investigation, the following was observed: (1) octahedral 6-vacancy voids can be formed during ion- or neutron- irradiation at temperatures lower than $0.4 T_{m}$, (2) for low temperatures this void can relax to a stable SFT and not grow to a large void, (3) if the void traps a hydrogen atom, it will not relax to the SFT but become a nucleus for void growth. The authors concluded that hydrogen-stabilized 6- and 7-vacancy clusters can serve as void nucleation sites for void growth in ion- and neutron- irradiated materials.

\section{Surface Effects}

Surface effects play a major role in controlling uptake and release of hydrogen from materials. In many early studies of gas-driven permeation, surface conditions, especially the presence of oxide layers, presented barriers to uptake of hydrogen. As we presented in an earlier section, the presence of such oxide layers resulted in significant reductions in hydrogen permeability. In recent years, hydrogen/material interaction studies have been done using energetically implanted hydrogen and neutral atomic hydrogen fluxes. Because in both of these cases, the molecular dissociation step is bypassed at the vacuum/metal interface, uptake, permeation and release of the hydrogen can manifest a different behavior than that for gas-driven permeation. For example, in some studies permeation was enhanced over that expected because oxide films or chemical contaminants on the upstream surface inhibited molecular recombination and release from that surface with a consequent increase in permeation through the material. Many models have been developed over the years to describe the key processes contributing to hydrogen permeation through metals. A recent publication by Andrew 1992 provides a good overview of these models and the operative processes at the vacuum/surface and surface/bulk interfaces.

In this section we summarize recent studies that have been made to determine the molecular recombination coefficient, $K_{r}$, that relates the outgoing flux from a material directly to the bulk hydrogen concentration just below the surface. As is customary for second order release processes, the outgoing flux, $\mathrm{J}$, is expressed by

$$
J=2 \sigma K_{r} c^{2}
$$

where $\sigma$ is a surface roughness factor, $K_{r}$ is the molecular recombination coefficient and $c$ is the bulk metal hydrogen concentration near the surface (Andrew 1992, and references therein). The factor $\sigma$ is an empirical factor to account for imperfect surfaces, i.e., surfaces that may have chemical impurities occupying surface sites or surfaces whose available area for adsorption/desorption is larger than the geometric area. The review includes results from experiments with plasma ions (Wilson 1987), with accelerator produced ions (Nagasaki $1992 \mathrm{a}$ and 1992b, and Anderl 1990) and with gas molecules and neutral atom fluxes (Haasz 1989, Andrew 1991a).

The results reported by Wilson 1987 were obtained from permeation experiments using 100$\mathrm{eV}$ deuterium plasma ions (1E20 D/m ${ }^{2}$-s) incident on MARZ-grade copper specimens at temperatures ranging from $570 \mathrm{~K}$ to $830 \mathrm{~K}$. The samples were annealed at $823 \mathrm{~K}$ prior to the experiments. Measured permeation rates were compared to predicted values using the DIFFUSE code with deuterium diffusivities and solubilities from Eichenauer 1957, and the Baskes' formulation for the recombination coefficient. A molecular sticking coefficient of 0.1 was required to fit the data. The recombination rate constant derived from this work was essentially constant at a value $6.7 \mathrm{E}-26 \mathrm{~m}^{4} / \mathrm{s}$ over the temperature range of the experiment. A constant recombination value with temperature is not surprising because in the Baskes' formulation, the 
temperature dependence is proportional to $\exp \left[\left(E_{s}-E_{d}\right) / k T\right]$ and, for copper, $E_{s}$ is nearly equal to $E_{d}$. An Auger spectrometer was used in this work to determine that the upstream surface did have carbon contamination, ( $<0.5$ monolayers), but the authors suggest this has little impact on permeation.

Anderl (1990) measured permeation rates through polycrystalline copper specimens at temperatures of $638 \mathrm{~K}$ and $723 \mathrm{~K}$ for an incident $3-\mathrm{keV} \mathrm{D}_{3}{ }^{+}$ion beam with a flux of $5 \mathrm{E} 19$ $\mathrm{D} / \mathrm{m}^{2} \mathrm{~s}$. Initially, values of $\mathrm{K}_{\mathrm{r}}$ were derived from the steady-state permeation values, assuming recombination-limited flow upstream and diffusion-limited flow to the downstream surface. Subsequently, TMAP4 simulation calculations were made to fit the measured permeation transients, with $\mathrm{K}_{\mathrm{r}}$ and $\mathrm{D}$ as adjustable parameters. This analysis yielded recombination coefficients of $3 E-24 \mathrm{~m}^{4} / \mathrm{s}$ and $6 \mathrm{E}-25 \mathrm{~m}^{4} / \mathrm{s}$ for sputter-cleaned copper at $723 \mathrm{~K}$ and $638 \mathrm{~K}$, respectively. These authors determined that sputter cleaning of the upstream copper surface resulted in an enhancement of the molecular recombination coefficient by factors of 6-8 over that of the downstream surface.

In two papers, Nagasaki 1992a and 1992b report on their efforts to determine the molecular recombination coefficient for copper. Ion-beam driven permeation experiments were conducted for high purity polycrystalline copper specimens using a $5-\mathrm{keV}, \mathrm{D}_{3}{ }^{+}$ion beam with fluxes varied from $0.2 \mathrm{E} 19 \mathrm{D} / \mathrm{m}^{2} \mathrm{~s}$ to $1.0 \mathrm{E} 19 \mathrm{D} / \mathrm{m}^{2} \mathrm{~s}$. Specimen temperatures ranged from $350 \mathrm{~K}$ to $770 \mathrm{~K}$. The backside surface of the specimen was sputter cleaned with an argon ion beam. Values for the molecular recombination coefficients were derived from the permeation data for temperatures between $520 \mathrm{~K}$ and $770 \mathrm{~K}$, a region for which the permeation was recombinationlimited upstream and diffusion-limited downstream. The analysis was based on the generalized formulation of Doyle 1985. In order to fit the data, the authors required the upstream recombination coefficient to be a factor of 7 larger than the downstream surface recombination coefficient. The derived recombination coefficients exhibited a trend with temperatures that could be fit either with the recombination expression of Pick 1985 or with an Arrhenius expression. For the temperature range $520 \mathrm{~K}$ to $770 \mathrm{~K}$, these expressions are, respectively,

and

$$
K_{1}\left(m^{4} / s\right)=3.62 E-26(T)^{-0.5} \exp (0.39 \mathrm{eV} / \mathrm{kT})
$$

$$
K_{1}\left(m^{4} / s\right)=8.71 E-28 \exp (0.41 \mathrm{eV} / \mathrm{kT})
$$

In the recombination coefficient expression of Pick 1985, the energy term in the exponent is $2\left(E_{s}-E_{c}\right)$, where $E_{s}$ is the solution enthalpy and $E_{c}$ is the activation energy for chemisorption. Applying this to the above data, the work of Nagasaki would suggest a chemisorption barrier of about $0.2 \mathrm{eV}$, assuming that $\mathrm{E}_{\mathrm{S}}=0.4 \mathrm{eV}$. The temperature variation in the recombination coefficient is in marked contrast to values determined by Wilson 1987 and Haasz 1989, both of which are constant with temperature and much lower.

Copper surface effects on permeation were investigated by Haasz 1989 using both hydrogen gas and atomic hydrogen-driven permeation experiments. The specimen used in this work was a copper-iron composite membrane with 32 micrometer of OFHC copper and 95 micrometers of high purity iron. Molecular fluxes were varied from $2.7 \mathrm{E} 22$ to $7.3 \mathrm{E} 25 \mathrm{H}_{2} / \mathrm{m}^{2}$-s. Specimen temperatures were varied from $570 \mathrm{~K}$ to $780 \mathrm{~K}$. From the diffusion-limited permeation data for $\mathrm{H}_{2}$, the $\mathrm{H}$ permeability for $\mathrm{Cu}$ was determined to be $2.0 \mathrm{E} 16 \exp (-0.64 \mathrm{eV} / \mathrm{kT}) \mathrm{H} / \mathrm{m} \mathrm{s} \mathrm{Pa} 0.5$. Hydrogen recombination coefficients for $\mathrm{Cu}$ were derived from both surface-limited molecular 
hydrogen permeation data and from the diffusion-limited atomic permeation data. Both approaches determined that

$$
\left(\sigma \mathrm{k}_{\mathrm{r}} \mathrm{S}^{2}\right)_{\mathrm{Cu}}=9.3 \mathrm{E} 19 \exp (-0.68 \mathrm{eV} / \mathrm{kT}) \mathrm{H}_{2} / \mathrm{m}^{2} \mathrm{~s} \mathrm{~Pa} .
$$

The authors used literature solubility data from Tanabe 1984 to derive values of $\left(K_{r}=\sigma k_{r}\right)$ from the above expression. This analysis yielded a value of $K_{r}$ of about $8 E-27 \mathrm{~m}^{4} / \mathrm{s}$, nearly independent of temperature. The authors noted that $\mathrm{K}_{\mathrm{r}}$ obtained from experiments with thermal energy incident particles were consistently lower than values obtained from experiments using ion implantation. The reason for this could be due to impurities present on the surfaces in the molecular and atomic hydrogen experiments. In the above experiment, the copper surface was characterized with an Auger spectrometer to be: $76 \% \mathrm{Cu}, 7 \% \mathrm{O}, 5 \% \mathrm{~S}, 5 \% \mathrm{C}, 3 \% \mathrm{Ca}, 2 \% \mathrm{Mn}$, and $2 \% \mathrm{Sb}$. Such impurities could be sputter-removed in experiments with energetic ions, resulted in higher recombination coefficients.

In experiments with copper-coated iron films, Andrew 1992 has investigated the role of Cu surface effects on hydrogen permeation. Experiments were conducted with both hydrogen molecules $\left(10^{-2}\right.$ to $\left.10^{4} \mathrm{H}_{2} / \mathrm{m}^{2}-\mathrm{s}\right)$ and with specimen temperatures ranging from $300 \mathrm{~K}$ to $600 \mathrm{~K}$. These experiments determined that the copper layer had no effect on the diffusionlimited permeation for the composite membrane but it did reduce the surface-limited rate and it affected the temperature dependence. Air exposure of the copper resulted in a further reduction in the surface-limited permeation. Atomic hydrogen-driven permeation experiments for the composite $\mathrm{Cu}$ - Fe membrane indicated that the presence of $\mathrm{Cu}$ led to a reduction in the value of $2 \sigma \mathrm{k}_{\mathrm{r}} \mathrm{S}^{2}$ with an increase in the activation energy, as compared to experiments for uncoated $\mathrm{Fe}$ membranes. These results determined an activation energy of $0.22 \mathrm{eV} /$ molecule $(0.11$ eV/atom) for the $\mathrm{Cu}$ surface (for the sticking probability of $\mathrm{H}_{2}$ on $\mathrm{Cu}$ ), a result that is consistent with activation barriers for absorption as determined from surface physics experiments.

\section{Multiple-layered Materials}

A limited number of experiments have been done to investigate the hydrogen permeation properties of bilayer materials. In this section, the results of permeation measurements on $\mathrm{Cu}-\mathrm{Ni}, \mathrm{Cu}-\mathrm{Fe}, \mathrm{Cu}-\mathrm{Pd}$, and $\mathrm{Cu}-\mathrm{W}$ composite membranes will be summarized.

Hydrogen gas, pressure-driven permeation experiments for $\mathrm{Cu}-\mathrm{Ni}$ and $\mathrm{Cu}-\mathrm{Fe}$ membranes have been reported by Tanabe 1986. These experiments were done using electrodeposited copper on substrates of high purity $\mathrm{Ni}$ and $\mathrm{Fe}$. The gas pressure was varied from $10^{3}$ to $10^{5} \mathrm{~Pa}$ and the specimen temperature was varied from $500 \mathrm{~K}$ to $1000 \mathrm{~K}$. Both permeation transient and steadystate permeation rates were measured. These results were compared to a theoretical description of the permeation process in duplex metal membranes that is based on the following assumptions: (1) hydrogen permeation is rate-limited by the bulk diffusion in the metal layers, (2) hydrogen solution in the metal is proportional to the square root of the hydrogen pressure, and (3) the hydrogen potential across the interface is continuous. For the $\mathrm{Cu}-\mathrm{Ni}$ membrane experiments, the authors determined that the observed permeation behavior (transient and steady-state) was consistent with the theoretical prescription. However, for the Cu-Fe membrane experiments, the observed steady-state permeation was consistent with theory, but the transient permeation was not. The authors suggested that for $\mathrm{Cu}-\mathrm{Fe}$, surface effects at the $\mathrm{Cu} / \mathrm{Fe}$ interface or bulk trapping in the $\mathrm{Fe}$ could have accounted for this 
discrepancy. It was noted by the authors that $\mathrm{Cu}$ and $\mathrm{Ni}$ are mutually soluble but $\mathrm{Cu}$ and $\mathrm{Fe}$ are not. Hence, it is reasonable to expect an interfacial barrier for the Cu-Fe membrane.

Hydrogen permeation measurements through bilayer copper-iron membranes have been reported by Haasz 1989. A brief description of these experiments is given in the earlier section on surface effects. These experiments were done to determine some of the bulk and surface properties of copper and iron. Surface properties obtained for copper were discussed earlier. In general, the interpretation of the measured permeation rates followed the conventional approach to describing permeation in multiple-layered membranes (see the paper for details). The authors did not observe any permeation behavior that was different from the classical theoretical description. Hence, we conclude that the interface between the $\mathrm{Cu}$ and $\mathrm{Fe}$ was not a significant controller of the permeation behavior of these duplex membranes.

Andrew and coworkers have reported hydrogen permeation measurements through coppercoated membranes of $\mathrm{Fe}$ and $\mathrm{Pd}$, (Andrew 1991a, 1991b). Key results from these experiments primarily concerned the influence of $\mathrm{Cu}$ surface effects on the duplex membrane permeation behavior as discussed earlier.

Permeation experiments on tungsten-coated copper specimens have been reported by Anderl 1990. The specimen used in these experiments was a 500-micrometer, high purity copper rod with a 0.5 micrometer sputter-deposited tungsten coating. Ion-driven permeation measurements were done using a $3 \mathrm{keV} \mathrm{D}_{3}{ }^{+}$ion beam with a flux density of $4.6 \mathrm{E} 19 \mathrm{D} / \mathrm{m}^{2}-\mathrm{s}$. The specimen temperature was $723 \mathrm{~K}$. TMAP4 calculations were done to simulate the observed permeation data. In order to achieve a good comparison between the measured and calculated data, the authors used recombination coefficients derived from experiments on pure tungsten and pure copper, literature values for the diffusivities, and with hydrogen solubility in tungsten increased substantially over that predicted using the tungsten solubility data from Wilson 1984. The authors suggested that an interfacial barrier between the copper and the tungsten coating could account for the observed permeation behavior.

\section{Assessment}

At the present time, there are no diffusivity and solubility data available specifically for the copper alloy under consideration for use in ITER. However in this section, we provide data from experimental testing of copper with various alloying elements, including $\mathrm{Cr}$ and $\mathrm{Ti}$. This information can be used as a guide to estimate the diffusivities and solubilities for the ITERrelevant alloy.

For working values, we recommend the composite diffusivity and solubility values given by Reiter et al. (1993)

$$
\begin{aligned}
& D=6.6 \times 10^{-7} \exp (-0.387 \mathrm{eV} / \mathrm{kT}) \quad \mathrm{m}^{2} / \mathrm{s} \quad 470 \text { to } 1200 \mathrm{~K} \\
& \mathrm{~S}=3.70 \times 10-5 \exp (-0.572 \mathrm{eV} / \mathrm{kT}) \quad \text { atom fraction } / \mathrm{Pa}^{1 / 2}
\end{aligned}
$$




\section{Graphite}

\section{Hydrogen transport}

Brice (1983) fit TRIM code results with an equation for implanted $\mathrm{H}$ concentration vs. depth at various $\mathrm{H}$ ion temperatures of 50 to $3200 \mathrm{eV}$, with and without $\mathrm{H}$ saturation, in $\mathrm{C}$ and TiC. The approach to saturation was modeled with the local mixing model vs. fluence and temperature. The isotopic exchange process (such as $T$ bombardment of a wall saturated with D) was also modeled.

Wilson and Hsu (1987) provided a general review of hydrogen in graphite, including the following topics: saturation of the surface layer diffusion on internal porosity transgranular diffusion and trapping lattice structure after irradiation particle control in tokamaks isotope changeover tritium behavior models and inventory estimates.

Langley (1987) reviewed hydrogen transport in graphite. Each carbon atom has four valence electrons: three sigma electrons forming strong covalent bonds, and one loosely bound pi electron that can bind hydrogen with an energy of about $4.3 \mathrm{eV}$. Natural and pyrolytic graphite are anisotropic, $2.26 \mathrm{~g} / \mathrm{cm}^{2}$, with very low porosity. Artificial graphite has crystallite sizes from 1-300 micrometers, crystallites formed into randomly oriented grains, isotropy, and large open porosity. Implanted ions saturate a surface layer at $\mathrm{H} / \mathrm{C} \sim 0.5$. The transition to an amorphous state occurs at $1 \mathrm{dpa}(450 \mathrm{~K})$ to about $30 \mathrm{dpa}(700 \mathrm{~K})$. The saturation level decreases from 0.5 (low temperatures) to about 0.1 (773 K). Below $973 \mathrm{~K}$ hydrogen transport is dominated by surface diffusion in the pores, and at higher temperatures, transport is dominated by diffusion within grains. Above $1473 \mathrm{~K}$ dissociation of $\mathrm{H}_{2}$ into $\mathrm{H}$ is rapid. The diffusion coefficient is $D_{0}=0.93 \mathrm{~cm}^{2} / \mathrm{s}, E_{d}=2.8 \mathrm{eV}$. A typical trap concentration is $\sim 20$ appm.

According to Causey (1989a) there are four processes by which tritium can be retained in graphite:

(1) saturation of the implant area. Since the implant area is thin, this process does not confine a substantial inventory of tritium. Saturation to $T / C \sim 0.6$ could result in about $3 \times 10^{17}$ $\mathrm{T} / \mathrm{cm}^{2}$, or about $0.3 \mathrm{~g}$ for TFTR. The implanted tritium is removed by high-temperature anneal at $1200 \mathrm{~K}$.

(2) co-deposition with carbon on surfaces.

(3) absorption on internal porosity.

(4) transgranular diffusion with trapping.

Möller (1989) described four types of graphite:

- highly oriented pyrolytic graphite (HOPG),

* pyrolytic graphite,

*amorphous glassy carbon (a-C:H) films containing $\mathrm{H} / \mathrm{C} \sim 0.5$, and

- isostatically compressed graphites.

HOPG samples become amorphous at about 1 dpa damage (at $373 \mathrm{~K}$ ). The extended local mixing model does not adequately account for wall inventory transients, saturated depth profiles, 
asymmetry of reemission transients during proton-deuteron switch-over experiments, and ion-induced reemission. Möller proposed a model involving molecular recombination in the bulk graphite, and was able to fit some data with the model equations. However, the model calculations of retained \% vs. temperature during anneal using only one trap binding energy fell off too steeply.

Wilson et al (1991) reviewed hydrogen transport phenomena in $\mathrm{C}, \mathrm{Mo}, \mathrm{W}$, and Be, including mathematical models for transport. About $30 \mathrm{eV}$ is typical for the production of Frenkel pairs, and a binding energy of $2.7 \mathrm{eV}$ is taken as a threshold for C-D bond breaking by nuclear knockoff (the formation of $D$ interstitials). One model (Brice et al.) assumed trap binding energies of 2.9 and $3.6 \mathrm{eV}$ for low and high damage states, with a maximum trap concentration of 0.44 traps per carbon atom, and gave a good fit to isotope exchange data after adjustment of empirical parameters. A "gas sputtering "model (Braun and Emmoth) assuming temperature dependent cross sections for ion induced detrapping also fit experimental data, but it would not predict the linear increase of trapped inventory at low fluences that has been observed. Another model (Wampler and Myers) considered retrapping of detrapped $\mathrm{H}$ atoms and estimated a characteristic length of $1.5 \mathrm{~nm}$ for the retrapping process, which was ascribed to atomic collisions rather than electronic energy loss. Langley's model accounted for recombinative release of $\mathrm{H}$ atoms removed from traps by irradiation effects. The Möller and Scherzer model, in which recombination occurred in the bulk, followed by rapid molecular diffusion to the surface, has been successful at predicting some experimental phenomena, such as density behavior in tokamaks. A recent model by Brice assumes a high activation energy for recombination, which leads to a high solute concentration, and a low trapping energy $\sim 0.1 \mathrm{eV}$. The actual solute fraction is not yet clear. A high-flux experiment $\left(\sim 10^{19} / \mathrm{cm}^{2} \mathrm{~s}\right)$ could test whether the saturation concentration increases or decreases with incident flux, which would help to distinguish between the Moller \& Scherzer model and the Brice model.

\section{Diffusivity}

Elleman (1978) measured pyrolytic carbon $D_{0}=330 \mathrm{~cm}^{2} / \mathrm{s}, E_{d}=4.27 \mathrm{eV}$.

The hydrogen in amorphous carbon/hydrogen (a-C:H) films is chemically bound and very immobile, with diffusivity $D<5 \times 10^{-22} \mathrm{~m}^{2} / \mathrm{s}$ at $453 \mathrm{~K}$. (Federici and Wu 1993)

Sixteen experimental data sets ( $D_{0}$ and $\left.E_{d}\right)$ were considered by Ashida and Watanabe (1991). The "compensation effect" refers to the approximately linear relationship of $\log \left(D_{0}\right)$ with $E_{d}$, as illustrated in their Figure 2. They assumed three diffusion channels in graphite: $D_{a}$ along the a-axis, $D_{c}$ along the $c$-axis, and $D_{b}$ along the grain boundary. The activation energies were taken from experimental values, and the pre-exponential factors were chosen to fit the data and compensation effect. An equation (their Eq. 5) is given for the effective diffusion coefficient in terms of $D_{a}, D_{b}, D_{c}$, and the path lengths for these processes. From experimental data they estimate $E_{a}=25 \mathrm{kcal} / \mathrm{mol}, E_{b}=60 \mathrm{kcal} / \mathrm{mol}$, and $E_{c}=93 \mathrm{kcal} / \mathrm{mol}$. The effective Arrhenius plot is not a straight line, but a combination of line segments in different temperature ranges. The significance of the three diffusion channels depends upon their effective path lengths $\mathrm{l}_{\mathrm{a}}, \mathrm{l}_{\mathrm{b}}$, and $I_{C}$. By varying these parameters, several curves of $D$ vs. $1000 / T$ are obtained that match various experimental data sets. This equation could help to predict diffusivity in graphite, given sufficient information about the grain geometry.

Diffusivity was decreased by neutron irradiation, but restored above 0.3 dpa.(Atsumi 1992) $\mathrm{H}$ saturation concentration in graphite at $(1000 / T)<1.5$ is described by the equation:

$$
H / C=0.0004 \exp (4050 / T) . \quad \text { (Baskes 1984) }
$$


Bulk tritium retention is proportional to the square root of the incident atom flux.

Causey (1979) found that for laminar $P y C \quad D_{0}=330 \mathrm{~cm}^{2} / \mathrm{s}, E_{d}=4.27 \mathrm{eV}$. Values were also given for $\mathrm{SiC}$ and $\mathrm{Si}$-doped $\mathrm{C}$. Addition of $\mathrm{H}_{2}$ to the sweep gas resulted in a different value of $\mathrm{D}$. The presence of $\mathrm{Si}$ increased the value of $\mathrm{D}$. The surface had pores extending about 25 micrometers in, so the release measurements gave an effective diffusion coefficient, rather than a true bulk value. It appeared that diffusion was governed by chemical bonding between $\mathrm{H}$ and $\mathrm{C}$ atoms. PyC had a permeability much lower than refractory metals, so it could be an excellent tritium barrier, if durable fabrication techniques could be developed.

Kechkhuashvili et al. (1990) measured the diffusivity of tritium in reactor graphite using isothermal anneals at temperatures from 500-1100 C. The results were

$\begin{array}{ll}\mathrm{D}\left(500{ }^{\circ} \mathrm{C}\right) & =6.2 \times 10^{-16} \mathrm{~cm}^{2} / \mathrm{s} \\ \mathrm{D}\left(700^{\circ} \mathrm{C}\right) & =4.8 \times 10^{-15} \mathrm{~cm}^{2} / \mathrm{s} \\ \mathrm{D}\left(900{ }^{\circ} \mathrm{C}\right) & =3.3 \times 10^{-14} \mathrm{~cm}^{2} / \mathrm{s} \\ \mathrm{D}\left(1100^{\circ} \mathrm{C}\right) & =2.1 \times 10^{-13} \mathrm{~cm}^{2} / \mathrm{s} .\end{array}$

Kushita et al. (1991) implanted tritium in graphite pseudo-monocrystals and observed its motion with an electron imaging camera. They deduced a diffusion coefficient of $2 \times 10^{-10}$ $\mathrm{cm}^{2} / \mathrm{s}$ at $\mathrm{T}>1775 \mathrm{~K}$. They concluded that tritium implanted in graphite with large crystal grains may be retained even after heating to $1975 \mathrm{~K}$ for prolonged periods, in contrast to release from small grains at lower temperatures.

Lamarche et al. (1986) derived a simple mathematical model of the hydrogen isotope ratio in a tokamak discharge and compared it with TFTR data taken during changeover from $D$ to $H$ or from $H$ to $D$. Isotopic exchange was very slow during discharges where the graphite limiter did not get very hot. Interpore diffusion in the $15 \%$ porous graphite with activation energy $0.15 \mathrm{eV}$ was hypothesized to account for the observed transport rates.

Langley (1987) found that the total hydrogen retained was about 50 times that in the surface saturation layer. Retention was greater at higher incident fluxes. Using the DIFFUSE code Causey estimated $17 \mathrm{ppm}$ traps at $4.3 \mathrm{eV}$, and grain surface diffusion coefficient $D_{0}=1.2$ $\mathrm{cm}^{2} / \mathrm{s}, E_{d}=0.9 \mathrm{eV}$.

Morita et al (1989) measured depth profiles of implanted hydrogen in isotropic graphite at various times, temperatures, and fluences, and deduced model parameters. Implanted hydrogen is mobile even at room temperature until it is trapped. The effective diffusion coefficient was inferred to be $D_{0}=9.2 \times 10^{-14} \mathrm{~cm}^{2} / \mathrm{s}, E d=0.20 \mathrm{eV}$ at $\mathrm{T}=473-873 \mathrm{~K}$.

Watanabe, Ashida, and Sonobe (1990) provide a table of diffusion coefficients for $T, D$, and $H$ in graphite, shown here as Table 5.1. There is a nearly linear relation between $\ln \left(D_{0}\right)$ and $E_{d}$, called the "compensation effect." 
Table 5.1. Diffusion coefficients of hydrogen isotopes in graphites, from Watanabe et al. $(1990)$.

\begin{tabular}{lll}
\hline Isotope & Do, $\mathrm{cm}^{2} / \mathrm{s}$ & $\mathrm{Ed}, \mathrm{eV}$ \\
$\mathrm{T}$ & 330 & 4.26 \\
$\mathrm{~T}$ & 0.0011 & 2.32 \\
$\mathrm{~T}$ & 0.0240 & 2.77 \\
$\mathrm{~T}$ & 8280 & 3.77 \\
$\mathrm{D}$ & 1.69 & 2.60 \\
$\mathrm{~T}$ & 0.00823 & 2.70 \\
$\mathrm{~T}$ & 0.00248 & 2.58 \\
$\mathrm{~T}$ & $2.78 \mathrm{E}-8$ & 1.09 \\
$\mathrm{~T}$ & $3.06 \mathrm{E}-8$ & 1.71 \\
$\mathrm{~T}$ & $4.19 \mathrm{E}-10$ & 1.48 \\
$\mathrm{~T}$ & $1.02 \mathrm{E}-11$ & 1.08 \\
$\mathrm{~T}$ & $3.61 \mathrm{E}-11$ & 1.05 \\
$\mathrm{H}$ & 1.00 & 2.64 \\
$\mathrm{D}$ & 1.00 & 2.60 \\
$\mathrm{~T}$ & 1.00 & 2.71 \\
\hline
\end{tabular}

Reiter et al. (1993) tabulated diffusivity and solubility for many types of graphite, as shown in Table 5.2 
Table 5.2. Diffusivity and solubility parameters for various types of graphite. From Reiter et al (1993).

\begin{tabular}{|c|c|c|c|c|c|}
\hline Type & $\begin{array}{l}D_{0} \\
m^{2 / s}\end{array}$ & atom & $\begin{array}{l}\text { So } \\
\text { fraction/Pa1/2 }\end{array}$ & $\begin{array}{l}E_{S} \\
\mathrm{eV}\end{array}$ & $\begin{array}{l}\text { Temp. Range } \\
\mathrm{K}\end{array}$ \\
\hline A-3 & 0.828 & 3.77 & & & $1073-1173$ \\
\hline$A L-2-400$ & $2.40 E-6$ & 2.78 & & & $973-1673$ \\
\hline$H-1$ & $8.23 E-7$ & 2.71 & & & $973-1273$ \\
\hline$H-2$ & $2.48 E-7$ & 2.69 & & & $973-1273$ \\
\hline G-32 & $2.78 E-12$ & 1.09 & & & $973-1273$ \\
\hline Papyex & 0.0330 & 4.27 & & & $1333-1673$ \\
\hline $\begin{array}{l}\text { Isograph-88 } \\
\text { (Toyo Tanso) }\end{array}$ & $1.69 E-4$ & 2.60 & $2.0 E-7$ & -0.197 & $\begin{array}{l}773-1173 \\
1123-1323\end{array}$ \\
\hline $\begin{array}{l}\text { ETP-10 } \\
\text { (lbiden) }\end{array}$ & $2.10 E-16$ & 0.443 & & & $460-1327$ \\
\hline $\begin{array}{l}\text { IG-110U } \\
\text { (Toyo Tanso) }\end{array}$ & $3.61 E-15$ & 1.05 & $5.0 \mathrm{E}-7$ & -0.189 & $\begin{array}{l}973-1173 \\
973-1273\end{array}$ \\
\hline HOPG & $3.06 E-12$ & 1.66 & & & $973-1273$ \\
\hline $\begin{array}{l}\text { PG-A } \\
\text { (Nippon Carbo }\end{array}$ & $\begin{array}{l}4.19 E-14 \\
\text { on) }\end{array}$ & 1.48 & & & $973-1273$ \\
\hline $\begin{array}{l}\text { YPD } \\
\text { (Toyo Tanso) }\end{array}$ & $1.02 E-15$ & 1.08 & & & $973-1273$ \\
\hline $\begin{array}{l}\text { POCOAXF } 5 Q \\
\text { (POCO Graphit }\end{array}$ & ite) & & $1.7 \mathrm{E}-7$ & -0.223 & $973-1273$ \\
\hline $\begin{array}{l}\text { IG-430U } \\
\text { (Toyo Tanso) }\end{array}$ & & & $1.06 \mathrm{E}-7$ & -0.207 & $1170-1340$ \\
\hline $\begin{array}{l}\text { ISO-630U } \\
\text { (Toyo Tanso) }\end{array}$ & & & $5.8 E-7$ & 0.083 & $1220-1340$ \\
\hline $\begin{array}{l}\text { ISO-880U } \\
\text { (Toyo Tanso) }\end{array}$ & & & $7.0 \mathrm{E}-7$ & -0.114 & $970-1340$ \\
\hline $\begin{array}{l}\text { ISO-2202U } \\
\text { (Toyo Tanso) }\end{array}$ & & & $1.25 E-8$ & -0.254 & $1120-1340$ \\
\hline
\end{tabular}


Some of these tritium diffusivities are illustrated in Figure 5.1.

Saeki (1983) studied variation of diffusivity with neutron irradiation damage at fluences of $1.7 \times 10^{21} / \mathrm{cm}^{2}$ (thermal) and $1.9 \times 10^{19} / \mathrm{cm}^{2}$ (E > $2 \mathrm{MeV}$ ). Interstitial $C$ atoms interfere with $\mathrm{H}$ diffusion between basal planes. A table of diffusivity values was given.

Saeki (1985) found that the degree of anisotropy of pyrolytic graphite strongly influences the tritium diffusion rate. Tritium diffuses primarily between basal planes. The release temperature, the activation energy, and the amount of tritium retained were higher in the anisotropic graphites, and the diffusion coefficients were much lower. Anisotropic (average of specimens $H-1$ and $H-2$ ): $E_{d}=2.64 \mathrm{eV}, D_{0}=0.0045 \mathrm{~cm}^{2} / \mathrm{s}$. Isotropic (specimen $\mathrm{G}-32$ ): $E_{d}$ $=1.09 \mathrm{eV}, \mathrm{D}_{\mathrm{O}}=2.78 \times 10^{-8} \mathrm{~cm}^{2} / \mathrm{s}$.

Saeki and Masaki (1989) found that the release rate of tritium from graphite powders was enhanced by addition of $\mathrm{H}_{2}$ to the $\mathrm{He}$ atmosphere. Diffusion appeared to be the dominant process, but surface effects, such as interactions of $\mathrm{H}_{2}$ with bound $\mathrm{T}$ atoms, were also important. The activation energy for diffusion was not affected by the presence of $\mathrm{H}_{2}$ in the atmosphere. 


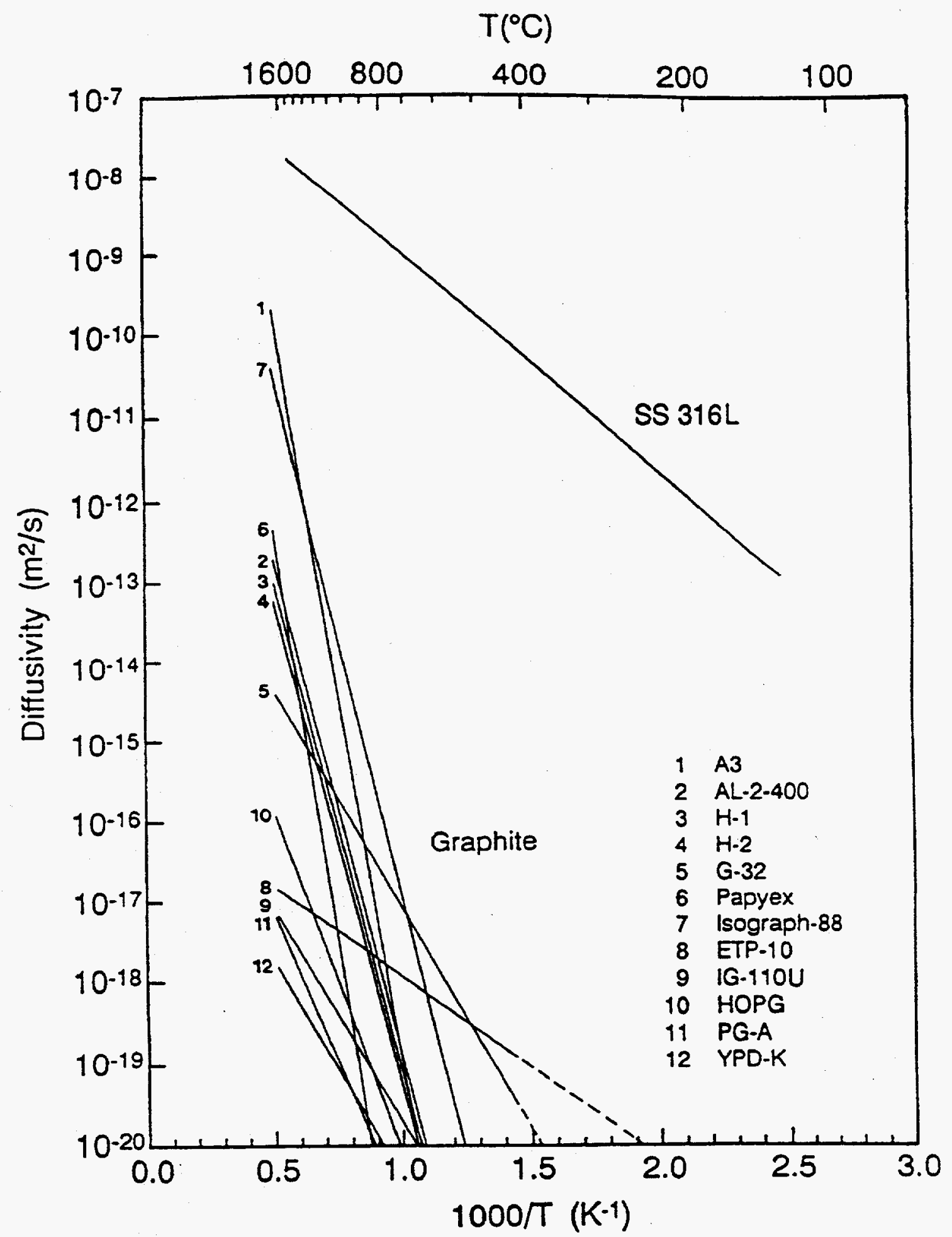

Figure 5.1. Tritium diffusivities in various types and grades of graphite. From Reiter et al (1993) 
Tanabe (1991) directed a low-energy deuterium atom beam onto a graphite target and observed $D$ retention. The retention grew proportional to $t^{1 / 2}$ and was not saturated at fluences of $3 \times 10^{21} / \mathrm{m}^{2}$ Retention decreased with increasing temperature and was below the detection threshold at $1400 \mathrm{~K}$. Implantation by a $1.5 \mathrm{keV} \mathrm{D}^{+}$ion beam yielded two orders of magnitude higher retention than the low-energy $\mathrm{D}$ atom beam. The second order rate coefficient and diffusion coefficient were estimated.

$$
D_{0}=2.1 \times 10^{-16} \mathrm{~m}^{2} / \mathrm{s}, E_{d}=0.445 \mathrm{eV} \text {. }
$$

The rate limiting process in previous estimates of the "diffusion coefficient in graphite" was not likely to be diffusion, so those results may overestimate $D$ at high $T$ and underestimate $D$ at low T.

The "diffusivity" values determined in the past by the adsorption-desorption method do not seem to be controlled by diffusion, so they should not be relied upon.(Tanabe 1994)

Atsumi et al (1987) measured $D$ for deuterium in isotropic graphite and found

$$
D=1.69 \exp (-2.60 \mathrm{eV} / \mathrm{kT}) \quad \mathrm{cm}^{2} / \mathrm{s} \text {. }
$$

Bulk diffusivity appears to be enhanced by the present of $H$ in the sweep gas, perhaps due to isotope exchange. Many different activation energies for diffusion have been reported, ranging from $0.45 \mathrm{eV}$ for hydrogen-saturated graphite, $1.1 \mathrm{eV}$ for isotropic graphite, $2.7 \mathrm{eV}$ for highly oriented graphite, up to $4.3 \mathrm{eV}$ for laminar pyrolytic carbon. The "best value" of $\mathrm{D}$ recommended by Wilson et al (1991) and by Causey (1989a) is:

$D=0.93 \exp (-2.8 \mathrm{eV} / \mathrm{kT}) \quad \mathrm{cm}^{2} / \mathrm{s}$

\section{Permeation}

According to Yamawaki and Namba (1991) the permeation rate of hydrogen through graphite is $J=\left(4 P / 9 x_{0}\right)\left(2 / \pi M R^{\prime} T\right)^{1 / 2} k_{p} R_{p} \beta / k^{2}$

where $P=$ gas pressure, $x_{0}=$ membrane thickness, $M=$ gas molecular weight, $T=$ temperature, $R^{\prime}=$ gas constant, $k_{p}=$ porosity, $R_{p}=$ "medium pore radius", $k^{2}=$ tortuosity, and $\beta=a$ factor to show the effect of pore size distribution.

Yamawaki $(1987,1991)$ found linear pressure dependence of permeability down to $0.01 \mathrm{~Pa}$.

\section{Solubility and retention}

Chiu (1992) observed mixing of implanted $H$ and $D$ to form $H D$ molecules in various types of graphite. Pre-damaging the sample with $10 \mathrm{keV} \mathrm{He}+$ bombardment enhanced the mixing. The amount of mixing did not depend upon the degree of overlap of the ion implantation vs. depth profiles. This is contrary to the hypothesis of subsurface molecule formation, and lends credence to the atomic diffusion model.

Thermal variation in the graphite causes effects that are significant for inventory estimation.(Brereton 1991) With short exposure times, large grain size and low temperatures will minimize tritium inventory. If the design uses small grain size, then high temperatures will reduce the inventory. Co-deposition can produce inventories of 50-100 $\mathrm{kg}(\mathrm{T}) /$ (burn-year). About $1 \mathrm{~kg}$ may be held up in tokamak graphite dust. Tritium in bulk 
graphite is vulnerable only if the temperature is raised to about $1500 \mathrm{~K}$ for a long time. Codeposited tritium (near the surface) is weakly held, and released rapidly as HTO during exposure to air at $300 \mathrm{C}$.

Elleman (1978) measured pyrolytic carbon $S_{O}=2.6 \times 10^{15}$ atoms $/ g$-atm $0.49, E_{S}=-1.44 \mathrm{eV}$, $1100-1500{ }^{\circ} \mathrm{C}$.

Langley (1987) ran a hydrogen glow discharge in a graphite cathode inside a sealed bell jar. The hydrogen pressure gradually decreased during the discharge, and the hydrogen retained in the graphite increased linearly with time, without saturation up to a concentration of almost $1017 / \mathrm{cm}^{2}$. The implanted hydrogen was immobile at temperatures below $1000 \mathrm{~K}$ until saturation was reached.

Graphite was irradiated at fluences up to $5.4 \times 10^{24} \mathrm{n} / \mathrm{m}^{2}(>1 \mathrm{MeV})$. $\mathrm{H}$ solubility was measured at 850 to $1050 \mathrm{C}$.(Atsumi 1992) The apparent activation energy for diffusion is $185 \mathrm{~kJ} / \mathrm{mol}$, close to the activation energy for hydrogen recombination of $184 \mathrm{~kJ} / \mathrm{mol}$, so dissociation and recombination may dominate transport. Activation energies of $251 \mathrm{~kJ} / \mathrm{mol}$ estimated from thermal desorption measurements may have an additional detrapping component. Inward migration should show a different activation energy than outward migration. After neutron irradiation to $2 \times 10^{24} / \mathrm{m}^{2}$, the $\mathrm{H}$ solubility increases by a factor of $20-60$ over that of unirradiated graphite. Solubility saturates at the 0.3 dpa damage level. The H/C concentration ratio is proportional to the square root of the pressure.

The solubility of $D$ in PyC is $S_{0}=5.1 \times 10^{-8} \mathrm{D} / \mathrm{C}, E_{S}=1.44 \mathrm{eV}$.(Causey 1979) Solubility is proportional to the square root of the pressure.

Causey (1987) estimated the inventory for CIT of $3 \mathrm{~g}(\mathrm{~T})$ in the bulk graphite and $10 \mathrm{~g}(\mathrm{~T})$ in redeposited carbon films. Tritium retention variations among different graphites and composites were a factor of 4.

Co-deposition can contain an atom fraction T/C $\sim 0.6$.(Causey 1989a) The tritium is released by annealing at $1200 \mathrm{~K}$. By deposition of multiple layers, the trapped deuterium has reached $10^{19} / \mathrm{cm}^{2}$ in experiments, and thicker depositions are possible. The in-vessel inventory predicted for TFTR was $2.1 \mathrm{~g}$, and for CIT, $13 \mathrm{~g}$, mostly in co-deposited layers.

Causey (1990) compared saturated implantation layers with co-deposited layers. Tritium fraction remaining vs. temperature curves for the two types of layers are similar both in vacuum and in air. Both required $T>1000 \mathrm{~K}$ anneal to release tritium in vacuum, and both released tritium to air at $600 \mathrm{~K}$, probably due to isotopic exchange with $\mathrm{H}$ in water vapor. The saturated layer is amorphous, with a variety of bonding sites. During irradiation the saturated layer crystallite size decreased from $100 \mathrm{~nm}$ to $0.5 \mathrm{~nm}$. A loss of vacuum accident in a fusion reactor could result in prompt release of much of the co-deposited and saturated layer tritium.

Coad (1989) measured deuterium retained in JET walls after various campaigns, with areal densities up to $10^{22} / \mathrm{m}^{2}$. During 1987 about $40 \%$ of the fuel gas was retained in the walls, mostly in co-deposited carbon layers. During venting to air, much of this could be released, so precautions will be needed to prevent release of substantial amounts of tritium to the reactor hall.

Tritium is retained in the saturated implantation layer, in the co-deposited film with $\mathrm{C}$, in graphite pores, and in bulk trapping.(Federici et al. 1994) For ITER the tritium in the saturated layer is small (a few grams). The tritium in the co-deposited layer would be about 
0.13 gram per $1000 \mathrm{~s}$ of operation, which could grow to a large inventory if the layer were not periodically removed. The tritium in the graphite pores is estimated to be a few grams. The tritium inventory in bulk graphite neutron-damage traps could be as high as 2000 appm at saturation, which would be excessive. In one estimate the tritium inventory reached $2 \times 10^{23}$ $\mathrm{T} / \mathrm{m}^{2}$, of which about half was from the co-deposited layer. For a surface area of $\sim 1000 \mathrm{~m}^{2}$, this inventory would be about $1 \mathrm{~kg}$ of tritium in the graphite.

Sawicki et al. (1989) implanted specimens of JET graphite limiter tiles at $293 \mathrm{~K}$ with $\mathrm{DT}^{+}$and $\mathrm{HT}^{+}$ions at $10-50 \mathrm{keV}$ at fluences up to $3 \times 10^{16} / \mathrm{cm}^{2}$. Depth profiling with nuclear reaction analysis showed that the profiles did not change during outgassing. Tritium release peaked at $1100-1400 \mathrm{~K}$, with $95 \%$ release at $1600 \mathrm{~K}$. This is indicative of single-step detrapping (molecule formation in the bulk) followed by rapid diffusion and release of the molecule.

Scherzer et al. (1976) measured the depth profiles at $300-800 \mathrm{~K}$ of deuterium implanted into basal oriented pyrolytic graphite. The observed profiles do not coincide with range or damage profiles, but are a combination of them. The profiles broaden at high temperatures. Trapping increases almost linearly up to saturation. The saturation value decreases with increasing temperature

Scherzer et al. (1989) implanted deuterium implanted at $300 \mathrm{eV}$ into graphite, then bombarded it with protons at 6,12 , and $20 \mathrm{keV}$ at temperatures of 93 to $573 \mathrm{~K}$. There appeared to be two release mechanisms, relating to detrapping by bombarding ions (high temperatures) and to achievement of hydrogen saturation (low temperatures).

Scherzer et al. (1990) first implanted $6 \mathrm{keV} D^{+}$to saturation, then implanted $3 \mathrm{keV} \mathrm{D}^{+}$. Subsequent bombardment with $6 \mathrm{keV} D^{+}$produced recycling coefficients $R>1$. Hydrogen is trapped near the end of its range. When the incident ion energy changes, the recycling coefficient of a tokamak wall will change, causing the inventory to increase or decrease.

Shirasu et al. (1991) measured the solubility of $H$ and $D$ in isotropic graphites IG $110 \mathrm{U}$ and POCO AXF-5Q at $p<20 \mathrm{kPa}, T=973-1273 \mathrm{~K}$. The data obeyed Sievert's Law, and dissolution was exothermic. The solubility constants for $D$ are
IG 110U:
$S_{0}=3.38 \times 10^{-7}$ atom fraction $/ \mathrm{Pa}^{1 / 2}$
POCO AXF-5Q:
$S_{0}=1.52 \times 10^{-7}$ atom fraction $/ \mathrm{Pa}^{1 / 2}$
$E_{S}=-0.226 \mathrm{eV}$
$E_{S}=-0.236 \mathrm{eV}$.

Some solubility data were already given along with diffusivity data in Table 5.2. Additional data are listed in Table 5.3. Solubility in a highly oriented graphite was much lower than in these isotropic graphites. Some of the solubility data are illustrated in Figure 5.2. 
Table 5.3. Solubility constant for hydrogen in graphites, from Shirasu et al. (1993)

\begin{tabular}{llll}
$\begin{array}{l}\text { Type of } \\
\text { Graphite }\end{array}$ & $\begin{array}{l}\text { So } \\
\text { fraction/Pa1/2 }\end{array}$ & $\begin{array}{l}\text { Es } \\
\mathrm{eV}\end{array}$ & $\begin{array}{l}\text { Temperature Range } \\
{ }^{\circ} \mathrm{C}\end{array}$ \\
IG 110U & $5.04 \mathrm{E}-7$ & -0.189 & $700-1000$ \\
POCOAXF-5Q & $1.67 \mathrm{E}-7$ & -0.223 & $700-1000$ \\
ISO 880U & $1.37 \mathrm{E}-7$ & -0.228 & $700-900$ \\
ISO 880U & $9.24 \mathrm{E}-9$ & -0.499 & $900-1000$ \\
EK98 & $4.13 \mathrm{E}-7$ & -0.140 & $700-800$ \\
EK98 & $9.24 \mathrm{E}-9$ & -0.493 & $800-1000$ \\
\hline
\end{tabular}

Stangeby et al. (1984) trapped sub-eV atomic $H$ and $D$ in pyrolytic and papyex graphite. The trapped fluences were about an order of magnitude lower than those obtained with $50 \mathrm{eV} \mathrm{D}^{+}$ion implantation. The deuterium penetrates deeper into the papyex than into the pyrolytic graphite.

Strehlow (1985) measured tritium uptake in various graphites at $448-1023 \mathrm{~K}$ at $\mathrm{p}\left(\mathrm{T}_{2}\right)=$ $0.14 \mathrm{~Pa}$ or $\mathrm{p}\left(\mathrm{T}_{2} \mathrm{O}\right)=0.04 \mathrm{~Pa}$ for several hours. The sorption capacity was a function of the BET surface area, because porosity facilitated tritium transport to the interior of the specimens. A few $\mathrm{mg}$ of tritium were sorbed per $\mathrm{kg}$ of graphite in specimens with low surface area $\left(\sim 1 \mathrm{~m}^{2} / \mathrm{g}\right)$.

Since hydrogen easily permeates through sintered graphite, all crystallites are exposed to the hydrogen gas.(Tanabe 1994) The degree of graphitization $G(0<G<1)$ is related to the grain size and porosity, so measurements of the apparent "solubility" should be judged with regard to the value of $G$ at which the measurements were taken. Such measurements indicate decreasing "solubility" with increasing values of $G$. The "true" solubility is probably the limit as $G \rightarrow 1$, which is lower solubility than past measurements. Gaseous hydrogen bonding to $C$ would lose $4.3 \mathrm{eV}$ to break the $\mathrm{H}-\mathrm{H}$ bond and gain $4 \mathrm{eV}$ in bonding to $\mathrm{C}$, for a net energy of $-0.3 \mathrm{eV}$, which is consistent with the apparent heat of solution. Hydrogen molecules may also accumulate in lenticular openings between the basal planes of graphite, increasing the apparent solubility at low temperatures. The "solubility" reported in past literature is probably due to trapping effects, and not the "true" value.

A limit of $2 \mathrm{~g}$ releasable tritium was set for the Burning Plasma Experiment (BPX). (Ulrickson 1992) Tritium trapped in bulk graphite was not considered vulnerable to release during an accident. The worst case scenario assumed $0.25 \mathrm{~T} / \mathrm{C}$ at $350^{\circ} \mathrm{C}$ in the codeposited $\mathrm{C}$ layer, which would accumulate 2 grams after about 35 shots. The expected case would reach the $2 \mathrm{~g}$ limit after 132-264 shots. Periodic helium/oxygen glow discharge cleaning was planned to remove the codeposited carbon film, with a removal rate $\sim 0.1 \mathrm{~nm} / \mathrm{s}$. Controlled air exposure to the torus at $350^{\circ} \mathrm{C}$ could also be used to remove carbon films from areas not reached by glow discharge cleaning. 


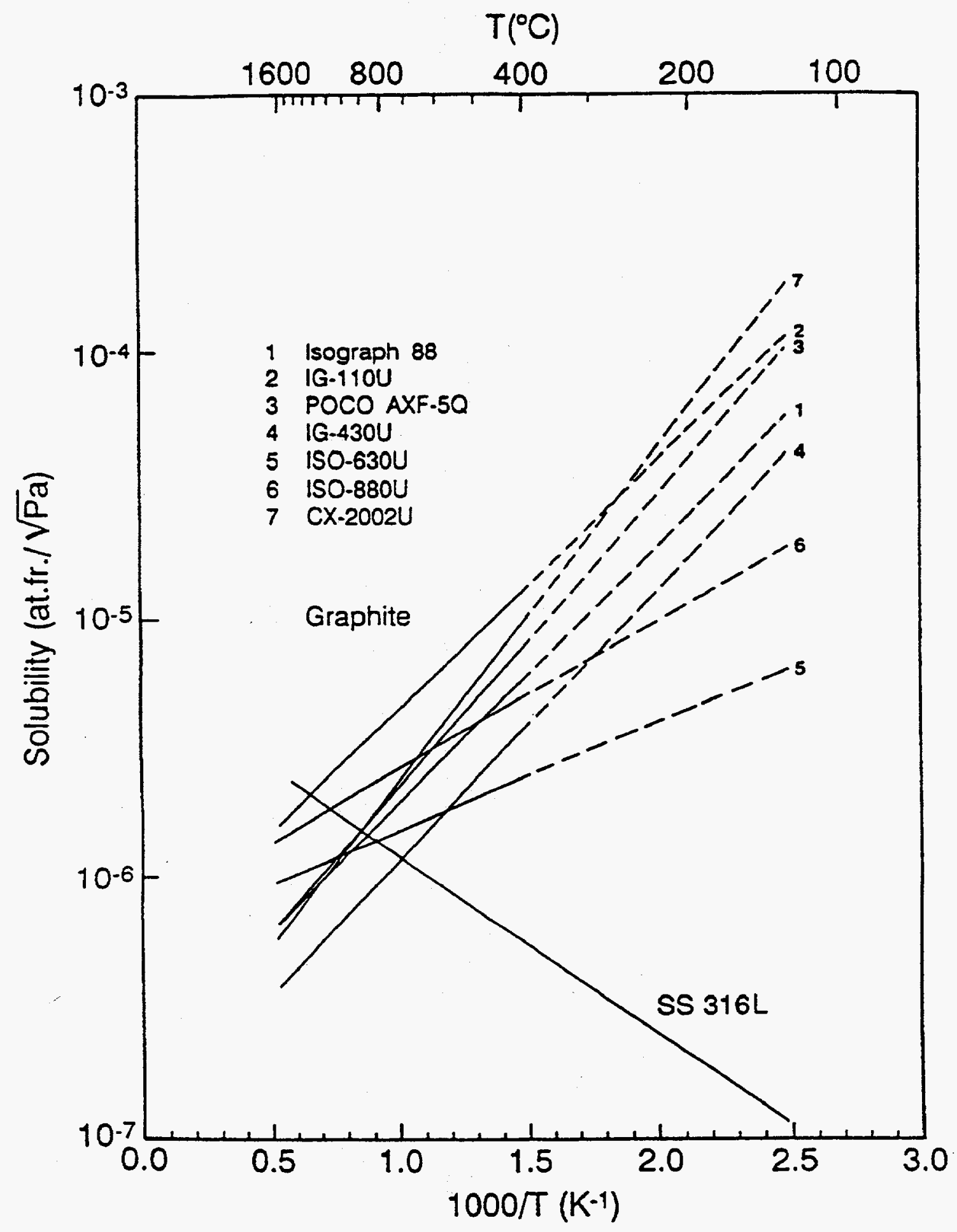

Figure 5.2 Tritium solubilities in various types and grades of graphite. From Reiter et al. (1993). 
Wampler et al. (1990) studied several types of graphite, with lattice damage produced by 6 $\mathrm{MeV} \mathrm{\textrm {C } ^ { + }}$ ions or by neutrons. A model was developed to relate tritium retention to lattice damage. The retained tritium mass may be estimated conservatively from

$$
\mathrm{T}=\mathrm{acm}
$$

where $\mathrm{a}=1.25 \times 10^{-7}$ /appm, $\mathrm{m}=$ graphite mass, and $\mathrm{c}=$ concentration of retained tritium given by

$$
c=c_{s}\left[1-\exp \left(-d / d_{s}\right)\right]
$$

$c_{S}=$ saturation concentration of traps, $d=$ damage (dpa), and $d_{S}=$ saturation damage (dpa).

For graphites H4512, POCO, and Graphnol N3M $c_{S}=450 \mathrm{appm}$ and $d_{S}=0.035 \mathrm{dpa}$. For the highly oriented pyrolytic graphite (HOPG) $c_{s}=80 \mathrm{appm}$. The actual value of tritium retention is likely to be lower than predicted by these equations, because

(1) tritium may not penetrate the entire bulk of the graphite;

(2) tritium uptake may be slower than the deuterium gas uptake measured here; and

(3) the tokamak tile operating temperature may be higher than this experiment temperature.

There are fewer solubility data than diffusivity data sets; but still a wide spread of values, with energies of solution from $-0.2 \mathrm{eV}$ to $-1.45 \mathrm{eV}$.(Wilson et al, 1991) Wilson et al (1991) and Causey (1989a) recommend the following as a "best value" for solubility:

$$
S=6.44 \times 10^{-5} \exp (0.2 \mathrm{eV} / \mathrm{kT}) \text { atom fraction } / \mathrm{atm}^{1 / 2} \text {. }
$$

\section{Chemical reactions}

Braganza (1978) bombarded graphite targets with $D^{+}$ions at 5-30 keV, and measured gas reemission. A methane production rate equation was derived and compared with data. Methane production was maximum at $750-850 \mathrm{~K}$. The cross section for ion-induced re-emission decreased from $3 \times 10^{-17} \mathrm{~cm}^{2}$ (at $3 \mathrm{keV}$ ) to $6 \times 10^{-19} \mathrm{~cm}^{2}$ (at $30 \mathrm{keV}$ ). First-order thermal desorption fit the data better than second order. Ion-induced release was important in methane production.

Methane production is maximum at $500-600^{\circ} \mathrm{C}$.(Braun 1984)

Hirooka et al (1990) studied graphites containing 1-30\% boron with plasma bombardment at 473-1873 K. The boron reduced erosion and hydrocarbon production. A boron concentration of $10 \%$ reduced the deuterium inventory by about an order of magnitude above $1273 \mathrm{~K}$, perhaps due to boron occupying trapping sites or deactivating unsaturated bonds. A $10 \%$ boron concentration hindered air oxidation almost completely at $1073 \mathrm{~K}$, and reduces steam oxidation by a factor of $1-3$ at $1373-1623 \mathrm{~K}$. The critical heat flux to induce cracking was about the same as for pure graphite.

Hirooka et al (1991) found that erosion rates were reduced by addition of boron to graphite. Deuterium retention was maximum at about $600 \mathrm{~K}$, where boron increased the deuterium retention in the graphite by up to a factor of two at high boron concentration ( $90 \%$ by weight). Boron increased oxidation resistance.

Roth and Bohdansky (1987) coated a $20 \mathrm{~nm}$ layer of ${ }^{13} \mathrm{C}$ onto ${ }^{12} \mathrm{C}$ substrate. During ion implantation $\mathrm{CH}_{4}$ was formed from ${ }^{13} \mathrm{C}$ only by ions with ranges less than $20 \mathrm{~nm}$. Therefore, the methane was formed at the end of the ion ranges. Release of the $C D_{4}$ is diffusion-limited. 
Vietzke et al. (1987) measured chemical erosion yields from amorphous carbon films. Atomic hydrogen produced $\mathrm{CH}_{3}$ radicals, $\mathrm{C}_{2} \mathrm{Hx}$, and $\mathrm{C}_{3} \mathrm{Hx}$ with a ratio of $1: 3 / 4: 1 / 2$. The total erosion yield was about 0.02 eroded carbon atoms per incident $\mathrm{H}$ atom. Hydrogen ion impact yielded mainly $\mathrm{CH}_{4}$, with smaller amounts of other hydrocarbons, and a total erosion yield of about $0.08 \mathrm{C} / \mathrm{H}$.

Vietzke and Philipps (1987) reviewed surface modifications of amorphous graphite films due to impact of $\mathrm{H}$ atoms and ions. The threshold for lattice damage by $\mathrm{D}$ was $50 \mathrm{eV}$. Electrical resistance increased by 8 orders of magnitude at high fluences of $3 \mathrm{keV}$ deuterons. Thermal conductivity changes were not measured. The physical sputtering yield was similar to that of pure graphite. Atomic deuterium predominantly formed $C D_{3}$, while energetic deuterium ions predominantly formed $C D_{4}$.

Vietzke et al. (1989) studied interaction of $\mathrm{H}$ atoms with graphite damaged and loaded by previous ion bombardment. The erosion yields were an order of magnitude higher than for pure graphite. The increased reactivity was believed to be related to dangling bonds produced by prior irradiation.

\section{Thermal gradient driven diffusion (Soret effect)}

No information on the Soret effect in graphite was found.

\section{Surface effects}

Seven basic processes occur in co-deposition of $H$ and $C$ (Federici and Wu 1993):

(1) adsorption of incident $\mathrm{H}$ and $\mathrm{H}_{2}$

(2) implantation of energetic $\mathrm{H}^{+}$ions and $\mathrm{cx}$ neutrals

(3) detrapping due to ion-induced desorption

(4) $\mathrm{C}-\mathrm{H}$ bond formation by chemisorption or by co-deposition

(5) thermal desorption of $\mathrm{H}$ and $\mathrm{H}_{2}$

(6) bulk diffusion

(7) erosion (physical sputtering, chemical sputtering, thermal sublimation, radiation enhanced sublimation). This study neglected chemisorption and bulk diffusion and incorporated model equations for the other processes. Three hydrogen states were modeled: implanted, adsorbed, and chemically bonded by co-deposition. The $\mathrm{H} / \mathrm{C}$ ratio in co-deposited films was about 0.38 (at $373 \mathrm{~K}$ substrate temperature), 0.03 (873 K) and 0.04 (1173 K).

Experimental data on walls samples from tokamaks indicated that films grew linearly with time. At $300 \mathrm{~K}$ the $\mathrm{H}$ deposition rate can be as high as $10^{20} \mathrm{H} / \mathrm{m}^{2} \mathrm{~s}$. Annealing in vacuum at $\mathrm{T}>1073$ $\mathrm{K}$ or in air at $\mathrm{T}>623 \mathrm{~K}$ was required to release all the hydrogen in the co-deposited layer. $A$ helium glow discharge was ineffective at removing the co-deposited film unless substantial oxygen ( 10\%) was added to the plasma.

Ashida et al. (1982-1992) studied chemical bonding of implanted $D$ with $C$ atoms, and found that $\mathrm{C}-\mathrm{D}$ and $\mathrm{C}_{2}-\mathrm{D}$ bonds were produced. Some methane was also produced above $500^{\circ} \mathrm{C}$. The reaction probabilities for production of $\mathrm{CO}$ were $.008\left(200{ }^{\circ} \mathrm{C}\right)$ and $0.022\left(900{ }^{\circ} \mathrm{C}\right)$. For production of $\mathrm{CO}_{2}$ the probabilities were $0.0004\left(200^{\circ} \mathrm{C}\right)$ and $0.0008\left(900^{\circ} \mathrm{C}\right)$. Radiation damage enhanced the reactivity of $\mathrm{C}$ with $\mathrm{O}$. At $525^{\circ} \mathrm{C}$ the $\mathrm{CH}_{4}$ yield was $0.07 \mathrm{CH}_{4}$ /ion incident, decreasing to 0.01 at $350^{\circ} \mathrm{C}$. Impurities like Fe can catalyze oxidation of C.(Ashida 1985) 
In an analysis of JET graphite limiters Bergsåker (1987) found hydrogen to depth of $1-5$ micrometers. $H$ was co-deposited with carbon to a concentration of $10^{22} / \mathrm{m}^{2}$.

Fernandez (1992) found that addition of boron to graphite increased the thermal desorption rate of $D_{2}$ and decreased the emission of deuterocarbons.

Franconi (1990) impregnated graphite with SiC and irradiated it with deuterons in PISCES-A at 573-1273 K. With pure CL5890PT isographite the deuterium concentration was $1.2 \times 10^{22} \mathrm{D} / \mathrm{cm}^{2}$, but with $\mathrm{SiC}$ in the graphite, the concentration dropped to $2 \times 10^{21} \mathrm{D} / \mathrm{cm}^{2}$.

Franzen (1992) implanted $3 \mathrm{keV} \mathrm{D}^{+}$into graphite at $\mathrm{T}=800-1800 \mathrm{~K}$, then monitored the reemitted $\mathrm{D}_{2}$ and $\mathrm{HD}$ by residual gas analysis. As the graphite temperature was increased, deuterium retention in the graphite decreased, and the re-emitted flux gradually shifted from about $95 \%$ molecular deuterium near $700 \mathrm{~K}$ to $95 \%$ atomic deuterium at $1850 \mathrm{~K}$.

Garcia-Rosales (1992) found that boron in the graphite suppressed chemical reactivity in the bulk. In the surface layer hydrocarbon formation persisted, perhaps due to boron depletion there.

Kitajima and Aoki (1989) exposed graphite to a hydrogen glow discharge, with pressure monitoring, Raman scattering, and SIMS analyses. The ion impact desorption cross section varied from $3 \times 10^{-17} \mathrm{~cm}^{2}$ at $373 \mathrm{~K}$ to about $2 \times 10^{-16} \mathrm{~cm}^{2}$ at $673 \mathrm{~K}$. The glow discharge caused refining of the microcrystallite and partial amorphous layer formation with hydrogen saturation.

R. A. Langley (1989b) implanted $H$ to saturation in AXF-5Q graphite, then bombarded it with $300-500 \mathrm{eV} \mathrm{He}$ ions. The ion-induced release cross section was $1.8 \times 10^{-16} \mathrm{~cm}^{2}$ (at $300 \mathrm{eV}$ ) and $1.4 \times 10^{-16} \mathrm{~cm}^{2}$ (at $500 \mathrm{eV}$ ). The presence or absence of carbon deposits did not vary the cross sections substantially.

Morita (1991) observed that carbon/metal films on surfaces suppressed sputtering. The effective detrapping rate of $\mathrm{D}$ atoms trapped in $\mathrm{Cr}_{7} \mathrm{C}_{3}$ was two order of magnitude higher than that in graphite. Thus, metal films may be useful to reduce tritium inventory in graphite.

Roth et al (1980) implanted deuterium at 1 and $8 \mathrm{keV}$ in papyex and pyrolytic graphite. The detrapping yields and cross sections were measured for impact of $0.79 \mathrm{MeV} \mathrm{H}^{+}, 0.4-2.5 \mathrm{MeV}$ ${ }^{3} \mathrm{He}^{+}$, and $0.4-1.6 \mathrm{MeV}{ }^{14} \mathrm{~N}^{+}$ions. Detrapping cross sections were on the order of 4-6 $\times 10^{-16} \mathrm{~cm}^{2}\left(\mathrm{~N}^{+}\right), 0.6-5 \times 10^{-18} \mathrm{~cm}^{2}\left(\mathrm{He}^{+}\right)$, and $10^{-19} \mathrm{~cm}^{2}(\mathrm{H}+)$. A table of cross sections was given.

Waelbroeck et al. (1989) used a model to predict oxygen and hydrogen transport into and out of the graphite surface. Repetitive glow discharges can be used to reduce the near-surface oxygen and hydrogen concentrations, in order to control plasma purity, plasma density, and tritium inventory.

Wampler and Doyle (1989) implanted carbon to saturation with $300 \mathrm{eV} \mathrm{D}$, then bombarded it with 0.6 and $1.2 \mathrm{keV} \mathrm{He}+$ and $3 \mathrm{keV} \mathrm{C}^{+}$ions. The ion bombardment increased deuterium release from the carbon with a yield up to $10 \mathrm{D}$ per incident ion. A model for $\mathrm{D}$ release from the TFTR limiter agreed with observed $D$ removal during supershot conditioning. Peak detrapping cross 
sections were $0.059 \mathrm{~nm}^{2}(3 \mathrm{keV} \mathrm{C}), 0.033 \mathrm{~nm}^{2}(1.2 \mathrm{keV} \mathrm{He})$, and $0.004 \mathrm{~nm}^{2}(0.6 \mathrm{keV}$ $\mathrm{He}^{+}$).

Winter (1987a, b) defined "carbonization" as the plasmachemical in situ deposition of homogeneous, thin, carbonaceous films on the entire first wall of a fusion device. Carbonization resulted in significant improvement of TEXTOR plasma performance, with regard to impurities and plasma density. The deposition was done by radiofrequency-assisted glow (RG) discharges containing hydrocarbon gases. The films were amorphous, semi-transparent, homogeneous without macroporosity, and contained a large fraction of hydrogen, $\mathrm{H} / \mathrm{C} \sim 0.4$. After application of a coating 300 monolayers thick, the coating lasted about 100 three-second discharges before metal impurities again reappeared. Isotope exchange in amorphous hydrocarbon films occurred predominantly via replacement reactions of implanted energetic particles. Carbonization might permit the use of carbon where graphite cannot be used because of swelling problems. The tritium inventory might be lower than with an all-graphite or all-stainless steel wall.

Recycling coefficients $R>1$ can occur with low wall temperatures, as saturated walls are heated by the plasma discharge. At high wall temperatures $R<1$ can be achieved, with good reproducibility of the plasma density evolution.

The thin carbonaceous films have density $1.4 \mathrm{~g} / \mathrm{cm}^{3}$ and average $\mathrm{C}-\mathrm{C}$ atomic distance $\sim 0.25$ $\mathrm{nm}$.(Winter et al. 1987c) They are semi-transparent, amorphous, and homogeneous down to about $1 \mathrm{~nm}$. During heating they release $\mathrm{H}_{2}$ and $\mathrm{CH}_{4}(\sim 3-10 \%)$, with peak $\mathrm{CH}_{4}$ desorption at about $773 \mathrm{~K}$. After release of the $\mathrm{CH}_{4}$ the films turn black.

Winter et al. (1987d) explained how wall pumping can be controlled. By short glow discharges at low wall temperatures $(<423 \mathrm{~K})$ the $H$ concentration in the carbonized wall surface can be increased, leading to $R>1$ (fueling) during tokamak discharges. The $H$ concentration can be decreased by outgassing in vacuum at $T>623 \mathrm{~K}$, leading to $R<1$ (pumping) during subsequent tokamak discharges. Keeping the TEXTOR wall and limiters at $623 \mathrm{~K}$ resulted in reproducible plasmas from shot to shot.

Yamaguchi et al (1991) compared permeability of isotropic graphites coated with amorphous carbon (a-C:H) or with pyrolytic carbon $(\mathrm{PyC})$. An a-C:H film < 10 micrometers thick did not affect the bulk graphite permeability, due to its porosity. Dense PyC films $>5$ micrometers thick totally suppressed the permeation at room temperature.

Yamashina and Hino (1989) surveyed different types of graphite for possible use in a fusion reactor first wall, including vacuum properties, thermal properties, mechanical properties, and interactions with plasmas. Fifteen institutions participated in the "Graphite Project Team" and studied 18 different types of graphite from seven manufacturers in Japan. Vacuum properties such as surface area, gas desorption and hydrogen permeation depended significantly on the graphite pore structure. Most of the graphites failed at about the same heat load, and they had about the same fracture toughness. Suriace morphology changes by ion bombardment and desorption of trapped ions were also studied.

Yamashina and Hino (1991) recommend that graphite walls be baked at $623-673 \mathrm{~K}$ to reduce the oxygen impurity level. Both outgassing and the effective surface area increase with graphite density, so low density graphite is adequate as a first wall material. Pyrolytic carbon cracks easily along the basal plane from high thermal shock loading. Chemical sputtering peaks at about $900 \mathrm{~K}$, and the yield can be suppressed by thin coatings of $\mathrm{Ti}, \mathrm{Fe}$, or $\mathrm{Cr}$ on the graphite. Carbon/carbon composite has good shock resistance and reasonable surface area and outgassing rates, so it can be used in high heat flux areas. Radiation enhanced sublimation (due to bombardment by keV DT ions) can have an erosion yield of $0.1-0.3$ at $T=1800-2000 \mathrm{~K}$, and a means of suppressing it is needed. 


\section{Surface recombination coefficient and dissociation coefficient}

Ichimura et al. (1987) give recombination coefficients for $H, D$, and T. For tritium: $\mathrm{k}_{\mathrm{r}}=2.63 \times 10^{-15} \exp (-0.61 \mathrm{eV} / \mathrm{kT}) \quad \mathrm{cm}^{4} / \mathrm{sec}-$ molecule.

K. Watanabe and K. Ashida (1985) implanted ions of H, D, or T into PG-A pyrolytic graphite and the measured the thermal desorption spectra, observing three peaks. The first peak was ascribed to hydrogen atoms trapped on the normal graphite lattice in the basal plane. From these data the activation energies for desorption were found to be $1.91 \mathrm{eV}$ for all three isotopes. The surface recombination coefficients were estimated to be:

$$
\begin{array}{lll}
\mathrm{k}_{r}\left(\mathrm{H}_{2}\right)=13.0 \times 10^{-19} \exp (-1.91 \mathrm{eV} / \mathrm{kT}) & \mathrm{cm}^{4} / \mathrm{s} \text {-molecule } \\
\mathrm{k}_{r}\left(\mathrm{D}_{2}\right)=7.18 \times 10^{-19} \exp (-1.91 \mathrm{eV} / \mathrm{kT}) & \mathrm{cm}^{4} / \mathrm{s} \text {-molecule } \\
\mathrm{k}_{r}\left(\mathrm{~T}_{2}\right)=5.26 \times 10^{-19} \exp (-1.91 \mathrm{eV} / \mathrm{kT}) & \mathrm{cm}^{4} / \mathrm{s}-\text { molecule }
\end{array}
$$

Pseudo-surface recombination factors were also derived.

\section{Trap site characterization and effects}

The Brice (1990) model accounted for four sources of recombination:

(1) direct recombination of the incident $H$ beam at the end of its range,

(2) recombination of beam-displaced $\mathrm{H}$ atoms,

(3) tunneling recombination, which accounts for thermal release properties, and

(4) diffusive recombination.

The diffusion coefficient for atomic $\mathrm{H}$ was extremely small, however. This model considered 2.8 $\mathrm{eV}$ traps and shallow traps $\left(E_{C}=0.42 \mathrm{eV}\right.$ ) inhibiting diffusion recombination. Three states of hydrogen were considered: "ground state" (excitation below $E_{C}$ ), "excited state" (excitation above $\mathrm{E}_{\mathrm{C}}$ ), and diffusing $\mathrm{H}_{2}$ molecules. A single set of model parameters gave reasonable fit to isochronal anneal $\mathrm{H}_{2}$ emission data, saturation inventory, and ion-induced release data.

Lomidze et al. (1994) developed a model based on the hypothesis that reemission is dominated by interaction of incident ions with deuterium in already filled $C D$ and $C D_{2}$ traps. The main reactions are:

$$
\begin{array}{lll}
C & k_{0} & \\
C & \cdots> & C D \\
C D+D & k_{1} & \\
& \cdots> & C D_{2} \\
C D+D & k_{1} & \\
& \cdots> & C+D_{2} \\
C D_{2}+D & -\cdots> & C D+D_{2}
\end{array}
$$

Based on these equations and experimental data, numerical values were estimated for the rate coefficients $\mathrm{kj}_{\mathrm{j}}$. Model predictions agreed with experimental data for several cases. At $T>1000$ $K$ the concentration of $C D_{2}$ traps was small, and about half the traps remained unfilled. This model may prove useful in predicting tritium behavior in fusion reactor graphite.

Isotropic graphite contains non-graphitized carbon atoms that act as trapping sites for $\mathrm{H}$ atoms, increasing $\mathrm{H}$ inventory.(Ashida 1988a) lon bombardment damage reduces crystallite size of 
graphite and leads to an amorphous-like structure. Three desorption peaks were identified in the thermal desorption spectra, and their mechanisms were determined. Mechanisms affecting the desorption spectra were discussed. Above $1000^{\circ} \mathrm{C}$ the crystallite size of graphite in which tritium was uniformly distributed was the primary determinant of the tritium inventory. After 7 hours annealing at $1000^{\circ} \mathrm{C}$ about $35 \%$ of the tritium remained in anisotropic graphite, but only a few \% remained in isotropic graphite.

Crystallite sizes of isotropic graphites were $10-30 \mathrm{~nm}$, while those of anisotropic graphites were about 100-300 $\mathrm{nm}$.(Ashida 1988b) Nongraphitized carbon in isotropic graphites acts as trapping sites for $\mathrm{H}$ atoms. The species producing $\mathrm{C}_{2} \mathrm{H}^{-}$is the hydrogen trapped in the nongraphitized portion of the samples, and the species producing $\mathrm{CH}^{-}$is the hydrogen trapped in the normal graphite lattice. Doping graphite with other elements greatly influences the behavior of implanted $\mathrm{H}$ atoms, and may be used to reduce the tritium inventory.

Braun and Emmoth (1984) implanted $\mathrm{D}^{+}$ions into $\mathrm{C}$ at $2-20 \mathrm{keV}$ and $25-1000{ }^{\circ} \mathrm{C}$. Below 500 ${ }^{\circ} \mathrm{C}$ ion induced detrapping was dominant, above $900^{\circ} \mathrm{C}$ thermal desorption was dominant, and both were significant between 500 and $900^{\circ} \mathrm{C}$. The ion induced detrapping cross section was found to be about $2-3 \times 10^{18} \mathrm{~cm}^{2}$.

The naturally occurring trap density was about 20 appm, while that from neutron damage may be $>0.1 \%$.(Brereton 1991) A damage trap level of $0.1 \%$ was reached after about $0.014 \mathrm{MW}$ $\mathrm{y} / \mathrm{m}^{2}$ (about $0.1 \mathrm{dpa}$ ). At $10 \mathrm{dpa}$, a damage trap concentration of $0.2 \%$ was expected. Tables of the ITER tritium inventory $\left(\mathrm{g} / \mathrm{m}^{3}\right)$ vs. grain size, trap concentration, gas pressure were given. The first wall tritium pressure was assumed to be $0.1 \mathrm{~Pa}$, and the divertor pressure was assumed to be $10 \mathrm{~Pa}$.

Brice et al. (1982) described the Extended Local Mixing Model, including effects of thermal release. Incident hydrogen was trapped where it stopped until saturation was reached. Above saturation additional hydrogen resulted in loss of hydrogen isotopes with isotopic mix corresponding to that of the saturated region. The theory gave good agreement with experimental data on thermal desorption and fluence. The volume of the disturbed region at the end of the implanted ion paths was about 40 trap sites (90 lattice sites), roughly equal to the volume of a sphere with radius $0.6 \mathrm{~nm}$, or about $0.7 \mathrm{eV} / \mathrm{trap}$ site. Beam-enhanced thermal transport promoted hydrogen from strong traps to weaker traps, and it accounted for half the $\mathrm{H}$ release at $800-900 \mathrm{~K}$.

In POCO graphite Causey (1986) found that below $1000 \mathrm{~K}$ retention was characterized by saturation of the near-surface region and by surface diffusion on internal porosity. Above $1000 \mathrm{~K}$, the retention appeared to be controlled by transgranular diffusion with decoration of high energy $(4.3 \mathrm{eV})$ traps.

Above $1100 \mathrm{~K}$ the tritium began to diffuse into graphite grains where it decorated high energy traps, resulting in tritium concentrations of $5-20$ appm. Tritium retention was maximum at about $1400 \mathrm{~K}$. (Causey 1987)

According to Causey (1989a) the trap energy of $4.3 \mathrm{eV}$ is about equal to $\mathrm{H}-\mathrm{C}$ bond energy, suggesting that chemical bonding is a major trapping mechanism. The observed trap density was 17 appm. Higher trap concentrations could be produced by neutron irradiation. A concentration $\sim 1 \%$ could trap $2.5 \mathrm{~kg}$ of tritium in 20 tonnes of graphite.

Causey (1992) found that boron-doped graphite retained 5-10 times less tritium than undoped graphite. The boron may attach to the tritium trapping sites and neutralize them. 
Fukuda (1989) measured single-peak thermal desorption spectra from pure graphite, and calculated desorption activation energies of $0.78 \mathrm{eV}$ for $\mathrm{H}_{2}$ and $1.81 \mathrm{eV}$ for $\mathrm{CH}_{4}$. With deposited metallic impurities, a second peak appeared in the $\mathrm{H}_{2}$ spectra corresponding to energies of 0.26 $\mathrm{eV}(\mathrm{Ti} / \mathrm{C}), 0.83 \mathrm{eV}(\mathrm{Cr} / \mathrm{C})$, and $1.24 \mathrm{eV}(\mathrm{Fe} / \mathrm{C})$. The metallic impurities (especially $\mathrm{Fe}$ ) decreased the emission of $\mathrm{CH}_{4}$.

Morita and Muto (1992) studied emission profiles with elastic recoil detection. The model accounts for recombination of activated hydrogen atoms with trapped $\mathrm{H}$ atoms and with other activated $\mathrm{H}$ atoms. The activation energies for detrapping are $0.60 \mathrm{eV}$ for both $\mathrm{H}$ and $\mathrm{D}$, and the activation energy for migration is $0.20 \mathrm{eV}$, so the effective binding energy at the trapping site is $0.40 \mathrm{eV}$, close to the $0.35 \mathrm{eV}$ determined by Brice.

Muto and Morita (1992) presented model equations for recombination of activated $\mathrm{H}$ atoms with trapped $\mathrm{H}$ atoms and with other activated $\mathrm{H}$ atoms. From a comparison of model predictions with experimental data, it was determined that recombination of activated $\mathrm{H}$ atoms with each other was dominant: the decay curve had an initial steep drop (almost all trap sites filled), followed by a very slow decline (due to strong retrapping in empty sites). The activation energy for thermally activated detrapping was $0.50 \mathrm{eV}$. Since the diffusion activation energy is $0.20 \mathrm{eV}$, the binding energy is about $0.30 \mathrm{eV}$, close to the $0.35 \mathrm{eV}$ determined by Brice.

Siegele et al. (1993) implanted highly oriented pyrolytic graphite (HOPG) with $10-30 \mathrm{keV}$ $\mathrm{D}_{3}{ }^{+}$at $293-773 \mathrm{~K}$ at fluences up to $10^{18} \mathrm{D} / \mathrm{cm}^{2}$. The implanted $\mathrm{D}$ was retained about $100 \%$ until saturation was reached $(0.4 \mathrm{H} / \mathrm{C}$ at $293 \cdot \mathrm{K})$. The damage rate measured by Rutherford Backscattering was about ten times that predicted by the TRIM code assuming $25 \mathrm{eV}$ displacement energy. At $773 \mathrm{~K}$ the damage accumulated almost exponentially, not linearly with fluence. The damage measured with RBS began to saturate well below the fluence where amorphization is observed by TEM.

Sugai et al.(1989) studied release of $\mathrm{H}_{2}$ and $\mathrm{HD}$ from a pulsed deuterium discharge over a carbon thin-film coated wall. With a $\mathrm{D}_{2}{ }^{+}$plasma much hydrogen was desorbed. In view of the linear relation between $\mathrm{H}$ emission and discharge current, the hydrogen molecule formation was probably due to a hydrogen abstraction process, where an incident beam atom or detrapped free atom recombines with an $\mathrm{H}$ atom trapped interstitially or chemically bonded. With a helium admixture, a wall pumping effect was observed, which was believed to be due to hydrogen trapping at interstitial vacancies.

A fit to experimental data by the DIFFUSE code yielded a trap density of 17 appm and trap energy of $4.3 \mathrm{eV}$, which is close to the bond energy of $\mathrm{H}$ and $\mathrm{C}$ in typical hydrocarbons.(Wilson et al 1991)

\section{Porosity}

Manufactured graphite contains hydrocarbons and hydrogen, which must be removed by conditioning before it is ready for use in a tokamak. Fine-grained graphite is porous and adsorbs gases, especially water vapor during exposure to air. Outgassing temperatures over $350^{\circ} \mathrm{C}$ are recommended for future machines.(Bohdansky 1989)

The surface has pores extending about 25 micrometers in, so the release measurements give an effective diffusion coefficient, rather than a true bulk value. (Causey 1979) 
Causey et al. (1986) found extensive interconnected surface porosity in POCO AXF-5Q graphite. There was probably chemisorption on internal porosity with diffusion along pore surfaces to deeper depths.

Causey et al. (1987) irradiated 12 types of graphite in the Tritium Plasma Experiment to measure tritium retention. The saturated layer contained only $20-30 \%$ of the total tritium retained. Surface diffusion along porosity moved the tritium to a depth of $2-3 \mathrm{~mm}$ during 1.5 hours.

There were up to $10^{9}$ pores $/ \mathrm{cm}^{3}$, with pore diameters ranging from $1 \mathrm{~nm}$ to $1 \mathrm{~mm}$.(Causey 1989a) High concentrations were reached, with no evidence of saturation at fluences over $2 \times 10^{20} / \mathrm{cm}^{2}$. Penetration of $2 \mathrm{~mm}$ was observed after 1.5 hours at $773 \mathrm{~K}$. This rapid deep penetration could be avoided by using pyrolytic graphite with little porosity.

Federici and Wu (1992) developed the "Tritium Inventory in Porous Materials" (TIPO) model and code to predict tritium inventory in porous materials such as graphite. The model assumes pores of radius $\mathrm{r}_{\mathrm{ip}}$, effective pore length $\mathrm{L}_{\mathrm{e}}$ surrounded by spherical grains of radius $\mathrm{ip}$. It describes migration along interconnected pores in terms of the Brunauer-Emmett-Teller $(B E T)$ surface area, porosity $\varepsilon_{p}$, $r_{i p}, L_{e}$, and $\mathrm{rg}$. At high temperatures $H$ is not absorbed on perfect basal planes of carbon, and only a fraction of the total BET surface area may be active in chemisorption. The internal graphite surfaces are covered with a number of sites at which $\mathrm{H}$ may be held. The flow in the pores is in the Knudsen diffusion regime, where molecules collide with the pore walls more frequently than with each other. After adjusting the model parameters, the model gives a good fit to experimental data on retained fluence in pyrolytic graphite at 300,600 , and $900 \mathrm{~K}$. For a carbon/carbon composite tokamak wall a maximum inventory $\sim 0.1 \mathrm{~g}(\mathrm{~T}) / \mathrm{m}^{2}$ wall area is predicted. Assuming porosity is roughly proportional $B E T$ area, the predicted tritium inventory increases almost linearly with BET area. More study is needed of the effects of impurities such as oxygen on tritium uptake and transport.

Kiyoshi et al.(1988) studied permeation of hydrogen through graphite at pressures of 0.5 to $100 \mathrm{~Pa}$ and temperatures of 290 to $983 \mathrm{~K}$. The graphite samples had thickness $1 \mathrm{~mm}$, density $1.91 \mathrm{~g} / \mathrm{cm}^{3}$, grain size 1 micrometer, pore size 0.1 micrometer, and $9 \%$ porosity. The permeation of hydrogen through graphite could be described in terms of molecular flow through pores in the graphite, and the permeability was proportional to $T^{-1 / 2}$.

G. Kögel et al. (1988) used positron lifetime measurements in a thin film of amorphous hydrogenated carbon. They concluded that at least $3 \%$ of the volume was occupied by micropores about $0.5 \mathrm{~nm}$ in diameter, which could facilitate diffusion of molecular $\mathrm{H}_{2}$.

Möller and Scherzer (1987) separately implanted $D$ and $H$ at different depths, and found evidence that molecules form in the bulk, then diffuse to the surface. If the atoms migrated to the surface and then recombined, then HD molecules should have been equal in number to $D_{2}$ molecules, but the observed ratio of $H D / D_{2}$ was only about $1 / 3$, which is consistent with molecular recombination near the implantation sites. Such subsurface recombination occurs only in highly radiation-damaged lattices. Microporosity may be important in facilitating this recombination.

\section{Permeation in layered structures}

Data on permeation through layered structures, such as graphite bonded to copper, were not found. 


\section{Transport along grain boundaries}

Transport along grain boundaries was studied by Ashida and Watanabe (1991), as discussed above under "diffusivity."

\section{Trapping and permeation at interfaces between materials}

Trapping and permeation at interfaces between materials was not discussed at length in the references consulted.

\section{Assessment}

A nuclear grade graphite is composed of grains with sizes $\sim 10$ microns. These grains are further composed of crystallites with sizes $\sim 5$ nanometers. The crystallite size is a measure of the degree of graphitization. Causey believes that hydrogen does not enter the crystallites. If $H$ is implanted into the crystallite, the crystallite cleaves open along the basal plane. There are both low-energy trap sites and $4.3 \mathrm{eV}$ trap sites on the crystallite surfaces. Solubility and diffusivity measurements are a measure of the migration controlled by the trapping and detrapping of hydrogen on the crystallite surface low energy trap sites (not on the larger grains). When graphite is damaged by radiation (neutrons, energetic atoms or ions) the crystallites become smaller and the total crystallite surface area increases, increasing the number of traps and the apparent solubility. This process also decreases the apparent diffusivity by decreasing the distance between trap sites. Tanabe showed the degree of graphitization to decrease with hydrogen implant fluence. Data of Saeki show diffusivity to be affected by radiation, and data of Atsumi show that the solubility increases with radiation damage or with the lack of graphitization. The saturated layer and the amorphous codeposited layer are almost identical, with the same hydrogen retention characteristics. These amorphous layers should not be called graphite, because they do not behave like graphite and do not retain hydrogen like graphite does. (R. A. Causey, private communication 1994)

Data needs for graphite include: (Federici et al. 1994)

- measurement of trap site concentrations in graphite irradiated by neutrons at high temperatures

- measurement of trap site concentrations in graphite irradiated by neutrons at high temperatures in the presence of specified impurities, such as boron.

- measurement of the effect of high particle fluxes on tritium retention in graphite. The high fluxes create a high gas pressure at the surface, which can drive more rapid permeation into pores and beyond.

- methods of removing the co-deposited layer.

A poor database exists for implanted layer phenomena, such as range distributions, trapping data, and thermal effusion data.(Möller 1989) The tritium inventory in large tokamaks will be dominated by bulk diffusion and codeposition processes. There is still much to be learned about the dynamics of tritium movement through graphite pores, chemical bonding, trapping on crystallites, and recombination in the bulk or on the surface and how these processes are influenced by radiation damage. According to Tanabe (1994) the true values of solubility and diffusivity are still to be determined.

For a general diffusivity of hydrogen in graphite we follow the recommendation of Wilson (1991) and Causey (1989a):

$$
D \approx 0.93 \exp (-2.8 \mathrm{eV} / \mathrm{kT}) \quad \mathrm{cm}^{2} / \mathrm{s} \text {. }
$$


However, the values of diffusivity for graphite vary widely (orders of magnitude). Rather than simply using this value, we recommend consulting the literature [such as Reiter et al (1993)] for the specific type of graphite being used.

Based upon Causey (1989a) and Atsumi et al. (1988) we recommend the following approximate value for hydrogen solubility in high-density isotropic graphite:

$$
S=6.4 \times 10^{-5} \exp (0.20 \mathrm{eV} / \mathrm{kT}) \text { atomic fraction/atm } 1 / 2
$$

This value is within the range of values found in Reiter et al. (1993).

Boron doping at small concentrations appears to reduce the graphite erosion rate, the hydrocarbon production rate, and the hydrogen inventory. The effects of metal surface films (such as $\mathrm{Cr}, \mathrm{Fe}$, and Ti) on graphite deserve further study, as they may help to reduce the hydrogen inventory. Where metal must be used instead of graphite, carbonization may help to reduce plasma contamination and hydrogen inventory. 


\section{Vanadium and Vanadium Alloys}

\section{Introduction}

Vanadium alloys have been proposed for fusion reactor applications, Smith 1985 . In particular, alloys with $\mathrm{Ti}$ and $\mathrm{Cr}$ substitutional elements have received much attention with $\mathrm{V} 20 \mathrm{Ti}$ and $\mathrm{V} 15 \mathrm{Cr} 5 \mathrm{Ti}$ having received extensive materials testing and with the alloy V5Cr5Ti proposed for ITER, Pick 1993. The primary motivation for use of such alloys lie in their good thermal conductivity properties, their inherent radiation resistance to void swelling and ductility loss, Smith 1985 and Gold 1980, and in their reduced level of induced radioactivity (low activation material), as compared to other candidate structural materials. A detailed assessment of the use of vanadium alloys for ITER applications has been reported recently, Van Witzenburg 1993.

One aspect of the evaluation of these materials for use in fusion applications concerns the material properties for hydrogen transport and retention. These data are of key importance to quantitative assessments of the trapping, permeation and release of tritium from first wall materials. Such assessments are required to support safety and environmental studies of ITER.

In this chapter we provide an up-to-date compilation and summary and an evaluation of the hydrogen transport and retention properties for vanadium and vanadium alloys. This information was gleaned from technical reports, journal articles, review papers and reference books that have been published in the last 20-30 years. The presentation of the information is arranged according to the following topics: (1) diffusivity, (2) solubility, (3) permeability, (4) trapping at interstitial impurities, (5) trapping at radiation-induced defects, (6) surface effects, and (7) thermotransport.

A general overview of the hydrogen transport properties for vanadium is found in many review articles and reference books that have been published over the years, many prepared in the context of fusion applications. Phase diagrams for the vanadium-hydrogen system are discussed in some detail by Libowitz 1972. We find that $\mathrm{V}-\mathrm{H}$ forms a continuous solid solution (alpha phase) above $473 \mathrm{~K}$ and at lower temperatures, the alpha and beta monohydride phases precipitate out. For, deuterium, the critical temperature that separates the pure alpha phase from the mixed phase region is $393 \mathrm{~K}$. There are large differences in the phase diagrams for $\mathrm{H}$ and $D$ and most likely $T$. Libowitz identified the experiments of Veleckis 1969 as defining the hydrogen solubility in vanadium, noting that the solubility is an inverse function of temperature. Hence vanadium is an exothermic absorber of hydrogen. An early survey of the diffusion and permeation properties of fusion-relevant materials is provided by Stickney 1972. This author selects the data of Veleckis 1969 for solubility and believes that the diffusion data from techniques like Nuclear Magnetic Resonance (NMR), neutron scattering, internal friction and the Gorsky effect may be inappropriate for fusion applications. His concern is that diffusion constants obtained by these methods may be enhanced because hydrogen concentrations are typically above the dilute solution range. (It should be noted that, in much of the work that uses these techniques, diffusivities corresponding to infinite dilution are deduced). Stickney prefers permeation data from absorption/desorption rate measurements. Two classic references for general properties of hydrogen in materials are the two monographs by Aledfeld and Volkl (Aledfeld 1978a, 1978b). In these references, the authors recommend values for diffusivity that are derived from the Gorsky effect, because the measurements are not sensitive to the surface effects of the material. Recommended diffusivities were derived from that data reported by the following: Schaumann 1970, Cantelli 1970, and Freudenberg 1978. 
Gas metal reactions for vanadium and vanadium alloys were reviewed by Svedberg 1980 for $O$, $\mathrm{N}, \mathrm{H}$ and $\mathrm{C}$ interstitals. Although the emphasis of the review concerned the influence of such interstitials on the mechanical properties of these materials, the authors identified the work of Veleckis 1969 for $\mathrm{H}$ solubility and that of Cantelli 1970 for $\mathrm{H}$ diffusivity. In the brief review by Lasser 1983, the authors identified the Gorsky effect $H, D$ experiments of Freudenberg 1978 and the T experiments of Qi 1983 as providing suitable diffusivity values of $H, D, T$ in pure $V$. These authors noted the effect of an oxide layer on tritium uptake and release behavior. A compilation of hydrogen isotope permeability in materials has been published by Steward 1983. In this report, the author uses solubility data from Veleckis 1969 and diffusivity data from Alefeld 1978a to derive a permeability expression suitable for the alpha phase $\mathrm{V}-\mathrm{H}$ system above 573K. Specifically in work related to tritium permeation considerations for the MARS direct convertor, Baskes 1984 used diffusivity data from Schaumann 1970 and solubility data from Kofstad 1959. These authors also noted that surface recombination was the significant rate-controlling process for hydrogen reemission from $V$. A more recent update on hydrogen diffusion in metals to that of Aldfeld 1978 is the review article by Fukai 1985. For $H$ transport in V, these authors recommend that data of Qi 1983 for temperatures $<573 \mathrm{~K}$, that of Lottner 1979 for temperatures >573K. Recently, Reiter 1993 published a very extensive compilation of data for hydrogen/tritium material interactions in fusion-relevant materials. For vanadium, that compilation for recommended values identified the recent tritium solubility data of Bleichert 1987 and an extensive evaluation of diffusivity data by Schober 1990 . Finally, a review of tritium retention properties for candidate first-wall materials, including vanadium, was made by Pick 1993. This review utilized the diffusivity and solubility data recommended by Reiter and addressed other phenomena that contributed to tritium transport and retention, like surface effects, hydrogen concentration due to stress and temperature gradient, alloy elements, and hydride formation.

Although this extensive published literature base presents an overview of hydrogen transport properties of $V$ and $V$-alloys, in many cases there is no clear traceability between the data presented in the articles and the results presented in the original source literature. In addition, little attention was given to hydrogen data for $V$ alloys. It is the intent of this data compilation effort, to summarize all of the relevant published information in such a way that there is a clear basis for the selection of hydrogen/tritium transport and retention data pertinent to fusion reactor issues. Furthermore, detailed information will be provided to demonstrate the influences of alloying elements on hydrogen transport in $V$ alloys.

\section{Diffusivity}

This section summarizes measured hydrogen diffusivity information for both pure $V$ and for $V$ with substitutional alloying elements, specifically $\mathrm{Ti}$ and $\mathrm{Cr}$. The influences of interstitial impurities $(\mathrm{O}, \mathrm{N}, \mathrm{C})$ on the hydrogen diffusivity will be addressed in another section. First we provide a brief overview of the techniques that have been used to obtain measured diffusivities.

\section{Experimental Techniques}

Many different techniques have been used to measure hydrogen diffusivities in materials. These include the following: (1) equilibrium gas phase hydrogen charging of a specimen at an elevated temperature followed by measurements of gas release from the heated specimen (absorption/thermal degas), (2) gas or ion-beam driven permeation measurements, (3) gasphase hydrogen charging followed by measurements of the Gorsky effect or of changes in specimen resistivity, (4) electrolytical hydrogen charging of a specimen followed by Gorsky effect or resistivity measurements, and (5) electrolytical hydrogen charging followed by thermal redistribution of hydrogen in the specimen and vacuum fusion analyses to assay specimen sections for hydrogen content. In all of the above approaches, the parameter of interest is measured as a function of time, such that the dependence of the measured observable 
can be related to hydrogen diffusivity in the specimen at the specified temperature. The first two approaches identified above are typically referred to as surface sensitive approaches, whereas, the remaining techniques are not surface sensitive. In the former case, careful consideration of surface conditions is important to an accurate determination of H-diffusivity values. On the other hand, the non-surface sensitive techniques often require sizable hydrogen concentrations of $\mathrm{H}$ in the material. Hence a concentration-dependent diffusivity is measured, rather than one corresponding to dilaue concentrations of $\mathrm{H}$. Consequently, much of the low temperature diffusivity data are obtained from the non-surface sensitive techniques, whereas permeation and gas absorption/thermal degas measurements are suitable for high-temperature diffusivity determinations.

Gorsky effect and resistivity measurements are important tools in experiments for which much of the recommended diffusivity data are generated. A brief description of these techniques follows. Measurements of the Gorsky effect entail measurements of the relaxation time of anelastic strain in a specimen that is prestressed and charged with hydrogen. Hydrogen interstitials in the stressed specimens migrate along the stress gradient, resulting in a relaxation of the strain (Schaumann 1970). This relaxation can be related to hydrogen diffusion rates. The resistivity of a material is a precise function of hydrogen content. Several authors have determined that, for vanadium, a change of 1.12 micro-ohm-cm of resistivity corresponds to a change in $\mathrm{H}$ atom concentration by $1 \%$. We thus note that resistivity measurements can then be used to precisely quantify hydrogen concentrations in materials and, if recorded as a function of time, they can provide a time dependence of the hydrogen concentration, a quantity that is relatable to $\mathrm{H}$ diffusivity in the specimen. Because both of these measurements are typically made for specimens with sizable hydrogen concentrations, it is often necessary to extrapolate the derived diffusivities to that considered for low, or infinitely dilate, hydrogen concentrations.

\section{Diffusivity in $v$}

A summary of relevant diffusivity data for hydrogen isotopes in pure vanadium is provided by Table 6.1 and Figure 6.1. The diffusivity data are presented in Table 6.1 in terms of the preexponential, $D_{0}$ in units of $\mathrm{m}^{2} / \mathrm{s}$, and the diffusion activation energy, $E_{d}$ in units of $m e V$, for a standard Arrhenius expression. Figure 6.1 provides a graphical comparison of diffusivities generated with the Arrhenius parameters of Table 6.1 over the applicable temperature ranges for the experiments. With the exception of the data from Cantelli 1970, the data based on Gorksy-effect and resistivity measurements are typically obtained from experiments that emphasize transport of hydrogen in vanadium at relatively low temperatures $(<600 \mathrm{~K})$. Only the work of Eguchi 1977, employing the absorption/thermal degas approach, covers diffusivity of hydrogen in vanadium at relatively high temperatures. No measurements cover the temperature range from $600 \mathrm{~K}$ to $800 \mathrm{~K}$.

These diffusivity data illustrate significant isotopic differences. In all cases, the activation energy for diffusion increases with increasing atomic mass. Similarly, the diffusivity preexperimental increases slightly with increasing atomic mass. As shown in Figure 6.1 , this results in faster diffusion rates for $H$ than for $D$ than for $T$. We note, however, that as the temperature increases, the isotopic differences become significantly less.

High-purity polycrystalline vanadium was used in all of the experiments. In most cases, additional heat treatment in high quality vacuum environment was done to reduce the level of $C$, $\mathrm{O}$ and $\mathrm{N}$ interstitial impurities. Such impurities are known to affect $\mathrm{H}$ diffusivity measurements in vanadium, a subject that is treated later in this review. In the work by Freudenberg 1978, diffusivities measured for super high purity and nominal purity vanadium were identical within experimental error. 
Table 6.1. Diffusivity data for hydrogen in vanadium

\begin{tabular}{|c|c|c|c|c|}
\hline \multirow{3}{*}{$\begin{array}{l}\text { Reference } \\
\text { Cantelli }(1970)\end{array}$} & \multicolumn{2}{|l|}{ Temperature } & \multirow{2}{*}{$\left(\mathrm{m}^{2} / \mathrm{s}\right) \times 10^{8}$} & \multirow{2}{*}{$\begin{array}{c}E_{D} \\
(m e V)\end{array}$} \\
\hline & \multirow{2}{*}{ Range $(\mathrm{K})$} & \multirow{2}{*}{ Isotope } & & \\
\hline & & & $\begin{array}{l}4.4(34)^{a} \\
3.1(26)\end{array}$ & $\begin{array}{ll}59 & (12) \\
73 & (8)\end{array}$ \\
\hline Schaumann (1970) & $300-600$ & $\begin{array}{l}H \\
D\end{array}$ & $\begin{array}{ll}3.5 & (14) \\
3.7 & (14)\end{array}$ & $\begin{array}{ll}50 & (8) \\
80 & (5)\end{array}$ \\
\hline Equchi (1977) & $810-1380$ & $H$ & 8.9 & 113 \\
\hline Freudenberg (1978) & $148-573$ & $\begin{array}{l}H \\
D\end{array}$ & $\begin{array}{ll}3.1 & (13) \\
3.8 & (11)\end{array}$ & $\begin{array}{ll}45 & (7) \\
73 & (5)\end{array}$ \\
\hline Tanaka (1979) & $196 \cdot 365$ & $\mathrm{H}$ & $1.8-3.1$ & $45(+8 /-22)$ \\
\hline Qi (1983) & $133-573$ & $T$ & $5.6 \quad(25)$ & 94 (8) \\
\hline Pine (1983) & $310-480$ & $\begin{array}{l}H \\
D\end{array}$ & $\begin{array}{ll}4.5 & (16) \\
5.8 & (12)\end{array}$ & $\begin{array}{l}59 \\
89\end{array}$ \\
\hline Peterson (1987) & $230-473$ & $\begin{array}{l}H \\
D\end{array}$ & $\begin{array}{ll}2.7 & (22) \\
4.0 & (13)\end{array}$ & $\begin{array}{ll}42 & (15) \\
72 & (6)\end{array}$ \\
\hline Reiter (1993) & $>250 \mathrm{~K}$ & $T$ & 5.6 & 94 \\
\hline \multicolumn{5}{|c|}{ a: Value in parenthesis is estimated percent uncertainty in the associated quantity } \\
\hline $\begin{array}{l}\text { Cantelli }(1979) \text { : } \\
\text { Schaumann (1970): } \\
\text { Eguchi (1977): } \\
\text { Freudenberg (1978): } \\
\text { Tanaka (1979): } \\
\text { Qi (1983): } \\
\text { Pine (1983): } \\
\text { Peterson (1987): } \\
\text { Reiter (1993): }\end{array}$ & \multicolumn{4}{|c|}{$\begin{array}{l}\text { Gorsky effect measurements. } \\
\text { Charged from gas phase, Gorsky effect measurements. } \\
\text { Equilibrium absorption/thermal degas. } \\
\text { Electrolytical charging, Gorsky effect measurements. } \\
\text { Electrolytical charging, resistivity measurement. } \\
\text { Charged from gas phase, Gorsky effect measurement. } \\
\text { Electrolytical charging, resistivity measurements. } \\
\text { Electrolytical charging, vacuum fusion gas analysis, Boltzman-Mantano } \\
\text { Review paper: Best results from Schober (1990). }\end{array}$} \\
\hline
\end{tabular}

For fusion application, Reiter selected the data of $\mathrm{Qi} 1983$ to be suitable for tritium transport in pure $V$. This selection is based on an extensive evaluation of the diffusivity data by Schober 1990. In addition, the diffusivity data from Freudenberg 1978 are recommended for $H$ and $D$ transport in vanadium over the temperature range $200 \mathrm{~K}$ to $600 \mathrm{~K}$. 


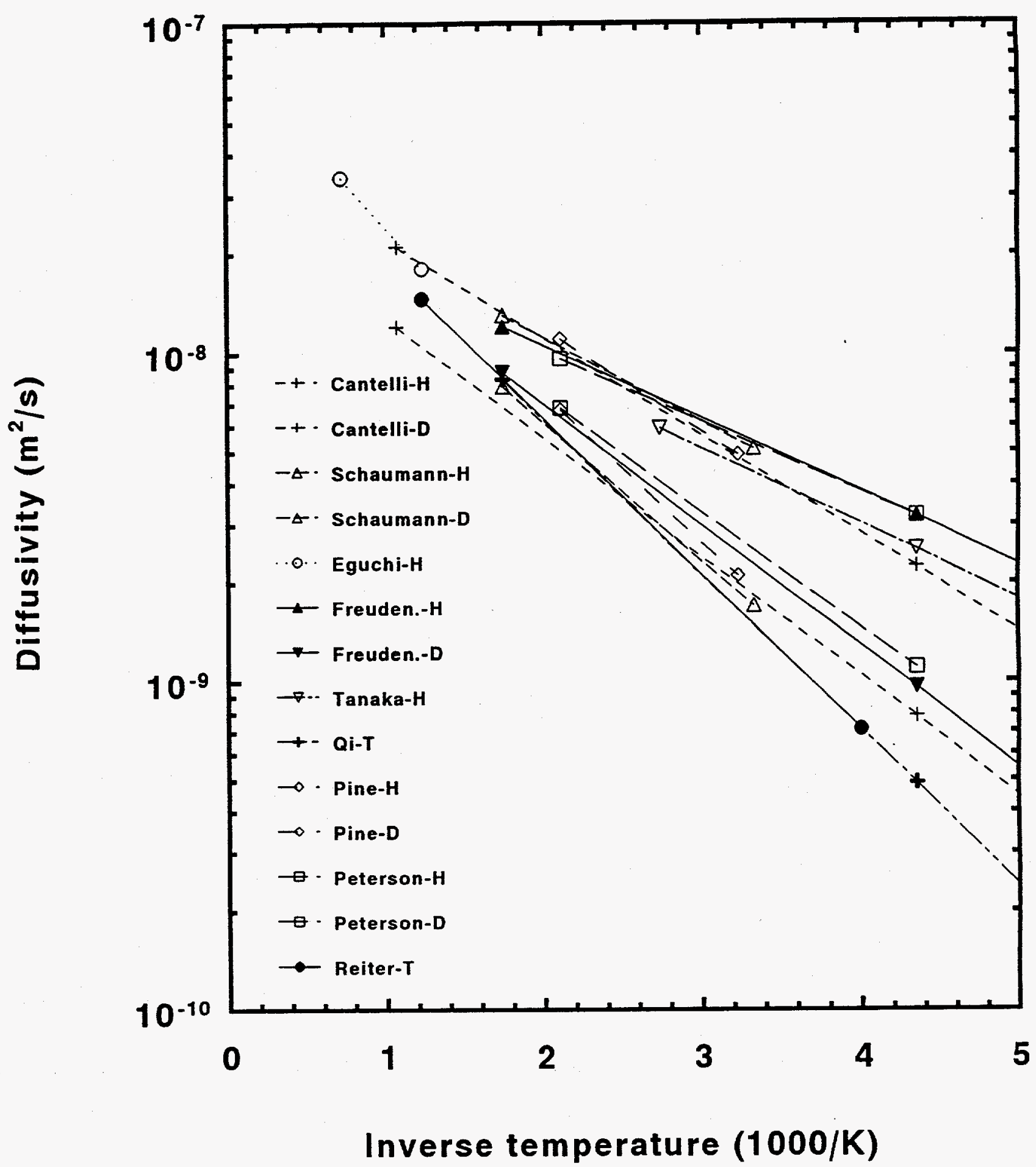

Figure 6.1. Comparison of measured diffusivities for $H, D$ and $T$ in vanadium. 


\section{Diffusivity in Vanadium Alloys}

A number of experimental and theoretical studies have been made to determine the influence of substitutional alloying elements on the diffusivity of hydrogen in vanadium alloys. We provide in Table 6.2 a summary of the pre-exponential and activation energy parameters for diffusion of $\mathrm{H}$ and $\mathrm{D}$ in vanadium alloys containing $\mathrm{Ti}$ and $\mathrm{Cr}$. Diffusivities calculated with these parameters are plotted in Figures 6.2 and 6.3 for temperature ranges applicable to the experiments. Figure 6.2 is divided into two parts with part (a) presenting the results of $H$ diffusivity measurements in $\mathrm{V}-\mathrm{Ti}$ and $\mathrm{V}-\mathrm{Cr}$, as reported by Pine 1983, and with part (b) presenting the Pine 1983 D-diffusivity data for the same $\mathrm{V}$ - $\mathrm{Ti}$ and $\mathrm{V}$-Cr alloy specimens. We also include in Figure 6.2 (b), the results of D-diffusivity measurements by Anderl 1987 for a $\mathrm{V} 15 \mathrm{Cr} 5 \mathrm{Ti}$ specimen. Detailed measurements of hydrogen diffusivity in $\mathrm{V}$ - $\mathrm{Ti}$ alloys have been reported by Tanaka 1929 and by Peterson 1987. The results of these experiments are displayed in Figure 6.3 parts (a) and (b) respectively. In both Figure 6.2 and 6.3, we show the diffusivity data measured by the experimenter for pure vanadium so that one can observe the relative changes in diffusivity that result from addition of the alloying elements.

Obvious systematic trends are noted in the diffusivity data as a function of alloying element concentration. In virtually all cases, the addition of $\mathrm{Ti}$ or $\mathrm{Cr}$ results in an increase in the diffusion activation energy along with an increase in the solubility pre-exponential. In general, the addition of $\mathrm{Ti}$ and $\mathrm{Cr}$ alloying elements results in a significant reduction in hydrogen diffusivity, relative to that for pure vanadium, over the applicable temperatures. For comparable concentrations, the Ti produces a larger reduction in diffusivity than that due to $\mathrm{Cr}$. The degradation of hydrogen diffusivity is more pronounced at low temperatures than at high temperatures.

We note from the data presented in Table 6.2 and Figures 6.2 and 6.3 that nearly all of the experimental data that concern alloy element affects are derived from experiments for which specimen temperatures are quite low $(<480 \mathrm{~K})$. One exception is the single experiment by Anderl 1987 who observed a significant reduction in deuterium diffusivity for the more complex $\mathrm{V} 15 \mathrm{Cr} 5 \mathrm{Ti}$ alloy developed for fusion materials applications. Systematic studies to determine the quantitative influence of substitutional alloy elements on hydrogen diffusivity for specimen temperatures greater than $480 \mathrm{~K}$ are needed for fusion applications.

Similar specimen preparation techniques and related measurement approaches were used in the experiments reported by Tanaka 1979, Pine 1983, and Peterson 1987. In all cases high purity $\mathrm{V}$ metal was used and the $\mathrm{V}-\mathrm{Ti}$ and $\mathrm{V}-\mathrm{Cr}$ alloy specimens were made by arc melting component materials in an inert gas environment. Following several arc melt steps to assure material homogeneity, the alloy material was rolled or swaged to achieve the appropriate form (foil or rod) for experiment. Prior to hydrogen charging, the specimens were annealed at high temperature in a vacuum environment to reduce $\mathrm{C}, \mathrm{O}$ and $\mathrm{N}$ interstitial impurities and to recrystallize the material. Somewhat different approaches were used to measure diffusionrelated changes in the hydrogen concentration in the electrolytically charged specimens. After establishing a uniform $H$ concentration, Tanaka 1979 measured resistivity changes as a function of time for step isothermal experiments. In contrast, Pine 1983 used an electrotransport approach to redistribute the electrolytically charged $\mathrm{H}$ to one end of the specimen, prior to measuring resistivity changes in the empty regions as a function of time and specimen temperature. The experiments by Peterson 1987 entailed electrolytical charging of $1 / 2$ the length of the rod specimen followed by redistribution of the hydrogen in stepped isothermal experiments that used vacuum fusion gas analysis to measure changes in hydrogen concentration in the empty region as a function of time. A Boltzman-Matano analysis approach was used by Peterson to obtain diffisivities. The experiment by Anderl 1987 used a $0.5 \mathrm{~mm}$ thick foil specimen, machined from an ingot of $\mathrm{V} 15 \mathrm{Cr} 5 \mathrm{Ti}$, in ion-beam driven permeation experiments. 
Diffusivity data for this work were obtained by measuring the time lag of the permeation transient.

Table 6.2. Diffusivity data for hydrogen in vanadium alloys

\begin{tabular}{|c|c|c|c|c|c|}
\hline \multirow[b]{2}{*}{ Reference } & \multirow[b]{2}{*}{ Alloy } & \multicolumn{2}{|c|}{$\bar{H}$} & \multicolumn{2}{|l|}{$\mathrm{D}$} \\
\hline & & $\begin{array}{c}D_{0} \\
\left(\mathrm{~m}^{2} / \mathrm{s}\right) \times 10^{8}\end{array}$ & $\begin{array}{c}E_{d} \\
(m e V)\end{array}$ & $\begin{array}{c}\mathrm{D}_{0} \\
\left(\mathrm{~m}^{2} / \mathrm{s}\right) \times 10^{8}\end{array}$ & $\begin{array}{l}E_{d} \\
(m e V)\end{array}$ \\
\hline Tanaka (1979) & V. $2 \mathrm{Ti}^{\mathrm{b}}$ & 3 & 56 & & \\
\hline$(196 \mathrm{~K}-365 \mathrm{~K})^{\mathrm{a}}$ & $\begin{array}{l}\text { V.4Ti } \\
\text { V1Ti } \\
\text { V2Ti } \\
\text { V4Ti } \\
\text { V5Ti } \\
\text { V9Ti } \\
\text { V14Ti } \\
\text { V19Ti }\end{array}$ & $\begin{array}{l}3.3 \\
5 \\
7 \\
11 \\
20 \\
60 \\
60 \\
60\end{array}$ & $\begin{array}{l}60 \\
76 \\
100 \\
120 \\
140 \\
190 \\
220 \\
230\end{array}$ & & \\
\hline $\begin{array}{l}\text { Pine }(1983) \\
(310 \mathrm{~K}-480 \mathrm{~K})\end{array}$ & $\begin{array}{l}\text { V3Ti } \\
\text { V8Ti } \\
\text { V4Cr } \\
\text { V10Cr }\end{array}$ & $\begin{array}{l}3.7(16)^{c} \\
11.8(2) \\
7.3(3) \\
17(35)\end{array}$ & $\begin{array}{l}75 \\
142 \\
95 \\
120\end{array}$ & $\begin{array}{l}7.7(10) \\
26(4) \\
7.0(6) \\
6.8(6)\end{array}$ & $\begin{array}{l}120 \\
183 \\
108 \\
110\end{array}$ \\
\hline $\begin{array}{l}\text { Peterson (1987) } \\
(230 \mathrm{~K}-473 \mathrm{~K})\end{array}$ & $\begin{array}{l}\text { V1Ti } \\
\text { V5Ti } \\
\text { V10Ti } \\
\text { V20Ti } \\
\text { V30Ti }\end{array}$ & $\begin{array}{l}3.7(40) \\
28(25) \\
34(26) \\
25(36) \\
26(31)\end{array}$ & $\begin{array}{l}49(20) \\
144(5) \\
168(4) \\
184(5) \\
200(4)\end{array}$ & $\begin{array}{l}3.8(11) \\
11.2(16) \\
11.5(26) \\
28(46) \\
21(52)\end{array}$ & $\begin{array}{l}75(3) \\
136(10) \\
158(4) \\
204(5) \\
221(6)\end{array}$ \\
\hline $\begin{array}{l}\text { Anderl (1987) } \\
(723 K-823 K)\end{array}$ & $\mathrm{V} 15 \mathrm{Cr} 5 \mathrm{Ti}$ & & & 1.4 & 110 \\
\hline $\begin{array}{ll} & \\
\text { a: } & \text { Temperature } \\
\text { b: } & \text { Alloy compo } \\
\text { c: } & \text { Value in par }\end{array}$ & $\begin{array}{l}\text { range for e } \\
\text { tion, V.2Ti } \\
\text { nthesis is th }\end{array}$ & $\begin{array}{l}\text { erimental date } \\
\text { presents } V \text { wi } \\
\text { estimated per }\end{array}$ & $\begin{array}{l}\text { atom } \% \mathrm{~T} \\
\text { Incertainty }\end{array}$ & the associated & quantity. \\
\hline $\begin{array}{l}\text { Tanaka (1979): } \\
\text { Pine (1983): } \\
\text { Peterson (1987): } \\
\text { Anderl (1987): }\end{array}$ & $\begin{array}{l}\text { Electrolytic } \\
\text { Electrolytic } \\
\text { Electrolytic } \\
\text { lon-beam }\end{array}$ & $\begin{array}{l}\text { al charging, re } \\
\text { al charging, re } \\
\text { al charging, vac } \\
\text { ermeation exp }\end{array}$ & $\begin{array}{l}\text { ity meas } \\
\text { ity meas } \\
\text { fusion ga } \\
\text { nt. }\end{array}$ & $\begin{array}{l}\text { ements. } \\
\text { analysis, Boltzn }\end{array}$ & -Mantano. \\
\hline
\end{tabular}


Diffusivity of $H$ in vanadium alloys (a)

Data from Pine(1983)

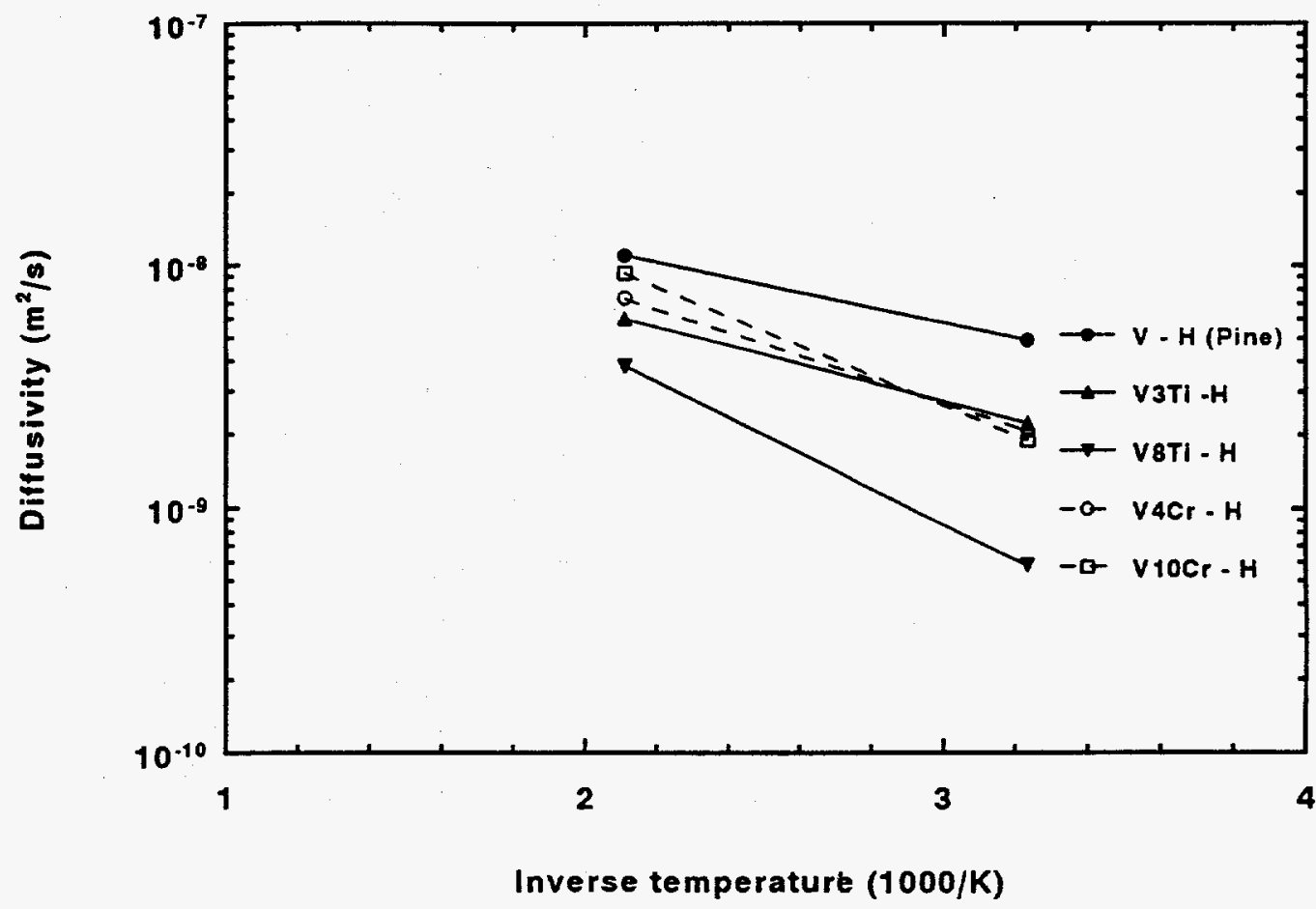

Diffusivity of $D$ in vanadium alloys (b)

Data from Pine(1983) and Anderl(1987)

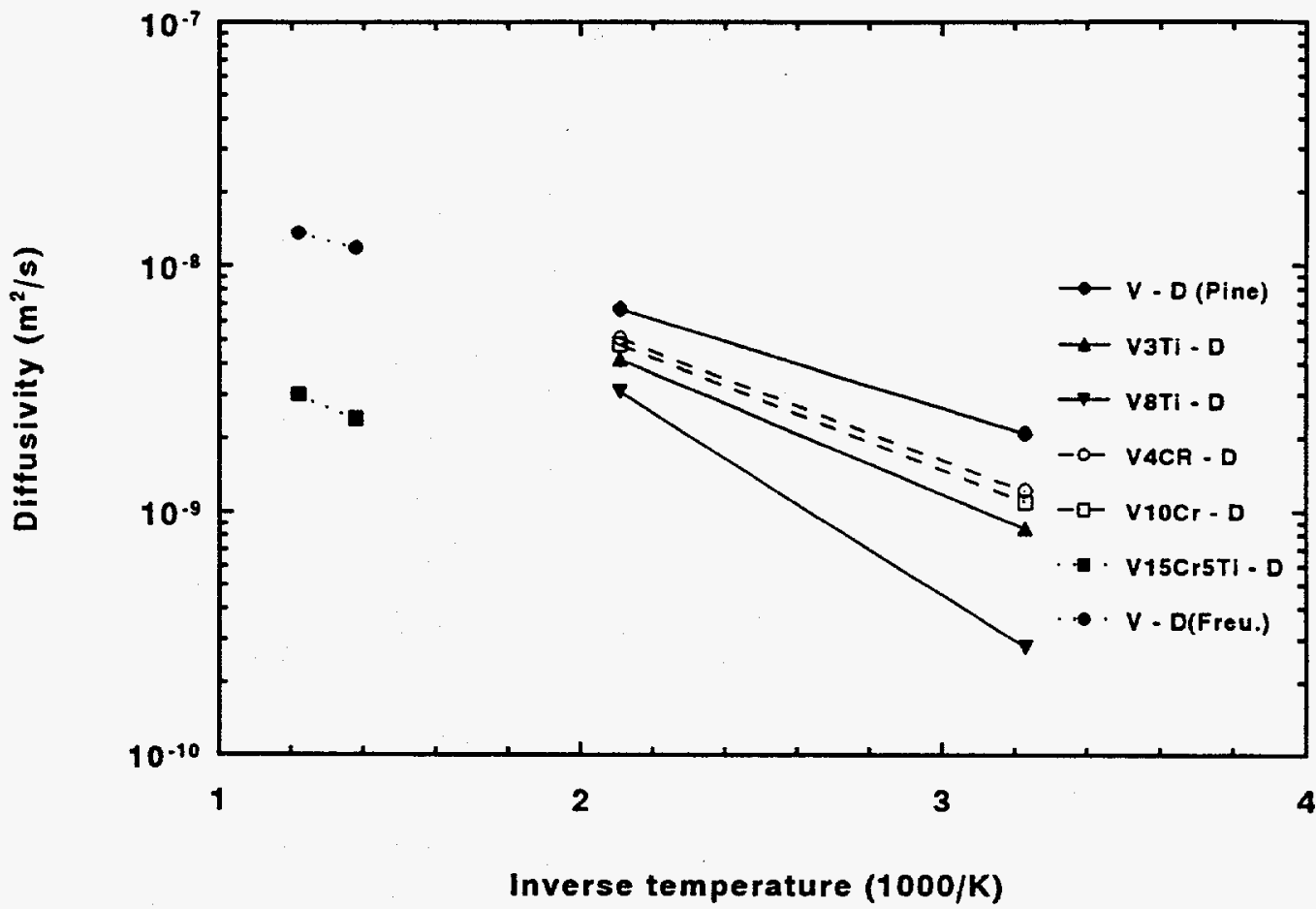

Figure 6.2. $\mathrm{H}$ and $\mathrm{D}$ diffusivities in $\mathrm{V}-\mathrm{Ti}$ and $\mathrm{V}-\mathrm{Cr}$ alloys, as reported by Pine 1993, and in V15Cr5Ti alloy, as reported by Anderl 1987. 
Diffusivity for $H$ in vanadium alloys (a)

Tanaka(1979)

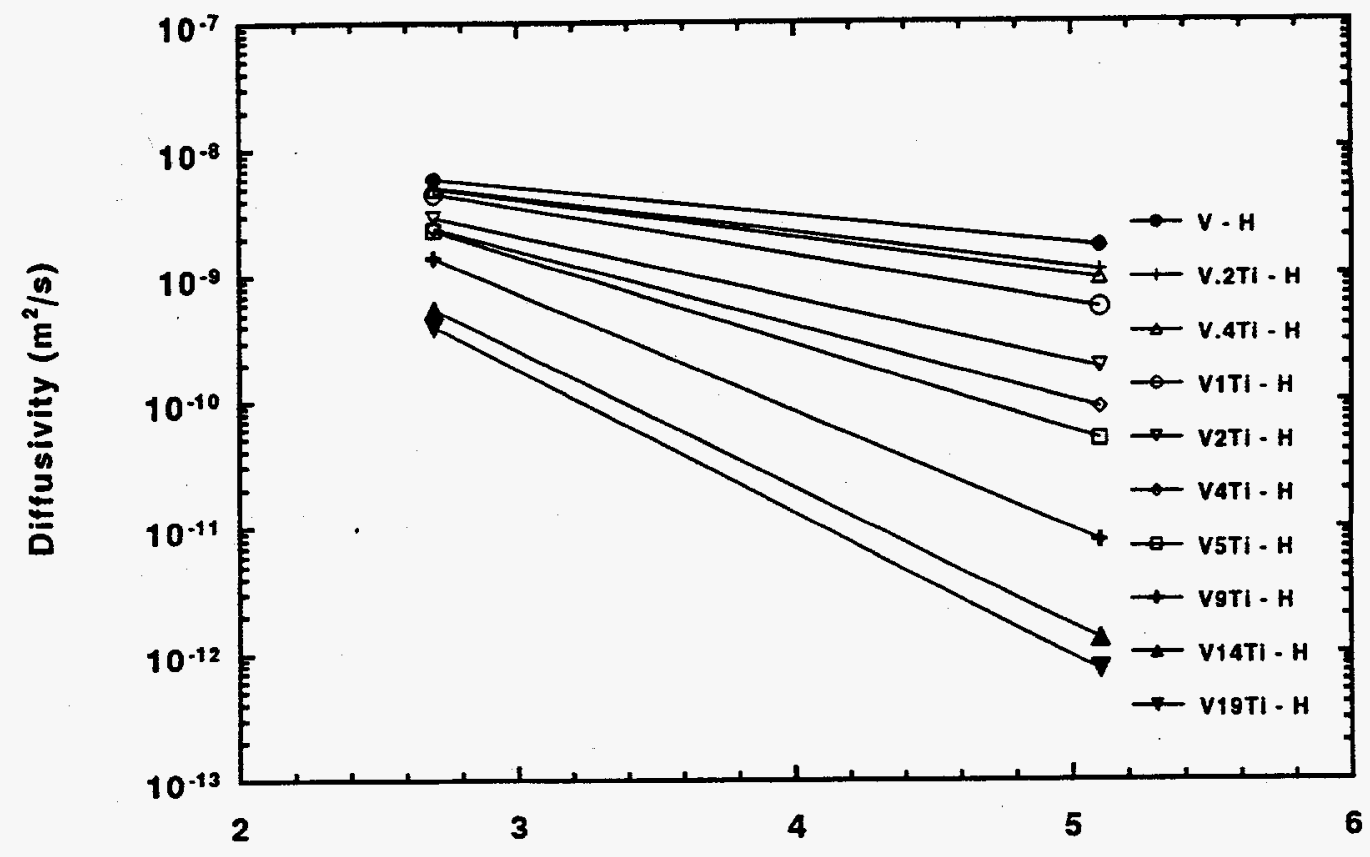

Inverse temperature(1000/K)

Diffusivity for $H, D$ in $V$ alloys (b)

Peterson(1987)

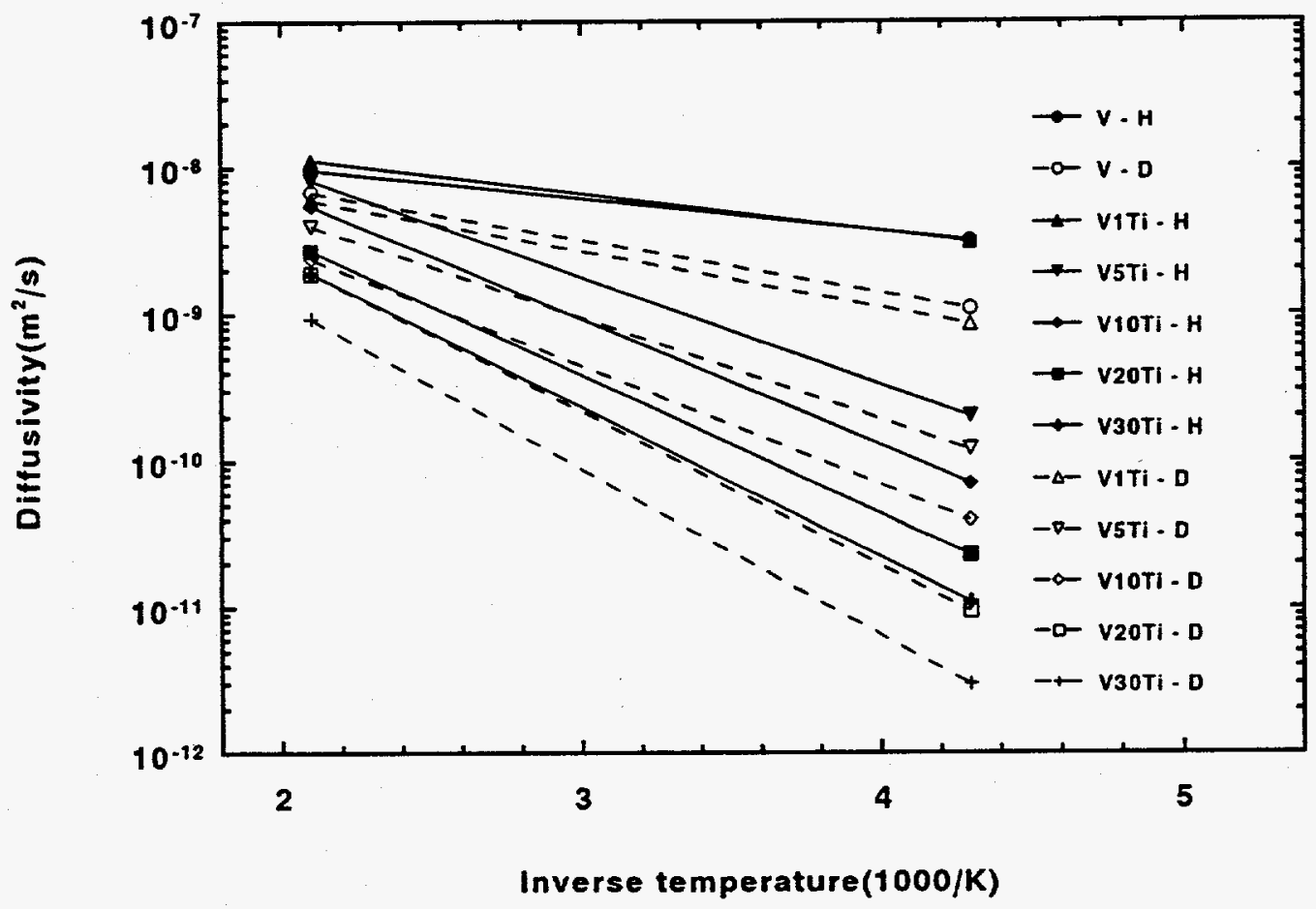

Figure $6.3 \mathrm{H}$ and $\mathrm{D}$ diffusivities in $\mathrm{V}-\mathrm{Ti}$ and $\mathrm{V}-\mathrm{Cr}$ alloys, as reported by Tanaka 1979 and Peterson 1987. 
In the experiments by Tanaka 1979, Pine 1983 and Peterson 1987, attempts were made to understand the reduction in diffusivity for alloy specimens by assuming that the $\mathrm{Ti}$ substitutional alloying elements served as trap sites for hydrogen. Tanaka analyzed his diffusivity experiments using the Oriani trap model, Oriani 1970, for effective diffusivity and estimated a binding energy of $0.15 \mathrm{eV}$ for $\mathrm{H}$ to Ti, at low Ti concentration. He speculated that the origin of the binding was electronic. A two-state trapping model was used by Pine 1983 to determine trap binding energies for $H$ and $D$ in specimens with different Ti concentrations. He estimated values of the binding energies to be $0.03 \mathrm{eV}$ for $\mathrm{H}$ and $0.062 \mathrm{eV}$ for $\mathrm{D}$ in $\mathrm{V} 3 \mathrm{Ti}$ and $0.102 \mathrm{eV}$ for $\mathrm{H}$ and $0.125 \mathrm{eV}$ for $\mathrm{D}$ in $\mathrm{V} 8 \mathrm{Ti}$. Because the binding energy was concentration dependent, Pine 1983 concluded that the trapping effects extended beyond the Ti nearest neighbor interstices. Similarly, Peterson 1987 used the Kircheim 1982 trapping model, that involved direct local interaction of $\mathrm{H}$ with isolated $\mathrm{Ti}$ atoms, to understand the diffusivity reduction. He concluded that the qualitative trends corresponded to a trapping interpretation, but the model could not quantitatively characterize the observed diffusion data. These experimenters found no evidence of increased $\mathrm{H}$ diffusion at high $\mathrm{H}$ concentration that could result from trap saturation.

Theoretical studies have been published by Shirley 1984 and McLellan 1987a, 1987b. The latter two specifically address $H$ diffusion in V-Ti alloys and Shirley 1984 provides a detailed theoretical framework to understand $\mathrm{H}$ trapping by metallic substitutional impurities in $\mathrm{Nb}, \mathrm{V}$, and Ta.

The framework of a statistical mechanical cell model for $\mathrm{H}$ diffusion in B.C.C. V-Ti solid solutions is given in McLellan 1987a. Diffusive motion of $\mathrm{H}$ takes place from tetrahedral site to nearest neighbor tetrahedral site. This model has the following features:

(1) there is not a unique trap site but many, according to the number of $\mathrm{Ti}$ atoms in the coordination shell of $Z$ lattice sites neighboring the interstitial (trap) sites,

(2) because of lattice dilatation, the spectrum of trapping energies depend upon specific volume and thus Ti-concentration,

(3) since the distribution of $\mathrm{H}$ atoms in the population of trapping sites varies with temperature, the time-averaged number of elementary jumps from a given trap type also varies with temp, and therefore, the activation energy for diffusion also varies with temperature.

In McLellan 1987a, the authors demonstrate that the model can predict the diffusivity and activation energy in the experimental work of Pine 1983 and Tanaka 1979. The model provides expressions for the ratio of binary alloy diffusivity as a function of $\mathrm{H}$ concentration and apparent activation energy versus $H$ concentration and temperature. In both experimental cases, the model expressions accurately predict the observed changes in the measured parameters. Apparent diffusivity is reduced and the apparent activation energy is increased as the substitutional alloy concentration increases, and the apparent activation energy decreases as the temperature increases. McLellan $1987 \mathrm{~b}$ extends the model application to the data of Peterson 1987 and demonstrates that the observed diffusivity data are consistent with the proposed trap model. Consistency between the three sets of experimental data for hydrogen diffusivity in the $\mathrm{V}-\mathrm{Ti}$ alloys is, therefore, demonstrated in the context of this model.

An earlier theoretical study by Shirley 1984 provides an excellent overview of the origin of trapping by metallic substitutional impurities in $\mathrm{Nb}, \mathrm{V}$ and $\mathrm{Ta}$. this investigation uses the method of lattice statics to calculate $H$ impurity binding energies for the elastic interaction and a phenomenological model for electronic interactions. In this theoretical development, the postulate is made that substitutional impurities trap hydrogen because of "stress-induced" 
interactions and electronic interactions. If a substitutional impurity expands the host lattice, the elastic contribution to the binding energy favors trapping (attractive) at the first and second nearest neighbor sites. If the substitutional impurity contracts the host lattice, the elastic contribution to the binding energy deters trapping (repulsive). With respect to the electronic interaction energy, if a substitutional impurity has an electron deficit relative to the host lattice, the electronic contribution to the binding energy favors trapping (attractive). If the substitutional impurity has an electron excess relative to the host lattice, the electronic contribution to the binding energy deters trapping (repulsive). This point can be summarized in the following "rule of thumb": impurities to the left of the host metal in the periodic table trap $\mathrm{H}$ (e.g. $\mathrm{Ti}, \mathrm{Zr}, \mathrm{Hf}$ in $\mathrm{V}$ ), and impurities to the right of the host metal do not trap $\mathrm{H}$, (e.g. Cr, $\mathrm{Mn}, \mathrm{Mo}$ in $\mathrm{V}$ ). When applied to the $\mathrm{V}-\mathrm{Ti}$ and $\mathrm{V}-\mathrm{Cr}$ binary alloys, the model predicts that the $\mathrm{H}$ binding energies are $-0.15 \mathrm{eV}$ for $\mathrm{V}-\mathrm{Ti}$ and $+0.13 \mathrm{eV}$ for $\mathrm{V}-\mathrm{Cr}$, in reasonable agreement with the experiments. Qualitatively, the above theoretical prescription does represent $H$ transport in $\mathrm{V}-\mathrm{Ti}$ alloys, in which measured diffusivities are significantly reduced relative to the pure metal. In contrast, this model does not predict the observed smaller reduction in $\mathrm{H}$ diffusivity for $\mathrm{V}-\mathrm{Cr}$ alloy.

\section{Solubility}

This section summarizes measured hydrogen solubility information for pure $V$ and for $V$ alloys with substitutional alloying elements, specifically $\mathrm{Ti}$ and $\mathrm{Cr}$. In general these data were derived from P-C-T isotherms that were measured for the samples. The measurements entailed the following: (1) gas absorption: charging of a heated specimen to equilibrium saturation by exposing the specimen to a known pressure of hydrogen gas, (2) gas desorption (thermal degas): measuring the total quantity of hydrogen released from the hot specimen in a vacuum environment. In some cases, electrolytical charging of hydrogen is used. Some experimenters used resistivity measurements to determine the quantity of hydrogen in the specimens.

The solubility data that are presented here pertain to the condition in which Sieverts law applies. That is, the relationship between the concentration, $C$, of hydrogen in the bulk and the hydrogen overpressure, $P$, is given by;

$$
C=S P 1 / 2
$$

where $S$ is the solubility constant. The temperature dependence of $S$ is given by the usual Arrhenius expression with So, the solubility pre-exponential, and $E_{S}$, the enthalpy of solution.

Many of the experiments concerning hydrogen solubility in vanadium were performed with the primary objective of determining thermodynamic parameters, such as the enthalpy and entropy of solution. In many cases, the measured P-C-T isotherms covered hydrogen concentration ranges that extended far beyond the applicability of Sieverts law. However, a portion of the measured data, usually for hydrogen atomic concentration less than $4 \%$, corresponded to Sieverts law. For those conditions in which Sieverts law describes the P-C-T relationships, Flanagan 1972 has shown that the thermodynamic parameters of solution at infinite dilution can be determined by;

$$
K_{S}=\left(1 / n_{S}\right) \exp (\Delta H / R T) \exp (-\Delta S / R)
$$

where, $n_{S}$ is the geometrically-limiting value for the $\mathrm{H} /$ metal atomic ratio, $K_{S}$ is the temperature dependent Sieverts constant (here $K_{S}$ is equivalent to $1 / S$, where $S$ is defined as above), $\Delta H$ is the relative partial molar enthalpy at infinite dilution and $\Delta S$ is the relative partial molar entropy of solution without the configurational contribution. By comparing the 
expression for $K_{S}$ to that for $1 / S$, we can easily identify the Arrhenius parameters for $S$ in terms of the thermodynamic parameters in $\mathrm{K}_{\mathbf{S}}$. Vanadium, like many B.C.C. metals, absorbs $H$ into tetrahedrally coordinated sites, so $n_{s}=6$.

\section{$H$ Solubility in Vanadium}

We present in Table 6.3 and in Figure 6.4 a summary of relevant solubility data as derived from many experimental studies. Here solubility has units of at. fr. $\mathrm{Pa}^{-1 / 2}$ and $E_{S}$ is in meV. Here at. fr. represents atom fraction, the ratio of the number of solute hydrogen atoms to the number of solvent host metal atoms. The table indicates both the temperature range and the pressure range over which the solubility measurements were made. The figure displays excellent agreement between the solubility data over a temperature range from $400 \mathrm{~K}$ to $1400 \mathrm{~K}$. The solubility parameters corresponding to Reiter 1993 were selected as most representative of the measured data, as evaluated by Schober 1990 and measured by Bleichert 1987.

In the following paragraphs we provide a brief description of pertinent details for the primary source literature to establish a firm traceability between the data presented here and that found in the original references. Kofstad 1959 presented a table of thermodynamic data (Table II in the reference) that was derived from his analysis of P-C-T isotherm. Reasonable values for Sieverts constant could not be derived from the data in the table as per the above expression relating $\mathrm{K}_{\mathrm{S}}$ to thermodynamic parameters. However, based on numerical vapor pressure isotherms presented in Table I of Kofstad, we plotted families of the $\mathrm{P}^{1 / 2} / \mathrm{NH}_{H}$ data as a function of inverse temperature for various hydrogen concentrations $N_{H}$ ranging from .005 atomic fraction to 0.12 atomic fraction. These semilog plots were linear over the temperature range of the experiment. The solubility data in Table 6.3 were derived from the measured data corresponding to a hydrogen concentration of 0.04 atomic fraction, a condition for which Sieverts law still applies.

Veleckis 1969 presented the results of his P-C-T isotherm experiments, as plots of $\mathrm{P}^{1 / 2}$ versus $N_{H}$, the atomic fraction of $H$, for various temperatures. In addition, they derived partial molar entropies and enthalpies from the data. Similar to the situation in using the data from Kofstad 1959, no reasonable Sieverts constant pre-exponential data could be derived from the tabulated thermodynamic data. Hence, the P-C-T isotherm data were replotted as families of $N_{H}$ versus inverse temperature for different pressures so that the appropriate Arrhenius parameters could be determined. Data that were plotted corresponded to pressures of $0.13 \mathrm{~atm}$, $0.30 \mathrm{~atm}, 0.53 \mathrm{~atm}$ and $0.82 \mathrm{~atm}$. In all cases the semilog plots were linear for temperatures less than $620 \mathrm{~K}$ and they converged to a hydrogen concentration of about $40 \%$ for different temperatures greater than $620 \mathrm{~K}$. The solubility parameters given in Table 6.3 correspond to a fit of the $N_{H}$ versus $1 / T$ data for a pressure of $0.82 \mathrm{~atm}$.

The experiments by Equchi 1974 measured $H$ solubility both in pure vanadium and in binary alloys with $\mathrm{Ti}$ and $\mathrm{Cr}$. Although plots of the atom fraction as a function of $10^{4} / \mathrm{T}$ were presented, only derived thermodynamic parameters were tabulated. Hence, Arrhenius parameters for solubility, as presented here, were determined from linear fits to the plots of hydrogen concentration versus $1 / \mathrm{T}$.

Low temperature hydrogen solubility measurements were made by Boes 1976. Although the authors did not provide suitable solubility parameters, Petersen 1985 fit their data to determine the Arrhenius parameters given in Table 6.3. 
Table 6.3. Solubility data for hydrogen in vanadium

\begin{tabular}{|c|c|c|c|c|}
\hline Reference & $\begin{array}{l}\text { Pressure } \\
\text { Range (MPa) }\end{array}$ & Isotope & (at. fr. $\mathrm{Pa}^{1 / 2}$ ) & $\begin{array}{l}E_{S} \\
(\mathrm{meV})\end{array}$ \\
\hline $\begin{array}{l}\text { Kofstad }(1959) \\
(440 \mathrm{~K}-730 \mathrm{~K})^{\mathrm{a}}\end{array}$ & & $\bar{H}$ & $2.2 E-6$ & -331 \\
\hline $\begin{array}{l}\text { Veleckis (1969) } \\
(519 \mathrm{~K}-827 \mathrm{~K})\end{array}$ & $<.08$ & $\mathrm{H}$ & $1.6 E-6$ & -353 \\
\hline $\begin{array}{l}\text { Eguchi }(1974) \\
(873 \mathrm{~K}-1473 \mathrm{~K})\end{array}$ & 0.1 & $\mathrm{H}$ & $3.6 \mathrm{E}-6$ & -293 \\
\hline $\begin{array}{l}\text { Boes }(1976) \\
(283 K-353 K)\end{array}$ & 0.1 & $\mathrm{H}$ & $1.7 E-6$ & -344 \\
\hline $\begin{array}{l}\text { Lynch (1978) } \\
\text { (473K-723K) }\end{array}$ & $<.05$ & $H$ & $2.1 E-6$ & -330 \\
\hline $\begin{array}{l}\text { Peterson (1985) } \\
\text { (700K-1200K) }\end{array}$ & & $H$ & $1.7 E-6$ & -344 \\
\hline Bleichert (1987) & $<0.2$ & $\begin{array}{l}H \\
D \\
T\end{array}$ & $\begin{array}{l}2.4 \mathrm{E}-6 \\
1.9 \mathrm{E}-6 \\
1.6 \mathrm{E}-6\end{array}$ & $\begin{array}{l}-331 \\
-341 \\
-358\end{array}$ \\
\hline Reiter (1993) & & $\mathbf{T}$ & $2.1 E-6$ & -333 \\
\hline
\end{tabular}

a: Temperature range for expermental data.

Kofstad (1959):

Veleckis (1969):

Eguchi (1974):

Boes (1976):

Lynch (1978):

Peterson (1985):

Bleichert (1987):

Rieter (1993):
Equilibrium gas absorption, thermal degas.

Equilibrium gas absorption, thermal degas.

Equilibrium gas absorption, thermal degas.

Electrolytical charging, thermal degas.

Equilibrium gas absorption, thermal degas.

Equilibrium gas absorption, thermal degas.

Equilibrium gas absorption, resistivity measurements.

Review paper, best results from Schober 1990 and Bleichert 1987.

Extensive P-C-T isotherms were measured by Lynch 1978 for pure $V$ and binary alloys with $\mathrm{Cr}$ and with temperatures ranging from $473 \mathrm{~K}$ to $723 \mathrm{~K}$. The results were reported as thermodynamic parameters. The Arrhenius solubility parameters presented in Table 6.3 were derived from the thermodynamic parameters from Lynch 1978, assuming $n_{s}=6$. These authors observed for their work, that Sieverts law applied for hydrogen concentrations up to an at. fr. of 0.2. 


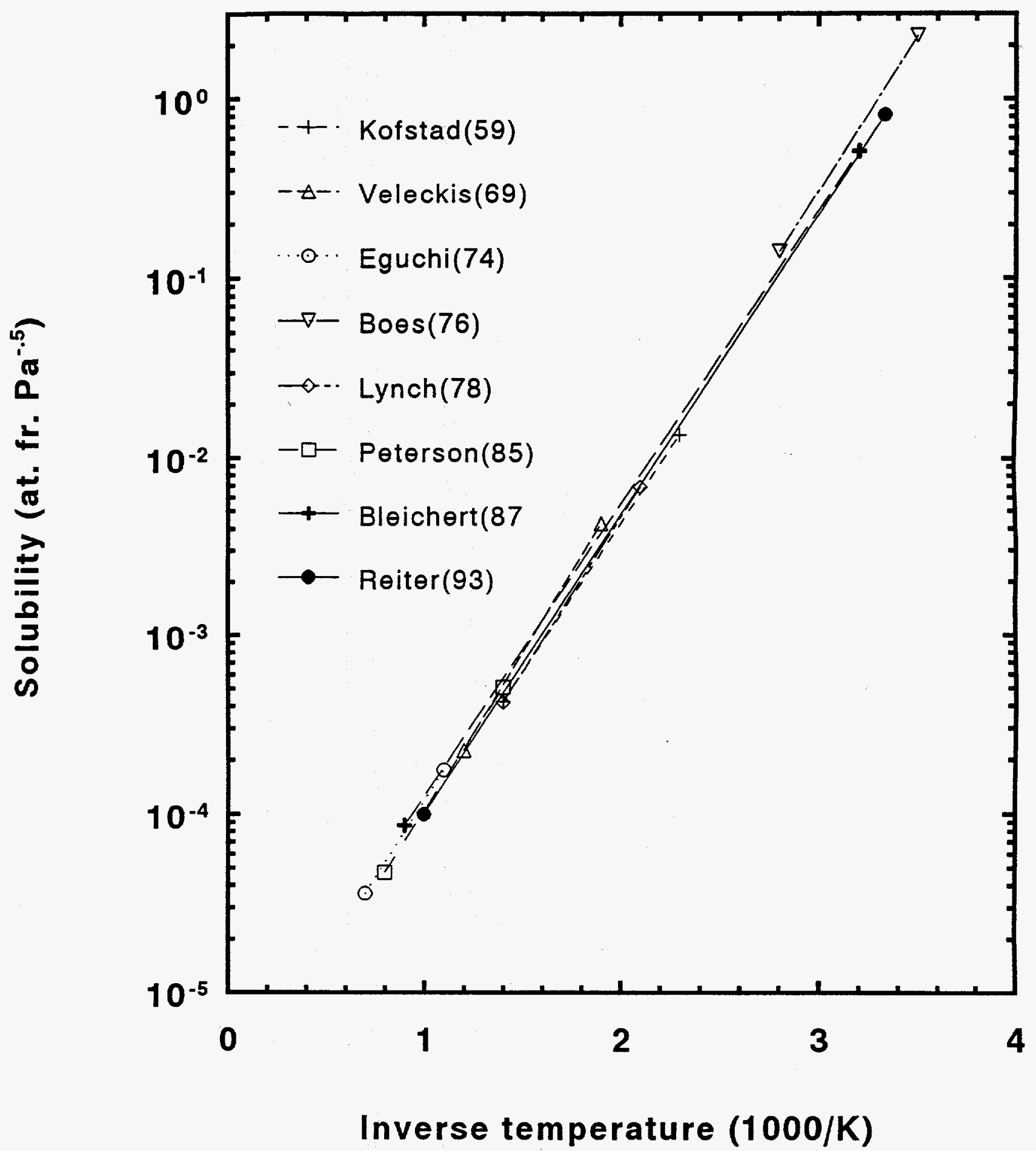

Figure 6.4. Comparison of $\mathrm{H}$-solubility data for vanadium. 
In the work reported by Peterson 1985, solubility data were obtained from P-C-T isotherms measured over the temperature range $700 \mathrm{~K}$ to $1200 \mathrm{~K}$ for pure $\mathrm{V}$. Plots of $\mathrm{P}^{1 / 2}$ versus the atomic concentration of $H$ showed Sieverts law applied for $H$ concentrations up to 0.05 . Arrhenius solubility parameters given in Table 6.3 were obtained from a linear fit to the semilog plot of $\mathrm{P}^{1 / 2} / \mathrm{NH}$ versus $1000 / \mathrm{T}$ data.

Bleichert 1987 used resistivity measurements to obtain solubility between gas-phase hydrogen and the alpha phase of $\mathrm{H}$ in V. From measurements made over the temperature range of $313 \mathrm{~K}$ to $1073 \mathrm{~K}$, these authors derived thermodynamic parameters for solution of $\mathrm{H}$. The Arrhenius results presented in Table 6.3 were derived from the thermodynamic data corresponding to $1073 \mathrm{~K}$ for $\mathrm{H}_{2}$ and $\mathrm{D}_{2}$, and $423 \mathrm{~K}$ to $573 \mathrm{~K}$ for $T_{2}$, using the above expression for $K_{\mathrm{s}}$. These authors indicated that for their measurements, Sieverts law applied for hydrogen concentrations up .045 at. fr.

\section{Hydrogen Solubility in Vanadium Alloys}

Summary information for the hydrogen solubility in vanadium binary alloys is given in Table 6.4 and in Figure 6.5 Table 6.4 presents the Arrhenius solubility parameters and indicates the temperature and pressure ranges over which the experiments were done. Solubilities, as a function of inverse temperature, are presented in Figure 6.5 (a) for $\mathrm{V}-\mathrm{Cr}$ and in Figure 6.5 (b) for V-Ti. These curves were computed using the parameters in Table 6.4. Clearly we observe from the figures, that, over the temperature ranges shown, the addition of $\mathrm{Cr}$ to $\mathrm{V}$ reduces the $H$ solubility relative to the pure metal, whereas, the addition of $\mathrm{Ti}$ results in an increase in hydrogen solubility. We note from the table that addition of $\mathrm{Cr}$ to $\mathrm{V}$ results in a systematic increase in the solution enthalpy (the alloy becomes less exothermic), whereas addition of $\mathrm{Ti}$ to $\mathrm{V}$ results in a systematic decrease in the solution enthalpy. On the other hand, the data for Equchi 1974 and Lynch 1978 indicate little change in the solubility preexponential. However, the data from Peterson 1985 indicate that the pre-exponential decreases slightly as the $\mathrm{Cr}$ concentration increases and it increases somewhat as the $\mathrm{Ti}$ concentration increases.

Some additional details from the source literature are presented in the following paragraphs to establish a more complete understanding of the impact of substitutional alloys on $\mathrm{H}$ solubility in $\checkmark$ binary alloys. Summary comments from the work of Lynch 1978 are as follows: (1) increases in the $\mathrm{Cr}$ content produce increases in the heat of solution, (2) the standard partial entropy is essentially unaffected by the $\mathrm{Cr}$ addition for hydrogen concentrations less than $20 \%$, (3) increase in the $\mathrm{Cr}$ content increases the enthalpy of dihydride formation while exerting no influence on the corresponding entropy, (4) apparent $\mathrm{H}-\mathrm{H}$ interactions are decreased by the presence of $\mathrm{Cr}$ (hence Sieverts law is applicable for hydrogen concentrations up to $20 \%$ but the solubility deviates from Sieverts law above this concentration), (5) analysis of the partial molar entropy of solution suggests that $\mathrm{Cr}$ atoms do not block potentially available interstitial sites for occupation by $\mathrm{H}$ atoms, and (6) the enthalpies are independent of temperature over the range studied.

Some of the findings from the work of Peterson 1985 include the following. The addition of alloying elements increases the hydrogen concentration regime over which Sieverts law applies. For example, for $\mathrm{V}-\mathrm{Cr}$, in the temperature range from $297 \mathrm{~K}$ to $473 \mathrm{~K}$, Sieverts law holds up to hydrogen concentrations of about $30 \%$. For $\mathrm{V}-\mathrm{Ti}$, in the temperature range from $223 \mathrm{~K}$ to $473 \mathrm{~K}$, Sieverts law held for hydrogen concentrations up to $50 \%$. From these observations we can infer that no thermodynamic correction factors are needed to interpret concentration 
Table 6.4. Solubility data for hydrogen in vanadium alloys

\begin{tabular}{|c|c|c|c|c|}
\hline \multirow[b]{2}{*}{ Reference } & \multicolumn{2}{|l|}{ Pressure } & $s_{0}$ & \multirow{2}{*}{$\begin{array}{c}E_{S} \\
(m e V)\end{array}$} \\
\hline & Range (MPa) & Alloy & (at. fr. $\mathrm{Pa}^{-1 / 2}$ ) & \\
\hline Eguchi (1974) & 0.1 & V1Tib & $3.6 E-6$ & -296 \\
\hline$(873 \mathrm{~K}-1473 \mathrm{~K})^{\mathrm{a}}$ & & $\begin{array}{l}\text { V3Ti } \\
\text { V5Ti } \\
\text { V10Ti } \\
\text { V1Cr } \\
\text { V3Cr } \\
\text { V5Cr } \\
\text { V10Cr }\end{array}$ & $\begin{array}{l}3.5 E-6 \\
3.3 E-6 \\
2.8 E-6 \\
3.9 E-6 \\
3.6 E-6 \\
3.7 E-6 \\
3.7 E-6\end{array}$ & $\begin{array}{l}-305 \\
-323 \\
-353 \\
-277 \\
-275 \\
-265 \\
-240\end{array}$ \\
\hline $\begin{array}{l}\text { Lynch }(1978) \\
(473 \mathrm{~K}-723 \mathrm{~K})\end{array}$ & $<.05$ & $\begin{array}{l}\mathrm{V} 2 \mathrm{Cr} \\
\mathrm{V} 6 \mathrm{Cr} \\
\mathrm{V} 10 \mathrm{Cr} \\
\mathrm{V} 15 \mathrm{Cr} \\
\mathrm{V} 20 \mathrm{Cr}\end{array}$ & $\begin{array}{l}2.4 E-6 \\
2.0 E-6 \\
2.4 E-6 \\
2.0 E-6 \\
2.5 E-6\end{array}$ & $\begin{array}{l}-321 \\
-315 \\
-296 \\
-284 \\
-256\end{array}$ \\
\hline $\begin{array}{l}\text { Peterson (1985) } \\
(700 \mathrm{~K}-1200 \mathrm{~K})\end{array}$ & & $\begin{array}{l}\text { V10Cr } \\
\text { V20Cr } \\
\text { V30Cr } \\
\text { V1Ti } \\
\text { V5Ti } \\
\text { V10Ti } \\
\text { V20Ti } \\
\text { V30Ti }\end{array}$ & $\begin{array}{l}1.1 \mathrm{E}-6 \\
7.5 \mathrm{E}-7 \\
5.0 \mathrm{E}-7 \\
3.4 \mathrm{E}-6 \\
2.4 \mathrm{E}-6 \\
2.7 \mathrm{E}-6 \\
8.2 \mathrm{E}-6 \\
1.0 \mathrm{E}-5\end{array}$ & $\begin{array}{l}-326 \\
-305 \\
-276 \\
-329 \\
-378 \\
-411 \\
-429 \\
-451\end{array}$ \\
\hline
\end{tabular}

a:

b:

Eguchi (1974):

Lynch (1978):

Peterson (1985):
Temperature range for experimental data.

Alloy composition $\mathrm{V} 1 \mathrm{Ti}$ represents $\mathrm{V}$ with 1 atom $\% \mathrm{Ti}$.

Equilibrium gas absorption, thermal degas.

Equilibrium gas absorption, thermal degas.

Equilibrium gas absorption, thermal degas.

profiles in hydrogen transport phenomenon such as diffusion and thermotransport within this concentration range. When hydrogen solution follows Sieverts law, there is constant matrixhydrogen interaction and no significant hydrogen-hydrogen interactions over the concentration range. The concept of anti-trapping or site blocking may explain the $\mathrm{Cr}$ data. The observed large increase in the terminal solid solubility limit in $\mathrm{V}-\mathrm{Ti}$, compared to pure $\mathrm{V}$, cannot be ascribed to simple trapping in a solid solution phase. The authors suggest that they relate to changes in free energy relationships for the hydride phase. 
Solubility of $\mathrm{H}$ in $\mathrm{V}-\mathrm{Cr}$ alloys (a)

Peterson(85), Lynch(78), Eguchi(74)

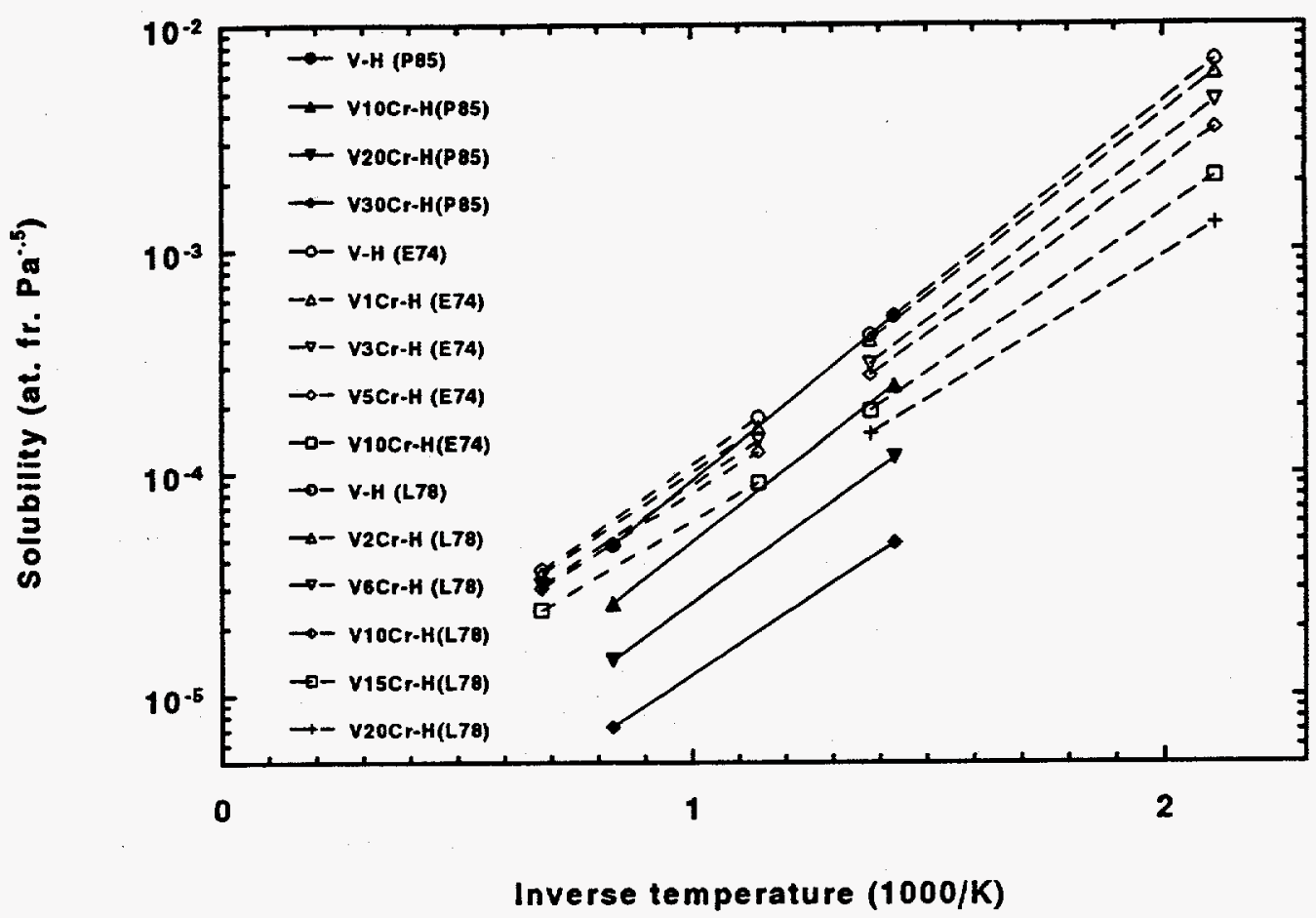

Solubility of $H$ in VTi alloys (b)

Peterson(1985) and Eguchi(1974)

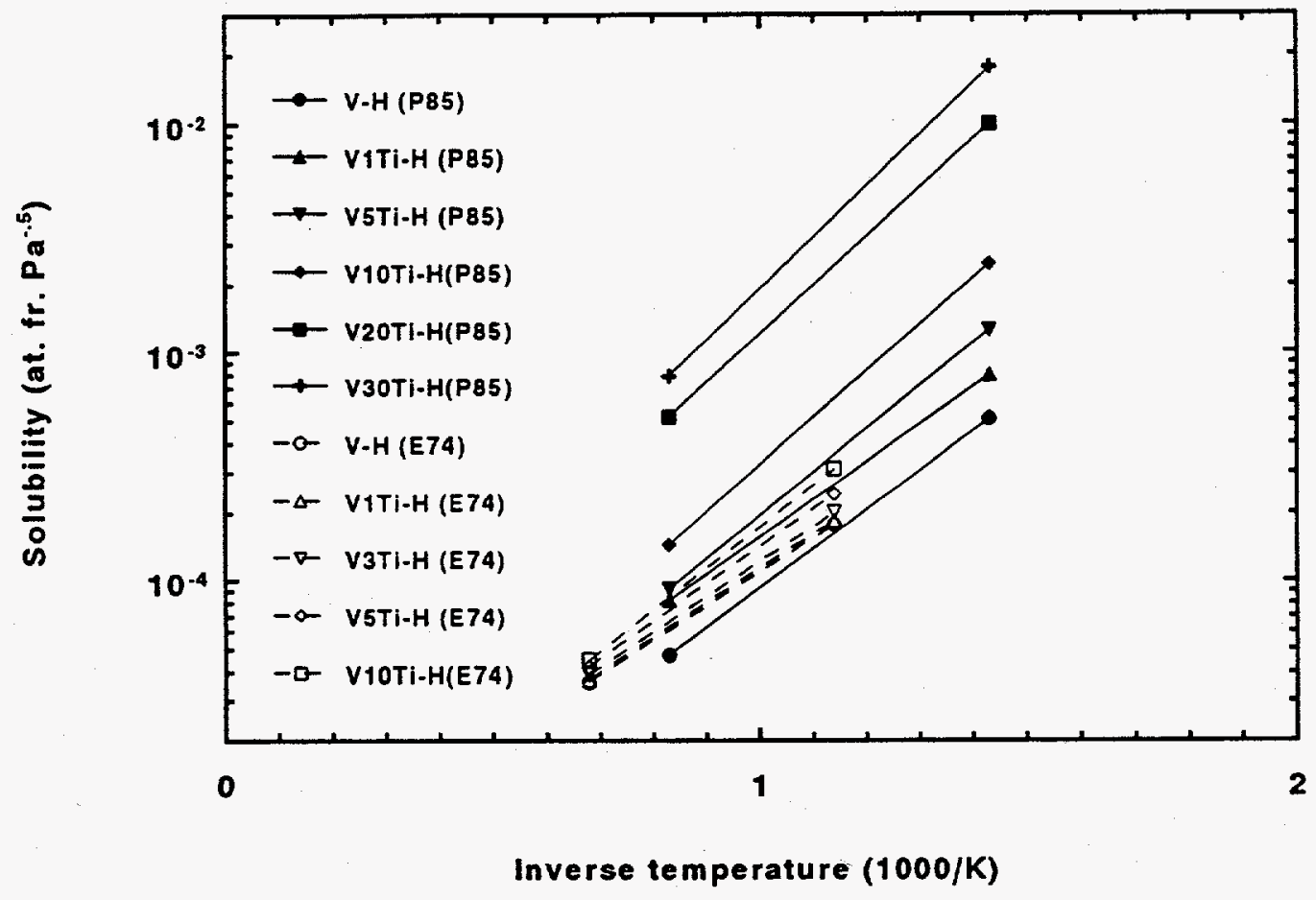

Figure 6.5 Comparison of solubility data for $\mathrm{H}$ and $\mathrm{D}$ in $\mathrm{V}-\mathrm{Ti}$ and $\mathrm{V}-\mathrm{Cr}$ alloys, as reported by Peterson 1985, Lynch 1978 and Eguchi 1974. 


\section{Permeability}

Steady-state flow of hydrogen through materials is often represented by its permeability in the material. As discussed in Steward 1983, the permeability is the product of the diffusivity and the solubility. Measurements of permeability are often obtained in permeation experiments for membrane samples.

Recent permeation experiments have been reported by Nishimura 1991 and Takata 1993 for hydrogen transport through vanadium. Both experiments employed the gas-driven permeation method to determine the hydrogen permeability for foil specimens.

In the experimental work reported by Nishimura 1991, permeability, diffusivity and solubility data were obtained from measurements for specimens of pure vanadium and of vanadium alloyed with nickel. Specimens used in the permeation experiments were electroplated with Pd to inhibit the influence of surface effects. The gas permeation experiments were conducted over the temperature range $423 \mathrm{~K}$ to $673 \mathrm{~K}$ for pressures ranging from 1E4 to 3E5 Pa. Permeability data values were derived from steady-state permeation rates and diffusivities were deduced using the time lag method to analyze the initial permeation rates. For pure $V$, the measured permeabilities ranged from $1.2 E_{17} \mathrm{H} / \mathrm{msPa}^{1 / 2}$ at $673 \mathrm{~K}$ to $1.2 \mathrm{E} 16 \mathrm{H} / \mathrm{msPa}^{1 / 2}$ at $473 \mathrm{~K}$. These values are somewhat less than values calculated using the recommended permeability expression presented below. Corresponding calculated values are 6.4E17 H/msPa ${ }^{1 / 2}$ and $5.2 E 18 \mathrm{H} / \mathrm{msPa}^{1 / 2}$ for $673 \mathrm{~K}$ and $473 \mathrm{~K}$, respectively. We note that the observed trend with temperature is opposite to that predicted with the calculated values. Measured values of permeabilities for the $\mathrm{V}-\mathrm{Ni}$ alloy specimens were less than those for pure $\mathrm{V}$ and the permeabilities decreased as the Ni composition increased. Apparent diffusivities derived from the permeation experiments were much less for the alloy specimens than for the pure $V$ specimens. Derived activation energies for diffusion were $0.2 \mathrm{eV}$ to $0.3 \mathrm{eV}$ for the V-Ni alloys, substantially larger than $0.045 \mathrm{eV}$ for pure V. Finally, solubility experiments over the temperature range $473 \mathrm{~K}$ to $673 \mathrm{~K}$ and for pressures of $1 \mathrm{E} 4 \mathrm{~Pa}$ to $3 \mathrm{E} 6 \mathrm{~Pa}$ revealed that the addition of $\mathrm{Ni}$ reduces the hydrogen solubility in vanadium, however the reduction is not as much as that observed for $\mathrm{Co}, \mathrm{Fe}$ or $\mathrm{Cr}$ additions.

The experiments reported by Takata 1993 were conducted for high purity, fully-annealed specimens of polycrystalline vanadium over the temperature range $300 \mathrm{~K}$ to $500 \mathrm{~K}$ and the pressure range $66.5 \mathrm{~Pa}$ to $2660 \mathrm{~Pa}$. Permeabilities derived from steady-state permeation measurements were systematically less than calculated values over the temperature and pressure range of the experiment. For temperatures of $400 \mathrm{~K}$ to $500 \mathrm{~K}$, and pressures of $66 \mathrm{~Pa}$ and $133 \mathrm{~Pa}$, the measured permeabilities were about $1 / 8$ the calculated values, but the temperature trend was similar. For temperatures between $270 \mathrm{~K}$ and $460 \mathrm{~K}$ and pressures of $532 \mathrm{~Pa}$ to $2660 \mathrm{~Pa}$, the observed permeabilities displayed a $\mathrm{P}^{3 / 2}$ pressure dependence. The authors concluded that for temperatures $>400 K$, observed permeation rates with $P^{1 / 2}$ dependence indicated a mixed alpha/beta phase for $\mathrm{V}-\mathrm{H}$. In a companion work by Suzuki 1993, these authors develop a theory for understanding $\mathrm{H}$ solubility in the mixed phase region.

To compute Arrhenius parameters for $\mathrm{H}$ permeability in pure vanadium, we recommend using the solubility data identified by Reiter 1993 and the diffusivity data reported by Freudenberg 1978. Using the Arrhenius parameters in Tables 6.3 and 6.1 , we compute the permeability activation energy to be $-0.288 \mathrm{eV}$ and the permeability pre-exponential to be

4.5E15 $\mathrm{H} / \mathrm{msPa}^{1 / 2}$. 


\section{Trapping at Interstitial Impurities}

It has been recognized for many years that the presence of interstitial impurities, like $\mathrm{C}, \mathrm{O}$ and $\mathrm{N}$, can have a significant impact on both hydrogen solubility and diffusivity, especially at low temperatures. In the following paragraphs we will summarize key results from selected experimental papers that concern impurity effects in $V$ and conclude with insights from $a$ theoretical paper on this subject.

In the work reported by Chang 1973, internal friction and resistivity measurements were made to determine the terminal hydrogen solubility limit (onset of hydride precipitation) of $V$ as a function of $\mathrm{C}, \mathrm{N}$ and $\mathrm{O}$ impurities. Impurity gases were introduced into outgassed and annealed high purity $V$ wires by a sequence of heat treatment and gas reaction procedures. Exact $H$ concentrations were determined using vacuum fusion gas analysis. Internal friction and resistivity measurements were made over the temperature range $200 \mathrm{~K}$ to $300 \mathrm{~K}$ to determine the onset of hydride precipitation. Compared to the work of Westlake 1967, Cannelli 1970 and Veleckis 1969 , the terminal solubilities reported for high purity vanadium were significantly less at comparable temperatures. Addition of $\mathrm{C}, \mathrm{O}$, and $\mathrm{N}$ impurities, expecially $\mathrm{O}$, to the vanadium resulted in an increase in $\mathrm{H}$ concentration for a given temperature. Derived terminal solubility data as a function of temperature for the specimens with impurities were very similar to those reported by Westlake 1967 and Cannelli 1970, causing the authors to conclude that the $H$ solubility results observed in the other work were impacted by impurities. Based on trapping analyses for the experimental data, Chang 1973 concluded that $\mathrm{H}-\mathrm{H}$ clusters trap at impurity sites with binding energies of $0.09 \mathrm{eV}$ for $\mathrm{OH}$ with binding energy increases if $0.14 \mathrm{eV}$ per atom for higher order clusters like $\mathrm{O}-\mathrm{H}-\mathrm{H}$. A binding energy of $0.135 \mathrm{eV} / \mathrm{pair}$ was estimated for $\mathrm{C}-\mathrm{H}$ and $\mathrm{N}-\mathrm{H}$.

Using the resistometric technique, Westlake 1975 investigated the influence of $O$ impurities on the $\mathrm{H}$ solubility limit for vanadium. Measurements were made over the temperature range $230 \mathrm{~K}$ to $325 \mathrm{~K}$, using high purity $V$ wire that was reacted with $\mathrm{O}_{2}$ to give $\mathrm{V}-\mathrm{O}$ samples with $\mathrm{O}$ at greater than $1000 \mathrm{ppm}$. The $\mathrm{V}$ wire was charged with $\mathrm{H}$ electrolytically. The key result from this study was that large concentrations of solute $O(1300$ to $6000 \mathrm{ppm})$ increased the apparent $\mathrm{H}$ solubility limit in a systematic way for temperatures between $230 \mathrm{~K}$ and $325 \mathrm{~K}$. The increases were largest at the lowest temperatures. Results are in qualitative agreement with those of Chang 1973.

lon-channeling studies and nuclear reaction analyses were conducted by Ozawa 1978, in a effort to investigate deuterium trapping by $O$ interstitials. Specimens doped with $O$ were prepared by arc melting $V(99.8 \%)$ with $V_{2} O_{3}$ powder. The specimens were charged with $D$ by heating them in a sealed container with $V D_{0.16}$ powder. Measurements were made for samples with varying $D$ and $O$ concentrations in $V$ to determine if $D$ formed $D-O$ clusters. Channeling angulardistribution measurements indicated that some $D$ atoms were trapped at octahedral interstitials in the host lattice where they coexisted with $O$ atoms. Normally, D occupies tetrahedral sites in $V$. These experiments provided direct evidence of $D$ trapping at $O$ in a metal.

More recently, Peterson 1988 reported the results of an extensive study to determine $H$ solubility and diffusivity in V-O alloys. P-C-T isotherms were measured at $297 \mathrm{~K}$ and $373 \mathrm{~K}$ and diffusion coefficients were obtained, using the Boltzmann-Matano method, as a function of $\mathrm{H}$ concentration for temperatures of $227 \mathrm{~K}, 297 \mathrm{~K}$ and $373 \mathrm{~K}$. Oxygen-doped specimens were made by arc melting pure $\mathrm{V}$ with $\mathrm{V}_{2} \mathrm{O}_{3}$ powder. Oxygen concentrations varied from $0.35 \%$ to 1.95 $\%$. For solubility experiments, the specimens were charged with $\mathrm{H}$ at $1125 \mathrm{~K}$ with a gas overpressure. Diffusivity specimens were charged electrolytically over a portion of the wire specimen. Key results from the solubility experiments were the following: (1) addition of 0 
caused only a small increase in the isopiestic solubility of $H,(2)$ Sieverts law was obeyed over a $\mathrm{H}$ concentration range up to $2.5 \%$, (3) trap binding energies were estimated to be $0.04 \mathrm{eV}$ to $.05 \mathrm{eV}$, using the Kircheim 1982 model, and (4) trap saturation (effect predicted by local deep trapping model) was not observed because small trap energies and dilute $\mathrm{H}$ and trap concentrations resulted in only a small fraction of traps being filled. In contrast to these solubility results, the diffusivity results indicated that the diffusion coefficients decreased considerably with $\mathrm{O}$ impurity and $\mathrm{H}$ concentration. Trap binding energies derived from the diffusivity data were somewhat larger $(0.09 \mathrm{eV}$ versus $0.05 \mathrm{eV})$ than those obtained from the solubility experiments. The higher binding energy values were consistent with those observed by Chang 1973.

A theoretical investigation into trapping of $\mathrm{H}$ by $\mathrm{O}$ and $\mathrm{N}$ impurities in $\mathrm{V}$ has been reported by Shirley 1983. The method of lattice statics was used to calculate $H$ impurity binding energies as function of location and orientation of $\mathrm{H}$ and the impurity atoms. Normal locations for $\mathrm{H}$ were considered to be tetrahedral sites and locations for O,were octahedral sites. Trapping was assumed to result from "stress-induced" or elastic interactions between the impurity and $H$ atoms. A comparison of the theoretical results to anelastic relaxation observed experimentally lead to the following proposal concerning two possible hydrogen-impurity defect structures: a third nearest neighbor pair with a binding energy of $0.11 \mathrm{eV}$ and a ring structure with the fourth and fifth nearest neighbors with a binding energy of $0.06 \mathrm{eV}$. The authors noted that the experimental binding energy of $0.09 \mathrm{eV}$, reported for polycrystalline $\mathrm{V}-\mathrm{O}-\mathrm{H}$ by Chang 1973 ,compared favorably to the estimates of binding energies in polycrystalline material, as derived using theoretical values that rangefrom $0.11 \mathrm{eV}$ to $0.05 \mathrm{eV}$ for $\langle 100\rangle$ and $\langle 110\rangle$ crystalline orientations, respectively. Based on the good agreement between theoretical prediction and experiment, the authors concluded that, indeed, elastic effects were responsible for trapping of $\mathrm{H}$ and $\mathrm{O}$ and $\mathrm{N}$ impurities in $\mathrm{V}$.

\section{Trapping at Radiation-induced Defects}

Hydrogen transport and retention in materials is strongly influenced by trapping at structural defects like vacancies, interstitials, vacancy clusters, voids, dislocaations, microscopic gas bubbles, etc.,( see Ch. 8. Trapping of Hydrogen in metals by $\mathrm{Ch}$. A. Wert, Alefeld 1978b). For fusion applications, the principal defect sites in structural materials like vanadium alloys will be neutron-induced point defects and small defect clusters, as well as, voids and microscopic gas bubbles evolving from gases generated by nuclear transmutation reactions. In the following paragraphs, we will briefly sumarize pertinent information that relates to hydrogen trapping at radiation-induced defects.

A general review of early radiation-effects work on vanadium alloys is that of Gold 1980. This reference provides a comprehensive review of the effects of high-energy neutron and ion irradiation on the mechanical properties, dimensional stability and microstructural response of unalloyed $V$ and $V$-based alloys. The emphasis of the review is on bulk effects, especially on those properties having the greatest impact on material use in a fission or fusion reactor environment. A key observation for vanadium alloys is that those with a few $\% \mathrm{Ti}$ exhibit marked resistance to void formation and swelling and to a drastic loss of ductility observed for many structural materials. Although the review treats the radiation response of the alloys with an emphasis on mechincal properties, it contains useful information on defect generation/characterization and void generation/growth phenomena that are relevant to hydrogen tyrapping in such irradiated material.

Experiments to investigate deuterium trapping by radiation-induced defects in $\mathrm{V}, \mathrm{Nb}$, and $\mathrm{Ta}$ have been reported by Yamaguchi 1980a, 1980b. These experiments entailed measurements of the depth profile for $D$ and for radiation-induced defects in specimens charged with $D$ by high temperature gas absorption and implanted with 250 - to $750-\mathrm{keV}$ He ions to generate the defect 
profile. The depth profile was measured by nuclear reaction analysis with the $\mathrm{D}\left({ }^{3} \mathrm{He}, \alpha\right) \mathrm{H}$ reaction. Depth profile of radiation-induced defects was obtained by ion-channeling measurements. Both profiles exhibited a good spatial correspondence, indicating trapping of deuterium in the radiation-induced defects. From measurements of the defect concentration for specimen temperatures ranging from room to $373 \mathrm{~K}$ and forboth heating annd cooling cycles, the authors found that deuterium left the defect region at high temperatures but returned at low temperatures. A binding energy of $0.11 \mathrm{eV}$ was estimated for $\mathrm{D}$ binding to the defect sites.

More recently, Kano 1993 reported on measurements that concerned the interaction of $\mathrm{H}$ with defects and on microstructural changes during dual ion iradiation. These experiments were done using $99.9 \%$, polycrystalline $V$ that was annealed at high temperatures to reduce $\mathrm{O}$ and $\mathrm{N}$ impurities. Ion beams used in this work included $3 \mathrm{MeV} \mathrm{Ni}{ }^{2+}$ with $\mathrm{H}^{+}$or $\mathrm{He}^{+}$. Energies of the $\mathrm{H}^{+}$and $\mathrm{He}^{+}$beams were adjusted from primary energies of $950 \mathrm{keV}$ and $1 \mathrm{MeV}$, respectively, using degrader foils, such that the range profile for $\mathrm{H}$ and $\mathrm{He}$ matched the displacement damage profile for the $\mathrm{Ni}^{+}$ions. Specimen preparations were done for a temperature range of $773 \mathrm{~K}$ to $973 \mathrm{~K}$; for displacement damage ranging from $1-50 \mathrm{dpa}$, and for gas injection of 15 to 60 appm/dpa for $\mathrm{H}$ and 30 appm/dpa for He. Transmission electron microscopy was used to characterize the specimens. Key results included the following: (1) $H$ strongly effects cavity formation in $\mathrm{V},(2)$ there is a critical radius of cavity under $\mathrm{H}-\mathrm{Ni}$, dual-ion irradiation that depends on irradiation temperature similar to that for $\mathrm{He}$, and (3) the dose, above which the cavity nucleation regime turns into a cavity growth regime, depends on H/dpa ratio, becoming smaller for higher H/dpa ratios.

\section{Surface Effects}

Surface effects play a major role in controlling uptake and release of hydrogen from materials. In many early studies of gas-driven permeation, surface conditions, especially the presence of oxide layers, presented barriers to uptake of hydrogen. As we noted in previous sections, oxide layers on vanadium samples was identified as a controlling factor in permeability measurements, Nishimura 1991. In this section we will summarize work that is relevant to understanding the influence of surface conditions on $\mathrm{H}$ transport and release from vanadium.

Surface scientists have been aware for some time of the difficulties in preparing and maintaining a clean surface of vanadium. Adams 1981, in an effort to prepare clean $V$ surfaces, discovered problems that were related to diffusion of $O$ back and forth between the bulk and the surface, depending on the specimen temperature. These workers identified $S$ and $C$ as initial impurities that could be removed by argon bombardment with the sample at $1123 \mathrm{~K}$ followed by additional heating to $1773 \mathrm{~K}$ in a vacuum. Fifteen hours of sputtering followed by 20 hours of heating gave a "clean surface" with evidence of a small oxide layer. The extent of D coverage was found to be dependent on specimen temperature, reaching a maximum surface coverage at $673 \mathrm{~K}$ and decreasing in surface coverage as the temperature increased above $773 \mathrm{~K}$. This changing surface condition was attributed to $O$ diffusion from bulk to surface for temperatures less than $673 \mathrm{~K}$ and $\mathrm{O}$ diffusion from surface to bulk for temperatures greater than $773 \mathrm{~K}$. To achieve a clean surface, the authors used Ar sputtering with the specimen at $673 \mathrm{~K}$. These observations were confirmed by Welter 1992-1993, who studied surface/volume segregation behavior of $O$ in $V$ by measuring $O$ surface concentrations for specimens heated in a UHV environment. According to this work, the temperature dependence of $O$ surface concentration could be described by an ideal solution model with a surface/volume segration enthalpy of $1.21 \mathrm{eV}$. Finally, Foord 1983 reported work on surface structure determinations in which bulk transport of $O$ and low pressure oxidation were identified as key contributors to changes in the surface structure. 
Experiments to measure hydrogen permeability for $V$ identified surface conditions as key controlling factors of permeation. In the early work reported by Van Deventer 1977, gas permeation experiments were made for MARZ grade $V$ foil with temperatures ranging from $473 \mathrm{~K}$ to $1123 \mathrm{~K}$. Surface characterization was done using Auger spectrometry, ion-microbe analyses and nuclear reaction analyses. Surface impurity layers, composed principally of $O$ and $C$, were found to reduce permeability by factors of several hundred. Impurity layers grew to thicknesses approaching 10 micrometers after long exposure of a heated specimen $(673 \mathrm{~K}$ to $1123 \mathrm{~K}$ ) to a vacuum quality of $1 \mathrm{E}-5$ to $1 \mathrm{E}-8$ torr.

Japanese researchers have investigated in some detail the influence of surface conditions on $\mathrm{H}$ permeation in vanadium. In the work reported by Namba 1982, gas-driven permeation experiments were made for electropolished $V$ foils $(99.9 \% V)$ at temperatures from $578 \mathrm{~K}$ to $1072 \mathrm{~K}$ and gas pressures of $0.2 \mathrm{~Pa}$ to $6.5 \mathrm{E} 4 \mathrm{~Pa}$. In the low pressure regime, measured permeation rates were linearly proportional to pressure, whereas, for higher driving pressures, permeation rates were proportional to the square root of pressure. Surface analyses for specimens retrieved from the permeation chamber revealed surface impurities of $C, O, N$ and S. Argon sputter guns, for in-situ cleaning of both upstream and downstream surfaces, were incorporated in the next series of gas-driven permeation experiments, Namba 1983. Steadystate permeation rates were measured for different surface treatments, e. g. no treatment, upstream surface sputter-cleaned, downstream surface sputter-cleaned, etc. In-situ sputter cleaning gave rise to increasing levels of permeation, with the greatest increase resulting from cleaning the upsstream surface. Surface analyses for the specimens, done in a different chamber, revealed that $O$ concentrations were least on sputter-cleaned surfaces and $S$ was identified as a prominent impurity on a downstream surface if the specimen was heated. The researchers concluded that surface processes were rate-determining for $\mathrm{H}$ permeation through $V$. In a comparitive study of gas-driven permeation through type 304 stainless steel, vanadium, and niobium, for temperatures between $663 \mathrm{~K}$ and $780 \mathrm{~K}$ and gas pressures of $10 \mathrm{~Pa}$ to $2 \mathrm{E} 4 \mathrm{~Pa}$, Namba 1984 concluded that permeation through steel was bulk-diffusion limited, whereas, permeation through $\mathrm{V}$ and $\mathrm{Nb}$ was controlled by surface adsorption/desorption processes. Additional insight into the relationship between surface impurities and permeation rates was achieved by incorporation of in-situ Auger analysis in the permeation chamber, along with argon sputter-cleaning capabilities, Yamawaki 1985. With this capability, the researchers discovered that $\mathbf{S}$ was the dominant surface impurity on a specimen that was sputter cleaned and heated to $923 \mathrm{~K}$. Permeation measurements indicated a correlation between changes in permeation rates and surface sulfur concentration, that is, falling permeation rates were correlated to rising S concentrations. In contrast to their earlier work, in which reduced permeation rates were attributed to oxide layers, these workers suggested that $S$ contributed a barrier effect to permeation. To explain these experiments, Yamawaki 1986 proposed an atomistic model for the hindrance of dissociative hydrogen adsorption due to surface-segregated $S$. Qualitatively, the model assumed surface segregated $S$ reduced the effective area for permeation.

In an effort to relate measured permeation rates to model simulations of $H$ transport, several studies have been made to determine surface molecular recombination rate factors for $V$. Kiyoshi 1986 conducted gas-driven permeation experiments for $99.8 \% \vee$ disc specimens that were heated between $620 \mathrm{~K}$ and $875 \mathrm{~K}$ and exposed to a gas pressure of $17 \mathrm{~Pa}$. The upstream surface was sputter-cleaned prior to a permeation experiment. After reaching steady-state permeation, the workers subjected the specimen to step changes in temperature and observed a transient change in permeation rates. By assuming surface-limited permeation, the authors were able to fit the observed permeation signals and deduce values for upstream and downstream surface recombination coefficients. In units of $\mathrm{m}^{4} / \mathrm{s}$, the upstream recombination coefficients were $4.2 \mathrm{E}-33$ at $775 \mathrm{~K}, 6.6 \mathrm{E}-34$ at $722 \mathrm{~K}$, and $8.3 \mathrm{E}-35$ at $666 \mathrm{~K}$, and corresponding downstream coefficients were $6.6 \mathrm{E}-34,3.3 \mathrm{E}-34$, and $1.7 \mathrm{E}-34$, respectively. These values are 
considerably smaller than those predicted by recombination models as presented below. In experiments that measured both $D$ ion-beam and gas-driven permeation, Yamaguchi 1989 obtained estimates of surface recombination coefficients that could be correlated with surface sulfur concentrations. For a specimen temperature of $773 \mathrm{~K}$, the upstream surface deuterium recombination coefficient varied from $1 E-30 \mathrm{~m}^{4} / \mathrm{s}$ to $1 E-31 \mathrm{~m}^{4} / \mathrm{s}$ as the surface sulfur concentration varied from $0 \%$ to $40 \%$. Downstream surface recombination coefficients varied from $1 \mathrm{E}-31 \mathrm{~m} 4 / \mathrm{s}$ to $1 \mathrm{E}-32 \mathrm{~m}^{4} / \mathrm{s}$. Using both ion-driven and gas-driven permeation experiments, Yamawaki 1989 obtained deuterium surface recombination coefficients for both sputter-cleaned and sulfur-saturated $V$ surfaces, for a temperature range of $666 \mathrm{~K}$ to $775 \mathrm{~K}$. Assuming that the surface recombination coefficient can be represented by an Arrhenius expression, they obtained an activation energy of $0.94 \mathrm{eV}$, and pre-exponential factors of $1.2 E-31 \mathrm{~m}^{4} / \mathrm{s}$ for the sputter-cleaned surface and $1.5 \mathrm{E}-32 \mathrm{~m}^{4} / \mathrm{s}$ for the sulfur-saturated surface. Further investigation into the effect of surface impurities on hydrogen recombination coefficients was reported by Yamawaki 1989 in which coefficients derived from earlier experiments ( Yamaguchi 1989) were compared to coefficients calculated using two models, Baskes 1980 and Pick 1985. The measured values were significantly less than the calculated values; $3.4 \mathrm{E}-28 \mathrm{~m}^{4} / \mathrm{s}$ for Baskes 1980 and $1.2 \mathrm{E}-28 \mathrm{~m}^{4} / \mathrm{s}$ for Pick 1985 . Assuming that the Pick model was applicable, the measured coefficients were compared to the Pick values and chemsorption activation energies were estimated for a sputter-cleaned surface and for a sulfur-saturated surface. This analysis yielded chemisorption energies of $0.16 \mathrm{eV}$ for a sputter-cleaned surface and $0.24 \mathrm{eV}$ for a surface saturated to $40 \%$ with $\mathrm{S}$. These workers concluded that the role of the impurity could be twofold: (1) the impurity serves as a blocking agent to inhibit dissociation/recombination from adjacent sites and (2) the impurity electronegativity could change the surface chemical state, thus introducing a chemisorption barrier.

Deuterium ion-driven permeation experiments were reported by Holland 1988 in which estimates of surface recombination coefficients were obtained for both $V$ and the alloy $\mathrm{V} 15 \mathrm{Cr} 5 \mathrm{Ti}$. For $\mathrm{V}$ specimen temperatures of $755 \mathrm{~K}$ and $678 \mathrm{~K}$, coefficients for an unsputtered surface were estimated to be $2 E-34 \mathrm{~m}^{4} / \mathrm{s}$ and $5 E-34 \mathrm{~m}^{4} / \mathrm{s}$, respectively. The effect of deuterium sputtering of the upstream surface was estimated to increase these coefficients by a factor of 6 to 10 . For $V 15 \mathrm{Cr} 5 \mathrm{Ti}$ at $733 \mathrm{~K}$, a coefficient of $4 \mathrm{E}-32 \mathrm{~m}^{4} / \mathrm{s}$ was determined for an unsputtered surface, and a sputter-enhancement factor of 9 was determined.

Estimates of the surface hydrogen recombination coefficients can be made using models by Baskes 1980 and by Pick 1985. These models require values for the solution enthalpy and Arrhenius prefactor for solubility. For this quantities, we recommend the values given in Table 6.3 under Reiter.

\section{Thermotransport}

A temperature gradient in a material may cause concentration gradients of solute atoms to develop due to thermotransport or thermomigration. As identified by Reiter 1993, hydrogen transport is characterized by a phenomenological parameter called $Q^{*}$, the heat of transport. In general, endothermic hydrogen absorbers(like nickel, iron and steels) have negative heats of transport, resulting in a reduction in hydrogen transport down the temperature gradient because of the Soret effect. On the other hand, exothermic hydrogen absorbers, like $\mathrm{V}, \mathrm{Nb}, \mathrm{Ta}$, and $\mathrm{Ti}$, have positive heats of transport in the range 300 to $1000 \mathrm{~K}$. Consequently, for these materials in fusion applications where the plasma side is much hotter than the coolant side, , tritium inventory and permeation to the coolant are increased because of thermotransport. In the following paragraphs, we will summarize relevant experimental information on heats of transport for $V$ and $V$ alloys. 
Thermotransport of $H$ and $D$ in V, Nb, and Ta has been investigated by Peterson 1982 in two temperature ranges, with mean specimen temperatures of $308 \mathrm{~K}$ and $448 \mathrm{~K}$. High purity specimens were electrolytically charged with $H$ or $D$ to concentration levels of about 1 at \%. Charged specimens were to an experimental arrangement that imposed a temperature gradient across the specimen. After a sufficient time for thermotransport to redistribute the hydrogen, the sample was retrieved and cut into sections for analysis of the gas contents, hence the hydrogen concentration profile in the specimen. Thermotransport of both isotopes was toward the cold end of the sample, and the redistribution of the solute increased with increasing atomic mass of the host metal. The heat of transport was greater for deuterium than for hydrogen. Heats of transport were determined to be $0.014 \mathrm{eV}$ for $\mathrm{H}$ and $0.05 \mathrm{eV}$ for $\mathrm{D}$. Within experimental error, there was no observed temperature dependence in the heat of transport.

Heats of transport for $\mathrm{H}, \mathrm{D}$, and $\mathrm{T}$ in $\mathrm{V}$ and $\mathrm{V}$ binary alloys ( with $\mathrm{Nb}, \mathrm{Ti}$, and $\mathrm{Cr}$ ) has been reported by Sugiaski 1986. Rod-shaped specimens, charged with hydrogen to a concentration of $1 \mathrm{at} \%$, were exposed to a temperature gradient from $23 \mathrm{~K}$ to $338 \mathrm{~K}$, with an axial gradient of $283 \mathrm{~K} / \mathrm{cm}$. After the hydrogen had redistributed because of thermotransport, the specimen was quenched and cut into halves. Each half of the specimen was analyzed for hydrogen contents. Heats of transport obtained for pure vanadium were reported as follows: $0.013 \mathrm{eV}$ to $0.02 \mathrm{eV}$ for $\mathrm{H}$ with average specimen temperatures of $308 \mathrm{~K}$ to $448 \mathrm{~K} ; 0.05 \mathrm{eV}$ to $0.06 \mathrm{eV}$ for $\mathrm{D}$ with the same average temperature range, and $0.077 \mathrm{eV}$ to $0.083 \mathrm{eV}$ for $\mathrm{T}$ with average temperatures of $348 \mathrm{~K}$ to $523 \mathrm{~K}$. These results indicate a stong isotopic dependence and give a hint of temperature dependence. The results agree with those reported by Peterson 1982.

In a more recent investigation, Sugisaki 1990 report the results of heat of transport measurements for tritium in vanadium at higher average temperatures than in the previous work. For temperatures of $343 \mathrm{~K}, 423 \mathrm{~K}$, and $523 \mathrm{~K}$, the measured heats of transport were $0.079 \mathrm{eV}+/-4 \%, 0.093 \mathrm{eV}+/-8 \%$, and $0.083 \mathrm{eV}+/-8 \%$, respectively.

\section{Assessment}

For diffusivity; the existing data are good (need measurements between $600 \mathrm{~K}$ and $800 \mathrm{~K}$ ); for permeability, data are poor because of surface oxide effects; for solubility, data are excellent in the regime that Sieverts law applies; for thermotransport, data are good but limited to temperatures less than 500K; recombination coefficient, wide disparity between measureed results and in comparison with model calculations; surface effects, much data to characterize surface, however the effect of surface conditions on hydrogen transport is known semiquantitativily at best; trap site characterization, data and understanding are good; porosity, no data; permeation in layered structures, very little data; permeation at interfaces, little data; oxide properties, much data and a semiquantitative understanding. The data listed in Tables 6.1 and 6.3 under Reiter 1993 provide reasonable values of the Arrhenius parameters for diffusivity and solubility for pure $V$. The data presented in Tables $6.2,6.4$ and 6.5 should be considered for analyses that require some consideration of alloying elements on diffusivity and solubility in $\mathrm{V}$ alloys. 


\section{Database Assessment}

The "operating history" of a plasma facing component (PFC) includes:

- original material composition and morphology

- fabrication history (such as cold work)

- PFC operating temperature history

- surface erosion and redeposition

- neutron irradiation energy spectrum and fluence

- hydrogenic ion implantation energy spectrum and fluence

- helium implantation energy spectrum and fluence

- plasma chamber gases $(\mathrm{H}, \mathrm{C}, \mathrm{N}, \mathrm{O}, \ldots)$ pressure histories

- impurities introduced from coolant

- annealing history.

It is difficult to reconcile experiments on specimens with diverse operating histories.

Interim recommendations for hydrogen diffusivity and solubility values for each material were given in the corresponding chapter and are summarized in the Abstract. For estimates of the recombination coefficients the theory of Pick and Sonnenberg is recommended, or the more complete theory of Richards if surface coverage is high. However, we highly recommend the use of surface recombination coefficients derived from experimental testing on materials that are representative of those for fusion applications. As we noted in this review, the surface recombination coefficients that are calculated with the model expressions are often substantially larger than measured values. The bottom line is that one has to properly account for surface impurities and other surface conditions that affect the recombination coefficient for realistic materials.

The results of this database assessment are summarized in Table 5, which shows a matrix of properties vs. materials, indicating the general quality of data currently available. An assessment of the data-base quality for $V$ is not included in the table. However, we can summarize it's status as follows. For diffusivity; the existing data are good (neeed measurements between $600 \mathrm{~K}$ and $800 \mathrm{~K}$ ); for permeability, data are poor because of surface oxide effects; for solubility, data are excellent in the regime that Sieverts law applies; for thermotransport, data are good but limited to temperatures less than 500K; recombination coefficient, wide disparity between measureed results and in comparison with model calculations; surface effects, much data to characterize surface, however the effect of surface conditions on hydrogen transport is known semi-quantitativily at best; trap site characterization, data and understanding are good; porosity, no data; permeation in layered structures, very little data; permeation at interfaces, little data; oxide properties, much data and a semiquantitative understanding.

Some parameters, such as diffusion coefficient and permeability in stainless steels, can be predicted with reasonable uncertainties (within a factor of two). Most parameters are known only with poor accuracy, due to the large number of variables that influence them.

It should be noted that for copper and vanadium, fusion applications will generally require the use of alloys of these materials. In general, the data base for hydrogen transport in alloys, with the exception of steels, is somewhat limited. However, for vanadium there is a reasonable set of data that pertain to hydrogen transport in binary alloys, with $\mathrm{Cr}$ and with $\mathrm{Ti}$. Although somewhat limited in temperature range, the data provide a guide to extrapolate from. Additional testing over a wider temperature range and for more complex alloys is required. The situation 
for alloys of copper is not as good. Although there has been some effort to measure the influence of alloying elements and impurities on hydrogen transport, the influence is known semiquantitatively at best, for a limited set of constituents. There is a need to for measurements on ITER-relevant alloy materials to assure a quantitative assessment of tritium transport and retention issues that relate to safety and environmental concerns.

Table 7.1. Availability of data for tritium interaction with Be, SS, Cu, C, and V.

\begin{tabular}{|c|c|c|c|c|}
\hline $\begin{array}{l}\text { Property } \\
\text { diffusivity }\end{array}$ & $\begin{array}{l}\mathrm{Be} \\
\text { very disparate }\end{array}$ & good, factor of 2 & $\frac{a u}{g 00 d}$ & $\begin{array}{l}\text { fair } \\
\text { (many forms) }\end{array}$ \\
\hline permeability & very disparate & good, factor of 2 & good & fair \\
\hline solubility & little data & disparate & $g 000$ & fair \\
\hline Soret effect & no data & one datum & no data & no data \\
\hline $\begin{array}{l}\text { recombination } \\
\text { coefficient }\end{array}$ & very disparate & disparate & disparate & fair \\
\hline surface effects & many questions & some data & much data & much data \\
\hline $\begin{array}{l}\text { trap site } \\
\text { characterization } \\
\text { and effects }\end{array}$ & some data & some data & some data & some data \\
\hline porosity & little data & one datum & some data & some data \\
\hline $\begin{array}{l}\text { permeation in } \\
\text { layered } \\
\text { structures }\end{array}$ & no data & oxides only & some data & no data \\
\hline $\begin{array}{l}\text { permeation at } \\
\text { interfaces }\end{array}$ & no data & some data & some data & no data \\
\hline oxide properties & little & little data & some data & (oxide=gas) \\
\hline
\end{tabular}




\section{Conclusions and Recommendations}

1. At present the database, especially for beryllium, is inadequate. Accurate prediction of the ITER tritium permeation and inventory will require better understanding of many processes (trapping, grain-boundary diffusion, permeation barrier failure, Soret effect, oxide layer growth and loss, bubble nucleation) and more precise quantification of most parameters. Most of the existing data base for transport and retention of hydrogen isotopes in materials was derived from laboratory experiments on materials that may not be fully representative of materials used in ITER. Additional testing is required, especially for alloys of $\mathrm{Cu}$ and $\mathrm{V}$ that may be used in ITER. This testing should simulate, as well as possible, the particle fluxes and energies and the surface conditions and material temperatures that we expect in ITER applications. .

2. Algorithms should be developed to predict

* porosity vs. operating history

- effects of porosity on tritium transport

- trap site nature, energy, and concentration vs. operating history

- effects of trap sites on tritium transport (such as the TMAP4 model)

- conditions under which rapid grain-boundary tritium transport would be expected, and the rate of such transport

- effects of thermal-gradient-driven tritium transport

3. Computer models of tritium behavior should be enhanced to include all the effects likely to influence tritium inventory and mobilization. Experiments should be simulated by computer models, such as TMAP4, whenever possible, and materials characterization techniques, such as nuclear reaction depth profiling, should be used to check the computer models.

4. Some of the required data, such as trap site energies and concentrations produced by neutron irradiation of $\mathrm{Be}$ at high temperatures, can be obtained by analysis of samples irradiated in fission reactors, but a $14 \mathrm{MeV}$ neutron source would be preferable.

5. Other data, such as porosity, can be obtained by analysis of targets irradiated by ion beams or by plasma in experiments such as PISCES and the Tritium Plasma Experiment.

6. Estimation of the ITER tritium source term for the ESECS depends more upon the properties of Be than of Cu or SS. 


\section{Acknowledgments}

This work was supported by the US Department of Energy, Office of Fusion Energy, under Contract DE-AC07-76ID01570. The following people have contributed research articles pertinent to this study:

D. Baldwin

R. A. Causey

G. Federici

A. A. Haasz,

Y. Hirooka,

Y. lijima

D. Kérouack

R. Macaulay-Newcombe

H. Moriyama

A. V. Naberenkov

M. Okamoto

M. A. Pick

M. Saeki

F. Scaffidi-Argentina,

B.M.U. Scherzer

H. Sugai,

M. Sugisaki

T. Tanabe

W. R. Wampler

P. Weinhold

N. Yoshida

The authors are grateful to P. Andrew, M. A. Pick, R. G. Macaulay-Newcombe, R. A. Causey, W. R. Wampler, G. A. Longhurst, and D. A. Petti for many helpful comments. 


\section{Appendix A. Bibliography on Beryllium}

E. Abramov, M. P. Riehm, D. A. Thompson, and W. W. Smeltzer (1990) "Deuterium permeation and diffusion in high-purity beryllium," Journal of Nuclear Materials 175, 9095.

J. E. Adams (1994) "A tritium data base for ITER materials," INEL Engineering Design File FSP-04, ITER Task Area SAE-2.

G. Alefeld and J. Völkl, Editors (1978a) Hydrogen in Metals, Basic Properties, SpringerVerlag, Berlin.

G. Alefeld and J. Völkl, Editors (1978b) Hydrogen in Metals /I Application-Oriented Properties, Springer-Verlag, Berlin.

C. Alexander et al. (1978) "Tritium diffusion in nonmetallic solids of interest for fusion reactors," North Carolina State University Final Report, DOE/ET/52022-5.

R. M. Al'tovskiy, A. A. Eremin, L. F. Eremina, L. A. Izhvanov, V. N. Fadeyev, and M. I. Urazbayev (1981), Russian Metallurgy (English Translation) 3, 51.

R. A. Anderl, M. R. Hankins, G. R. Longhurst, R. J. Pawelko, and R. G. Macaulay-Newcombe (1992) "Hydrogen transport behavior of beryllium," Journal of Nuclear Materials 196-198, 986-991.

P. Andrew, C. J. Caldwell-Nichols, J. P. Coad, et al. (1992a) "The tritium cleanup experiment in JET," Journal of Nuclear Materials 196-198, 143-148.

P. L. Andrew, A. T. Peacock, and M. A. Pick (1992b) "Interpretation of deuterium pumping by plasma-facing beryllium surfaces," Journal of Nuclear Materials 196-198, 997-1001.

P. L. Andrew and A. A. Haasz (1992c) "Models for hydrogen permeation in metals," Journal of Applied Physics 72, 2749-2757.

P. L. Andrew, J. P. Coad, J. Ehrenberg, et al. (1993) "Experiments on the release of tritium from the first wall of JET," Nuclear Fusion 33, 1389-1404.

D. L. Baldwin, O. D. Slagle, and D. S. Gelles (1989) "Tritium release from irradiated beryllium at elevated temperatures," PNL-SA-16998.

D. L. Baldwin (1991) "Comparison of results of tritium and helium behavior in irradiated beryllium," Beryllium Technology Workshop, Clearwater Beach, FL, November 20, 1991, EGG-FSP-10017.

D. L. Baldwin (1993a) "Tritium release kinetics in irradiated beryllium," Second International Workshop on Ceramic Breeder Blanket Interactions, Paris, France, September $22-24$.

D. L. Baldwin (1993b) "Tritium release studies of irradiated beryllium," Workshop on Beryllium for Fusion Applications, Karlsruhe, Germany, October 4-5, Report KfK 5271. 
D. L. Baldwin and M. C. Billone (1993) "Diffusion/desorption of tritium from irradiated beryllium," 6th International Conference on Fusion Reactor Materials, Stresa, Italy, September 27 - October 1. Draft.

M. I. Baskes (1980) "A calculation of the surface recombination rate constant for hydrogen isotopes on metals," Journal of Nuclear Materials 92, 318-324.

R. Bastasz (1984) "Hydrogen bombardment of the oxide layer on beryllium," Thin Solid Films $12,127-133$.

J. M. Beeston, L. G. Miller, G. R. Longhurst, and R. A. Causey (1990) "Gas retention in irradiated beryllium," EGG-FSP-9125.

J. M. Beeston, G. R. Longhurst, R. S. Wallace, and S. P. Abeln (1992) "Mechanical properties of irradiated beryllium," Journal of Nuclear Materials 195, 102-108.

R. Behrisch, R. S. Blewer, J. Borders, R. Langley, J. Roth, B. M. U. Scherzer, and R. Schulz, (1980) "Implantation of $5 \mathrm{keV}$ deuterium in BeO," Radiation Effects 48, 221-224.

F. F. Bentley (1963) "Solubility and diffusion of gases in beryllium," ASD-TDR-62-1018. sol \& dif: $\mathrm{N}, \mathrm{O}$ and $\mathrm{H}$ in $\mathrm{Be} ; \mathrm{T}=750-1050^{\circ} \mathrm{C}$. purity not specified.

H. Bergsáker, J. P. Coad, R. Behrisch, et al. (1990) "Deposition of carbon and beryllium and retention of deuterium on probes in the scrape-off layer of JET," Journal of Nuclear Materials 176 \& $177,941-946$.

M. C. Billone, C. C. Lin, and D. L. Baldwin (1991) "Tritium and helium behavior in irradiated beryllium," Fusion Technology 19, 1707-1714.

M. C. Billone (1993) "Optimization of beryllium for fusion blanket applications," Workshop on Beryllium for Fusion Applications, Karlsruhe, Germany, 4-5 October 1993. Report KfK5271, p.4-35.

M. C. Billone, M. Dalle Donne, and R. G. Macaulay-Newcombe (1994) "Status of beryllium development for fusion applications," 3rd International Symposium on Fusion Nuclear Technology. (received in Draft form)

R. Boivin and B. Terreault (1992) "Laser desorption study of beryllium's hydrogen recycling properties at high temperature," Journal of Nuclear Materials 187, 117-121.

R. A. Causey, W. L. Hsu, and B. E. Mills (1990) "Tritium retention and migration in beryllium," Journal of Nuclear Materials $176 \& 177,654-660$.

R. A. Causey and K. L. Wilson (1993) "Tritium inventory and permeation in the ITER beryllium," 6th International Conference on Fusion Reactor Materials, Stresa, Italy, September 27 - October 1, Draft.

M. Dalle Donne, F. Scaffidi-Argentina, C. Ferrero, and C. Ronchi (1993a) "Modeling of swelling and tritium release in irradiated beryllium," 6th International Conference on Fusion Reactor Materials, Stresa, Italy, September 27 - October 1, Draft.

M. Dalle Donne, F. Scaffidi-Argentina, C. Ferrero, and C. Ronchi (1993b) "Computer simulation of tritium retention and release in irradiated beryllium," Workshop on Beryllium for Fusion Applications, Karlsruhe, Germany, October 4-5, published as Report KfK 5271. 
E. A. Denisov, T. N. Kompaniets, A. A. Kurdyumov, S. N. Mazayev, and Yu. G. Prokofiev (1994) "Comparison of hydrogen inventory and transport in beryllium and graphite materials," no report number.

L. Dörr, T. Eberle, J. Lebkücher, H. Werle (1993) "Long-time tritium release from irradiated beryllium (SIBELIUS irradiation)," Workshop on Beryllium for Fusion Applications, Karlsruhe, Germany, October 4-5, published as Report KfK 5271.

W. Eckstein, R. Behrisch, B. M. U. Scherzer, J. Roth (1993) "Properties of beryllium as a plasma facing material," Workshop on Beryllium for Fusion Applications, Karlsruhe, Germany, 4-5 October 1993. Report KfK-5271, p.233-251

J. Ehrenberg, V. Philipps, L. De Kock, R. A. Causey, and W. L. Hsu (1990) "Analysis of deuterium recycling in JET under beryllium first wall conditions," Journal of Nuclear Materials $176 \& 177,226-230$.

H. Eleveld, A. van Veen, M. Clement, M. de Moor (1994) "Helium defect interactions in vanadium and beryllium," Plasma Devices and Operations 3, 65-78.

C. E. Ells and E. C. W. Perryman (1959) "Effects of neutron-induced gas formation on beryllium," Journal of Nuclear Materials 1, 73-84.

G. Federici, R. Causey, P. L. Andrew, and C. H. Wu (1994) "Tritium retention in candidate next-step protection materials: engineering key issues and research requirements," Third International Symposium on Fusion Nuclear Technology ISFNT-3, Los Angeles, 27 June - 1 July.

J. P. Fidelle, L. R. Allemand, M. Rapin, and B. Hocheid (1967) Colloque sur L'Hydrogene dans les Metaux, Valduc, p.210.

J. D. Fowler Jr., R. A. Causey, D. Chandra, T. S. Elleman, and K. Verghese (1976) "Abstract: Tritium diffusion in ceramic materials for thermonuclear reactors," J. Vac.Sci. Technol. 13, 401-402.

J. D. Fowler, D. Chandra. T. S. Elleman, A. W. Payne, and K. Verghese (1977) "Tritium diffusion in Al2O3 and BeO," Journal of the American Ceramic Society 60, 155-161.

E. Fromm and H. Jehn (1984) Bulletin of Alloy Phase Diagrams 5, 324.

D. S. Gelles and H. L. Heinisch (1991) "Neutron damage in beryllium," Beryllium Technology Workshop, Clearwater Beach, FL, November 20.

D. S. Gelles, M. Dalle Donne, G. A. Sernyaev, and H. Kawamura (1993) "Radiation effects in beryllium used for plasma protection," 6th International Conference on Fusion Reactor Materials, Stresa, Italy, September 27-October 1.

L. D. Horton, P. Andrew, G. Bracco, et al. (1992) "Hydrogen, deuterium, and tritium isotope exchange experiments in JET," Journal of Nuclear Materials 196-198, 139-142.

W. L. Hsu, R. A. Causey, B. E. Mills, J. Ehrenberg, and V. Philipps (1990) "Transient release of deuterium from beryllium after plasma ion implantation," Journal of Nuclear Materials $176 \& 177,218-225$. 
M. Huguet, A. C. Bell, S. J. Booth, et al. (1992) "Technical aspects of the first JET tritium experiment," Fusion Engineering and Design 19, 121-131.

E. Ishitsuka, H. Kawamura, H. Sugai, M. Tanase, and H. Nakata (1990) "Experiments on tritium behavior in beryllium (2) - tritium released by recoil and diffusion," JAERI-M 90013. (Abstract of paper in Japanese.)

C. E. Johnson, D. L. Baldwin, and J. P. Kopasz (1993) "Tritium release from beryllium discs and lithium ceramics in the SIBELIUS experiment," 6th International Conference on Fusion Reactor Materials, Stresa, Italy, September 27-October 1.

P. M. S. Jones and R. Gibson (1967a) "Hydrogen in Beryllium," AWRE 0-2/67.

P.M.S. Jones and R. Gibson (1967b) "Hydrogen in beryllium," Journal of Nuclear Materials $21,353-354$.

H. Kawamura, E. Ishituka, A. Sagara, K. Kamada, H. Nakata, M. Saito, and Y. Hutamura (1990) "Retention of deuterium implanted in hot-pressed beryllium," Journal of Nuclear Materials $176 \& 177,661-665$.

D. Kéroack and B. Terreault (1993a) "Laser desorption study of deuterium implanted in beryllium," 6th International Conference on Fusion Reactor Materials, Stresa, Italy, September 27-October 1.

D. Kéroack, F. Schiettekatte, B. Terreault, G. G. Ross (1993b) "Laser desorption and depth profiling study of hydrogen and deuterium implanted in beryllium," Workshop on Beryllium for Fusion Applications, Karlsruhe, Germany, 4-5 October 1993. Report KfK-5271, p.319330 .

R. A. Langley (1979) "Interaction of implanted deuterium and helium with beryllium: radiation enhanced oxidation," Journal of Nuclear Materials $85 \& 86,1123-1126$.

L. Leblanc and G. G. Ross (1993) "Ranges and variances of $0.2-1.0 \mathrm{keV}$ hydrogen and deuterium ions implanted into $\mathrm{Be}, \mathrm{C}$ and $\mathrm{Si}$," Nuclear Instruments and Methods in Physics Research B 83, 15-20.

R. Lässer (1989) Tritium and Helium-3 in Metals, Springer-Verlag, Berlin.

M.-B. Liu, I. Sheft, and D. M. Gruen (1979) "Deuterium trapping in ion-bombarded beryllium," Journal of Nuclear Materials 79, 267-269.

G. R. Longhurst (1990) "Tritium behavior in ITER beryllium," EGG-FSP-9304.

G. R. Longhurst (1991) "Beryllium research at the INEL," Beryllium Technology Workshop, Clearwater Beach, FL, November 20, EGG-FSP-10017.

G. R. Longhurst (1993a) "A simplified model for tritium permeation transient predictions when trapping is active," 6th International Conference on Fusion Reactor Materials, Stresa, Italy, September 27-October 1.

G. R. Longhurst, R. A. Anderl, T. J. Dolan, M. R. Hankins, and R. J. Pawelko (1993b) "Research of beryllium safety issues," Workshop on Beryllium for Fusion Applications, Karlsruhe, Germany, 4-5 October 1993, Report KfK 5271, p. 164-171. 
G. R. Longhurst (1994) "Modeling tritium implantation in pitted beryllium," INEL Engineering Design File ITER/US/94/SA-7.

G. R. Longhurst and T. J. Dolan (1994) "In-vessel tritium source term for ITER," Report ITER/US/TE-SA-22 (October 1 DRAFT).

V. Lossev and J. Küppers (1992) "Interaction of hydrogen atoms with beryllium (0001) surfaces," Journal of Nuclear Materials 196-198, 953-957.

V. Lossev and J. Küppers (1993) "Adsorption of hydrogen on Be(0001) surfaces," Surface Science 284 (1993) 175-185.

R. G. Macaulay-Newcombe, D. A. Thompson, and W. W. Smeltzer (1991) "Deuterium diffusion, trapping and release in ion-implanted beryllium," Fusion Engineering and Design 18, 419-424.

R. G. Macaulay-Newcombe, D. A. Thompson, and W. W. Smeltzer (1992) "Thermal absorption and desorption of deuterium in beryllium and beryllium oxide," Journal of Nuclear Materials 191-194, 263-267.

R. G. Macaulay-Newcombe and D. A. Thompson (1994) Journal of Nuclear Materials, to be published.

J. L. Maienschein, F. E. McMurphy, and V. L. Duval (1988) "Increase of tritium permeation through resistance metals are $323 \mathrm{~K}$ by lattice defects," Fusion Technology 14, 701-706.

A. P. Martinelli, A. T. Peacock, and R. Behrisch (1992) "Deuterium trapping and impurity collection on a 1990 JET Be belt limiter," Journal of Nuclear Materials 196-198, 729-734.

W. Moller, B. M. U. Scherzer, and J. Bohdansky (1985) "Retention and release of deuterium implanted into beryllium," IPP-JET Report 26.

S. M. Myers, P. M. Richards, W. R. Wampler, and F. Besenbacher (1989) "Review article: lon-beam studies of hydrogen-metal interactions," Journal of Nuclear Materials 165, 9-64.

S. M. Myers, M. I Baskes, H. K. Birnbaum, J. W. Corbett, G. G. DeLeo, S. K. Estreicher, E. E. Haller, P. Jena, N. M. Johnson, R. Kirchheim, S. J. Pearton, and M. J. Stavola (1992) "Hydrogen interactions with defects in crystalline solids," Reviews of Modern Physics 64, 559-617.

A. R. Palmer et al. (1964) Journal of Nuclear Materials 14, 141.

A. T. Peacock, J. P. Coad, F. Lama, R. Behrisch, A. P. Martinelli, B. E. Mills, M. Pick, J. Partridge, J. C. B. Simpson, and Y. K. Zhu (1990) "Impurity coverage and deuterium inventory of beryllium and carbon first wall components after beryllium operation in JET," Journal of Nuclear Materials 176 \& 177, 326-331.

J. P. Pemsler and R. W. Anderson (1961) "Literature survey of gases in beryllium," NMI9805.

J. P. Pemsler and E. J. Rapperport (1964) "Hydrogen in proton-bombarded beryllium: agglomeration and diffusion," Transactions of the Metallurgical Society AIME 230, 90-94. 
M. A. Pick and K. Sonnenberg (1985) "A model for atomic hydrogen-metal interactions application to recycling, recombination and permeation," Journal of Nuclear Materials 131, 208-220.

M. A. Pick and P. L. Andrew (1993) "Review of tritium retention in first wall materials," JET-P(93)93, 6th International Conference on Fusion Reactor Materials, Stresa, Italy, 1 October.

K. B. Ray, J. B. Hannon, and E. W. Plummer (1990) "An experimental study of hydrogen adsorption on beryllium," Chemical Physics Letters 171, 469-474.

P. M. Richards (1988) "Surface-limited hydrogen release and uptake in metals," Journal of Nuclear Materials 152, 246-258.

G. G. Ross and B. Terreault (1986) "Ranges of 0.7-2.1 keV hydrogen ions in Be, C and $\mathrm{Si}$," Nuclear Instruments and Methods in Physics Research B15, 61-65.

G. G. Ross and B. Terreault (1990) "ERD measurements of the mean ranges and variances of 0.75-2.0 keV deuterium ions in Be, $\mathrm{C}$ and $\mathrm{Si}$," Nuclear Instruments and Methods in Physics Research B45, 190-193.

G. Saibene, R. Sartori, A.Tanga, A. Peacock, M. Pick, and P. Gaze (1990) "Hydrogen recycling coefficient in beryllium: experimental determination and a test simulation of the density evolution in a JET plasma discharge," Journal of Nuclear Materials $176 \& 177,618-623$.

R. Sartori, G. Saibene, D. H. J. Goodall, E. Usselmann, P. Coad, and D. Holland (1990) "Deuterium release measurements in the Be phase of JET and determination of tritium content in the exhaust gas," Journal of Nuclear Materials 176 \& 177, 624-629.

B. M. U. Scherzer, B. S. Blewer, R. Behrisch, R. Schulz, J. Roth, J. Borders, and R. Langley (1979) "Radiation induced detrapping of implanted deuterium in $\mathrm{BeO}$ by high energy ${ }^{3} \mathrm{He}$ and proton irradiation," Journal of Nuclear Materials 85 \& 86, 1025-1029.

F. Schiettekatte, D. Kéroack, G. G. Ross, and B. Terreault (1993) "H and D depth profiles in implanted and laser-annealed beryllium," Nuclear Instruments and Methods in Physics Research B.

K. T. Scott and L. L. Wassell (1966) "Diffusional release of tritium from irradiated BeO," Atomic Energy Research Establishment Harwell report AERE-R 5102.

V. I. Shapovalov and Yu. M. Dukel'skii (1988) "The beryllium-hydrogen phase diagram," Russian Metallurgy 5, 201-203.

P. C. Souers ( 1980) Hydrogen Properties for Fusion Energy, University of California Press, Berkeley.

S. A. Steward (1983) "Review of hydrogen isotope permeability through materials," UCRL53441 .

R. E. Stickney (1972) "Diffusion and permeation of hydrogen isotopes in fusion reactors: a survey," in D. M. Gruen, Editor, The Chemistry of Fusion Technology, Plenum Press, New York, p.241-319. 
W. A. Swansiger (1986) "Summary abstract: tritium solubility in high purity beryllium," Journal of Vacuum Science and Technology A4, 1216-1217.

B. Terreault, D. Kerouack, G. G. Ross, R. G. Saint-Jacques, F. Schiettekatte, K. Touhouche, and $P$. Zheng (1994) "High temperature $H$ and D behavior in solid and liquid beryllium," Proc. 11 th Conf. on Plasma Surface Interactions.

D. A. Thompson and R. G. Macaulay-Newcombe (1994) "Annual Report, deuterium absorption and desorption in potential fusion reactor materials," CFFTP 1-9425, DRAFT.

K. Touhouche and B. Terreault (1994) "Surface microstructure of high temperature beryllium implanted with deuterium," Mat. Res. Soc. Symp. Proc. 316, 987-992.

$H$. Verbeek and W. Eckstein (1974) "Radiation blistering after $\mathrm{H}^{+}, \mathrm{D}^{+}$, and $\mathrm{He}^{+}$ion implantation into surfaces of stainless steel, Mo, and Be," in S. T. Picraux, E. P. EerNisse, and F. L. Vook, Editors, Applications of Ion Beams to Metals, Plenum Press, New York, 1974.

R. Vianden, E. N. Kaufmann, and J. W. Rodgers (1967) "Impurity lattice location in ionimplanted beryllium: measurements and systematics," Physical Review B 22, 63-79.

W. R. Wampler (1984) "Retention and thermal release of deuterium implanted in beryllium," Journal of Nuclear Materials 122 \& 123, 1598-1602.

W. R. Wampler (1992) "Trapping of deuterium in beryllium," Journal of Nuclear Materials 196-198, $981-985$.

K. L. Wilson, R. A. Causey, W. L. Hsu, B. E. Mills, M. F. Smith, and J. B. Whitley (1990) "Beryllium -- a better tokamak plasma-facing material?" Journal of Vacuum Science and Technology A8, 1750-1759.

K. L. Wilson (1991) "Beryllium needs for plasma facing components," Beryllium Technology Workshop, Clearwater, FL, November 20.

S. Yamaguchi, K. Ozawa, Y. Nakai, and Y. Sugizaki (1984) "Data on trapping and re-emission of energetic hydrogen isotopes and helium in materials, Supplement 1," JAERI-M-84-093, DE85 701296,

Y. M. Zakaria, R. G. Macaulay-Newcombe, and D. A. Thompson (1993) "Thermal desorption of implanted helium from beryllium," Workshop on Beryllium for Fusion Applications, Karlsruhe, Germany, 4-5 October 1993, Report KfK 5271. 


\section{Appendix B. Bibliography on Stainless Steel and Inconel}

This list only contains a sampling of the great amount of information available on the interaction of hydrogen with stainless steels and inconel. Most of the work prior to 1980 is not included here.

M. I. Abbas, and G. Farrell, (1992) "Trapping and replacement of 25-1000 eV deuterium in silicon, stainless steel, and molybdenum," Vacuum, vol. 43, numbers 1/2, pp. 149-152.

P. M. Abraham, T. S. Elleman, and K. Verghese, (1978) "Diffusion and trapping of tritium in grain boundaries of 304L stainless steel," Journal of Nuclear Materials 73, pp. 77-88.

I. Aitchison, D. Khatamian, and J. den Hartog (1993) "Permeation study of breakdown and repair of barrier oxide at alloy surfaces," Zeitschrift fur Physikalische Chemie Bd. 181, 441447.

R.A. Anderl, G.R. Longhurst, D.F. Holland and D.A. Struttmann, (1985) "Permeation of deuterium implanted into fusion reactor materials", Fusion Technology 8, 2299-2305.

R. A. Anderl, D. F. Holland, \& G. R. Longhurst, (1990) "Hydrogen transport behavior of metal coatings for plasma-facing components," Journal of Nuclear Materials 176 \& 177, pp. 683-689.

P. Andrew and M. Pick (1994) "Review of tritium retention in first wall materials," to be published in Journal of Nuclear Materials.

M. I. Baskes (1980) "A calculation of the surface recombination rate constant for hydrogen isotopes on metals," Journal of Nuclear Materials 92, 318-324.

M. I. Baskes, W. Bauer, K. L. Wilson, (1982) Tritium permeation in fusion reactor first walls," Journal of Nuclear Materials 111 \& 112, pp. 663-666.

M. I. Baskes, D. K. Brice, D. B. Heifetz, H. F. Dylla, K. L. Wilson, B. L.

Doyle, W. R. Wampler, and J. L. Cecchi, (1984) Tritium inventory and permeation in TFTR," Journal of Nuclear Materials 128 \& 129, pp. 629-635.

R. S. Blewer, R. Behrisch, B. M. U. Scherzer, and R. Schulz, (1978) "Trapping and replacement of $1-14 \mathrm{keV}$ hydrogen and deuterium in 316 stainless steel," Journal of Nuclear Materials 76 \& 77, pp. 305-312.

P. Børgesen, B.M.U. Scherzer and W. Möller, (1986) "Surface recombination of deuterium implanted into SS304", Nuclear Instruments and Methods in Physics Research B15, pp. 540545.

M. Braun, B. Emmoth, F. Waelbroeck, and P. Wienhold, (1980) "Determination of deuterium surface recombination rates on stainless steel," Journal of Nuclear Materials 93 \& 94, pp. $861-865$.

D. K. Brice, (1982) "Hydrogen trapping in fusion materials due to ion irradiation: Implications for neutron irradiation," Journal of Nuclear Materials 108 \& 109, pp. 389-394. 
D. K. Brice, B. L. Doyle, W. R. Wampler (1982) Journal of Nuclear Materials 111\&112, 598.

D. K. Brice, and B. L. Doyle, (1984) "Steady state hydrogen transport in solids exposed to fusion reactor plasmas," Journal of Nuclear Materials 120, pp. 230-244.

V. I. Bugarya, S. A. Grashin, A. V. Pereslavtsev, Yu. M. Pustovoit, V. S. Svishchev, A. I. Livshits, and M. E. Notkin, (1986) "Hydrogen permeability in stainless steel interacting with TM-4 tokamak plasma," Soviet Atomic Energy 59, pp. 584586.

R. D. Calder, T. S. Elleman, and K. Verghese, (1973) Grain boundary diffusion of tritium in 304- and 316-stainiess steels," Journal of Nuclear Materials 46, pp. 46-52.

G.R. Caskey, Jr., and R.D. Sisson, Jr. (1981) "Hydrogen solubility in austenitic stainless steel", Scripta Metallurgical, Vol. 15, pp. 1187-1190.

R. A. Causey, and L. M. Steck (1984) "The effect of gamma radiation on the diffusion of tritium in 304 stainless steel," Journal of Nuclear Materials 122 \& 123, pp. 1518-1522.

R. A. Causey, R. A. Kerst, and B. E. Mills (1984) "The effect of surface composition on plasma driven permeation of deuterium through 304 stainless steel," Journal of Nuclear Materials 122 \& 123, pp. 1547-1552.

R. A. Causey, L. M. Steck, and R. Van Namen (1985) "Diffusion and solubility of tritium in part A Prime Candidate Alioy," Fusion Technology 8, 2384-2387.

B. Q. Deng, Q. R. Huang, L. L. Peng, O. Mao, J. J. Du, Z. Lu, and X.Zh Liu, (1992) "Measurement of hydrogen solubility, diffusivity and permeability in HR-1 stainless steel," Journal of Nuclear Materials 191-194, pp. 653-656.

R.S. Dickson, (1990) "Tritium interactions with steel and construction materials in fusion devices", CFFTP G-9039 (AECL 10208).

B.L. Doyle and D.K. Brice, (1987) "The influence of displacement damage on deuterium permeation in 316 stainless steel", Journal of Nuclear Materials 145-147, pp. 288-291.

H.F. Dylla, J.L. Cecchi and R.J. Knize, (1984) "Measurements of the hydrogenic recombination coefficient for the TFTR vacuum vessel", Journal of Nuclear Materials 121, 243.

T. S. Elleman, and K. Verghese, (1974) "Surface effects of tritium diffusion in niobium, zirconium and stainless steel," Journal of Nuclear Materials 53, pp. 299-306.

O. Gautsch, and G. Hoddap, (1988) "Deuterium permeability of the austenitic stainless steel AISI 316," Journal of Nuclear Materials 152, pp. 35-40.

D. M. Grant, D. L. Cummings, and D. A. Blackburn, (1987) "Hydrogen in 304 Steel: Diffusion, permeation and surface reaction," Journal of Nuclear Materials 149, pp. 180-191.

D. Grant, D. Cummings, and D. Blackburn (1989) "Hydrogen permeation in 304 and 306 stainless steels," Zeitschrift fur Physikalische Chemie 164, 1585-1590. 
A. M. Hassanein and D. K. Sze (1984) "Survey of data for permeation of hydrogen and its isotopes through steel alloys," Argonne National Laboratory, unpublished.

E. Hashimoto, and T. Kino, (1985) "Hydrogen permeation through type 316 stainless steels and ferritic steel for a fusion reactor," Journal of Nuclear Materials 133 \& 134, pp. 289291.

T. Hirabayashi, Y. Sun, H. Yamamoto, Y. Toida and M. Saeki, (1991) "Chemical and topographical properties of tritium-resistant stainless steel surfaces formed by chromium diffusion coating", Journal of Nuclear Materials 182, pp. 135-144.

T. Hirabayashi and M. Saeki, (1984) "Sorption of gaseous tritium on the surface of type 316 stainless steel", Journal of Nuclear Materials 120, pp. 309-315.

T. Hirabayashi, M. Saeki and E. Tachikawa, (1984) "A thermal desorption study of the surface interaction between tritium and type 316 stainless steel", Journal of Nuclear Materials 126, pp. 38-43.

T. Hirabayashi, M. Saeki and E. Tachikawa, (1985) "Chemical decontamination of the tritium-sorbing surface of type 316 stainless steel", Journal of Nuclear Materials 136, pp. $179-185$.

T. Hirabayashi, M. Saeki, and E. Tachikawa (1986) "Sorption and desorption of tritium on the surface of Type 316 stainless steel," Proceedings of the International Symposium on Fusion Reactor Blanket and Fuel Cycle Technology, Tokai-mura, Ibaraki, Japan, October 27-29.

T. Hirabayashi, M. Saeki, T.A. Sasaki and K.W. Sung, (1989) "Sorption of tritium on surface-modified type-316 stainless steel", Fusion Engineering and Design 10, pp. 287-291.

T. Hirabayashi, S. Poosittisak, Y. Sun and M. Saeki, (1990a) "Tritium sorption and chemical and topographical properties of a stainless steel surface modified with chromium", Journal of Nuclear Materials 173, pp. 26-33.

T. Hirabayashi, Ki.W. Sung, T.A. Sasaki and M. Saeki, (1990) "Change in tritium-sorption property of stainless steel by thermal surface oxidation", Journal of Nuclear Materials 175, pp. 78-83.

T. Hirabayashi, Ki.W. Sung, T.A. Sasaki and M. Saeki, (1990) "Change in tritium-sorption property of stainless steel by thermal surface oxidation", Journal of Nuclear Materials 175, pp. 78-83.

T. Hirabayashi, Y. Sun and M. Saeki, (1990) "Formation of a tritium-resistant surface of stainless steel by chromium diffusion coating", Journal of Nuclear Materials 175, pp. 177183.

H. H. Johnson, (1989), "Interface and diffusion control of hydrogen transport," Sripta Metallurgica 23, pp. 1265-1268.

A. J. Kallas, T. L. Rising, E. L. Childs, (1987) "Tritium permeation through characterized films on type 304L stainless steel," FRP-4050.

Hiroji Katsuta, and Kazuo Furukawa, (1981) "Hydrogen and Deuterium Transport through Type 304 Stainless Steel at Elevated Temperatures," Journal of Nuclear Science and Technology 18, pp. 143-151. 
R.A. Kerst and W.A. Swansiger, (1984) "Plasma driven permeation of tritium in fusion reactors", Journal of Nuclear Materials 122 \& 123, pp. 1499-1510.

N. Kishimoto, T. Tanabe, T. Suzuki, and H. Yoshida, (1985) "Hydrogen diffusion and solution at high temperatures in 316 L stainless steel and nickel-base heat-resistant alloys," Journal of Nuclear Materials 127, pp. 1-9.

P. Kim, Y. Sougawa, M. Nomura, M. Okamoto, and Y. Fujii (1992) "Mechanism of plasma driven permeation," Fusion Technology 21, 833-838.

Robert A. Langley, (1984) "Hydrogen trapping, diffusion and recombination in austenitic stainless steels," Journal of Nuclear Materials 128 \& 129, pp. 622-628.

A. D. LeClaire (1983) "Permeation of gases through solids III - an assessment of measurements of the steady state permeability of $\mathrm{H}$ and its isotopes through $\mathrm{Ni}$ and through several high Ni commercial alloys and steels," AERE-R 10846.

A. D. Le Claire, (1984) "Permeation of hydrogen isotopes in structural alloys," Journal of Nuclear Materials 122 \& 123, pp. 1558-1559.

M. R. Louthan, Jr. and R. G. Derrick (1975) Corrosion Science 15, 565.

N.M. Masaki, T. Hirabayashi, and M. Saeki, (1989) "Study on sorption of tritium on various material surfaces and its application to decontamination of tritium-sorbing materials", Fusion Technology, Vol. 15.

S.M. Myers and W.R. Wampler, (1982) "Trapping and surface permeation of deuterium in helium-implanted stainless steel", Journal of Nuclear Materials 111 \& 112, pp. 579-583.

S.M. Myers, (1983) "Trapping and Surface Recombination of Deuterium in Fusion Reactor Metals", IEEE Transaction on Nuclear Science, Vol. NS-30, No. 2.

S.M. Myers, G.R. Caskey, Jr., D.E. Rawl, Jr., and R.D. Sisson, Jr., (1983) "Ion-Beam Profiling of ${ }^{3} \mathrm{He}$ in Tritium-Exposed Type 304L and Type 21-6-9 Stainless Steel", Metallurgical Transactions A, Vol. 14A, pp. 2261.

S.M. Myers, W.R. Wampler and F. Besenbacher, (1984) "Trapping and surface recombination of ion-implanted deuterium in stainless steel", J. Appl. Phys. 56 (6).

S.M. Myers, W.R. Wampler, R. Besenbacher, S.L. Robinson and N.R. Moody, (1985) "lon Beam Studies of Hydrogen in Metals", Materials Science and Engineering, 69 pp. 397-409.

Takashi Namba, Mihio Yamawaki, and Masayoshi Kanno, (1984) "Surface processes of hydrogen transport in fusion reactor materials," Journal of Nuclear Materials 128 \& 129 , pp. 646-651.

B. Navinsek, M. Peternell, and A. Zabkar, (1980) "Blistering and deuterium trapping induced by $D+$ ion bombardment in metal alloys," Journal of Nuclear

M. Okamoto, T. Yoshida, M. Takizawa, M. Aida, M. Nomura and Y. Fujii, (1988) "PDP of hydrogen isotopes in a low temperature plasma", Fusion Technology, 14, 689-694. 
M. Okamoto, P. Kim, M. Takizawa, M. Aida, and Y. Fujii (1992) "isotope effect in PDP of hydrogen," Fusion Technology 21, 753-759.

T-S. Perng, and . J. Altstetter, (1986) "Effects of deformation on hydrogen permeation in austenitic stainless steels," Acta Metallurgica 34, 1771-1781.

T-S. Perng, and . J. Altstetter, (1990) "Hydrogen effects in austenitic stainless steels," Materials Science and Engineering, A129, pp. 99-107.

M. R. Piggott, and A. C. Siarkowski, (1972) Hydrogen diffusion through oxide films on steel," Journal of The Iron and Steel Institute, De. 1972, pp. $901-905$.

P. A. Platonov, I. Ye. Tursonov, V. I. Levit, V. M. Dorovskoy, and L. A. Yelesin (1989) "Effect of hydrogen on irradiated stainless steel,"

B.G. Polosuhin, E.P. Baskakov, E.M. Sulimov, A.P. Zyryanov, Yu.S. Shestakov, G.M. Kalinin, Yu.S. Strebkov and A.G. Dobrynskih, (1992) "Hydrogen isotope permeability through austenitic steels $18 \mathrm{Cr}-10 \mathrm{Ni}-\mathrm{Ti}$ and $16 \mathrm{Cr}-11 \mathrm{Ni}-3 \mathrm{Mo}-\mathrm{Ti} "$, Journal of Nuclear Materials 191-194, pp. $219-220$.

B. G. Polosukhin, A. P.Zyrianov, E. M. Sulimov, and G. M. Kalinin (1993) "A parameter study of hydrogen isotope transfer in austenite steels during neutron irradiation," 6th International Conference on Fusion Reactor Materials, Stresa, Italy, October 1.

A. E. Pontau, M. I. Baskes, K. L. Wilson, L. G. Haggmark, J. Bohdansky, B. M. U. Scherzer, and J. Roth, (1982) "Deuterium retention in helium-damaged stainless steel: Detrapping energy," Journal of Nuclear Materials 111 \& 112, pp. 651-653.

F. Reiter, J. Camposilvan, M. Caorlin, G. Saibene and R. Sartori, (1985) "Interaction of hydrogen isotopes with stainless steel 316 L", Fusion Technology, Vol. 8.

F. Reiter, J. Camposilvan, M. Caorlin, A. Perujo, and S. Tominetti, (1991) "Recycling of hydrogen from stainless steel surfaces under ITER/NET conditions," Journal of Nuclear Materials 179-181, pp. 316-318.

M. F. Riehm, W. W. Smeltzer, and D. A. Thompson (1986) "Hydrogen-solid interactions and tritium permeation barriers," CFFTP-G-86041.

M. F. Riehm (1990) "The diffusion and solution of hydrogen isotopes in solids and the development of a hydrogen permeation barrier," PhD Thesis, McMaster University, Hamilton, Ontario, Canada.

E. Rota, F. Waelbroeck, P. Wienhold, and J. Winter (1982) "Measurements of surface and bulk properties for the interaction of hydrogen with Inconel 600," Journal of Nuclear Materials $111 \& 112,233-239$.

M. Saeki, T. Hirabayashi, Y. Aratono, M. Nakashima, N.M Masaki and E. Tachikawa, (1992) "Chemical behavior of tritium in/on various materials", Fusion Technology, Vol. 21.

B.M.U. Scherzer, P. Børgesen and W. Möller, (1986) "Diffusion and trapping of deuterium in stainless steel", Nuclear Instruments and Methods in Physics Research B15, pp. 375-381. 
Hangqi Shan, Aiju Wu, Qingwang Chen, (1991) "The behavior of diffusion and permeation of tritium through 316L stainless steel," Journal of Nuclear

Materials 179-181, pp. 322-234.

C.Q. Shan, A.J. Wu, Y.J. Li, Z.Q. Zhao, Q. W.Chen, Q. R.Huang, and S. L. Shi (1992) "The

behavior of diffusion and permeation of tritium through $316 \mathrm{~L}$ stainless steel with coating of TiC and TiN + TiC," Journal of Nuclear Materials 191-194, 221-225.

V. M. Sharapov, (1986) "Hydrogen permeability of the first wall of a thermonuclear reactor," Soviet Atomic Energy 60, pp. 457-466.

James M. Stone, (1981) "Deuterium permeation and surface effects," Proceedings of the Conference on Environmental Degradation of Engineering Materials, Blacksburg, VA, September 21-23, DP-MS-81-27.

M. Sugisaki, H. Furuya, K. Ono and K. Idemitsu, (1984) "Tritium solubility in SUS-316 stainless steel" Journal of Nuclear Materials, Vol. 120, No. 1, pp. 36-40.

M. Sugisaki, H. Furuya, H. Ueki and S. Ejima, (1985) "Surface reaction and bulk diffusion of tritium in SUS-316 stainless steel", Journal of Nuclear Materials 133 \& 134, pp. 280-283.

R. A. Surette, and R. G. C. McElroy, (1988) "Regrowth, retention and evolution of tritium from stainless steel," Fusion Technology 14, pp. 1141-1146.

W. A. Swansiger and R. Bastasz, (1979) "Tritium and deuterium permeation in stainless steels: Influence of thin oxide films," Journal of Nuclear Materials 85 \& 86 , pp. $335-339$.

Y. Takahashi and S. Tanaka, (1986) "Sorption and desorption of tritium on the surface of type 316 stainless steel", Proceedings of the International Symposium on Fusion Reactor Blanket and Fuel Cycle Technology.

T. Tanabe, Y. Yamanishi, K. Sawada and S. Imoto, (1984) "Hydrogen transport in stainless steels", Journal of Nuclear Materials 122 \& 123, pp. 1568-1572.

T. Tanabe, Y. Yamanishi, K. Sawada and S. Imoto, (1986) "Role of surface oxide on hydrogen transport in stainless steel", Proceedings of the International Symposium on Fusion Reactor Blanket and Fuel Cycle Technology, Tokai-mura, Ibaraki, Japan, October 27-29.

T. Tanabe, (1991) "Comments on the paper "The compensation effect on diffusion constants of hydrogen in metals" by K. Watanabe, K. Ashida and M. Sonobe, J. Nucl. Mater. 173 (1990) 294", Journal of Nuclear Materials 182, pp. 270-273.

M. Terasawa, K. Fukushima, S. Nakahigashi, K. Ebisawa, and M. limura (1986) "Helium irradiation effect on hydrogen isotope permeation in austenitic stainless steel," Japanese Journal of Applied Physics 25, 1106-1110.

E. W. Thomas, (1980) "Retention and re-emission of $0.125-1 \mathrm{keV}$ deuterium in stainless steel," Journal of Applied Physics 51, pp. 1176-1183.

E. W. Thomas, and M. Braun, (1982) "Dynamic measurements of implanted deuterium retention and release in stainless steel and carbon," Journal of Nuclear Materials 111 \& 112, pp. 654-656. 
G. J. Thomas (1981) "Hydrogen trapping in fcc metals," Proceedings of the 3rd International Conference on Effect of Hydrogen on Behavior of Metals, Moran, WY, Aug.26-31, Metall.Soc. of AIME, Warrendale, PA, pp. 77-85.

F. Waelbroeck, P. Wienhold, and J. Winter (1982) "Thermally activated processes in hydrogen recycling," Journal of Nuclear Materials 111\&112, 185-198.

P. Wienhold, R. E. Clausing, and F. Waelbroeck (1980a) "Comparison of experimental results and numerical calculations of hydrogen recycling from stainless steel," Journal of Nuclear Materials 93\&94, 540-541.

P. Wienhold, M. Profant, F. Waelbroeck, and J. Winter (1980b) "Computer code PERI for the calculation of recycling, volume distribution, and permeation of hydrogen in first wall materials of tokamaks," Journal of Nuclear Materials 93\&94, 866-870.

P. Wienhold, F. Waelbroeck, and J. Winter (1982a) "Influence of a heat flux on the hydrogen recycling from the tokamak walls," Journal of Nuclear Materials 111\&112, 240-242.

P. Wienhold, F. Waelbroeck, and J. Winter (1982b) "Ways to reduce the permeation through, inventory in, and outgassing out of the first wall of INTOR," Journal of Nuclear Materials $111 \& 112, \quad 248-250$.

F. Winter, F. Waelbroeck, P. Wienhold, and T. Schelske (1982) "Permeation probes for the characterization of the atomic hydrogen flux to a tokamak wall," Journal of Nuclear Materials $111 \& 112,243-247$.

J. Winter, F. G. Waelbroeck, P. Wienhold, E. Rota, and T. Banno (1984) "Characterization of the first wall of TEXTOR with respect to hydrogen recycling," J. Vac. Sci. Technol. A2, 679685 .

K. L. Wilson, and M. I. Baskes (1978a) "Thermal desorption of deuterium-implanted stainless steel," Journal of Nuclear Materials 74, pp. $179-184$.

K.L. Wilson and M.I. Baskes, (1978b) "Deuterium trapping in irradiated 316 stainless steel", Journal of Nuclear Materials 76 \& 77, pp. 291-297.

K. L. Wilson, (1979a) "Hydrogen trapping studies in fusion first wall materials," IEEE Transactions on Nuclear Science, vol. NS-26, No. 1, pp. 1296-1301.

K.L. Wilson and A.E. Pontau, (1979b) "The temperature dependence of deuterium trapping in fusion reactor materials", Journal of Nuclear Materials 85 \& 86, pp. 989-993.

K. L. Wilson (1981) "Hydrogen recycling properties of stainless steels," Journal of Nuclear Materials 103\&104, 453-464.

S. Yamaguchi, K. Ozawa, Y. Nakai, and Y. Sugizaki (1984) "Data on trapping and re-emission of energetic hydrogen isotopes and helium in materials, Supplement 1," JAERI-M-84-093, DE85 701296,

M. Yamawaki, K. Yamaguchi, T. Kiyoshi and T. Namba, (1987) "Surface segregation of impurities on 304 SS and its effect on ion driven permeation of deuterium", Journal of Nuclear Materials 145-147, pp. 309-312. 
M. Yamawaki, K. Yamaguchi, S. Tanaka, T. Namba, T. Kiiyoshi and Y. Takahashi, (1989) "Effect of surface impurities on the hydrogen recombination coefficient of first-wall materials", Journal of Nuclear Materials 162-164, pp. 1071-1076.

N. Yoshida, N. Ashizuka, T. Fujiwara, T. Kurita and T. Muroga, (1988) "Radiation damage and deuterium trapping in deuterium ion irradiated austenitic stainless steel", Journal of Nuclear Materials 155-157, pp. $775-780$.

N. Yoshida, T. Kurita, T. Fujiwara and T. Muroga, (1989) "Trapping of deuterium injected in austenitic stainless steel at elevated temperatures", Journal of Nuclear Materials 162-164, pp. $1082-1087$.

N. Yoshida, A. Nagao, K. Tokunaga, K. Tawara, T. Muroga, T. Fujiwara, S. Itoh and the TRIAM Group, (1992) "Radiation damage and impurity behavior in the superconducting tokamak TRIAM-1M under steady-state operation", Radiation Effects and Defects in Solids, Vol. 124, pp. 99-108. 


\section{Appendik C. Bibliography on Copper and Copper Alloys}

G. Alefeld and J. Völkl, editors, (1978a), Hydrogen in Metals I, Basic Properties, Springer Verlag, Berlin, Heidelberg, New York.

G. Alefeld and J. Völkl, editors, (1978b), Hydrogen in Metals II, Application-Oriented Properties, Springer Verlag, Berlin, Heidelberg, New York.

R.A. Anderl, D.F. Holland and G.R. Longhurst, (1990) "Hydrogen transport behavior of metal coatings for plasma-facing components", Journal of Nuclear Materials $176 \& 177$, pp. 683689.

P. L. Andrew and A. A. Haasz, (1992), "Models for hydrogen permeation in materials", J. Appl. Phy. 72, No. 7, p 2749.

P.L. Andrew and A.A. Haasz, (1991a) "Effect of thin copper and palladium films on hydrogen permeation through iron", Journal of the Less-Common Metals, 172-174, pp. 732-739.

P.L. Andrew and A.A. Haasz, (1991b) "Hydrogen permeation through copper-coated palladium", J. Appl. Phys. 70 (7), p 3600.

M. I. Baskes, (1980), J. Nucl. Mater. 92, p 318.

D.R. Begeal, (1978) "Hydrogen and deuterium permeation in copper alloys, copper-gold brazing alloys, gold, and the in situ growth of stable oxide permeation barriers", J. Vac. Sci. Technol., 15 (3), p 1146.

Yu. I. Belyakov and Yu. I. Ebezdin, (1968), "An investigation of the temperature dependence of hydrogen permeability through $\mathrm{Cu}$ and its alloys", Uch. Zap. Leningrad. Gos. Univ. Ser. Fiz. Nauk. 345, p 44. English translation, National Bureau of Standards publication PB-250 $833,(1974)$

F. Besenbacher, B. Bech Nielsen and S.M. Myers, (1984) "Defect trapping of ion-implanted deuterium in copper", J. Appl. Phys. 56 (12), p 3384.

G.R. Caskey, Jr., A.H. Dexter, M.L. Holzworth, M.R. Louthan, Jr., and R.G. Derrick, (1976)

"The Effect of Oxygen on Hydrogen Transport in Copper", Corrosion, Vol. 32, No. 9, p. 370.

G.R. Caskey, Jr. and W.L. Pillinger, (1973) "Effect of trapping on hydrogen permeation in copper", Dupont de Nemours, Report DP-MS-73-53.

B. L. Doyle and D. K. Brice, (1985), " Steady state hydrogen transport in solids", Rad. Effects. 89, p 21.

W. Eichenauer, W. Loser, and H. Witte, ((1965), Z. Metall. 56, p 287.

W. Eichenauer and A. Pebler, (1957), Z. Metall. 48, p 373. English translation, AEC-tr3360 .

H.D. Falter, G.H. Deschamps, R.S. Hemsworth and P. Massmann, (1990) "Implantation and reemission of hydrogen and helium in the beam-stopping panels of a $10 \mathrm{MW}$ iron beam line", Journal of Nuclear Materials 176 \& 177, pp. 678-682. 
A.A. Haasz, P.L. Andrew and A.B. Antoniazzi, (1989) "Measurement of hydrogen permeation through bilayer copper-iron membranes", J. Vac. Sci. Technol. A 7 (3), p 1042.

Y. Fukai and H. Sugimoto, (1985), " Diffusion of hydrogen in metals", Advances in Physics 34, No. 2, p 263.

J. K. Gorman and W. R. Nardella, (1962), Vacuum 12, p 19.

P. B. Johnson and T. R. Armstrong, (1978), "In-situ detection of radiation blistering and dynamic deuterium depth profiling during $D^{+}$bombardment of solids", Nucl. Inst. Meth. 148, $p$ 85.

P. B. Armstrong and T. R. Armstrong, (1977), " The dynamics of radiation blistering and near surface deuterium retention in deuteron-irradiated copper", Appl. Phys. Lett. 31, No. 5, p 325.

L. Katz, M. Guinan and R.J. Borg, (1971) "Diffusion of $\mathrm{H}_{2}, \mathrm{D}_{2}$, and $\mathrm{T}_{2}$ in Single-Crystal Ni and Cu", Physical Review B, Vol. 4, No. 2, p 330.

R. Lasser, (1989), Tritium and ${ }^{3} \mathrm{He}$ in Metals, Springer Verlag, Berlin, Heidelberg, New York.

B. Lengeler, S. Mantl and W. Triftshauser, (1978), J. Phys. F8, p 1691.

J.L. Maienschein, F.E. McMurphy and V.L. Duval, (1988) "Increase of tritium permeation through resistant metals at $323 \mathrm{~K}$ by lattice defects", Fusion Technology Vol. 14, p 2360.

J. Maienschein, V. DuVal, F. McMurphy and F. Uribe, (1985) "A novel technique for measurement of tritium permeation through resistant materials near room temperature: Demonstration of method with copper at 50-170_C", Fusion Technology, Vol. 8, p 701.

A. Maroni and E. H. Van Deventer, (1979), "Materials considerations in tritium handling systems", J. Nucl. Mater. 85\&86, p 257.

R. B. McLellan, (1973), "Solid solutions of hydrogen in gold, silver and copper", J. Phys. Chem. Solids 34, p 1137.

S. M. Meyers, P. M. Richards, W. R. Wampler, and f. Besenbacher, (1989), " ion beam studies of hydrogen-metal interactions", J. Nucl. Mater. 165, pp 9-64.

H.A. Michelsen and D.J. Auerbach, (1991) "A critical examination of data on the dissociative adsorption and associative desorption of hydrogen at copper surfaces", J. Chem. Phys. 94 (11).

D.J. Mitchell, (1982a) "Deuterium trapping by impurities in copper", J. Vac. Sci. Technol., 20 (4), p 1048.

D.J. Mitchell, J.M. Harris, R.C. Patrick, E.P. Boespflug and L.C. Beavis, (1982b) "Deuterium permeation through copper with trapping impurities", J. Appl. Phys. 53 (2), p 970.

T. Nagasaki, R. Yamada and H. Ohno, (1992) "Recombination coefficients of deuterium on metal surfaces evaluated from ion-driven permeation", Journal of Nuclear Materials 191194, pp. 258-262. 
T. Nagasaki, R. Yamada and H. Ohno, (1992) "lon-driven permeation and surface recombination coefficient of deuterium for copper", J. Vac. Sci. Technol. A 10 (1), p 170.

T. Nagasaki, R. Yamada and H. Ohno, (1991) "Permeation of deuterium implanted into copper", Journal of Nuclear Materials 179-181, pp. 335-338.

W. G. Perkins, (1973), "Permeation and outgassing of vacuum materials", J. Vac. Sci. Technol. 10, No. 4, p 543.

W. G. Perkins and D. R. Begeal, (1972), "Permeation and diffusion of hydrogen in Ceramvar, copper, and Ceramvar-copper laminates", Sandia Laboratories Report SC-DC-71 4493.

M.T. Robinson, A.L. Southern and W.R. Willis, (1960) "Diffusion of Deuterium in DeuteronIrradiated Copper", Journal of Applied Physics, Vol. 31, No. 8, p 1474.

Y. Shimomura, R. Nishiguchi, T. Diaz de la Rubia and M.W. Guinan, (1992) "Computer simulation of void formation in residual gas atom free metals by dual beam irradiation experiments", International conference on Evolution in Beam Application, Report \#INIS-JP. 007, pp. 723-728.

P. Clark Souers, (1986), Hydrogen Properties for Fusion Energy, Univ. of California Press, Berkeley, Los Angeles London.

S. A. Steward, (1983), "Review of hydrogen isotope permeability through materials", UCRL53441, Lawrence Livermore National Laboratory, Livermore, California.

W.A. Swansiger, (1988) "Measurement of the solubility of tritium in copper and gold at high pressures", Fusion Technology Vol. 14, p 631.

T. Tanabe, (1989) "On the estimation of tritium retention and permeation in metallic first wall", Fusion Engineering and Design 10, pp. 325-330.

T. Tanabe, Y. Furuyama and S. Imoto, (1987) "Hydrogen ion driven permeation through metals", Journal of Nuclear Materials 145-147, pp. 305-308.

T. Tanabe, Y. Furuyama, N. Saitoh and S. Imoto, (1987) "Determination of Deuterium Diffusion Coefficient in Metals by Ion Driven Permeation Technique", Transactions of the Japan Institute of Metals, Vol. 28, No. 9, pp. 706-714.

T. Tanabe, K. Sawada and S. Imoto, (1986) "Hydrogen Diffusion and Permeation through Duplex Membrane of $\mathrm{Cu}-\mathrm{Ni}$ and $\mathrm{Cu}-\mathrm{Fe} "$ ", Transactions of the Japan Institute of Metals, Vol. 27, No. 5 , pp. 321-327.

C. L. Thomas, ( 1967), " Solubility of hydrogen in solid copper, silver, and gold obtained by a rapid quench and extraction technique", trans. AIME 239, p 485.

W. R. Wampler, T. Schober and B. Lengeler, (1976) "Precipitation and trapping of hydrogen in copper", Philosophical Magazine, Vol. 34, No. 1, pp. 129-141.

W. R. Wampler, (1976) "Investigation of the scattering of conduction electrons in copper from interstitial hydrogen using the de Haas-van Alphen effect", Kernforschungsanlage Jülich Report. 
K. L. Wilson, (1984), "Hydrogen and helium trapping", in Nuclear Fusion, special issueData Compendium for Plasma Surface Interactions, p 28.

K.L. Wilson, R.A. Causey, M.I. Baskes and J. Kamperschroer, (1987) "Hydrogen isotope retention and release from copper", J. Vac. Sci. Technol A 5 (4), p 2319.

K. Yamakawa, I. Mukouda and V. Shimomura, (1992), " Void formation in neutron-irradiated Cu and Cu alloys", J. Nucl. Mater. 191-194, p 396.

M. Yamawaki, K. Yamaguchi, S. Tanaka, X. Liu and J.P. Qian, (1992) "Surface segregation of a low-Z element and its impact on interaction with hydrogen", Journal of Nuclear Materials 196-198, pp. 592-595. 


\section{Appendix D. Bibliography on Graphite}

(Only the abstract was available for articles marked @.)

"K. Akaishi, M. Asano, Y. Kubota, A. Miyahara, "Hydrogen Wall Pumping on Electron-Beam Evaporation of Graphite During Radiofrequency Discharge with Hydrogen," Journal of Vacuum Science \& Technology A-Vacuum Surfaces and Films, 1991, V9, N5, P2747-2751.

V. Kh. Alimov, A. E. Gorodetsky, and A. P. Zakharov, "Types of traps for deuterium implanted into graphite," Journal of Nuclear Materials 186 (1991) 27-32.

S. Amemiya, H. Miwa, T. Masuda, Y. Tsurita, K. Ishikawa, T. Katoh, "Trapping, detrapping and replacement of deuterium implanted into graphite," Journal of the Vacuum Society of Japan vol.28, no.5, p. 314-16, 1985. @

S. Aronowitz, S. Chang, "Adsorption and recombination of hydrogen atoms on a model graphite surface," Astrophysical Journal vol.293, no.1, pt.1 p.243-50, 1 June 1985.

K. Ashida, K. Ichimura, M. Matsuyama, H. Miyake, and K. Watanabe, "Trapped states of deuterium implanted into graphite and the thermal desorption," Journal of Nuclear Materials $111 \& 112$ (1982) $769-774$.

K. Ashida, K. Ichimura, and K. Watanabe, "Two different species of deuterium implanted into a pyrolytic graphite observed by XPS-SIMS," Journal of Vacuum Science and Technology A1 (1983) $1465-1468$

K. Ashida, K. Ichimura, M. Matsuyama, and K. Watanabe, "Thermal desorption of hydrogen, deuterium, and tritium from pyrolytic graphite," Journal of Nuclear Materials 128 \& 129 (1984) 792-797.

K. Ashida, K. Kanamori, K. Ichimura, M. Matsuyama, and K. Watanabe, "Chemical erosion of graphite by oxygen," Journal of Nuclear Materials 136 (1985) 284-286.

K. Ashida and K. Watanabe, "Capture and thermal release of hydrogen isotopes by/from graphite-effect of iron impurity doped graphite surface and recombination factors," Toyama University Research Bulletin 6 (1986a) 25-38.

K. Ashida, K. Kanamori, K. Ichimura, M. Matsuyama, and K. Watanabe, "Surface modification of pyrolytic graphite due to deuterium and helium ion bombardments," Journal of Nuclear Materials 137 (1986b) 288-291.

K. Ashida, K. Ichimura, M. Matsuyama, and K. Watanabe, "Thermal desorption of deuterium from graphite doped with iron," Journal of Nuclear Materials 148 (1987) 217-223.

K. Ashida, M. Matsuyama, and K. Watanabe, "Trap and release of hydrogen, deuterium, and tritium by/from graphite," Fusion Technology 14 (1988a) 735-740.

K. Ashida, K. Kanamori, and K. Watanabe, "Surface characterization of various graphite by x-ray photoelectron, secondary ion mass, and Raman spectroscopies," Journal of Vacuum Science and Technology A6 (1988b) 2232-2237.

K. Ashida and K. Watanabe, "Diffusion constants of tritium in graphites and compensation effect," Journal of Nuclear Materials 183 (1991) 89-95. 
H. Atsumi, S. Tokura, M. Miyake, "Thermal desorption measurement of deuterium from graphite exposed to D/sub $2 /$ gas atmosphere at elevated temperatures," Technol. Rep. Osaka Univ. (Japan) $v$ 37:1889-1908 Oct. 1987 p 255-261.

H. Atsumi, "Solubility and diffusivity of gas atoms in graphite," Kinki Daigaku Rikogakubu Kenkyu Hokoku (Japan) v 25. Sep. 1989 p 201-208. @

H. Atsumi, M. Iseki, T. Shikama, "Neutron irradiation effect on hydrogen solubility in graphite," Kinki Daigaku Rikogakubu Kenkyu Hokoku (Japan) v 27 Sep 1991 p 247-254. @

H. Atsumi, O. Higashi, M. Iseki, T. Shikama, "Hydrogen absorbing properties of graphite for fusion reactors," Kinki Daigaku Rikogakubu Kenkyu Hokoku (Japan) v 28. Sep 1992 p 221-229. @

H. Atsumi, M. Iseki, T. Shikama, "Hydrogen solubility and diffusivity in neutron-irradiated graphite," Journal of Nuclear Materials (Netherlands) v 191-194:pt.A. Sep 1992 p 368-372.

M. Baskes, K. Wilson, D. Brice, B. Doyle, W. Wampler, D. Heifetz, H. Dylla, J. Cecchi, "Tritium inventory and permeation in TFTR," J. Nucl. Mater. (Netherlands) v 128/129 Dec. 1984 p 629-635.

R. Behrisch, P. Børgesen, J. Ehrenberg, M. Wielunski, A. P. Martinelli, H. Bergsåker, B. Emmoth, J. P. Coad, A. Miyahara, and K. L. Wilson (eds.) "Hydrogen and deuterium retention in wall samples of JET," Proceedings of the Japan-US Workshop P-92 on plasma material interaction/high heat flux data needs for the next step ignition and steady state devices, Nagoya Univ. (Japan). Inst. of Plasma Physics, 26 Jan. 1987, p 268-272

H. Bergsáker, B. Emmoth, R. Behrisch, J. Ehrenberg, A. Martinelli, J. Coad, S. Erents, G. McCracken, J. Partridge, "Hydrogen isotope retention in the JET limiters," J. Nucl. Mater. (Netherlands) $\vee 145-$ 147 Feb. 1987.

J. Bohdansky, R. A. Causey, C. D. Croessmann, A. E. Pontau, and J. B. Whitley, "Preconditioning of graphite and its influence on the gas desorption," Journal of Nuclear Materials 162-164 (1989) $861-864$.

C. Braganza, S. Erents, G. McCracken, "Interactions of 5-30 keV deuterons with a carbon surface," J. Nucl, Mater. (Netherlands) v 75:2, Aug. 1978 p. 220-225.

M. Braun, B. Emmoth, "Deuterium implantation in carbon at elevated temperatures," J. Nucl. Mater. (Netherlands) $\vee$ 128/129. Dec. 1984 p 657-663.

S. J. Brereton, "Tritium systems interactions for systems code applications and safety analysis," EGG-FSP-9628 (1991).

D. K. Brice, B. L. Doyle, and W. R. Wampler, "Extended local mixing model for hydrogen retention and isotope exchange," Journal of Nuclear Materials 111 \& 112 (1982) 598-605.

D. Brice, B. Doyle, W. Wampler, S. Picraux, L. Haggmark, "Retention and Recycling of Plasma Edge Hydrogen Isotopes in Carbon and TiC," J. Nucl. Mater. 114, (2-3), 277-291 Feb. 1983

D. Brice, "A model of hydrogen implantation into graphite including bulk recombination by tunneling," Nuclear Instruments \& Methods in Physics Research, Section B (Beam Interactions with Materials and Atoms) vol. B52, no. 2, p.140-53, Dec. 1990. 
R. A. Causey, T. S. Elleman, and K. Verghese, "Hydrogen diffusion and solubility in pyrolytic carbon," Carbon 17 (1979) 323-328.

R. A. Causey and K. L. Wilson, "Retention of $100 \mathrm{eV}$ deuterium and tritium in Papyex graphite," Journal of Nuclear Materials 138, 57-64 (1986).

R. Causey, K. Wilson, "Retention of deuterium and tritium in Papyex graphite," J. Nucl. Mater. (Netherlands) v 138:1, Mar 1986a p 57-64.

R. Causey, M. Baskes, K. Wilson, "Retention of deuterium and tritium in POCO AXF-5Q graphite," J. Vac. Sci. Technol., A v 4:3, May 1986b p 1189-1192.

R. Causey, W. Hsu, A. Pontau, K. Wilson, "The in-vessel tritium inventory for the Compact Ignition Tokamak," Proceedings of the 12th symposium on fusion engineering 1987 p 101-103.

R. Causey, K. Wilson, "Tritium retention in graphite," Proceedings of the Japan-US workshop on tritium technology, Japan Atomic Energy Research Inst., Jan. 1987

p 202-208.

R. A. Causey, "The interaction of tritium with graphite and its impact on tokamak operations," Journal of Nuclear Materials 162-164 (1989a) 151-161.

R. Causey, W. Chrisman, W. Hsu, R. Anderl, B. Wishard, "Tritium release from a codeposited layer of carbon and tritium during air exposure," J. Vac. Sci. Technol., v 7:3 May (1989b), p 1078-1082.

R. A. Causey, W. R. Wampler, and D. Walsh, "Comparison of the thermal stability of the codeposited carbon/hydrogen layer to that of the saturated implant layer," Journal of Nuclear Materials 176-177 (1990) 987-991.

R. Causey, W. Wampler, O. Buzhinshij, "Tritium retention characteristics of several low-Z materials," Journal of Nuclear Materials (Netherlands), Dec. 1992 p 977-980.

S. Chiu, A. Haasz, "Molecule formation due to sequential and simultaneous exposure of graphite to $\mathrm{H}^{* *}$ plus and $D^{* *}$ plus," Journal of Nuclear Materials v 196-98 Dec. 1 1992. p 972-976.

S. Chiu and A. A. Haasz (1994) "Thermal release of simultaneously implanted $\mathrm{H}+$ and $\mathrm{D}+$ from graphite," Journal of Nuclear Materials 210, 34-42.

J. Coad, A. Miyahara, K. Wilson, "Hydrogen and deuterium retention in wall samples of JET," Proceedings of the Japan-US Workshop P-92 on plasma material interaction/high heat flux data needs for the next step ignition and steady state devices, Nagoya Univ. (Japan) May 1987 p 268-272. @

J. Coad, G. Saibene, R. Sartori, J. Simpson, R. Behrisch, J. Ehrenberg, W. Wang, H. Bergsaker, B. Emmoth, J. Partridge, "The retained deuterium inventory in JET and implications for tritium operation," J. Nucl. Mater., v 162-164 Apr. 1989 p 164.

J. Davis, A. Haasz, O. Auciello, P. Stangeby, B. Doyle, "Measurement of Retained Deuterium by Laser Thermal Desorption for carbon exposed to Sub-eV Atomic Deuterium," Journal of Nuclear Materials $v$ $128-129,1984,788-791$.

J. W. Davis and A. A. Haasz, "Hydrocarbon formation due to hydrogen ion impact on amorphous hydrogenated carbon films," Journal of Nuclear Materials 149 (1987) 349-351. 
J. Davis, A. Haasz, D. Walsh, "Flux and fluence dependence of $\mathrm{H}$ sup + trapping in graphite," Journal of Nuclear Materials (Netheriands) v 176/177 Dec. 1990 p 992-999.

J. Davis, A. Haasz, D. Walsh, "Flux and fluence dependence of $\mathrm{H}^{* *}$ plus trapping in graphite," Journal of Nuclear Materials v 176-77 Dec. 1990 p 992-999 1990.

J. W. Davis and A. A. Haasz, "Re-emission of hydrogen and deuterium from graphite for temperatures between 1000 and $1600 \mathrm{~K}, "$ Journal of Nuclear Materials 183 (1991) 2219-232.

J. W. Davis, A. A. Haasz, and C. H. Wu, "Synergistic erosion of graphite due to simultaneous bombardment by $C_{+}$and $H_{+}, "$ Journal of Nuclear Materials 196-198 (1992) 581-586.

P. De Miranda, F. Fassini, "New methodology for the determination of hydrogen permeation parameters in layered materials," Journal of Materials Science v 28 n 19 Oct. 1 1993. p 5148-5154.

B. Doyle, "Retention and release of hydrogen in graphite and related materials," Sandia National Labs., SAND-81-0037C, 1980 p 8.

H. Dylla, G. Schmidt, R. Sissingh, R. Causey, A. Pontau, K. Wilson, "Tritium consumption and tritium inventory in TFTR and CIT," Proceedings of the Japan-U.S. Workshop P-118 on Vacuum Technologies for Fusion Devices (IPPJ-T-38) p.73-86 1988 1-5 Aug. 1988

H. Dylla, K. Wilson, "Tritium retention in TFTR," Princeton Univ., NJ Plasma Physics Lab., Sandia National Labs., Albuquerque, NM, Apr. 1988 p 130.

J. Ehrenberg, P. Coad, L. De Kock, S. Erents, A. Gondhalekar, D. Goodall, J. Hancock, P. Harbour, T. Jones, G. McCracken, "Hydrogen and helium recycling in tokamaks with carbon walls," J. Nucl. Mater., v 162-164 Apr. 1989 p 164.

T. Elleman, L. Zumwalt, K. Verghese, J. Powell, C. Eterno, "Hydrogen transport and solubility in nonmetallic solids," American Nuclear Society, CONF-780508-P2, 1978 p 763-770.

S. Erents, P. Stangeby, "Effect of a bias potential on deuterium trapping in the carbon thermal desorption probe on DITE," J. Nucl. Mater. (Netherlands) v 111 Nov.-Dec. 1982 p 165-167.

G. Federici and C. H. Wu, "Modeling of plasma hydrogen isotope behavior in porous materials (graphites/carbon-carbon composites," Journal of Nuclear Materials 186 (1992) 131-152.

G. Federici, C. Wu, "Modeling of the interaction of hydrogen plasma with amorphous carbon films redeposited in fusion devices," Journal of Nuclear Materials v 207 Dec 1993. p 62-85, 1993.

G. Federici, R. Causey, P. L. Andrew, and C. H. Wu, "Tritium retention in candidate next-step protection materials: engineering key issues and research requirements," Third International Symposium on Fusion Nuclear Technology ISFNT-3, Los Angeles, CA, June 27-July 1, 1994.

V. Fernandez, J. Bardon, E. Gauthier, C. Grisolia, "Thermodesorption Studies of Boron Doped Graphite Exposed to a Low-Energy High-Density Deuterium Plasma," Journal of Nuclear Materials, 1992, V196, Dec (Dec), p1022-1026.

P. Fischer, R. Hecker, H. Rohrig, D. Stover, "On the behaviour of tritium in reactor graphites," Journal of Nuclear Materials vol.64, no.3, p. 281-8, Feb 1977.

E. Franconi, M. Rubel, B. Emmoth, "Deuterium Implanted in C + SiC and CL5890PT Materials," High Temperature Science, 1990, V28, P189-193. 
P. Franzen, W. Moeller, B.M.U. Scherzer, "Reemission of deuterium from graphite at temperatures above $1100 \mathrm{~K}$," Journal of Nuclear Materials, on Metallurgy, Ceramics and Solid State Physics in the Nuclear Energy Industry (Netherlands) v 172:3. Aug 1990 p 293-296.

P. Franzen, E. Vietzke, A. A. Haasz, J. W. Davis, and V. Philipps, "Atomic re-emission of hydrogen from pure and boronized graphites at temperatures above $1000 \mathrm{~K}$," Journal of Nuclear Materials 196-198 (1992) 967-971.

P. Franzen, B.M.U. Scherzer, and W. Moeller, "Re-emission of deuterium from pure and boronized graphite," (Max-Planck-Inst., Nuclear Instruments and Methods in Physics Research, Section B (Netherlands) v 67:1-4. Apr. 1992 p 536-539.

S. Fukuda, T. Hino, and T. Yamashina, "Desorption processes of hydrogen and methane from clean and metal-deposited graphite irradiated by hydrogen ions," Journal of Nuclear Materials 162-164 (1989) 997-1003.

H. Fukutani, A. Yamada, K. Yagi, S. Ooe, K. Higashiyama, H. Kato, T. Iwata, "Reflection and Photoemission-Studies of Neutron-Irradiated Graphite," Journal of the Physical Society of Japan, 1990 , V59, N9, P 3089-3092.

C. Garcia-Rosales and J. Roth, "Chemical sputtering of pyrolytic graphite and boron doped graphite USB15 at energies between 10 and $1000 \mathrm{eV}$," Journal of Nuclear Materials 196-198 (1992) 573576.

E. Gauthier, J. Bardon, J.P. Palmari, A. Grosman, "Thermodesorption of graphite exposed to a deuterium plasma," Europhysics Conference Abstracts (Switzerland) v 13B. 1989 p 1015-1018. @

Y. Gotoh, O. Okada, "C 1s binding-energy shift of pyrolytic graphite bombarded by keV-deuterium ions," J. Nucl. Sci. Technol. (Tokyo) (Japan) v 21:3. Mar 1984, p 205-214

Y. Gotoh, "Chemical shift of graphite basal face due to keV-deuterium bombardment," Fusion Technology, v 6:2, Sep 1984 p 424-427.

Y. Gotoh, H. Shimizu, and H. Murakami, "High resolution electron microscopy of graphite defect structures after keV hydrogen ion bombardment," Journal of Nuclear Materials 162-164 (1989) $851-855$.

I. Gudowska, "Studies of first wall materials, exposed to fusion plasmas and irradiated with particle beams," Royal Inst. of Tech., Stockholm (Sweden) Manne Siegbahn Inst. of Physics, Stockholm (Sweden), 1993 (154 p). @

A. Haasz, J. Davis, "Report on the study of erosion and H-recycle/inventory of carbon/graphite," Canadian Fusion Fuels Technology Project CFFTP G-9034, Apr. 1990.

A. Haasz, J. Davis, "Erosion and hydrogen retention of graphite for first wall use in fusion reactors," Canadian Fusion Fuels Technology Project CFFTP G-9040, June 1990.

A. A. Haasz, J. W. Davis, "Fluence dependence of deuterium trapping in graphite," Journal of Nuclear Materials, vol.209, no.2, p.155-60, April 1994.

Y. Hasebe, M. Sonobe, K. Morita, "Isotopic Effect in Ion-Induced Re-emission of Hydrogen Implanted into Graphite," Journal of Nuclear Science and Technology, 1992, V29, N9 (Sep), P 859-865. 
T. Hino, Y. Hirohata, S. Fukuda, M. Hashiba, T. Yamashina, "Characterizations of graphite as a fusion first wall material," Hokkaido Daigaku Kogakubu Kenkyu Hokoku (Japan) v 139 Feb 1988 p 107116. @

Y. Hirooka, W. Leung, R. Conn, D. Goebel, B. LaBombard, R. Nygren, K. Wilson, r. Conn, Y. Hirooka, R. Moyer, D. Goebel, W. Leung, R. Nygren, W. Corbett, R. Lehmer, Y. Ra, G. Tynan, K. Dippel, K. Finken, A. Hardtke, W. Kohlhaas, G. Wolf, P. Vandenplas, M. Messian, G. Van oost, R. Weynants, E. Franconi, A. Miyahara, A. Sagara, W. Gauster, J. Koski, R. McGrath, J. Watkins, M. Malinowski, "Hydrogen pumping and release by graphite under high flux plasma bombardment," California Univ., Los Angeles, CA Plasma Physics Group Aug 1988 p 2, UCLA/PPG-1171. @

Y. Hirooka, R. W. Conn, D. M Goebel, B. LaBombard, R. Lehmer, W. K. Leung, and R. E. Nygren, "Deuterium pumping and erosion behavior of selected graphite materials under high-flux plasma bombardment in PISCES-A - effects of surface pores and machined grooves," Journal of Nuclear Materials 162-164 (1989) 1004-1012.

Y. Hirooka, R. Conn, R. Doerner, M. Khandagle, R. Causey, K. Wilson, D. Croessmann, J. Whitley, D. Holland, G. Smolik, T. Sogabe, "Bulk-boronized graphites for plasma-facing components in ITER," Journal of Nuclear Materials (Netherlands) v 176/177. Dec 1990 p 473-480.

- Y. Hirooka, R. Conn, M. Khandagle, G. Chevalier, T. Sogabe, T. Marsuda, H. Ogura, H. Toyoda, H. Sugai, "Interactions of bulk-boronized graphites with deuterium plasmas in the Pisces-B facility," Fusion Technology (United States) v 19:4 July 1991 p 2059-2069.

E. Hoinkis, "Chemisorption of Hydrogen on Porous Graphites at Low Pressure and at Elevated Temperature," Journal of Nuclear Materials, 1991, V182 May-(May-June)

p 93-106.

W. L. Hsu and R. A. Causey, "Pumping of hydrogen during plasma-graphite interaction," Proceedings of the 33rd National Symposium of the American Vacuum Society October 1986, Baltimore, MD, USA.

W. Hsu, R. Causey, "Pumping of hydrogen during plasma--graphite interaction," J. Vac. Sci. Technol., A $\vee$ 5:4 July 1987 p 2768-2772.

P. Hucks, K. Flaskamp, and E. Vietzke, "The trapping of thermal atomic hydrogen on pyrolytic graphite," Journal of Nuclear Materials 93 \& 94 (1980) 558-563.

K. Ichimura, K. Ashida, M. Matsuyama, K. Watanabe, A. Miyahara, K. Wilson, "Trapping-release behaviours of hydrogen isotopes in/from graphite: Modification by the presence of Fe impurity," Proceedings of the Japan-US Workshop P-92 on plasma material interaction/high heat flux data needs for the next step ignition and steady state devices, Nagoya Univ. (Japan) May 1987 p 384-401. @

K. Ichimura, K. Ashida, M. Matsuyama, and K. Watanabe (1987) "Interactions between tritium and graphite," IPPJ-AM-50, Toyama University.

K. Ichimura, E. Takamura, and M. Sano, "Hydrogenation of CsC8 graphite intercalation compound by atomic hydrogen," Nuclear Instruments and Methods A320 (1992) 604-605. @

N. Kechkhuashvili, D. Kurdiani, R. Salukvadze, "Dependence of the coefficient of tritium diffusion from graphite on annealing temperature," AN SSR, 1990 p 109 (188 p).

R. Kerst, W. Swansiger, "Plasma Driven Permeation of Tritium in Fusion Reactors," Journal of Nuclear Materials, 1984, V123, N1-3,P1499-1510. @ 
M. Kitajima, K. Aoki, "Hydrogen trapping behavior of graphite exposed to glow discharge," Fusion Technology 1988 V.2., 1989 p 1093-1098.

T. Kiyoshi, T. Namba, M. Yamawaki, "Hydrogen permeation through graphite," J. Nucl. Mater., v 155-157:pt.A. July 1988 p 230-233.

G. Kögel, D. Schödlbauer, and W. Trifsthäuser, "Investigation of micropores in amorphous hydrogenated carbon by a pulsed positron beam," Physical Review Letters 60 (1988) 1550-1553.

G. Kögel, D. Schödlbauer, W. Trifsthăuser, and J. Winter (1989) "On the investigation of amorphous hydrogenated carbon by positron annihilation," Journal of Nuclear Materials 162-164, 876-880.

J. Kovacks, A. Denis, E. Garcia, "Numerical-Analysis of the Permeation Equations for a Single Type of Irreversible Traps," Memoires et Etudes Scientifiques De La Revue De Metallurgie, 1992, V89, N11 (NOV), P693-703. @

K. Kushita, I. Youle, A. Haasz, J. Sawicki, "Tritium diffusion in pseudo-monocrystal graphite, observed with a tritium imaging camera," Journal of Nuclear Materials (Netherlands) $\vee$ 179181 :pt.A. Mar-Apr. 1991 p 235-238.

D. B. Kuzminov. S. L. Kanashenko, A. E. Gorodetsky, and A. P. Zakharov, "Interaction of deuterium atoms with radiation defects in graphite," Journal of Nuclear Materials 185 (1991) 123-129.

H. Kwast, R. Muis, J. Boshoven, "Tritium retention in neutron irradiated graphites, CFC's and doped C composites," Apr 1993 (23 p) Report Number(s): ECN-C-93-017. @

P. LaMarche, H. Dylla, P. McCarthy, M. Ulrickson, "Hydrogen isotope exchange and conditioning in graphite limiters used in the Tokamak Fusion Test Reactor," J. Vac. Sci. Technol., A v 4:3 May 1986 p $1198-1202$.

R.Langley, J. Bohdansky, W. Eckstein, J. Roth, E. Taglauer, H. Verbeek, P. Mioduszewski, E. Thomas, K. Wilson, "Data compendium for plasma-surface interactions," Nucl. Fusion, IAEA, 1984 p 117.

R. Langley, "Retention of hydrogen in graphite," J. Vac. Sci. Technol., A v 5:4 July 1987 p 22052209.

R. Langley (1989a) "Graphite as a plasma-facing material in fusion experiments," Proc IEEE 13th Symp Fusion Eng. Proceedings - Symposium on Fusion Engineering, v 1 . p 522-528.

R. A. Langley, "Helium-ion-induced release of hydrogen from graphite," Journal of Nuclear Materials $162-1654$ (1989b) 1030-1034.

M. A. Lomidze, A. E. Gorodetsky, S. L. Kanashenko, V. Kh. Alimov, and A. P. Zakharov, "Model for deuteron retention and reemission in graphites in a wide range of temperatures and energies," Journal of Nuclear Materials 208 (1994) 313-323.

C. Mak, B. Koehler, J. Brand, S. George, "Surface diffusion of hydrogen on carbon-covered Ru(001) surfaces studied using laser-induced thermal desorption," Journal of Chemical Physics vol.87, no.4 p. 2340-5, 15 Aug. 1987.

R. McGrath, J. Koski, R. Watson, R. Causey, C. Croessmann, J. Dempsey, M. Hosking, K. Neimer, A. Russo, J. Salmonson, J. Stephens, M. Smith, J. Watkins, J. Whitley, "Design considerations for ITER (International Thermonuclear Experimental Reactor) plasma facing components," Sandia National Labs., SAND-89-0901, July 1989 p 110. @ 
C. Mendoza, F. Ruette, "Atomic-Hydrogen Interaction With a Cluster-Model Graphite SurfaceChemisorption, Coverage and H-2 Surface Recombination," Catalysis Letters, 1989, V3, N1, p 89-97.

W. Möller and B. M. U. Scherzer, "Subsurface molecule formation in hydrogen-implanted graphite," Applied Physics Letters 50 (1987) 1870-1872.

W. Moeller, "Hydrogen trapping and transport in carbon," J. Nucl. Mater., v 162-164 Apr 1989 p 164.

C. Moreau, P. Fargier-Richard, R. Saint-Jacques, P. Cielo, "Thermal diffusivity of plasma-sprayed tungsten coatings," Surface and Coatings Technology (Switzerland) v 61:1-3. 3 Dec 1993 p 67-71. @

K. Morita, "Metal sputtering and hydrogen retention in metal-carbon composite layer materials," Fusion Technology (United States) v 19:4,Jul 1991 p 2083-2091.

K. Morita and Y. Muto, "Isotopic effect in thermal re-emission of hydrogen from graphite at elevated temperatures," Journal of Nuclear Materials 196-198 (1992) 963-966.

Y. Muto, K. Morita, "Isothermal Re-emission of Hydrogen Implanted Into isotropic Graphite," Journal of Nuclear Science and Technology, 1992, V29, N10 (Oct.), P 980-987.

T. Nagasaki, M. Saidoh, R. Yamada, H. Ohno, "Ion-Driven Permeation and Surface Recombination Coefficient of Deuterium for Ion," Journal of Nuclear Materials, 1993, V202, N3 (July), P228-238. @

S. Nagata, S. Yamaguchi, B. Bergsåker, and B. Emmoth, "lon-induced release of H and D implanted in Be, C, Si, and SiC," Nuclear Instruments and Methods in Physics Research B33 (1988) 739-743.

K. Nakayama, S. Fukuda, T. Hino, T. Yamashina, "Thermal desorption process and surface roughness of POCO graphite irradiated by hydrogen ion beam," J. Nucl. Mater. (Netherlands) v 145-147 Feb 1987. @

K. Niwase, T. Tanabe, M. Sugimoto, and F. E. Fujita, "Modification of graphite structure by D+ and $\mathrm{He}+$ bombardment," Journal of Nuclear Materials 162-164 (1989) 856-860.

"The Net Device - Plasma-Facing Components," Fusion Engineering and Design, 1993, V21, Feb (Feb), P213-293.@

"Overall evaluation of graphite as plasma facing material," Nippon Genshiryoku Gakkaishi/Journal of the Atomic Energy Society of Japan v 35 n 12 Dec 1993. p 1066-1075. @

L. Peng, C. Yan, Z. Cao, K. Huang, Y. Zheng, S. Qian, J. Luo, "Hydrogen Recycling and Its Control on HL1 Tokamak," Journal of Nuclear Materials, 1992, V196, DEC (DEC), P520-524. @

V. Philipps, E. Vietzke, M. Erdweg, and K. Flaskamp, "Thermal desorption of hydrogen and various hydrocarbons from graphite bombarded with thermal and energetic hydrogen," Journal of Nuclear Materials $145-147$ (1987) 292-296.

V. Philipps, A. Miyahara, K. Wilson, "Comments on recycling and hydrogen inventory," Proceedings of the Japan-US Workshop P-92 on plasma material interaction/high heat flux data needs for the next step ignition and steady state devices, Nagoya Univ. (Japan) May 1987 p 408-410. @ 
V. Philipps, A. Pospieszczyk, J. Winter, H. Essier, M. Eroweg, L, Konen, J. Linke, B. Schweer, J. Seggern, B. Unterberg, E. Vietzke, E. Wallura, "Behavior of Carbon and Boron Carbon Materials at High-Temperatures in Textor," Journal of Nuclear Materials, 1992, V196, Dec , p.1106-1111. 3115.

J. Pillath, J. Winter, and W. Waelbroeck, "Influence of an a-C:H layer on the gas and plasma driven permeation of hydrogen through iron," Proceedings of E-MRS Symposium on Amorphous Hydrogenated Carbon Films, Strasbourg, France, June 2-5, 1987, to be published in J. Physique.

J. Pillath, J. Winter, and F. Waelbroeck, "Hydrogen transport and particle-induced hydrogen release in carbonization layers," Journal of Nuclear Materials 162-164 (1989) 1046-1051.

J. Pillath and J. Winter, "Particle-induced desorption of hydrogen from a-C:H at low impact energies," Journal of Nuclear Materials 176 \& 177 (1990) 319-325.

"C. Pitcher, O. Auciello, A. Haasz, P. Stangeby, "Interaction of a sub-eV H/sup $0 /$ atom beam with carbon. Methane production and hydrogen retention," J. Nucl. Mater. (Netherlands) v 128/129, Dec 1984 p 597-600.

"Proceedings of the Japan-US Workshop on Tritium Technology," (P89 in the Japan-US Fusion Cooperation Program) (JAERI-M 86-189), Jan. 1987. @

F. Reiter, K. S. Forcey, and G. Gervasini, "A compilation of tritium-material interaction parameters in fusion reactor materials," EUR 15217 EN (1993).

J. Roth, B. Scherzer, R. Blewer, D. Brice, S. Picraux W. Wampler, "Trapping, detrapping and replacement of keV hydrogen implanted into graphite," J. Nucl. Mater. (Netherlands) v 93:94, Oct. 1980 p 601-607.

J. Roth and J. Bohdansky, "Mechanism of hydrocarbon formation upon interaction of energetic hydrogen ions with graphite," Applied Physics Letters 51 (1987) 964-966.

M. Rubel, B. Emmoth, H. Bergsaker, P. Wienhold, V. Dunaev, V. Sukhomlinov, "Deposition and indepth penetration of deuterium in carbon tibre composites," Journal of Nuclear Materials (Netherlands) Dec 1992 p 285-291.

M. Saeki, "Influence of radiation damage on diffusivity of tritium in graphite," Int. J. Appl. Radiat. Isot. (United Kingdom) v 34:4, Apr 1983 p 739-742.

M. Saeki, "Effects of pyrolytic carbon structure on diffusivity of tritium," J. Nucl. Mater. (Netherlands) v 131:1, Mar 1985 p 32-36.

M. Saeki, N. Masaki, "Release enhancement of tritium from graphite by addition of hydrogen," Radiochim. Acta (Germany, Federal Republic of) v 46:3 1989 p 163-167.

J. A. Sawicki, J. Roth, and L. M. Howe, "Thermal release of tritium implanted in graphite studied by $T(d, a l p h a) n$ nuclear reaction depth profiling analysis," Journal of Nuclear Materials 162-164 (1989)1-6 ?

B. Scherzer, R. Behrisch, W. Eckstein, U. Littmark, J. Roth, M. Sinha, "Temperature dependence of trapping and depth profiles of 6 to $15 \mathrm{keV}$ deuterium in carbon," $20 \mathrm{~J}$. Nucl. Mater. (Netherlands) v 63, Dec 1976 p 100-105. 
B. Scherzer, R. Langley, W. Möller, J. Roth, R. Schulz, "Influence of damage on the thermal release of deuterium implants in graphite," Nucl. Instrum. Methods Phys. Res. (Netherlands) v 194:1-3, 15 Mar 1982 p $497-500$.

B. M. U. Scherzer, J. Wang, and W. Möller, "Temperature dependence of ion-induced detrapping of deuterium in graphite," Journal of Nuclear Materials 162-164 (1989) 1013-1018.

B. M. U. Scherzer, J. Wang, and W. Möller, "Trapping and release of D from 'saturated' implants in graphite," Journal of Nuclear Materials $176 \& 177$ (1990) 208-212.

Y. Shirasu, S. Yamanaka, M. Miyake, "Preliminary study on hydrogen solubility in graphite," Technology Reports of the Osaka University vol. 40, no. 1986-2003 p.35-40 15 April 1990.

Y. Shirasu, S. Yamanaka, M. Miyake, "Solubility of hydrogen isotopes in graphite," Journal of Nuclear Materials (Netherlands) v 179-181:pt.A., Mar-Apr 1991 p 223-226.

Y. Shirasu, S. Yamanaka, and M. Miyake, "Thermodynamic analysis of hydrogen solubility in graphite," Journal of Nuclear Materials 200 (1993) 218-222.

R. Siegele, J. Roth, B.M.U. Scherzer, S. J. Pennycook, "Damage and deuterium trapping in highlyoriented pyrolytic graphite," Journal of Applied Physics vol.73, no.5 p.2225-33, 1 March 1993.

P. Stangeby, O. Auciello, A. Haasz, B. Doyle, "Trapping of sub-eV hydrogen and deuterium atoms in carbon," J. Nucl. Mater. (Netherlands) v 123:1-3, May 1984 p 1592-1597.

R. A. Strehlow, "Chemisorption of tritium on graphites at elevated temperatures," 32nd National Vacuum Symposium, American Vacuum Society, Houston, TX, November 19-22 (1985).

H. Sugai, S. Yoshida, H. Toyada, "Hydrogen retention and release dynamics of amorphous carbon films exposed to a hydrogen plasma," Journal: Applied Physics Letters vol.54, no.15 p.1412-14, April 1989.

T. Tanabe, A. Miyahara, K. Wilson, "Estimation of retention, permeation and recycling," Proceedings of the Japan-US Workshop P-92 on plasma material interaction/high heat flux data needs for the next step ignition and steady state devices, Nagoya Univ. (Japan) May 1987 p 350-360. @

T. Tanabe and Y. Watanabe (1991) "Hydrogen behavior in graphite at elevated temperatures," Journal of Nuclear Materials (Netherlands) 179-181, 231-234.

T. Tanabe, H. Atsumi, "Bulk hydrogen retention in graphite at elevated temperature," Journal of Nuclear Materials vol.209 no.1 p.109-12, March 1994.

T. Tanabe, M. Fujitsuka, H. Shinno, T. Shikama, "Irradiation behavior of carbon-boron-titanium materials," ASTM Special Technical Publication n 1175 1994. Publ. by ASTM, Philadelphia, PA, USA.p 1283-1291,1994. @

E. Thomas, M. Braun, "Dynamic measurements of implanted deuterium retention and release in stainless steel and carbon," J. Nucl. Mater. (Netherlands) v 111, Nov.-Dec 1982 p 654-656.

M. Ulrickson, R. Goldston, J. Brooks, H. Dylla, G. Neilson, K. Wilson, "A tritium inventory management scheme for BPX," CONF-910968 1992 p 1008-1011 (1236 p).

H. Vernickel, "Influence of plasma-induced heating on re-emission of hydrogen from graphite targets," J. Nucl. Mater. (Netherlands) v 128/129, Dec 1984 p 708-712.

$$
\text { D- } 10
$$


E. Vietzke, K. Flaskamp, V. Philipps, G. Esser, P. Wienhold, and J. Winter, "Chemical erosion of amorphous hydrogenated carbon films by atomic and energetic hydrogen," JOURNAL OF NUCLEAR MATERIALS 145-147 (1987) 443-447.

E. Vietzke and V. Philipps (1987) "Surface modification due to hydrogen-graphite interaction," Nuclear Instruments and Methods in Physics Research B23, 449-457.

E. Vietzke, V. Philipps and K. Flaskamp (1989) "Chemical reactivity of atomic hydrogen on graphite pre-irradiated by hydrogen and carbon ion bombardment," Journal of Nuclear Materials 162-164, 898-903.

F. Waelbroeck, T. Banno, H. G. Esser, L. Könen, V. Philipps, P. Wienhold, and J. Winter (1989) "The use of the RG conditioning system to examine some recycling mechanisms occurring in an all-carbon surrounding," Journal of Nuclear Materials 162-164, 496-502.

W. Wampler, B. Doyle, A. Pontau, "Hydrogen and deuterium in graphite limiters from TFTR, PDX and PLT," J. Nucl. Mater. (Netherlands) v 145-147 Feb 1987. @

W. Wampler and B. L. Doyle (1989) "Release of deuterium from carbon during low-energy helium and carbon ion bombardment," Journal of Nuclear Materials 162-164, 1025-1029.

W. R. Wampler, B. L. Doyle, R. A. Causey, and K. Wilson (1990) "Trapping of deuterium at damage in graphite," Journal of Nuclear Materials 176 \& 177, 983-986.

K. Watanabe and K. Ashida, "Desorption mechanisms of hydrogenated isotopes implanted into graphite and recombination factors," Annual report of the Tritium Research Center, Toyama University, Japan, Vol. 5 (1985) 42-52.

K. Watanabe, K. Ashida, and M. Sonobe, "The compensation effect on diffusion constants of hydrogen in metals," Journal of Nuclear Materials 173 (1990) 294-306.

S. Whiteway, W. Caley, L. Iyer, V. Holmes, "Permeability, Solubility and Diffusivity of Hydrogen in Carbon and Alloy Rail Steel at 500-660 deg C," Can. Metall. Q. 22,(3), 341-345 July-Sept. 1983. @

K. L. Wilson and W. L. Hsu (1987) "Hydrogen recycling properties of graphite," JOURNAL OF NUCLEAR MATERIALS 145-1'47, 121-130.

K. L. Wilson, R. Bastasz, R. A. Causey, D. K. Brice, B. L. Doyle, W. R. Wampler, W. Moller, B. M. U. Scherzer, and T. Tanabe, "Trapping, detrapping, and release of implanted hydrogen isotopes," Atomic and Plasma-Material Interaction Data for Fusion, Volume 1, International Atomic Energy Agency, Vienna, 1991, p.35-50.

J. Winter, "Carbonization in tokamaks," Journal of Nuclear Materials 145-147 (1987a) 131144.

J. Winter, "Surface conditioning of fusion devices by carbonization: hydrogen recycling and wall pumping," Journal of Vacuum Science and Technology A5 (1987b) 2286-2292.

J. Winter, H. G. Esser, P. Wienhold, V. Philipps, E. Vietzke, K. H. Besocke, W. Moller, and B. Emmoth, "Properties of carbonization layers relevant to plasma-surface-interactions," Nuclear Instruments and Methods in Physics B23 (1987c) 538-543. 
J. Winter, H. G. Esser, F. Waelbroeck, and P. Wienhold, "Wall pumping experiments in TEXTOR," 14th European Conference on Controlled Fusion and Plasma Physics, Madrid, June 22-26, 1987d.

R. Wistrom, P. Børgesen, S. Sass, "Deuterium Trapping in Evaporated Metal-Films 1. Characterization of the Trapping, "ACTA Metallurgica et Materialia, 1993, V41, N12 (DEC), P3549. 3555. @

K. Yamaguchi, Y. Suzuki, S. Tanaka, M. Yamawaki, "Effect of coatings on the hydrogen permeability of graphite," Journal of Nuclear Materials (Netherlands) v 179-181:pt.A. Mar-Apr 1991 p 242-245.

S. Yamanaka, Y. Sato, H. Ogawa, Y. Shirasu, M. Miyake, "Poisoning effect on solubility of hydrogen isotopes in getter materials," Journal of Nuclear Materials (Netherlands) v 179-181:pt.A., MarApr 1991 p 303-307. @

T. Yamashina, T. Hino, "Plasma-surface interactions of graphite as nuclear fusion material," Applied Surface Science (1985) v 48-49 $n$ 4. Publ by Elsevier Science Publ BV (North-Holland),

Amsterdam, Neth.p 483-497 1991. @

T. Yamashina, T. Hino, "Overall evaluation study for isotropic graphite as fusion first wall material in Japan," J. Nucl. Mater., v 162-164 Apr 1989 p 164.

T. Yamashina, T. Hino, "Characterization of graphite as fusion first wall material and evaluation of stability against plasmas," Journal of Nuclear Science and Technology (Tokyo) (Japan) v 27:7 July 1990 p 589-600.

T. Yamashina and T. Hino, "Plasma-surface interactions of graphite as nuclear fusion material," Applied Surface Science $48 / 49$ (1991) 483-497.

M. Yamawaki, A. Miyahara, K. Wilson, "Hydrogen permeation through graphite," Proceedings of the Japan-US Workshop P-92 on plasma material interaction/high heat flux data needs for the next step ignition and steady state devices, Nagoya Univ. (Japan) May 1987 p 402-407. @

M. Yamawaki and T. Namba, "Permeability of hydrogen isotopes and surface segregation of impurities in first wall materials for fusion reactor," Journal of Nuclear Science and Technology (Tokyo) (Japan) $\checkmark$ 28:2, Feb 1991 p 178-184.

S. Yoshida, H. Sugai, H. Toyoda, "Hydrogen release and retention dynamics of amorphous carbon layers exposed to a hydrogen/helium plasma," Jpn. J. Appl. Phys., Part 2 (Japan) v 28:6, June $1989 p$ 1101-1108.@

I. Youle, A. Haasz, K. Kushita, "Diffusion and retention of tritium in graphite," Proceedings p.13/218 vol.3, 1989. @

I. Youle, A. Haasz, "Retention of sub-eV atomic tritium and protium in pyrolytic graphite," Journal of Nuclear Materials (Netherlands) v 182, May-June 1991 p 107-112. 


\section{Appendix E. Bibliography on Vanadium}

D.L. Adams and H.B. Nielsen, (1981), "The preparation and surface structure of clean V(110)," Surf. Sci. vol. 107, pp 305-320.

G. Alefeld and J. Völkl, editors, (1978a), Hydrogen in Metals I, Basic Properties, Springer Verlag, Berlin, Heidelberg, New York.

G. Alefeld and J. Völkl, editors, (1978b), Hydrogen in Metals II, Application-Oriented Properties, Springer Verlag, Berlin, Heidelberg, New York.

R.A. Anderl, G.R. Longhurst and D.A. Struttmann, (1987) "Permeation of Deuterium Implanted into V-15Cr-5Ti", Journal of Nuclear Materials, 145-147, pp. 344-347.

M. I. Baskes, (1980), J. Nucl. Mater. 92, p 318.

M.I. Baskes, A.E. Pontau, K.L. Wilson and W.L. Barr, (1984) "Tritium Permeation Considerations in the MARS Direct Convertor", Journal of Nuclear Materials, $122 \& 123$, pp. $1511-1517$.

W. Bauer and G.J. Thomas, (1974) "Helium and Hydrogen Re-emission During Implantation of Molybdenum, Vanadium and Stainless Steel", Journal of Nuclear Materials 53, pp. 127-133.

H. Bleichert and H. Wenzel, (1987), "Variable Solubility of the Hydrogen Isotopes, Protium, Deuterium and Tritium in Vanadium," Phys. Stat. Sol. B, Vol 144, \#1, pp 361-373.

N. Boes and $H$. Zuchner, (1976), "Measurement of the solubility of hydrogen in vanadium, niobium and tantalum with a new electrochemical method," Berichte der Bunsen-Gesellechaft, Bd. 80 ,, No. 1, pp. 22-27.

G. Cannelli and F. Mazzolai, (1970), J. Phys. Chem. Solids, vol. 31, p1913.

H.Y. Chang and C.A. Wert, (1973) "The Solubility and Trapping of Hydrogen in Vanadium", Acta Metallurgica, Vol. 21, p. 1233.

B.L. Doyle and D.K. Brice, (1985), "Steady state hydrogen transport in solids," Rad. Effects 89 p. 21.

H. Eleveld, A. van Veen, M. Clement, and M. DeMoor, (1994), "Helium defect interactions in vanadium and beryllium," Plasma Devices and Operations, vol 3, p 65.

T. Eguchi and S. Morozumi, (1974), "Influence of alloying elements on the solubility of hydrogen in vanadium," J. of the Japan Institute of Metals, 38, \#11, pp 1025-30.

T. Eguchi and S. Morozumi, (1977), J. Japan Inst. Metal, vol. 41, p795.

T.B. Flanagan and W.A. Oates, (1972), "Thermodynamics of Metal/Hydrogen Systems," Berichte de Bunsen-Gesellschaft, Bd 76, No. 8, pp. 706-714.

J.S. Foord, A.D.C. Reed and R.M. Lambert, (1983), "The (100) surfaces of chromium and vanadium: reconsiderations of their structure and reactivity," Surf. Sci. vol 129, pp. 79-91.

E-1 DRAFT October 7, 1994 
U. Freudenberg, J. V_Ikl, J. Bressers and G. Alefeld, (1978) "Influence of impurities on the diffusion coefficient of hydrogen and deuterium in vanadium", Scripta Metallurgica Vol. 12, pp. $165-167$.

Y. Fukai and H. Sugimoto, (1985), "Diffusion of hydrogen in metals," Advances in Physics 34 , No. 2, $\mathrm{p} 263$.

R.E. Gold and D.L. Harrod, (1980), "Radiation Effects in vanadium and vanadium-based alloys," International Metals Reviews, Vol 25, Nos 5 and 6, p 232.

D.F. Holland and R.A. Anderl, (1988) "Implantation-driven Tritium Permeation in Vanadium Alloy Fusion Reactors", Fusion Technology, Vol. 14, p 707.

J.L. Jones, B.J. Merrill and D.F. Holland, (1986) "Predicting Tritium Movement and Inventory in Fusion Reactor Subsystems using the TMAP Code", Proceedings of 11 th Symposium on Fusion Engineering, IEEE Cat. No. $86 \mathrm{CH} 2251-7$, pp. 631.

F. Kano, Y. Arai, K. Fukuya, N. Sekimura and S. Ishino, (1993) "The effect of hydrogen on microstructural changes using dual ion irradiation", Journal of Nuclear Materials, 203, pp. $151-157$.

M. Kano, N. Kagawa, S. Koike, K. Furuya and T. Suzuki, (1989) "Response to the comment on superdiffusion of hydrogen in vanadium measured by the permeation method", Scripta Metallurgica, Vol. 23, pp. 1035-1036.

M. Kano, N. Kagawa, S. Koike, K. Furuya and T. Suzuki, (1988) "Superdiffusion of hydrogen in vanadium measured by the permeation method", Acta metall., Vol. 36, No. 6, pp. 1553-1562.

R. Kircheim, (1982), "Solubility, diffusivity and trapping of hydrogen in dilute alloys, deformed and amorphous metals - II," Acta metall. Vol. 30, pp. 1069-1078.

T. Kiyoshi, T. Namba and M. Yamawaki, (1986) "Anomalous Hydrogen Permeation Behavior of Vanadium Caused by its Temperature Change", Proceedings of a Symposium on Fusion Reactor Blanket and Fuel Cycle Technology, University of Tokyo, pp. 199-202.

P. Kofstad and W.E. Wallace, (1959), "Vapor pressure studies of the vanadium-hydrogen system and thermodynamics of formation of vanadium-hydrogen solid solutions," J. Am. Chem. Soc. Vol 81, pp. 5019-5022.

J.C. Langeberg and R.B. McLellan, (1973) "Thermodynamics of B.C.C. Solid Solutions of Hydrogen in Niobium, Vanadium and Tantalum", Acta Metallurgica, Vol. 21, p 897.

R. Lasser and H. Wenzl, (1983) "Tritium in Vanadium", Proceedings of the 12th Symposium on Fusion Technology, 1982, Commission of the European Community Report, EUR 7983 EN.V2, Pergamon Press, Oxford, pp. 783-788.

V. Lottner, J. W. Haus, A. Heim, and K. W. Kehr, (1979), J. Phys. Chem. Solids, vol. 40, p 557.

G.G. Libowitz, (1972) "Condensed Phase Metal-Hydrogen Systems and Their Role in Controlled Fusion Reactors", in The Chemistry of Fusion Technology, edited by D.M. Gruen, Plenum Press. 
G.R. Longhurst, R.A. Anderl and D.A. Struttmann, (1986) "A Comparison of ImplantationDriven Permeation characteristics of Fusion Reactor Structural Materials", Journal of Nuclear Materials, 141-143, pp. 229-233.

G.R. Longhurst, R.A. Anderl and D.A. Struttmann, (1986) "Implications of Recent Implantation-Driven Permeation Experiments for Fusion Reactor Safety", Paper presented at Third Tritium Technology Workshop, Naka Fusion Research Establishment JAERI.

J.F. Lynch, J.J. Reilly and F. Millot, (1978), "The absorption of hydrogen by binary vanadium-chromium alloys," J. Phys. Chem. Solids, Vol. 39, pp. 883-890.

R.B. McLellan and M. Yoshihara, (1987), "The diffusion of hydrogen in B.C.C. V-Ti solid solutions," J. Phys. Chem. Solids, Vol 48, No. 7, pp. 661-665.

R.B. McLellan, (1987) "Hydrogen Diffusion in V-Ti Solutions", Scripta Metallurgica, Vol. 21, pp. 1263-1265.

H. Nakajima, M. Yoshioka and M. Koiwa, (1987) "Electromigration of Hydrogen in Vanadium and its Alloys", Acta metall., Vol. 35, No. 11, pp. 2731-2736.

H. Nakajima, M. Yoshioka and M. Koiwa, (1987) "Thermomigration of Hydrogen and Deuterium in Vanadium, its Alloys, Niobium and Tantalum" Transactions of the Japan Institute of Metals, Vol. 28, No. 12, pp. 949-956.

T. Namba, M. Yamawaki and M. Kanno, (1984) "Surface Processes of Hydrogen Transport in Fusion Reactor Materials", Journal of Nuclear Materials, 128 \& 129, pp. 646-651.

T. Namba, M. Yamawaki and M. Kanno, (1983) "Effect of Argon lon Sputtering of Surface on Hydrogen Permeation through Vanadium, (II) Effect of Sputtering on Both Side Surfaces", Journal of Nuclear Science and Technology Vol. 20, No. 9, pp. 752-761.

T. Namba, H. Miyaguchi, M. Yamawaki and M. Kanno, (1982) "Hydrogen permeation through vanadium and the effect of surface impurity layer on it", Journal of Nuclear Materials 105, pp. 318-325.

C. Nishimura, M. Komaki and M. Amano, (1991) "Hydrogen Permeation Characteristics of Vanadium-Nickel Alloys", Materials Transactions, JIM, Vol. 32, No. 5, pp. 501-507.

R. A. Oriani, (1970), Acta. Metall. vol. 18, p 147.

K. Ozawa, S. Yamaguchi, Y. Fujino, O. Yoshinari, M. Koiwa and M. Hirabayashi, (1978) "Channeling studies on the trapping of deuterium in vanadium by oxygen interstitials", Nuclear Instruments and Methods 149, pp. 405-410.

D. T. Peterson and M. F. Smith, (1982), "Thermotransport of Hydrogen and Deuterium in Vanadium, Niobium, and Tantalum," Metall. Trans. A, vol 13A, p 821.

D.T. Peterson and S.O. Nelson, (1985), "Isopiestic Solubility of Hydrogen in Vanadium Alloys at Low Temperatures," Metallurgical Transactions, Vol. 16A, p. 367.

D.T. Peterson and B.J. Schlader, (1988) "Solubility and Diffusion of Hydrogen in VanadiumOxygen Alloys", Metallurgica Transactions A, Vol. 19A, p 67.

E-3 DRAFT October 7, 1994 
D.T. Peterson and H.M Herro, (1987) "Hydrogen and Deuterium Diffusion in VanadiumTitanium Alloys", Metallurgica Transactions A, Vol. 18A, p 249.

M.A. Pick and D.O. Welch, (1979), "Hydrogen absorption in the niobium-vanadium system," Zeit. fur Phys. Chemic Neul Folge, Bd. 114, pp. 37-43.

M. A. Pick and K. Sonnenberg (1985) "A model for atomic hydrogen-metal interactions application to recycling, recombination and permeation," Journal of Nuclear Materials 131, 208-220.

M.A. Pick and P.L. Andrew, (1993), "Review of Tritium Retention in First Wall Materials," paper presented at 6th International Conference on Fusion Reactor Materials, Stressa, Italy, also, Joint European Torus Report, JET-P(93) 93.

D.J. Pine and R.M. Cotts, (1983) "Diffusion and electrotransport of hydrogen and deuterium in vanadium-titanium and vanadium-chromium alloys", Physical Review B, Vol. 28, No. 2, p 641.

D.J. Pine and R.M. Cotts, (1983), "Diffusion of hydrogen in vanadium-based BCC alloys", in Electronic Structure and properties of hydrogen in metals, Plenum Press, New York, p 465.

D.J. Pine and R.M. Cotts, (1984) "Accurate measurement of hydrogen diffusivity in metals", Rev. Sci. Instrum. 55 (4), pp 614-616.

R. Qi, J. Volkl, R. Lasser and H. Wenzel, (1983), "Tritium diffusion in V, Nb and Ta," J. Phys. F: Met. Phys. 13, p 2053.

F. Reiter, K.S. Forcey, G. Gerwasini, (1993), "A Compilation of Tritium-Material Interaction Parameters in Fusion Reactor Materials," Joint Research Centre Report EUR 15217 EN, Commission of the European Communities, ISPRA.

R.J. Roy and T.R.P. Gibb, (1966), "X-ray diffraction studies of the effect of traces of hydrogen in vanadium," J. of Phys. Chem., Vol. 70, No. 11, pp. 3753-3755.

H. Sakagucki, H. Shirai, K. Nishioka, T. Suenobu, H. Tanaka and G. Adachi, (1992), "Hydrogen permeability for oxide-metal multilayered films," J. of Alloys and Compounds, 185. No 2, pp 295-300.

G. Schaumann, J. V_|kl and G. Alefeld, (1970), "The diffusion coefficients of hydrogen and deuterium in vanadium, niobium and tantalum by Gorsky-effect measurements," Phys. Stat. Sol. 42, p 401.

T. Schober and W. Pesch, (1979), "The Systems vanadium-hydrogen and vanadiumdeuterium," Zeit. f_r Phys. Chemic Neul Folge, Bd. 114, pp. 37-43.

T. Schober, (1990), KFA Julich Report, Jul 2347.

A.I. Shirley and C.K. Hall, (1984) "Trapping of Hydrogen by Metallic Substitutional Impurities in Niobium, Vanadium, and Tantalum", Acta metall. Vol. 32, No. 1, pp. 49-56.

A.I. Shirley, C.K. Hall and N.J. Prince, (1983) "Trapping of Hydrogen by Oxygen and Nitrogen Impurities in Niobium, Vanadium and Tantalum", Acta metall. Vol. 31, No. 7, pp. 985-992.

E-4 DRAFT October 7, 1994 
S.A. Steward, (1983), "Review of hydrogen isotope permeability through materials," UCRL53441, Lawrence Livermore National Laboratory, Livermore, CA.

R.E. Stickney, (1972), "Diffusion and Permeation of Hydrogen Isotopes in Fusion Reactors: A Survey," in The Chemistry of Fusion Technology, edited by D.M. Gruen, Plenum Press, p. 241.

M. Sugisaki, (1986), "Tritium diffusion in metals under thermal gradient," in Proc. JapanUS Workshop on Tritium Technology, Japan Atomic Energy Research Institute report JAERI-M $86-189$, p. 186.

M. Sugisaki, T. Ichigi, K. Hashizume and H. Furuya, (1990) "Heat of transport $Q^{*}$ of tritium in Vanadium: General characteristics of $Q^{*}$ of hydrogen isotopes in group V metals", Journal of the Less-Common Metals, 161, pp. 213-222.

T. Suzuki and K. Takata, (1993) "Permeation of hydrogen in vanadium: II: Theoretical details", Materials Science and Engineering, A163, pp. 99-105.

R.C. Svedberg and R.W. Buckman, Jr., (1980) "Gas-metal reactions in vanadium and vanadium-base alloys", International Metals Reviews Vol. 25, Nos. 5 and 6, p 223.

K. Takata and T. Suzuki, (1993) "Permeation of hydrogen in vanadium I. Experimental details", Materials Science and Engineering, A163, pp. 91-97.

S. Tanaka and H. Kimura, (1979) "Solubility and Diffusivity of Hydrogen in Vanadium and its Alloys around Room Temperature", Trans. JIM, Vol. 20, p 647.

E.H. Van Deventer, T.A. Renner, R.H. Pelto and V.A. Maroni, (1977) "Effects of surface impurity layers on the hydrogen permeability of vanadium", Journal of Nuclear Materials 64 , pp. 241-248.

W. Van Witzenburg and B. Van Der Schaaf, editors (1993), "Assessment of Vanadium Alloys for ITER Application," ECN Report, ECN-RX-93-082.

E. Veleckis and R.K. Edwards, (1969), "Thermodynamic Properties in the Systems VanadiumHydrogen, Niobium-Hydrogen, and Tantalum-Hydrogen," J. Phys. Chem., Vol. 73, No 8, p 683.

J. VölkI, et al. , (1975), Proc. of Sixth International Conference Internal Friction and Ultrasonic Attenuation in Solids, p485.

J.M. Welter and H.N. Wachendorf, (1982-83), "Surface segregation of oxygen in vanadium," Appl. of Surf. Sci., vol 14, pp. 173-182.

D. Westlake, (1967),Trans. Am. Inst. Min. Engrs., vol. 239, p1341

D.G. Westlake and S.T. Ockers, (1975) "The Isotope Effect and the Influence of Interstitial Impurities on the Hydrogen Solubility Limit in Niobium and Vanadium", Metallurgica Transactions A, Vol. 6A, p 399.

K. Yamaguchi, S. Tanaka, M. Yamawaki and T. Namba, (1989) "Simultaneous ion- and gasdriven permeation of hydrogen isotopes through first wall material", Fusion Engineering and Design, 10, pp. 337-341.

S. Yamaguchi, O. Yoshinari, J. Takahashi, Y. Fujino, K. Ozawa, H. Naramoto, M. Koiwa, and M. Hirabayashi, (1980), Proceedings of JIMIS-2, Hydrogen in Metals, Sandai, p 249.

E-5 DRAFT October 7, 1994 
M. Yamawaki, T. Namba, T. Kiyoshi, T. Yoneoka and M. Kanno, (1985) "Hydrogen Permeation of Vanadium and in-situ Surface Analysis", Journal of Nuclear Materials, $133 \& 134$, pp. 292-296.

M. Yamawaki, T. Kiyoshi, T. Namba, and M. Kanno, (1986), "Effects of Surface Segregated Sulfur upon Hydrogen Permeation of Vanadium," Z, for Phys. Chem. Neue Folge, Bd 147, pp 115-122.

M. Yamawaki, K. Yamaguchi, S. Tanaka, T. Namba, T. Kiyoshi and Y. Takahashi, (1989) "Effect of surface impurities on the hydrogen recombination coefficient of first-wall materials", Journal of Nuclear Materials, 162-164, pp. 1071-1076.

M. Yamawaki, S. Tanaka and T. Kiyoshi, (1989) "Analysis of transient permeation behavior of hydrogen isotope caused by abrupt temperature change of first wall and blanket wall material", Fusion Engineering and Design, 10, pp. 331-335.

H. Zuchner, (1989), "Comment on Superdiffusion of Hydrogen in Vanadium Measured by the Permeation Method," Scripta Metall. 23, pp 1033-1034. 